\title{
LA COMUNICACIÓN PÚBLICA
}

DE LA CIENCIA EN EL CENTRO

DE LA POLÍTICA CIENTÍFICA 


\section{María de los Ángeles Erazo Pesántez}

\section{AGRADECIMIENTOS}

El presente trabajo de tesis doctoral debe lo mejor que pueda ofrecerse a la orientación, sugerencias y estímulo de sus directores, Dr. Manuel Calvo Hernando y Dr. Ángel Badillo Matos. Su conclusión es reflejo del trabajo constante y del loable ejemplo inspirado por personas tan valiosas, como son: Carl Sagan, Stephen Hawking, Ana M ${ }^{a}$ Sánchez Mora, León Olivé, Pablo del Río, Stuart Blume, Ángel Espina, entre otros, quienes me apoyaron en la búsqueda y comprensión del cometido social de la ciencia y la tecnología. A todos ellos mi mayor reconocimiento y gratitud.

La elaboración de esta tesis fue posible gracias al auspicio de varias instituciones. De manera especial agradezco el apoyo de la Universidad de Salamanca (USAL), que me otorgó una beca financiada por el Grupo Santander Central Hispano para cursar el programa de "Doctorado en Antropología de Iberoamérica", de octubre de 2003 a septiembre de 2006. También agradezco a la Agencia Española de Cooperación Internacional, por la beca concedida a inicios de 2003 para estudiar el "Máster en Ciencia, Tecnología y Sociedad: Cultura y Comunicación en Ciencia y Tecnología”, en la USAL. Esta tesis se sustenta en una investigación desarrollada a partir del aporte académico brindado por esos programas.

La orientación y el análisis que promueve el programa de "Máster en Antropología Médica”, de la Universidad de Ámsterdam, también fue primordial para enriquecer el contenido de esta investigación y, consecuentemente, para solicitar la mención de Doctor Europeus. Este Máster lo cursé entre septiembre de 2007 y agosto de 2008, gracias a una beca concedida por la Organización de los Países Bajos para la Cooperación Internacional en Educación Superior (NUFFIC). 
Un agradecimiento especial a Rudi Plantinga, mi pareja, el hombre que con su respaldo y amor me motiva a seguir luchando por mis sueños; al igual que mis padres, hermanos y amigos. Gracias a ellos y a todos quienes me ofrecieron su incondicional apoyo durante la elaboración de esta tesis.

\section{TABLA DE CONTENIDO DE LA TESIS DOCTORAL}

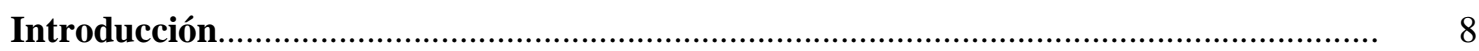

A. Planteamiento del problema de investigación....................................... 9

B. Justificación........................................................................... 11

C. Formulación de hipótesis....................................................... 12

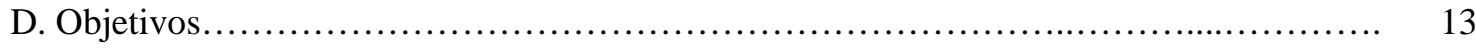

E. Marco Teórico............................................................................. 15

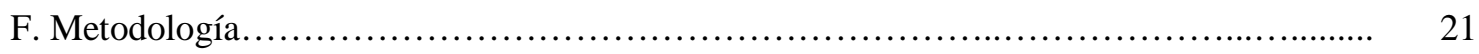

F.1. Metodología correspondiente a la investigación empírica..................... 22

F.2. Procedimiento ............................................................. 25

F.3. Técnicas empleadas...................................................................... 28

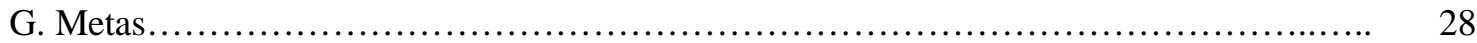

H. Breve descripción del contenido de la Tesis..................................................... 29

Capítulo 1: Contexto de la investigación......................................................................... 33

1.1. Estudios de Comunicación Pública de la Ciencia............................... 33

1.1.1. Estudios de Periodismo Científico...................................... 36

1.1.2. Diversidad de términos................................................. 40

1.1.3. Educación y Comunicación de la ciencia.................................... 43

1.1.4. Divulgar la ciencia con creatividad.................................. 45

1.2. Comunicación de la ciencia desde los Estudios CTS........................................... 47

1.3. Análisis de la CPCT en el 'nuevo contrato social sobre la ciencia'................................. 50 


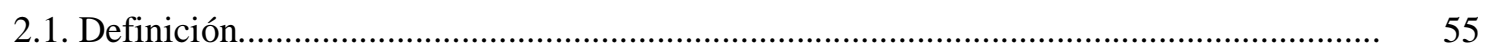

2.2. Características................................................................................................. 58

2.3. Pirámide de la СРСТ ............................................................... 60

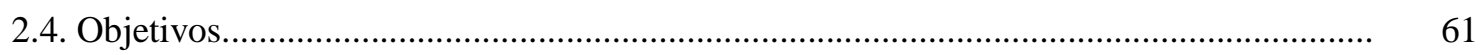

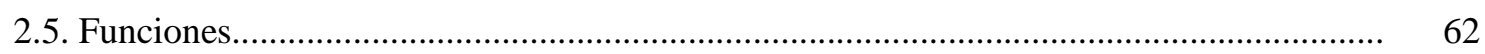

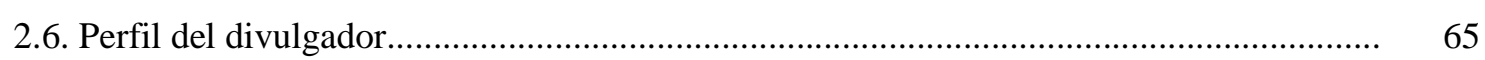

2.7. Decálogo del divulgador de la ciencia........................................ 68

Capítulo 3: Problemas de la comunicación pública de la ciencia y la tecnología........ 73

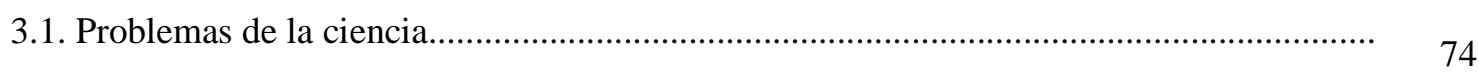

3.1.1. Más de cien años de creatividad científica.................................................... 76

3.1.2. Aumento de términos científicos.................................................................. 82

3.1.3. Límites de la enseñanza e inversión................................................................... 83

3.1.4. La ciencia que no se comunica, no existe...................................................... 85

3.2. Problemas de la comunicación...................................................................................... 87

3.2.1. Del lenguaje científico al lenguaje cotidiano.................................................... 90

3.2.2. En español o en inglés.................................................................................. 91

3.3. Problemas de la sociedad.......................................................................................... 93

3.3.1. Aporte de los m.c.m. a la comunicación de la ciencia....................................... 97

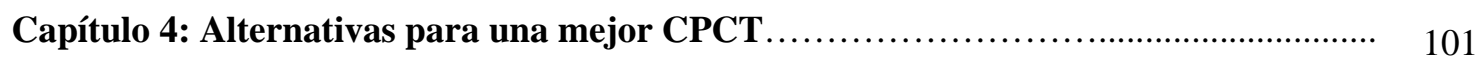

4.1. Estrategias de la educación no formal............................................................................ 104

4.1.1. Actualización............................................................................ 106

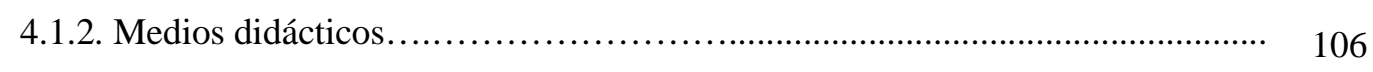

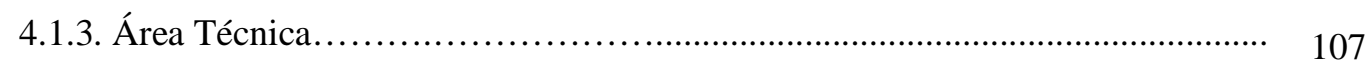

4.1.4. Aprendizaje potencialmente significativo..................................................... 108

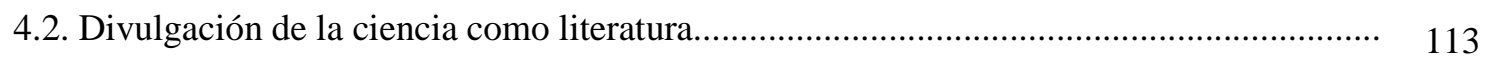

4.2.1. Ciencia y literatura................................................................................... 114

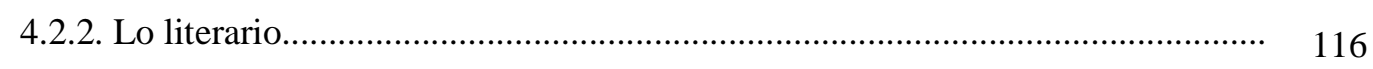

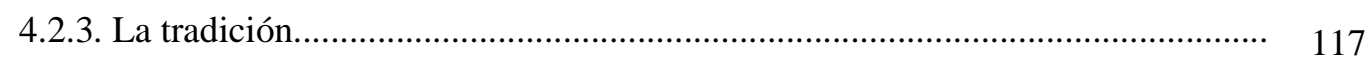

4.2.4. Teoría de la recepción................................................ 119 
4.2.5. Ejemplos de divulgación de la ciencia como literatura

4.3. Propaganda científica.............................................................................................. 123

4.3.1. Un ejemplo de propaganda científica: A golear con ciencia............................. 126

4.4. El imaginario audiovisual de la ciencia desde un enfoque sociocultural................. 134

4.4.1. Comunicar la ciencia al público desde un enfoque sociocultural: propuesta desde la perspectiva Genético Cultural................................... 136

4.4.2. Análisis sobre el imaginario audiovisual de la CyT........................ 138

4.5. Estudio de caso: Proyecto Café Scientifique en Ecuador........................... 140

4.5.1. Objetivos del proyecto.......................................... 142

4.5.2. Metas del proyecto................................................ 143

4.5.3. Características del proyecto............................................ 143

4.5.4. Conformación del Comité Científico.................................... 144

4.5.5. Miembros del Comité Organizador.................................... 145

4.5.6. Patrocinadores económicos........................................ 146

4.5.7. Auspiciantes institucionales................................................ 146

4.5.8. Público destinatario................................................. 147

4.5.9. Periodicidad e información adicional.................................. 147

4.5.10. Características de las tres primeras ediciones........................... 147

4.5.11. Evaluación de avances del proyecto................................. 154

Capítulo 5: CPCT dentro de la Política Científica.................................. 158

5.1. Razones para evaluar la Política Nacional de Ciencia, Tecnología e Innovación.......... 159

5.1.1. El reto es cerrar la brecha científica y pasar del análisis global a la acción local................................................................. 164

5.2. "Ciencia y tecnología: patrimonio social de los ecuatorianos"......................... 166

5.2.1. Antecedentes legales de transición de SENACYT y FUNDACYT................ 168

5.3. Principios que rigen la Política Nacional de Ciencia, Tecnología e Innovación............ 170

5.3.1. Líneas de acción de esta Política....................................................... 171

5.3.2. Surge el 'Sistema Nacional de Ciencia, Tecnología, Innovación y Saberes Ancestrales', en el Ecuador.............................................. 171

5.4. Resoluciones, Acuerdos y Mandatos sobre CTI aprobados por jefes de Estado y de Gobierno, ministros y altas autoridades de CyT ........................................................... 172

5.4.1. Principales temas de interés regional............................................... 173

5.4.2. Prioridades programáticas estratégicas.............................................. 174 
5.4.3. Primera Jornada Andina sobre Políticas de CTI........................... 176

5.4.3.a) Lineamientos de Política Regional Andina............................... 177

5.4.3.b) Criterios Estratégicos................................................. 178

5.4.3.c) Programas Estratégicos.................................................. 178

5.4.3.d) Tipos de acciones.................................................. 179

5.4.3.e) Influencia de la cooperación regional y del BID.......................... 182

5.5. Aporte desde la Comunicación Pública de la Ciencia y la Tecnología................... 184

5.6. Programa Nacional de Comunicación Pública de la Ciencia y la Tecnología........................................................ 187

5.6.1. Objetivos del Programa Nacional de CPCT............................................ 189

5.6.2. Compromisos desde el sector educativo............................... 190

5.6.3. Compromisos desde la comunicación.......................................... 191

5.6.4. Compromisos desde la comunidad científica....................................... 192

Capítulo 6: Análisis de la relación entre biomedicina y conocimientos locales, a partir de estudios de Antropología Médica y de CPCT ..................................................... 194

6.1. Introducción a la investigación empírica...................................... 195

6.1.1. Declaración del problema de investigación.............................. 197

6.1.2. Objetivos........................................................ 198

6.2. Contexto y metodología............................................................ 199

6.2.1. Contexto nacional................................................. 199

6.2.2. Contexto provincial.................................................. 204

6.2.3. Configuración del estudio: Otavalo...................................... 204

6.2.4. Caso de estudio: centro de salud Jambi Huasi............................ 208

6.2.5. Relación FICI-Jambi Huasi................................................... 210

6.2.6. Metodología............................................................. 212

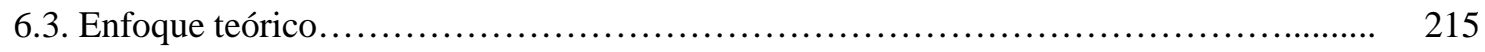

6.3.1. Anteriores perspectivas teóricas sobre pluralismo médico............................. 219

6.3.2. Conocimiento local: medicina tradicional indígena....................................... 224

6.3.3. Biomedicina y conocimientos locales................................... 226

6.3.4. Construcción intercultural de la salud...................................... 233

6.3.5. Conocimiento indígena............................................... 235

6.3.6. El rol de la comunicación..................................................... 238

6.4. Presentación y análisis de los datos........................................... 242 
6.4.1. Origen y desarrollo del centro de salud Jambi Huasi.......................... 242

6.4.2. Características de los pacientes de Jambi Huasi........................... 254

6.4.3. Espacios de trabajo................................................ 264

6.4.4. Sueldos / Remuneraciones ¿Cómo ha cambiado?............................................... 269

6.4.5. Reuniones y colaboración.................................................... 275

6.4.6. Referencias: casos de embarazo y parto................................ 282

6.4.7.Reconocimiento de profesionales de la medicina tradicional indígena.......................................................... $\quad 289$

6.4.8. Discusión sobre la investigación empírica............................................ 291

Capítulo 7: Conclusiones y orientaciones...................................................................... 298

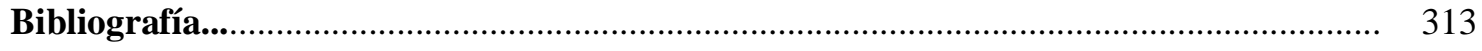

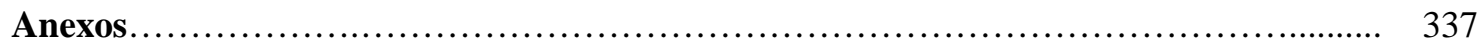

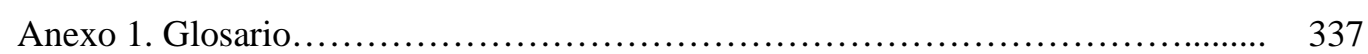

Anexo 2. Personas entrevistadas en la investigación descrita en el Capítulo 6........ 343

Anexo 3. Parto tradicional en posición vertical...................................... 345

Anexo 4. Fotos de informantes................................................ 350

Anexo 5. Descripción del Programa Nacional de "Postgrado en Comunicación Pública de la Ciencia y Tecnología”, del Ecuador........................ 360 


\section{INTRODUCCIÓN}

¿De qué tamaño es el hombre comparado al Universo? Del tamaño de una arena, de un leve soplo de viento, del tamaño de su historia, del tamaño de su tiempo. ¿De qué tamaño es el hombre comparado con su tiempo, comparado con la arena, comparado con el viento? Del tamaño de su mente, donde cabe el Universo.

(Gonzalo Chanocua)

La ciencia, la tecnología y la innovación se han convertido en el principal soporte de las sociedades contemporáneas; por eso, en muchos países tienen asignado un estatuto de política de Estado.

Para que las políticas públicas en ciencia, tecnología e innovación generen un impacto positivo en la sociedad, éstas deben valorar y promover la participación ciudadana en la toma de decisiones sobre estos temas. Esta premisa, planteada a través de literatura existente (Aguilar, 2000; Bañón, 2003; Cardoso, 2006; Castañeda, 2007), sugiere promover más cultura científica en el público general y una participación más activa, por parte de los científicos, en las preocupaciones de la vida cotidiana. Esta interacción exige dar mayor 
impulso a la Comunicación Pública de la Ciencia y la Tecnología (CPCT), según lo expresan varios analistas de la materia, como Pierre Fayard (1989, 1999, 2004), Manuel Calvo Hernando (2005), León Olivé (2000, 2004, 2007) y Mónica Lozano (2005).

\begin{abstract}
Sobre el desarrollo de sistemas de producción de conocimiento científico y tecnológico y de resolución de problemas específicos, debe disiparse la idea de que se trata de asuntos sólo de expertos. Al respecto es imprescindible desarrollar políticas de educación y de comunicación pública de la ciencia y la tecnología, que incluyan a todos los sectores: los gubernamentales, los empresariales, a las propias comunidades científicas y tecnológicas, así como a los pueblos indígenas, para que se entienda que el desarrollo de los sistemas tecnológicos y tecnocientíficos es un asunto de todos, aunque hay maneras diversas de apropiarse de ellos, de producirlos y de aprovecharlos. Tales políticas deben fomentar la cultura científica y tecnológica, entendida como la incorporación en las prácticas cotidianas de valores y formas de entender el mundo y resolver problemas que provienen de prácticas científico-tecnológicas, pero respetando plenamente la diversidad cultural, por lo que al mismo tiempo el diseño, la evaluación de políticas educativas y de ciencia y tecnología deben hacerse mediante una participación efectiva de los miembros de los diferentes pueblos, de manera acorde con sus características culturales (Olivé, 2004: 7).
\end{abstract}

Por eso conviene impulsar la СРCT, para fomentar la cultura científica, la apropiación social del conocimiento científico, la conciencia cívica y la participación ciudadana en la toma de decisiones sobre políticas públicas en ciencia y tecnología, desde una visión interdisciplinaria y sociocultural (Erazo, 2007: 119-136)

\title{
A. Planteamiento del problema de investigación
}

La falta de políticas públicas en ciencia y tecnología, orientadas a la solución de problemas nacionales, ha conducido a varios países de Iberoamérica —como Ecuador-a un estado de extrema dependencia en los aspectos económico, industrial, político, científico y tecnológico. Este problema es analizado de forma detallada en el libro entitulado Claves 
del desarrollo científico y tecnológico de América Latina (Sebastián, 2007). Esta obra, escrita por varios analistas y editada por el español Jesús Sebastián, empieza recordando que el desarrollo científico a principios del siglo XX estuvo asociado, especialmente en América del Sur, al positivismo europeo y a esquemas de modernización, basados en buena medida en la inmigración europea, la atracción de capitales y la adquisición de conocimiento externo. En este contexto, "las demandas por una investigación local son casi inexistentes, por lo que el incipiente desarrollo de las capacidades científicas se produce de manera autónoma" (Sebastián, 2007: VII-VIII).. De esta manera la ciencia incumple con su cometido social, por no contribuir al desarrollo adecuado de los pueblos.

Con el fin de analizar este problema y de plantear alternativas de solución, se sugiere una relación más cercana y permanente entre la ciudadanía, la comunidad científica y autoridades encargadas de establecer políticas públicas en ciencia y tecnología.

La ciencia y la tecnología cambian las formas de vida de la gente, y es éste uno de los rasgos que más agudamente se están notando en la transición a la sociedad del conocimiento. La decisión de cuáles cambios en las formas de vida son deseables y cuáles no, corresponde a la gente, no a los expertos, ni a los Estados ni a las entidades super-estatales. Pero como no hay un único punto de vista, ni uno solo que sea el correcto, debe haber discusión pública acerca de cuáles cambios en la forma de vida de una comunidad o de un pueblo son deseables y éticamente aceptables, es decir, cuáles son aceptables bajo la discusión y participación de los diversos puntos de vista y de intereses y valores presentes en las sociedades actuales, desde el nivel global hasta los niveles locales. Para esto es indispensable la elaboración de normas de convivencia armoniosa y de cooperación constructiva intercultural y entre pares, que deberían estar en la base de una sociedad del conocimiento, plural, multiculturalista, democrática y justa (Olivé, 2004: 10) ${ }^{1}$.

\footnotetext{
${ }^{1}$ Según León Olivé, "una sociedad es justa si, y sólo si, cuenta con las condiciones que aseguren la satisfacción de las necesidades básicas de todos sus miembros, de acuerdo con la determinación de esas necesidades que hagan ellos mismos" (Olivé, 2004: 6).
} 
Para lograrlo, es fundamental el aporte de la СРCT. A partir de estas consideraciones, para la elaboración de esta Tesis se decidió focalizar el problema de investigación en el análisis de las políticas públicas en ciencia y tecnología, a partir del estudio, desarrollo y aplicación de estrategias de CPCT, sustentadas en un modelo de comunicación democrático y sociocultural.

\section{A.1. Enunciado del Problema}

A.1.1. ¿Cómo comunicar públicamente la ciencia y la tecnología sin perder rigurosidad, de manera que estos conocimientos logren ser apropiados por públicos amplios y cumplan con el objetivo de generar una visión más crítica sobre su desarrollo y aplicación, en Ecuador y en más países de Iberoamérica?

A.1.2. ¿Cómo contribuir desde la Comunicación Pública de la Ciencia y la Tecnología en Política Científica, para promover la participación ciudadana y transparencia en la toma de decisiones sobre políticas públicas en ciencia, tecnología e innovación?

\section{B. Justificación}

El tema de investigación propuesto para esta Tesis Doctoral fue seleccionado a partir de criterios provenientes de estudios de Comunicación Pública de la Ciencia y Tecnología, y de Antropología Médica.

El problema de dependencia económica, industrial, política, científica y tecnológica, antes referido, ha generado graves consecuencias para la población ecuatoriana, por eso algunas personas intentan mejorar su calidad de vida en otros países. Esto ha ocurrido con 
ecuatorianos y ecuatorianas que decidieron emigrar de su país, desde 1998, a raíz de la crisis política y económica que ha amenazado la estabilidad del Ecuador.

La búsqueda de soluciones que permitan superar esta crisis y ofrecer nuevas alternativas de trabajo, anima a recordar que la ciencia y la tecnología tienen un cometido social y, para que se cumpla, es fundamental el aporte de la de la СРCT; porque, la ciencia que no se comunica no existe para el público general, a pesar de que la gestión de nuestra sociedad depende cada vez más de los avances científicos y tecnológicos. No en vano la Declaración de los Derechos Humanos señala, en su Artículo 27: "Toda persona tiene derecho a tomar parte libremente en la vida cultural de la comunidad, a gozar de las artes y a participar en el progreso científico y en los beneficios que de él resulten”.

Todas las ramas de la ciencia pueden tener efectos positivos o negativos en el ambiente, en la ecología, en el cuerpo humano, en el sector laboral, en la guerra y en la paz. Esto implica, para países como Ecuador, la necesidad urgente de asignarle a la investigación científica y al desarrollo tecnológico un estatuto de política de Estado, del cual podrán derivarse políticas públicas como medio indispensable para acceder al crecimiento y al desarrollo justo del país.

Esta es la razón que justifica, en gran medida, la elaboración de esta Tesis Doctoral, ${ }^{2}$ para analizar el aporte que ofrecen la Antropología Médica, la Comunicación Pública de la Ciencia y la Tecnología (СРCT) y la ejecución de adecuadas políticas públicas en ciencia y tecnología; con el fin de promover la participación ciudadana en estos temas, tal como lo exige el nuevo "Sistema Nacional de Ciencia, Tecnología, Innovación y Saberes Ancestrales" del Ecuador, el cual fue aprobado oficialmente el 28 de septiembre de 2008.

\footnotetext{
${ }^{2}$ Esta consideración justifica, de manera especial, el desarrollo del quinto capítulo de esta Tesis, porque en éste se analiza el aporte de la CPCT en el marco de las políticas públicas en ciencia y tecnología.
} 


\section{Formulación de hipótesis}

Para el desarrollo de esta investigación, se formularon las siguientes hipótesis:

3.1. La expansión y la complejidad de la ciencia ha generado la utilización de técnicas y de terminologías que dificultan la comprensión de su lenguaje; esta situación ha extendido una gran brecha en la comunicación entre científicos y el público en general.

3.2. La adecuada aplicación del modelo democrático y sociocultural de Comunicación Pública de la Ciencia y Tecnología (CPCT); el cine y la literatura como recursos narrativos; las iniciativas de la educación no formal como espacios de capacitación; el diseño de un mejor currículum cultural y mediático para la televisión y la ejecución de un Programa Nacional de СРСТ constituyen alternativas idóneas para promover la cultura científica en Ecuador.

3.3. El desarrollo y ejecución de un Programa Nacional de "Postgrado en Comunicación Pública de la Ciencia y Tecnología" puede contribuir a la formación de profesionales interesados en incidir positivamente para fomentar la cultura científica, la participación ciudadana y la transparencia en la toma de decisiones sobre políticas públicas en ciencia, tecnología e innovación.

3.4. Desde el ámbito de la Antropología Médica es posible comprobar que "la cura es sólo uno de los muchos objetivos o resultados de la elección médica”, tal como lo anunció la antropóloga médica Libbet Crandon Malamud.

\section{Objetivos}




\section{D.1. Objetivo General:}

Promover en Ecuador el desarrollo y aplicación de proyectos y de políticas públicas en ciencia, tecnología, salud e innovación, a partir de estudios de Antropología Médica y de Comunicación Pública de la Ciencia y Tecnología. Esta propuesta destaca la inclusión de representantes de todos los sectores: gubernamentales, empresariales, académicos, de las comunidades científicas y tecnológicas, así como de la sociedad civil; pues, de esa manera, será posible fomentar la cultura científica, una conciencia cívica y más participación ciudadana en la toma de decisiones sobre esos temas.

\section{D.2. Objetivos Específicos}

D.2.1. Realizar un estudio comparativo de políticas científicas establecidas en varios países de Iberoamérica, con el fin de contribuir a la formulación de políticas públicas que resulten adecuadas para fortalecer el "Sistema Nacional de Ciencia, Tecnología, Innovación y Saberes Ancestrales” del Ecuador.

D.2.2. A partir de este estudio, contribuir al diseño y desarrollo de un Programa Nacional de "Postgrado en Comunicación Pública de la Ciencia y Tecnología" en Ecuador, sobre la base de los Estudios de Ciencia, Tecnología y Sociedad, y promoviendo la aplicación de un modelo de comunicación democrático y sociocultural.

D.2.3. Aportar en el diseño, desarrollo y aplicación de nuevos proyectos de CPCT que fomenten la participación ciudadana en temas de ciencia y tecnología, en Ecuador.

D.2.4. Desarrollar una investigación empírica que considere el aporte de los estudios de Antropología Médica y de Comunicación Pública de la Ciencia y Tecnología, para analizar la relación de los conocimientos y prácticas provenientes de la biomedicina y de la medicina tradicional indígena. Esta investigación aportará elementos de gran 
relevancia para la ejecución del nuevo "Sistema Nacional de Ciencia, Tecnología, Innovación y Saberes Ancestrales” en el Ecuador.

\section{E. Marco Teórico}

La falta de una teoría completa o definitiva sobre СРCT, en el sentido estricto del término y desde el ámbito de la comunicación o de la antropología, dificulta la profundización del marco teórico. Sin embargo, la experiencia desarrollada en varios países permite justificar un avance notable a partir de iniciativas forjadas por la Universidad Nacional Autónoma de México (UNAM), por la Universidad de Salamanca (USAL) y por la Organización de Estados Iberoamericanos (OEI).

Varios son los científicos que se han esmerado por transmitir socialmente el conocimiento científico, entre quienes destacan: Albert Einstein, George Gamov, Isaac Asimov, Carl Sagan, Jacques Cousteau, Arthur C. Clark, Stephen Hawking, Julio Verne, Manuel Calvo Hernando, Pierre Fayard, Ana María Sánchez Mora, León Olivé, entre otros. Pero el análisis y comunicación de la ciencia y de sus avances no sólo compete a la comunidad científica, sino a todos los sectores de la sociedad.

Hasta finales del siglo XIX, el conocimiento científico formaba un solo cuerpo, que era conocido con el nombre de filosofía natural (Sánchez Mora, A.M., 1998: 9). El público en general tenía acceso a este conocimiento, gracias a la comunicación directa y permanente que mantenían los científicos con la sociedad. Pero el panorama cambió en el siglo XX, especialmente luego de la segunda guerra mundial, porque la expansión y la complejidad de la ciencia motivó la utilización de técnicas y de terminologías que dificultaron la 
comprensión de su lenguaje (Calvo, 1999).Esta situación empezó a extender una gran brecha en la comunicación de científicos y el público en general.

No obstante, la СРCT ha demostrado ser el camino idóneo para unir esa brecha y, consecuentemente, para suprimir la microfísica del poder que genera el monopolio del conocimiento científico, para fortalecer la democracia, para lograr que todos podamos apreciar la influencia de la ciencia en nuestra vida diaria y participar con mejores argumentos en los debates nacionales (Olivé, 2007).

De las reflexiones emitidas por miembros del grupo de científicos de Cambridge ${ }^{3}$ se deduce que la mayor preocupación por divulgar el cometido social de la ciencia surgió en la década de 1930, en Inglaterra. Pero fue a partir de la obra clásica de Robert Merton, en 1950, que se desarrolló la Sociología de la ciencia (Storer, 1977; Merton, 1977; Merton, 1992; Barnes, 1980), como una disciplina de rápido crecimiento y una rama tardía de la Sociología del conocimiento. Consecuentemente, empezó a evolucionar el cuadro sobre estudios de la ciencia, sin prescindir de los factores sociales. En el libro intitulado The sociology of science: An episodic memoir, Robert Merton (1977) compartió su experiencia en torno al nacimiento y desarrollo de la sociología de la ciencia.

Otra circunstancia significativa de esa época fue que se planteara el llamado problema de "las dos culturas". En el ensayo "The Two Cultures and the Scientific Revolution" (1956), el científico y novelista Charles Percy Snow expuso la tesis de que la cultura occidental estaba escindida en dos bandos que se ignoraban mutuamente: el de los humanistas y el de los científicos. Esta bifurcación ha sido descartada en varios estudios realizados durante las dos últimas décadas.

\footnotetext{
${ }^{3}$ Este grupo lo conformaban marxistas y simpatizantes del socialismo, y lo encabezaba John Desmond Bernal, autor de The Social Function of Science.
} 
Después de la Segunda Guerra Mundial, el proyecto de occidente fue científicotecnológico, prioritariamente; aunque una enorme porción de la sociedad seguía habitando un mundo cultural libresco. Los que cambiaban las cosas en el ámbito global — decía Charles Percy Snow - eran los ingenieros, los biólogos, los físicos y los químicos; mientras que los intelectuales de tradición humanista seguían pensando en cuestiones políticas, morales y jurídicas, con pautas pre-científicas. La única solución que se proponía, entonces, era repensar la educación.

Desde este punto de vista, hay consenso en el hecho de que una mejor comprensión de la ciencia depende, en gran medida, de una buena educación, de cultura científica. No obstante, en tanto se adopten las reformas necesarias para que mejore la enseñanzaaprendizaje de las ciencias en el sistema educativo, conviene impulsar la realización de actividades que estén fuera de la enseñanza académica formal y que promuevan una visión más crítica de la ciencia desde la recreación, la información y el análisis contextualizado del conocimiento científico. En este sentido, destaca el aporte de la СРCT.

Algunos estudios referentes a la transmisión social de conocimientos científicos (Isita, 1995) han enmarañado los conceptos: difusión científica, divulgación de la ciencia, popularización de la ciencia, apropiación social del conocimiento científico, periodismo científico y comunicación científica pública; mientras que otros los han considerado sinónimos. Para no crear confusiones, en este trabajo se emplea el término: Comunicación Pública de la Ciencia y Tecnología (CPCT).

A partir de algunas definiciones expuestas en obras sobre Estudios de Ciencia, Tecnología y Sociedad (CTS), y por autores como Pierre Fayard (1989, 1999, 2004), Quintanilla y Escribano (2005); Olivé (2000); Ana María Sánchez Mora (1998) y Rolando Isita Tornell (1995), en esta Tesis se entiende por СРCT a la "práctica social que consiste en 
la recreación de conocimientos científicos y tecnológicos —de forma contextualizada, crítica y sin perder rigurosidad—, a fin de que éstos logren ser apropiados por públicos amplios para generar una visión más crítica sobre su desarrollo y aplicación" .

La CPCT es una práctica sociocultural que se inscribe dentro de una sociedad determinada, con orientaciones político-culturales definidas y con un manejo discursivo adecuado para públicos específicos. Comprende proyectos y actividades de ampliación y actualización del conocimiento científico, que pueden realizarse desde la educación no formal, a través de los medios de comunicación y en espacios abiertos para el diálogo.

Para sustentar el desarrollo de las hipótesis planteadas en esta investigación se valoró el aporte teórico transmitido por Daniel Jacobi y Bernard Schiele (1988), Pierre Piganiol (1974), Manuel Calvo Hernando (1999), Pierre Fayard (1988, 1990, 1993, 1995, 1999, 2004), Javier Fernández del Moral y Francisco Esteve Ramírez (1993), Ignacio Fernández Bayo (1988), Jack Meadows (1986), Maurice Goldsmith (1999), Luis Estrada Martínez (1992), Martha Tappan y Aarón Alboukrek (1992), Francisco López Rupérez (1985), Wendy Nelson Espeland y Elisabeth S. Clemens (1988), Ana María Sánchez Mora (1998) y Rolando Isita Tornell (1995), Daniel Gil y Amparo Vilches (2004), entre otros autores.

El análisis de las hipótesis también se fundamenta en información transmitida a través de estudios y congresos organizados, en México, por la Dirección General de Divulgación de la Ciencia y el Instituto de Investigaciones Filosóficas de la Universidad Nacional Autónoma de México (UNAM), el Consejo Nacional de Ciencia y Tecnología (CONACYT) de México, la Academia Mexicana de Ciencias (AMC), la Sociedad Mexicana de Divulgación de la Ciencia y la Técnica (SOMEDiCYT), y la Sociedad Mexicana para el Progreso de la Ciencia y la Tecnología (SOMPROCYT). 
También fue de gran apoyo la información y capacitación recibida en España, a través del Master en Ciencia, Tecnología y Sociedad; del Instituto de Estudios de la Ciencia y la Tecnología, y del Programa Interuniversitario de "Doctorado en Antropología de Iberoamérica", de la Universidad de Salamanca; además del aporte bibliográfico ofrecido por el Consejo Superior de Investigaciones Científicas (CSIC), la Fundación COTEC, la Fundación Española para la Ciencia y la Tecnología (FECYT) y la OEI.

A esta orientación bibliográfica se suma la experiencia académica y de investigación obtenida en el Programa Avanzado de "Master en Antropología Médica" de la Universidad de Ámsterdam, en Holanda. Esta formación ha sido de gran utilidad para desarrollar parte de esta Tesis Doctoral; sobre todo, la parte referente al aporte de estudios de antropología médica y comunicación para la formulación de adecuadas políticas públicas en ciencia y tecnología. Esta contribución permite, además, justificar los requerimientos académicos y administrativos que exige la Universidad de Salamanca, con el fin de otorgar la Mención de "Doctor Europeus" en el título de doctorado.

Al analizar las dos primeras hipótesis, esta investigación permite explicar por qué conviene anular la discordia entre los lenguajes científico y popular; abrir espacios de educación no formal, que promuevan la actualización y aprendizaje de temas de ciencia y tecnología; ampliar el ejercicio de la divulgación científica a través del cine y la literatura; impulsar la adecuada aplicación del modelo de propaganda científica y del modelo de comunicación democrático; a más de promover un mejor diseño del currículum cultural y mediático de la televisión, para que su programación realmente aporte a la apropiación social del conocimiento científico y tecnológico, y una visión más crítica sobre su desarrollo y aplicación. 
Se propone usar la teoría del aprendizaje significativo (Ausubel, 1963) para la alternativa de la educación no formal; la Teoría de la Recepción (Iser, 1972; Sánchez Mora, A.M., 1995), para divulgar la ciencia como literatura, y, para la propaganda científica, el análisis de los ocho propiospectos (creencias, valores, tradiciones, hábitos, fobias, filias, símbolos y conocimientos) que considera el mexicano Rolando Isita Tornell (1995), al momento de identificar al público meta.

Para evaluar el impacto de la televisión en la infancia; sobre todo, en la creación de imaginarios sobre ciencia y tecnología, se consideró la teoría histórico-cultural, de L. Vygotski (Del Río et als. 2004; Vygotski, 1973 y 1978).

Una de las hipótesis específicas que se formuló para el desarrollo de un estudio de caso empírico, es: que las narrativas (cine, novela) cubren la función del paradigma, la macroestructura del imaginario, mientras que las noticias cubren una función más limitada (microestructuras). Para demostrarlo, se analizará la presencia de la ciencia en los diversos géneros comunicativos de la televisión. Con este análisis, se destacará el importante rol (función para construir la representación de la realidad) que cumplen las narrativas en la CPCT y en la enseñanza de la ciencia y la tecnología.

Para el desarrollo de la tercera hipótesis, referente al diseño y ejecución de un Programa Nacional de "Postgrado en Comunicación Pública de la Ciencia y Tecnología", esta investigación se sustenta en los denominados Estudios de Ciencia, Tecnología, Sociedad e Innovación (CTS+I), ${ }^{4}$ y propone la aplicación de un modelo de comunicación democrático y sociocultural, que valore el aporte de la participación ciudadana y la percepción pública del

\footnotetext{
${ }^{4}$ Desde esta perspectiva se analiza la dimensión social de la ciencia, la tecnología y la innovación, tomando en consideración sus antecedentes sociales y sus consecuencias sociales y ambientales (García et als., 2001:125).
} 
conocimiento científico y tecnológico. Para el efecto, también se consideran técnicas y estrategias adecuadas para el diseño, gestión y evaluación de proyectos de CPCT.

Para el desarrollo de la cuarta hipótesis, como perspectiva teórica se adoptó la denominada "Antropología Médica Crítica", porque este enfoque permite analizar temas de salud desde el contexto político y económico que influye en las relaciones humanas y en los comportamientos sociales.

En esta investigación empírica, que se detalla en el Capítulo 6, también se combinó la perspectiva de política económica con un enfoque simbólico; además de considerar los conceptos de "salud intercultural" e "híbrido cultural". A través del análisis de estos conceptos es posible sustentar un análisis crítico sobre la concepción de relaciones interculturales, con el fin de pasar de la tolerancia al respeto de las diferentes formas culturales.

Información más detallada sobre el Marco Teórico que sustenta el desarrollo de cada una de las hipótesis de esta investigación, podrá leerse en los próximos capítulos de la tesis.

\section{F. Metodología}

El diseño de esta investigación es Explorativa o Descriptiva; por tanto, es no experimental o ex post-facto, ${ }^{5}$ pues no considera la manipulación deliberada de los hechos ni de las variables, sino que supone un enfoque retrospectivo y variables que ocurrieron sin

\footnotetext{
${ }^{5}$ Según Kerlinger (1983), la investigación Ex Post Facto es un tipo de “...investigación sistemática en la que el investigador no tiene control sobre las variables independientes, porque ya ocurrieron los hechos o porque son intrínsecamente manipulables" (Kerlinger, 1983: 269). Lo mismo sostienen Hernández, Fernández y Baptista (1991), cuando dicen que en la investigación Ex Post Facto los cambios en la variable independiente ya ocurrieron y el investigador tiene que limitarse a la observación de situaciones ya existentes. De su parte, Leedy (1993) define la investigación Ex Post Facto como un proceso inverso a la investigación experimental.
} 
la intervención directa del investigador (Briones, 1995; Bunge, 1983 y 1993; De Gortari, 1985; Hernández et als., 1994; Kerlinger, 1983; Leedy, 1993; Rojas, 1980; Rodríguez et al., 1995; Zorrilla et al., 1994).

Lo que ofrece esta tesis es una amplia descripción del panorama que caracteriza a la Antropología Médica y a la CPCT, así como la aplicación del marco teórico que caracteriza a estas disciplinas en una investigación empírica que se desarrolló al norte del Ecuador, para brindar referentes adecuados que permitan promover mayor cultura científica, conciencia cívica, transparencia y más participación ciudadana en toma de decisiones sobre políticas públicas en ciencia, tecnología, salud e innovación.

\section{F.1. Metodología correspondiente a la investigación empírica}

En el trabajo de campo de la investigación empírica (que está detallada en el Capítulo 6) se adoptó un diseño exploratorio.

Se consideró experiencias de representantes de la biomedicina, de la medicina tradicional indígena y de pacientes que asistieron al centro de salud Jambi Huasi, del 21 de mayo al 8 de julio de 2008 .

Como técnicas de recopilación de datos se optó por la observación, por el empleo de entrevistas semi-estructuradas y a profundidad; así como por la recopilación de material documental. Las entrevistas y la observación se aplicó especialmente en las salas de consulta, en los corredores y en más lugares correspondientes al centro de salud Jambi Huasi. También se entrevistó a funcionarios de salud que laboran en la capital de la provincia de Imbabura, Ibarra, y en la capital del Ecuador, Quito.

Con respecto a la muestra: se entrevistó a 8 personas que trabajan como proveedores de salud en el centro Jambi Huasi; a 3 pacientes de este centro y a 10 representantes de 
diversas instituciones (3 investigadores académicos, 2 coordinadores del Ministerio de Salud Pública del Ecuador; 2 representantes de la Dirección Provincial de Salud de Imbabura; 1 director del Hospital San Luis de Otavalo, y 2 representantes del Municipio de Otavalo).

Durante las dos primeras semanas de trabajo de campo también se aplicó entrevistas en la ciudad de Cotacachi, que pertenece a otro cantón de la provincia de Imbabura. En esa ciudad se entrevistó a dos representantes del programa de salud Jambi Mascaric y a dos representantes del Programa de Salud Cantonal Intercultural de Cotacachi.

Por tanto, para sustentar el contenido de esta investigación empírica se entrevistó, en Ecuador, a 25 personas. Quince entrevistas fueron previamente estructuradas e incluyeron preguntas abiertas; en la mayoría de los casos se consideró relevante la historia personal del entrevistado/a.

El tiempo total de observación en el centro de salud Jambi Huasi fue de aproximadamente 40 horas, durante el periodo de trabajo de campo.

También se pudo acceder al reporte médico de consultas realizadas entre el 2 y el 27 de junio de 2008, en el centro de salud Jambi Huasi. Estos datos fueron proporcionados por personal de salud de Jambi Huasi, e incluyen tanto las consultas de profesionales biomédicos, como las que ofrecieron representantes de la medicina tradicional indígena. A partir de datos cuantitativos, fue posible elaborar gráficos que ilustran y/o confirman el análisis que se presenta a lo largo del sexto capítulo.

En cuanto al plan de recolección y análisis de datos, en esta investigación empírica se exploró los siguientes aspectos: 
1. ¿De qué manera están presentes la biomedicina y el conocimiento local (que es la denominada "medicina tradicional indígena" en esta investigación) en la práctica de la atención primaria de salud que ofrece el centro Jambi Huasi?

2. ¿La distinción entre los conocimiento y prácticas provenientes de la biomedicina y del conocimiento local ha perdido su pertinencia, o acaso estas dos formas de conocimiento están conflicto en la práctica de la atención primaria de salud, en el centro Jambi Huasi?

3. ¿Cuáles son las estrategias de comunicación que utiliza el centro Jambi Huasi, en la atención primaria de salud, y cómo éstas influyen en la relación existente entre biomedicina y conocimiento local?

Para responder al primer punto, se analizó la práctica de la biomedicina y de la medicina tradicional indígena en los servicios de atención primaria de salud, desde la perspectiva de los beneficiarios (pacientes) y proveedores de esa atención; a más de explorar el tipo de comunicación que se promueve entre estos grupos.

Para responder al segundo punto, durante el trabajo de campo se intentó observar si la clásica distinción entre biomedicina y medicina tradicional indígena se ha vuelto menos clara con el tiempo, y cómo las dos formas de conocimiento y la práctica influyen mutuamente.

La respuesta al tercer punto se sustenta en entrevistas realizadas a pacientes y a proveedores de salud (tanto de la biomedicina como de la medicina tradicional indígena); así como en la observación de los procesos de comunicación que los caracteriza. Porque, en esta investigación, se dio especial énfasis a la influencia de las estrategias de comunicación 
utilizadas por representantes de la biomedicina, de la medicina tradicional indígena y por los pacientes que asisten al centro de salud Jambi Huasi.

Acerca de las consideraciones éticas, en esta investigación se trabajó con honestidad, para garantizar la credibilidad de los resultados. Por esta razón, durante el trabajo de campo la autora de esta investigación se presentó ante sus informantes como lo que era: una estudiante del programa avanzado de "Master en Antropología Médica", de la Universidad de Ámsterdam (Holanda), y del programa interuniversitario de "Doctorado en Antropología de Iberoamérica”, de la Universidad de Salamanca (España).

Los objetivos de esta investigación fueron explicados claramente a todos los informantes, antes de entrevistarlos. El permiso para realizar el trabajo de observación y entrevistas en Jambi Huasi fue concedido por la directora de este centro de salud, la Dra. Myriam Conejo. A cada persona entrevistada se le solicitó previamente su autorización, para grabar la entrevista.

Para proteger el bienestar de los informantes, a todos se les consultó si preferían mantener su nombre en el anonimato; pero sólo tres de las 25 personas entrevistadas solicitaron ser identificados con un nombre ficticio en el contenido de la tesis.

Durante esta investigación se respetó los valores culturales, creencias y normas locales de las fuentes de información.

\section{F.2. Procedimiento}

- Analizar algunas políticas científicas desarrolladas en España, México y Ecuador, con el fin de valorar cuáles han resultado más idóneas para fortalecer el Sistema Nacional de Ciencia, Tecnología e Innovación de sus respectivos países. 
- El análisis anterior sirve de referente para proponer un mejor diseño de políticas públicas en ciencia y tecnología, cuya aplicación resulte adecuada para Ecuador, para contribuir a superar en este país su estado de extrema dependencia económica, industrial, científica y tecnológica.

- El análisis propuesto en esta investigación también valora los efectos culturales y cognoscitivos que tiene la ciencia en las nuevas generaciones. De ahí que se proponga el diseño de un modelo de CPCT más completo, democrático y sociocultural, que considere las relaciones existentes entre las distintas formas de organización social. Este análisis contempla las siguientes categorías: 1) institucionalización, 2) mediaciones y 3) agentes sociales.

- Desarrollo de un marco teórico y conceptual que permita comprender el estudio de la CPCT en países de Iberoamérica.

- Como trabajo empírico se desarrolló una investigación que analiza la relación entre biomedicina y conocimiento local, en los servicios de atención primaria, a partir de experiencias y estrategias desarrolladas por el centro de salud Jambi Huasi, el cual se encuentra ubicado en la ciudad de Otavalo, provincia de Imbabura, Ecuador.

- Propuesta de diseño, desarrollo y ejecución de un Programa Nacional de "Postgrado en Comunicación Pública de la Ciencia y Tecnología", sobre la base de los Estudios CTS y del modelo de comunicación democrático y sociocultural.

- Asimilación y aplicación del aprendizaje recibido en los diplomados de "Divulgación de la ciencia" y de "Estudios Filosóficos y Sociales de Ciencia y Tecnología", cursados en la UNAM, México; en los programas de "Master en Ciencia, Tecnología y Sociedad (CTS)" y de "Doctorado en Antropología de 
Iberoamérica”, de la Universidad de Salamanca, España; así como en el Programa Avanzado de "Master en Antropología Médica", de la Universidad de Ámsterdam, Holanda.

- Estudio de la propuesta de comunicar públicamente la ciencia y la tecnología como una experiencia narrativa: revisión de la Teoría de la recepción propuesta por Wolfgang Iser, para estudios literarios.

- Investigación bibliográfica, hemerográfica y a través de ponencias presentadas en congresos internacionales, sobre las siguientes teorías:

a) Teoría histórico - cultural de Vygotski y la construcción mediada de la conciencia. Conceptos principales.

b) Teoría genético - cultural, que supone la evolución integrada y su repercusión, para definir las alternativas y trayectorias de desarrollo futuro, tanto a nivel individual como sociocultural.

- Empleo de las anteriores teorías, a) y b), en el análisis de contenido cualitativo y cuantitativo desarrollado en una muestra de programas de televisión, en España. Este análisis de contenido permitió demostrar el nivel de preferencia de la dieta audiovisual que consumió el público joven e infantil de España, del 3 al 9 de noviembre de 2003. La autora de esta tesis participó en ese equipo de investigación y analizó la parte correspondiente al imaginario audiovisual de la ciencia y la tecnología.

- Analizar la trascendencia de la ética en el trabajo de СРCT; tanto para la comunidad científica como para los comunicadores públicos de la ciencia y la tecnología. 
- Estudios de caso, a partir de la aplicación del modelo democrático y sociocultural de la СРСТ: diseño y coordinación del Café Scientifique en Ecuador.

\section{F.3. Técnicas empleadas}

- En el trabajo de campo de esta investigación, las principales técnicas de recopilación de datos fueron entrevistas semi-estructuradas y a profundidad. También se aplicó la técnica de observación y la recopilación de material documental.

- Entrevistas a investigadores que analizan el aporte de la Comunicación Pública de la Ciencia y Tecnología, así como la Antropología Médica, para el desarrollo de políticas públicas en ciencia y tecnología.

- Estudio de Mercado destinado a evaluar la demanda del Programa Nacional de "Diplomado en Comunicación Pública de la Ciencia", en provincias cercanas al lugar donde están ubicadas las tres universidades que resultaron seleccionadas para su ejecución, en Ecuador.

\section{G. Metas}

Como una muestra de la aplicación que puede tener la línea de investigación formulada en esta Tesis Doctoral, la parte inicial de su investigación sirvió para sustentar el diseño y desarrollo de un Programa Nacional de "Postgrado en Comunicación Pública de la Ciencia 
y Tecnología” en Ecuador, ${ }^{6}$ a partir de enero de 2006. Información más detallada sobre las características, avances y proyección de este programa nacional podrá leerse en un Anexo de esta Tesis.

Este programa fue considerado de fundamental importancia para la articulación, consolidación y fortalecimiento del "Sistema Nacional de Ciencia, Tecnología, Innovación y Saberes Ancestrales" del Ecuador; por eso contó, desde el inicio, con el respaldo económico e institucional de la Secretaría Nacional de Ciencia y Tecnología (SENACYT) y de la Fundación para la Ciencia y Tecnología (FUNDACYT). A este respaldo se ha sumado el auspicio de otras organizaciones, como: Organización de Estados Iberoamericanos (OEI); Convenio Andrés Bello (CAB); Instituto de Investigación para el Desarrollo, de Francia; Embajada de Francia; Sociedad Francesa de Exportación de Recursos Educativos; Grupo REDES, de Argentina; Laboratorio de Periodismo Científico, de Brasil; Universidad Nacional Autónoma de México (UNAM); Instituto Internacional de Periodismo Preventivo y Análisis Internacional, España, la Universidad de Salamanca (USAL), entre otras instituciones y organismos internacionales.

Una meta interesante de esta tesis es promover la inclusión de la Antropología Médica en la malla curricular de programas de postgrado relacionados con estudios de Medicina, Comunicación de la Ciencia y Antropología.

\section{H. Breve descripción del contenido de la Tesis}

\footnotetext{
${ }^{6}$ La autora de esta tesis, María de los Ángeles Erazo, participó en el diseño y coordinación nacional de este programa de Postgrado durante el año 2006. Desde enero hasta agosto de 2007 dirigió la ejecución del programa de "Diplomado en Comunicación Pública de la Ciencia" a nivel nacional.
} 
En el primer capítulo de esta Tesis destaca un marco teórico y conceptual, con el fin de comprender los antecedentes y el alcance de los estudios de Comunicación Pública de la Ciencia y Tecnología (СРCT) en países de Iberoamérica. También se ofrece un análisis sobre la importancia y repercusión de los Estudios de Ciencia, Tecnología y Sociedad, para el desarrollo de investigaciones sobre СРСТ.

En el segundo capítulo se exponen las principales generalidades de la divulgación de la ciencia, luego de analizarla como un fenómeno comunicacional. Se explica su definición, sus características, objetivos, funciones y el perfil del divulgador.

El tercer capítulo aborda los más frecuentes problemas de la СРСТ, que surgen por el acelerado avance de la ciencia, por la especialidad de su lenguaje y por la falta de cultura científica.

El cuarto capítulo presenta alternativas para una mejor СРСТ, tales como: 1) la apertura de espacios de educación no formal, que promuevan la actualización y aprendizaje de temas científicos y tecnológicos; 2) la divulgación de la ciencia a través del cine y la literatura; 3) la adecuada aplicación del modelo de propaganda científica y del modelo de comunicación democrático; 4) análisis del imaginario audiovisual de la ciencia y tecnología, desde un enfoque sociocultural.

El quinto capítulo ofrece un análisis contextualizado sobre el tema general y el problema específico que justifican la elaboración de esta Tesis. Se exponen las razones por las que conviene evaluar la Política Nacional de Ciencia, Tecnología e Innovación (PNCTI), así como las principales características de esta Política en Ecuador. También se analiza el aporte de la Comunicación Pública de la Ciencia y la Tecnología (СPCT) en la formulación y el desarrollo de la PNCTI, a más de proponerse el diseño, desarrollo y ejecución de un 
Programa Nacional de CPCT; el cual atribuye compromisos a los siguientes sectores: educativo, científico y comunicativo.

El sexto capítulo gira en torno a la investigación empírica que desarrolló la autora de esta tesis en el centro de salud Jambi Huasi. Este centro está ubicado en la ciudad de Otavalo, ubicada en la provincia de Imbabura, al norte del Ecuador. En esta investigación se analizó la relación de conocimientos y prácticas que caracterizan a la biomedicina (también llamada "medicina occidental" o "medicina convencional) y al conocimiento local (que, en esta investigación, es la medicina tradicional indígena). La mencionada investigación fue aplicada del 21 de mayo al 8 de julio de 2008, en el centro de salud Jambi Huasi (término Kichwa que significa "Casa de la Salud").

La información proveniente de esta investigación empírica devela algunas dificultades para llevar a la práctica una relación de igualdad, respeto y cooperación entre los conocimientos y prácticas de la biomedicina y la medicina tradicional indígena.

Esta investigación es relevante para la sustentación de esta tesis, porque ofrece elementos que permiten identificar algunas dificultades en el proceso de ejecución y consolidación del "Sistema Nacional de Ciencia, Tecnología, Innovación y Saberes Ancestrales" del Ecuador, el cual fue aprobado en septiembre de 2008.

Por tanto, el desarrollo del sexto capítulo también guarda coherencia con el título general de esta tesis, que es: "La comunicación pública de la ciencia en el centro de la política científica”. Porque, a partir de esta investigación, se concluye que la falta de comunicación, o problemas de incomunicación, impiden que haya buenas relaciones entre los profesionales biomédicos, los representantes de la medicina tradicional indígena y los pacientes del centro de salud Jambi Huasi. 
Para el desarrollo de la investigación empírica, que se detalla en el sexto capítulo, se propuso cumplir los siguientes objetivos:

\section{Objetivo general:}

1. Analizar la relación de los conocimientos y prácticas provenientes de la biomedicina y de la medicina tradicional indígena, en el centro de salud Jambi Huasi de Otavalo, a partir de estudios de Antropología Médica y de Comunicación Pública de la Ciencia.

\section{Objetivos específicos:}

\section{Analizar:}

2. Cómo la biomedicina y la medicina tradicional indígena están relacionadas en los servicios de salud que oferta el centro de salud Jambi Huasi, de Otavalo.

3. Si la distinción entre conocimientos y prácticas de la biomedicina y la medicina tradicional indígena ha desaparecido, o carece de relevancia en Jambi Huasi, o si la relación entre esas dos formas de conocimiento refleja conflicto en este centro de salud.

4. El rol de la comunicación en la relación de conocimientos y prácticas que caracterizan a la biomedicina y a la medicina tradicional indígena, en la experiencia del centro de salud Jambi Huasi.

De los capítulos descritos anteriormente, derivan las conclusiones que se presentan en la parte final de esta Tesis. 


\section{CAPÍTULO 1}

\section{CONTEXTO DE LA INVESTIGACIÓN}

La comunicación de la ciencia es un puente que une a ésta con el resto del universo cultural y social.

Constituye una parte del quehacer científico y refleja la voluntad de hacer una ciencia vinculada a la sociedad; pero todavía hay científicos, políticos y funcionarios que no entienden este papel decisivo tanto de los investigadores como de los periodistas y escritores.

(Manuel Calvo Hernando)

\subsection{Estudios de Comunicación Pública de la Ciencia y Tecnología}


La Comunicación Pública de la Ciencia y la Tecnología (CPCT) es una práctica sociocultural que se inscribe dentro de una sociedad determinada, con orientaciones político-culturales definidas y con un manejo discursivo adecuado para públicos específicos. Comprende actividades de ampliación y actualización del conocimiento científico, que pueden realizarse desde la educación no formal, a través de los medios de comunicación y en espacios abiertos para el diálogo (Erazo, 2007: 23).

Al momento, pocos son los estudios que se refieren a СРCТ y, menos, los que incluyen en su análisis todos los componentes del proceso comunicativo (Jacobi et als., 1988). Hay más escrito desde la experiencia práctica que a partir de teorías, modelos o estrategias útiles para comunicar públicamente la ciencia.

Cada día es más necesario tender un puente entre la investigación científica y la población. Es indispensable que la ciencia se vuelva parte de la cultura y que la gente sienta que puede entenderla aunque no se dedique a ella. Para establecer este puente se requiere reflexionar seriamente sobre el proceso de comunicación de la ciencia (Trigueros, 1991).

La anterior opinión explica una de las principales razones para abordar la divulgación de la ciencia como fenómeno comunicacional; hecho que han intentado plasmar varios autores, desde diversos enfoques.

Los franceses Daniel Jacobi y Bernard Schiele consideran tres enfoques en su estudio sobre comunicación pública de la ciencia: el sociológico, el sociolingüístico y el del protagonista de la divulgación (al cual denominan paradigma del tercer hombre) (Jacobi, 1985: 847).

Jacobi es más conocido que Schiele por sus estudios referentes al empleo de imágenes. En su artículo intitulado "References iconiques et modeles analogiques dans des discours de vulgarisation scientifique", Jacobi advierte que los signos icónicos empleados en la 
divulgación de la ciencia pertenecen a diferentes categorías: al lenguaje simbólico, a la semiología gráfica y a procesos de visualización. Por tanto, concluye que las imágenes cumplen múltiples funciones, a más de agregar comprensión al texto de divulgación científica (Jacobi, 1985: 847-867).

Otro enfoque lo ofrece Pierre Piganiol, sobre la base del volumen de conocimientos que se generan y que se incrementan anualmente. A su problema de estudio lo denomina gestión de los conocimientos y lo indaga desde: 1) la dinámica de la ciencia y sus consecuencias; 2) la documentación; 3) la enseñanza; 4) las empresas; 5) la acción política; 6) los métodos y sus límites; 7) la enajenación y la participación.

La gestión de conocimientos aparece como una nueva función de la sociedad, función que se desea ver con claridad, transparente y no oculta. [...] El volumen de los conocimientos constituye la base de la mayoría de las dificultades de la civilización moderna, paradójicamente es también la base de sus éxitos (Piganiol, 1974).

Piganiol dice que la enseñanza debería adaptarse al incremento de conocimientos, pero sin que ello implique una segregación entre estudios científicos y literarios. Argumenta que una forma de lograrlo es aplicando un programa que contemple elementos de los medios de comunicación, de la lógica, de las ciencias, de las realidades de la vida en sociedad, de nuestra historia y de la geografía del globo; sin olvidar lo que forma la sensibilidad, el cuerpo y el carácter. "Para alcanzar esta meta, es indispensable reformar las actitudes de la enseñanza, totalmente", expone en el artículo titulado "La gestión de los conocimientos".

Ve con beneplácito que la mayoría de los gobiernos se hayan preocupado por establecer una "política científica" en sus países; no obstante, cuestiona que en ésta se hayan discriminado las tareas de documentación y de divulgación. 
Es necesario que los estudios que han de ser utilizados por los gobiernos sean conocidos por los 'elegidos', pero también por los electores —aclara Piganiol—. El problema de la democracia moderna es probablemente el del acceso a los estudios previos a las decisiones; el aumento del volumen de los conocimientos suscita la aparición de un nuevo derecho: el de conocer cómo son tratados y resueltos (Piganiol, 1974: 331-354).

Para enfrentar el creciente volumen de información y su adaptación a los diversos contextos, Piganiol sugiere como modelo el árbol de pertinencia, que comprende: meta fijada, misiones para alcanzarla, medios globales para poner en marcha las operaciones, componentes de esos medios y materias primas. Advierte que no es suficiente saber trazar ese árbol, pues cree indispensable situar cada estamento en una escala de valores y entender que sus elementos forman una red, no un simple árbol, porque son elementos que interactúan entre sí. Por tal motivo, prefiere usar la noción de sistema.

\subsubsection{Estudios de periodismo científico}

Uno de los principales analistas del periodismo científico es Manuel Calvo Hernando, quien fundó la Asociación Española y la Asociación Iberoamericana de Periodismo Científico; actualmente es presidente de Honor de la primera y secretario General de la segunda. En sus escritos explica los problemas que impiden a la ciencia ganar espacio en los medios de comunicación; analiza las dificultades con el lenguaje y las fuentes científicas, y expone algunas sugerencias para informarse e informar mejor sobre la ciencia.

Calvo Hernando afirma que los problemas en Comunicación Pública de la Ciencia y la Tecnología (СРCT) provienen de la extensión y complejidad de la ciencia, del auge informativo, de los vertiginosos progresos científicos, de seudociencias, de la falta de cultura científica y del reto de precisión e inmediatez que exigen los medios de comunicación. Estos y más problemas son descritos en el tercer capítulo. 
Un valioso aporte de Calvo Hernando constituye la tesis doctoral que defendió, en la Universidad de San Pablo / Centro de Estudios Universitarios, de Madrid, España. Ésta lleva por título: La ciencia como material informativo. Relaciones entre el conocimiento y la comunicación, en beneficio del individuo y de la sociedad. Esta tesis, que defendió a sus 76 años, refleja su perseverancia y empeño por aprender todo el tiempo y por enseñar a partir del ejemplo.

En esta tesis se analizan los problemas que surgen al divulgar disciplinas básicas de la cultura y de la ciencia; las relaciones entre el conocimiento y la comunicación; el proyecto histórico, político y estratégico de la СРCT, y varias consideraciones sobre lo que el autor llama grandes movimientos de nuestra época: la acción cultural científica, el periodismo científico y la divulgación del conocimiento al público. También aborda las prácticas de la comunicación científica pública en la era de la información y el discurso de la divulgación en América Latina.

Para brindar bases que permitan elaborar una teoría de la comunicación pública del conocimiento, Manuel Calvo Hernando analiza los objetivos y los tipos de divulgación científica, a partir del desfase registrado entre comunidad científica y sociedad; y compara el discurso literario con los que provienen de la ciencia y del habla cotidiana.

Calvo Hernando dice que sus tres amores son: la familia, el periodismo científico e Iberoamérica (CSIC, 2007: 63). Fue invitado especial del "I Encuentro Iberoamericano: El Periodismo Científico en el Siglo XxI”, que se efectuó en Quito, del 28 al 30 de octubre de 1999, con auspicio del Centro Internacional de Estudios Superiores de Comunicación para América Latina (CIESPAL), la Red de Universidades de Latinoamérica (UREL), la Fundación FIDAL y la Fundación para la Ciencia y la Tecnología (FUNDACYT). En este encuentro 
presentó oficialmente su libro El nuevo periodismo de la ciencia que, en su introducción, anuncia:

[...]el progreso científico y la explosión comunicativa trastornan y modifican conceptos y prácticas de estas dos fuerzas gigantescas de nuestro tiempo - el conocimiento y la información - y obligan a los profesionales de la ciencia y del periodismo a la reflexión rigurosa e integradora (Calvo, 1999).

El director de la tesis doctoral de Calvo Hernando fue Pierre Fayard, otro gran analista del periodismo científico y de la comunicación científica pública. Estas son algunas de las obras en las que Fayard analiza y destaca el aporte de estas actividades: La communication scientifique publique (1988), La culture scientifique (1990), Sciences aux quotidiens (1993), y Fusion chaude (1995), La Comunicación Pública de la Ciencia: hacia la sociedad del conocimiento (2004).

En una ponencia titulada "Periodismo científico europeo", Fayard destaca el fenómeno de movilización social que suele ocasionar el avance vertiginoso de la ciencia y de la tecnología en las estructuras sociales, económicas o culturales —estructuras a las que él llama tradicionales - A este fenómeno de movilización social denomina Comunicación Científica Pública (CCP) y lo identifica en el conjunto de las industrias culturales, dentro del movimiento generalizado de profesionalización y rentabilización de las actividades comunicativas.

La CCP es un concepto que aparece por las perturbaciones que provocan las innovaciones científicas y tecnológicas en la vida, en el trabajo o en el pensamiento. Abarca las actividades de comunicación que tienen contenidos científicos divulgadores y que están destinadas al público no especialista. Utiliza técnicas de la publicidad, el espectáculo, las 
relaciones públicas, la divulgación tradicional y el periodismo, entre otras. Pero excluye de su campo de estudio la comunicación entre especialistas y la enseñanza especializada de las ciencias. En este contexto, la divulgación aparece como un medio para cautivar al público, porque celebra la grandeza de la ciencia y de sus posibilidades, ya que provoca sueños y admiración a quien la escucha.

En varios de sus escritos, Fayard recomienda a las ciencias de la comunicación y de la información que incluyan a la investigación de la Comunicación Científica Pública en su área de estudio (Fayard, 1990, 2004).

Javier Fernández del Moral y Francisco Esteve Ramírez (1993) también se refieren al periodismo científico en Fundamentos de la información periodística especializada [referencia]. En esta obra cuestionan la falta de un enfoque global respecto de los niveles en que debe realizarse la transmisión social del conocimiento científico.

Ante este problema, ellos sugieren la aplicación de instrumentos metodológicos, como la Teoría General de Sistemas, para abordar la información especializada e identificar sus interacciones con el sistema científico en su conjunto, con los distintos niveles de la comunicación científica, y con los niveles de cultura de varios grupos sociales. Confían en la Teoría General de Sistemas, porque con ésta han logrado identificar correspondientes isomórficas (que tienen la misma forma) entre varias disciplinas científicas y, consecuentemente, han podido intercambiar experiencias y resultados sin que se oponga la diferencia de contenidos ni la naturaleza de sus componentes.

De acuerdo con estos supuestos, Javier Fernández del Moral y Francisco Esteve Ramírez creen posible la formación de una teoría o modelo multidisciplinario (Fernández del Moral y Esteve Ramírez, 1993: 63). 
Ignacio Fernández Bayo, colaborador de distintas publicaciones y responsable de las páginas de ciencia del extinto semanario El Globo, opina que el periodismo científico español está repleto de problemas, de obstáculos, de incomprensiones, de celos y de desinformación. Por tanto, considera necesario clarificar qué se entiende por periodismo científico, por qué es importante, y por qué no se lo debe seguir considerando la cenicienta de los medios de comunicación (Fernández Bayo, 1988: 57).

Formar, informar y entretener son tres funciones que suelen atribuirse al periodismo. Fernández Bayo cree que las revistas científicas de España logran cumplir con el primer objetivo; no obstante, cuestiona la ausencia de información cotidiana, permanente y completa, al equipararla con el despliegue que los medios ofrecen al mínimo suceso político, deportivo o económico.

Como ejemplo de la falta de actualidad y de regularidad en la cobertura diaria de temas científicos o tecnológicos, refiere el caso de los premios Nóbel en física, en química, en biología, y en medicina y fisiología. Porque, luego de la noticia que informa el nombre y el tema de investigación de los ganadores, poco o nada se publica sobre los nuevos avances, las investigaciones y los desarrollos que surgen de esos trabajos, ni sobre la vigencia o eliminación de sus resultados. De ahí que Javier Fernández Bayo advierta:

Estamos muy lejos de situar cada tema en su justo lugar y de ofrecer al lector [...] la mayor información posible, fundamentalmente sobre todo lo que le pueda afectar más directamente, [...] porque la incorporación de las ciencias a los criterios de la cultura personal es una indiscutible necesidad individual (Fernández Bayo, 1988: 57 y 58).

Su opinión descarta al periodismo científico como único medio para incorporar las ciencias a los criterios de cultura de cada individuo; más bien, promueve el aumento de autodidactas en temas de ciencia y de tecnología y la apertura de nuevos espacios de 
Comunicación Pública de la Ciencia y la Tecnología (CPCT). Para no limitar su estudio al área de los medios de comunicación, la Universidad Nacional Autónoma de México (UNAM) y otras instituciones mexicanas prefieren usar el término divulgación de la ciencia, en lugar de periodismo científico. En España y en otros países europeos suelen hablar de comunicación pública de la ciencia.

\subsubsection{Diversidad de términos}

Son diferentes los términos que suelen emplearse, en varios países, para referirse a la СРСТ. Un autor que aporta al análisis del tema es Jack Meadows, porque aborda los problemas de conceptos, definiciones y las causas que plantearon la necesidad de hacer investigaciones históricas sobre СРCT.

En su criterio, el fenómeno de la transmisión social de conocimientos científicos surgió como una necesidad insatisfecha a finales del siglo XVII, cuando el surgimiento de la aproximación cuantitativa, matemática, del conocimiento del mundo físico rebasó a la mayoría de los lectores asiduos a estos temas (Meadows, 1986: 341-346).

Maurice Goldsmith estudia otro aspecto que se considera en el siguiente capítulo: el perfil del divulgador de la ciencia. Compara a este profesional con el crítico de arte y, por eso, lo llama crítico científico.

Su planteamiento es multidisciplinario, va más allá del concepto de divulgación, ya que sugiere al crítico científico que estudie no sólo cursos de ciencia general, sino también de historia y de filosofía de la ciencia y la tecnología; sobre la importancia y el significado de las artes, sobre las técnicas y la psicología de la comunicación (Goldsmith, 1999: 1 y 2).

Las funciones que le asigna el precitado autor a este profesional son: elaborar una imagen panorámica del sistema científico; ver el futuro a través de lo que se sabe del 
pasado; clasificar las similitudes en la experiencia científica; mantener la integridad de la ciencia, interpretarla y comunicarla de manera que "la gente entienda su poética y deje de temerla".

Uno de los principales problemas al momento de divulgar la ciencia es la especialidad del lenguaje científico. De ahí que uno de los ganadores del premio Kalinga de la UNESCO, el mexicano Luis Estrada Martínez, afirme que al plantearse la relación entre los lenguajes científico y común, lo que ordinariamente se busca es señalar la gran incomunicación que hay entre los científicos y el resto de la humanidad.

\footnotetext{
Las dificultades provienen no sólo porque el lenguaje científico es muy especializado, sino también de que el conocimiento está expresado en un contexto poco conocido. En la divulgación, la forma tradicional de superar estas dificultades consiste en el empleo de analogías, de metáforas y de otros recursos semejantes, lo cual no está exento del riesgo de deformar el mensaje (Estrada, 1992: 69-76).
}

En "El discurso de la divulgación de la ciencia” de Martha Tappan Velásquez y Aarón Alboukrek (1992) se ofrecen pautas metodológicas generales, pero fundamentales, para elaborar textos de divulgación científica. Tanto en la forma como en el fondo del texto, destacan el manejo de niveles de lengua.

El primer nivel que identifican es el conceptual, cuya influencia se manifiesta por la cantidad de conceptos-antecedentes y de elementos contextualizadores. Dicen que la contextualización se presenta en todos los niveles: en la introducción, en el planteamiento de los contextos temáticos e intrínsecos, en la narración y en el recurso de lo reconocible (Tappan et al., 1992: 273-278).

Otro nivel importante en el discurso de la divulgación es la reformulación, que implica replantear la terminología empleada en un texto científico, con la finalidad de lograr mayor 
comprensión en el público meta. Este replanteamiento supone el uso de sinónimos, definiciones, ejemplos, analogías y paráfrasis, según Tappan y Alboukrek.

Un tercer nivel es el estilo. Al igual que los dos anteriores, su influencia se refleja más en la forma que en el fondo del texto. En el discurso de divulgación, tiende a ser menos formal que en el discurso científico. Este factor remite a los precedentes y está determinado por el tipo de vocabulario, las construcciones sintácticas, las definiciones, los ejemplos y las analogías que se incluyan en el texto de divulgación (Tappan et al., 1992: 273-278).

\subsubsection{Educación y comunicación de la ciencia}

En su estudio titulado Educación científica y enseñanza de las ciencias (1985), Francisco López Rupérez señala que la educación científica es el ámbito propio de la interfase ciencia-sociedad. Supone que una educación científica que logre transmitir actitudes positivas frente a la ciencia - como tarea colectiva, frente a sus logros o frente a su historia-, contribuirá indirectamente a desarrollarla; porque generará mayor número de ciudadanos interesados por la ciencia y, consecuentemente, aumentará la oferta de espacios científicos en los medios de comunicación.

López Rupérez está convencido de que el incremento del nivel científico de un país, a mediano y largo plazo, dependerá de la actividad que se realice en la interfase cienciasociedad (López Rupérez, 1985: 915-916).

El efecto que atribuye López Rupérez a la educación científica podrá alcanzarse de manera más inmediata y eficaz por medio de la educación no formal, que comprende toda actividad organizada, sistemática y educativa que se realiza fuera del marco del sistema 
oficial, para facilitar determinadas clases de aprendizaje a subgrupos particulares de la población, tanto para adultos como para niños. ${ }^{7}$

Para analizar qué puede aportar realmente una adecuada educación científica y tecnológica, a la formación de una "cultura ciudadana”, Daniel Gil (2004) se refiere a las posibles contribuciones en los siguientes aspectos: 1) En la toma de decisiones acerca de los problemas a los que se enfrenta la humanidad. 2) En la formación de un espíritu crítico. 3) En el disfrute personal (Gil, 2004: 4).

La mayoría de estudios, de análisis y de reflexiones sobre la divulgación científica se concentra en la perspectiva del emisor — que es el paradigmático tercer hombre en los estudios de Daniel Jacobi y Bernard Schiele (1988), o el denominado crítico científico en la obra de Maurice Goldsmith (1999) — . Pocos autores analizan esta actividad desde la perspectiva del receptor.

Wendy Nelson Espeland y Elisabeth S. Clemens son parte de esa minoría, que se evidencia en el libro Buyin Blood and Selling Truth: Organizational Theory and Cultural Analysis. En esta obra investigan el contenido de los mensajes de popularización de la ciencia, a partir del enfoque de las organizaciones sociales y del contexto cultural. Para el efecto, consideraron una campaña de compra-venta de sangre que se realizó en Estados Unidos y que fue muy cuestionada por el público, porque puso en conflicto algunos de sus valores culturales (Espeland et al., 1988).

Sobre la base de este estudio, Espeland y Clemens describen los elementos que se ponen en juego entre la intencionalidad de un mensaje relacionado con algún tópico científico y la

\footnotetext{
${ }^{7}$ Argumento expuesto por la Subdirección de Educación No Formal, adscrita a la, Dirección General de Divulgación de la Ciencia de la UNAM (Extraído en enero de 2002 desde: http://www.dgdc.unam.mx/vincu.html)
} 
respuesta social de quienes reciben ese mensaje, cuando se llegan a afectar valores socialmente aceptados.

Estas autoras sostienen que los grupos sociales no son simples receptores pasivos de insumos culturales; sino que, a la vez, son continente y contenido de los valores culturales. Por eso recomiendan considerar, en los discursos institucionales, un contexto que especifique cómo las organizaciones captan, interpretan y se apropian de los elementos que conforman su entorno cultural y, en consecuencia, cómo ayudan a reproducir y a transformar su entorno.

\subsubsection{Divulgar la ciencia con creatividad}

La mexicana Ana María Sánchez Mora también destaca la perspectiva del receptor en su obra titulada La divulgación de la ciencia como literatura (Sánchez Mora, A.M., 1998). Para el efecto, aplica en divulgación científica la Teoría de la Recepción que Wolfgang Iser sugirió usar en análisis literarios.

Según Iser, "el texto solamente toma vida cuando es concretizado", es decir, que no pierde su carácter virtual, hasta que es leído. Su Teoría de la Recepción supone que el lector es el elemento que concreta el texto creado por el autor. "La convergencia de texto y lector dota a la obra literaria de existencia y [...] esta consideración es muy importante para la divulgación. En efecto, si la divulgación no toma en cuenta al receptor puede perder su sentido primordial: comunicar”, afirma Sánchez (Sánchez Mora, A.M., 1998: 150).

El mexicano Rolando Isita Tornell también expone una propuesta interesante en su tesis doctoral que titula Ciencia y Propaganda en España (1995). Una de sus premisas 
fundamentales es considerar a la ciencia como parte de la cultura; esta opinión la sustenta con estudios realizados por John Bernal, Ruy Pérez Tamayo y Amílcar Herrera.

Isita concibe la cultura como un sistema global, conformado por tres subsistemas: el ideológico, el científico y el social. En este contexto, dice que la ciencia es un sistema especial que tiene sus propios valores y tradiciones legitimadas por sus resultados; que su capital humano, en cambio, es producto de la sociedad en la que está inmersa la actividad científica, y que no hay manera de sustentar ninguna modernidad ni progreso económico si no existe en su base el desarrollo científico y su aplicación. Cree fundamental que el divulgador contemple en su trabajo la influencia de los tres subsistemas de la cultura. Le sugiere cuestionarse cuáles son los valores que priman en la población a la que destina sus mensajes, cuál es el imaginario colectivo y qué estrategias o políticas de Estado rigen en el ámbito científico.

Su investigación va más allá del análisis de conceptos relacionados con la divulgación científica o de estudios preliminares sobre el tema: propone un modelo de divulgación que denomina Propaganda científica, el cual se comenta en el cuarto capítulo de esta Tesis.

Este comunicador advierte que la propaganda científica no es buena ni mala, sino eficaz o ineficaz. Para que sea eficaz, debe elaborarse sobre la base de datos que contemplen las características del público destinatario.

Isita recuerda que la propaganda puede inducir deliberadamente conductas, valores, creencias, fobias o filias a favor o en contra de una idea, de una persona, de partidos políticos, de Estados y de naciones. Que su ámbito de operación es el ideológico y el social; que se dirige a los sentimientos y no a la razón, aunque nada excluye que se pueda usar la razón dirigida a los sentimientos. Que, para que sea verosímil y eficaz, debe tomar en consideración la historia, las tradiciones, los valores, los símbolos y las creencias de las 
personas a quienes va dirigida su acción y que, ésta, debe estar vinculada a programas de gobierno.

Aunque los medios de comunicación pueden ser responsables del entusiasmo colectivo, ya que son vías de escape de la realidad circundante y legitiman las emociones, no conviene circunscribir a estos la aplicación de una propaganda científica, sino aprovechar todos los ámbitos en donde tenga expresión la cultura, en cualquiera de sus manifestaciones. Así lo recomienda Rolando Isita. Dice que una meta de la propaganda científica es la superación de los miedos que surgen de la naturaleza, del Universo y del entorno social; pero, sin que ello implique suplir o imponer a la creencia el conocimiento científico. "Lo ideal es sustentarse en la creencia colectiva para ofrecer una explicación científica y que, aunque convivan ambas ideas, la gente sepa identificar sus diferencias y argumentar sus fundamentos". (Isita, 1995: 66).

Los enfoques bosquejados en este capítulo fundamentan de manera teórica la búsqueda de alternativas que permitan superar el primer enunciado del problema que motivó la elaboración de esta Tesis, es decir: ¿Cómo comunicar públicamente la ciencia y la tecnología sin perder rigurosidad, de manera que estos conocimientos logren ser apropiados por públicos amplios y cumplan con el objetivo de generar una visión más crítica sobre su desarrollo y aplicación, en Ecuador y en más países de Iberoamérica?

\subsection{Comunicación de la ciencia desde los Estudios CTS}

Los estudios sobre ciencia, tecnología y sociedad (más conocidos por el acrónimo CTS) se presentan como un análisis crítico e interdisciplinario de la ciencia y la tecnología en el 
contexto social, con el objetivo de entender los aspectos generales del fenómeno científicotecnológico $^{.8}$

Estos estudios surgieron a finales de la década de los años 60 y a inicios de los 70 del siglo XX, como una reacción académica contra la tradicional concepción esencialista y triunfalista de la CYT, que puede resumirse en una simple ecuación, en el llamado "modelo lineal de desarrollo": +ciencia = +tecnología $=$ +riqueza= +bienestar social (López Cerezo, 1998: 2).

Este modelo lineal presenta a la CYT como formas autónomas de la cultura, como actividades valorativamente neutrales, como una alianza heroica de conquista cognitiva y material de la naturaleza; tal concepción suele presentarse en diversos espacios del ámbito académico y de los medios de comunicación. En su fundamentación académica está la visión clásica del positivismo sobre la naturaleza de la ciencia y su cambio temporal, cuya formulación canónica procede del Positivismo Lógico (García et als., 2001: 120).

No obstante, Ciencia, Tecnología y Sociedad configuran una triada más compleja que una simple serie sucesiva y lineal. Los Estudios CTS analizan sus relaciones recíprocas con más detenimiento, desde un enfoque interdisciplinario que comprende una diversidad de orientaciones académicas, como la filosofía de la ciencia y la tecnología, la sociología del conocimiento científico o la historia de la ciencia y la tecnología; a más de promover ámbitos de reflexión y propuestas de cambio institucional, como la ética ingenieril o los estudios de evaluación de tecnologías.

Uno de sus aspectos innovadores es la caracterización social de los factores responsables del cambio científico. Estos estudios intentan comprender la dimensión social de la CYT,

\footnotetext{
${ }^{8}$ Este análisis está más detallado en libros referentes a Estudios CTS, muchos son auspiciados por la OEI.
} 
tanto desde el punto de vista de sus antecedentes sociales como de sus consecuencias sociales y ambientales; es decir, tanto por lo que atañe a los factores de la naturaleza social, política o económica que modulan el cambio científico-tecnológico, como por lo que concierne a las repercusiones éticas, ambientales o culturales de ese cambio (García et als., 2001: 125).

Desde este enfoque, se propone entender la CYT como un proceso o producto inherentemente social, donde los elementos no epistémicos o técnicos (por ejemplo: valores morales, convicciones religiosas, intereses profesionales, presiones económicas, etc.) desempeñan un papel decisivo en la génesis y consolidación de las ideas científicas y de los artefactos tecnológicos. Últimamente se incluye en sus análisis el tema de la innovación, por eso ahora también se le denomina: Estudios CTS+I.

Análisis propuestos desde los Estudios CTS han conectado los campos de estudio académico y el activismo social en los niveles de reflexión ética. En el campo de la investigación, promueven una nueva visión no esencialista y socialmente contextualizada de la actividad científica.

En el campo de la Política pública, han defendido la regulación social de la CYT; por eso promueven la creación de diversos mecanismos democráticos que faciliten la apertura de los procesos de toma de decisiones en cuestiones concernientes a políticas científicotecnológicas.

En el campo de la educación, esta nueva imagen de la CYT en sociedad ha cristalizado la aparición de programas y materias CTS en la enseñanza secundaria y universitaria de varios países, con apoyo de organismos intergubernamentales como la UNESCO o la Organización de Estados Iberoamericanos para la Educación, la Ciencia y la Cultura (OEI). 
Desde los estudios CTS se cuestionan la aplicación del modelo de déficit, lineal o "topdown" (cuando se considera al público como un grupo homogéneo, pasivo y víctima de un “déficit” cognitivo o cultural), en el ejercicio de la Comunicación Pública de la Ciencia y la Tecnología. Recomiendan emplear un modelo de comunicación más democrático y horizontal, valorando el aporte de estudios sobre percepción pública de la ciencia y la tecnología.

En Iberoamérica, los estudios CTS+I han sido más promovidos por la OEI. En Ecuador también se está impulsando este tipo de estudios a través del Programa Nacional de "Postgrado en Comunicación Pública de la Ciencia y Tecnología", del cual se ofrece información más detallada al final de esta tesis, en el Anexo 5.

Desde la perspectiva de los estudios CTS+I se espera que la innovación mejore la calidad de vida de los ciudadanos y que favorezca el crecimiento económico, promoviendo al mismo tiempo la sensibilidad e implicación ciudadana en ese proceso, junto con la comprensión pública de sus incertidumbres, desafíos, riesgos y beneficios.

\subsection{Análisis de la CPCT en el contexto del 'nuevo contrato social sobre la ciencia'}

La investigación que se detalla en el Capítulo 6 de esta tesis permite discutir los límites y posibilidades que tiene la Comunicación Pública de la Ciencia y la Tecnología (CPCT) en el contexto de países en vías de desarrollo, como es el caso del Ecuador, para contribuir a la generación e implementación de lo que se ha denominado el nuevo contrato social sobre la ciencia. 
Porque la idea de que la ciencia y la tecnología son medios que permiten satisfacer las necesidades de la población y fortalecer los valores sociales, y que por tanto deben ser sostenidas y apoyadas por la sociedad, se ha expresado como la base sobre la cual se establece el contrato social sobre la ciencia. Esta idea aparece con diferentes matices desde el siglo XVIII, e incluso desde el nacimiento de la ciencia moderna.

La necesidad de establecer un nuevo contrato social sobre la ciencia se vislumbra como una forma de volver a la idea inicial de que la ciencia y la tecnología pueden contribuir a la solución de problemas sociales. Pero, para lograrlo, es necesario un nuevo control social sobre la ciencia por parte de la sociedad que la valora y la financia. Por tanto, el planteamiento de este nuevo contrato se sitúa en el corazón de dos temas fundamentales para los países de América Latina: la pregunta sobre el desarrollo y la pregunta sobre la democracia y la participación ciudadana. (Lozano, 2008: 2,6, 7)

A partir de esta discusión, conviene considerar los cuatro retos que propuso la investigadora Mónica Lozano (2008:1) para la aplicación de la CPCT en países latinoamericanos. Estos cuatro retos son: (1) la necesidad de tener una mirada crítica a los problemas de exclusión social; (2) su participación en la definición de los problemas sociales y en la promoción de la participación pública en ciencia y tecnología; (3) la inclusión de una perspectiva desde las políticas públicas en ciencia y tecnología, y (4) la necesidad de una redefinición conceptual de la comunicación de la ciencia.

Durante las dos últimas décadas, la CPCT ha transitado en el ámbito internacional de posturas que privilegian la transmisión unidireccional de conocimientos científicos a un público que se asume desconocedor de la ciencia, a posturas que privilegian procesos participativos y de doble vía, en la relación entre ciencia y sociedad, y en donde más que transmitir contenidos científicos se intenta promover un diálogo entre científicos y la 
sociedad (Lozano, 2008: 9). Es decir, que la tendencia ha sido pasar del denominado modelo de déficit en la comunicación (cuyo énfasis es por tres aspectos: contenido, medio y público), a la propuesta de un modelo democrático y sociocultural en la comunicación (que fomenta la participación pública en la definición de políticas y toma de decisiones en política científica y tecnológica $\mathrm{y}$, particularmente, en la evaluación participativa de tecnologías).

A continuación se presentan las diferencias fundamentales entre estos dos modelos de comunicación:

\begin{tabular}{|l|l|}
\hline \multicolumn{1}{|c|}{ MODELO DE DÉFICIT } & \multicolumn{1}{|c|}{ MODELO DEMOCRÁTICO } \\
\hline $\begin{array}{l}\text { Privilegia los científicos y enfatiza una línea } \\
\text { de comunicación a una vía, desde los } \\
\text { expertos hacia el público lego. }\end{array}$ & $\begin{array}{l}\text { Busca establecer una relación de igualdad } \\
\text { entre científicos y no científicos, y enfatiza } \\
\text { el diálogo entre expertos y público lego, } \\
\text { como condición previa para la satisfactoria } \\
\text { resolución de los desacuerdos. }\end{array}$ \\
\hline $\begin{array}{l}\text { Privilegia el científico sobre otras formas de } \\
\text { experticia. }\end{array}$ & $\begin{array}{l}\text { Reconoce la existencia de múltiples (y } \\
\text { ocasionalmente conflictivas) formas de } \\
\text { experticia y busca acomodarlas todas a } \\
\text { través de debates públicos abiertos y } \\
\text { constructivos. }\end{array}$ \\
\hline $\begin{array}{l}\text { Privilegia el conocimiento formal como la } \\
\text { llave de la relación entre ciencia y público. }\end{array}$ & $\begin{array}{l}\text { Considera un amplio rango de factores, } \\
\text { incluidos conocimiento, valores (intereses) } \\
\text { y relaciones de poder y confianza. }\end{array}$ \\
\hline
\end{tabular}

Fuente: Este cuadro analítico se elaboró a partir de la propuesta de Durant (1999), sobre modelos de comprensión pública de la ciencia, la ingeniería y la tecnología.

Para Durant (1999) el surgimiento del modelo democrático puede entenderse como respuesta a los cambios estructurales de la sociedad democrática a finales del siglo XX, dentro de un contexto de la globalización. (Lozano, 2008:10). 
Al analizar el nuevo contrato social y los retos que éste plantea a la CPCT, se identifica que el común denominador en la evolución de las políticas públicas en ciencia y tecnología, y de los modelos de comunicación, ha sido el desplazamiento hacia enfoques más participativos y democráticos, en los que se reconoce la existencia de una pluralidad de actores sociales con intereses, fines, valores y conocimientos distintos. Igualmente, las concepciones de la ciencia y la tecnología han transitado hacia modelos que las entienden como fenómenos sociales y culturales atravesados por estas pluralidades.

Como bien señala la investigadora Mónica Lozano, la discusión que está en la base de este proceso identifica a la comunicación como una actividad que no es neutra políticamente. En este contexto, aclara que los objetivos de la CPCT, la visión de ciencia y tecnología y la noción de público que se construye responden, por una parte, a las formas en que se desenvuelve la ciencia y la tecnología en contextos sociales y culturales específicos y, por otra, a los intereses y valores y las visiones de sociedad y desarrollo de quienes llevan a cabo esta actividad (Lozano, 2008:10).

Es desde este marco que Lozano sugiere pensar el papel de la comunicación en la construcción de un nuevo contrato social para la ciencia y la tecnología, y en su contribución al desarrollo social a través de éstas, en especial para el contexto de los países en desarrollo.

El primer reto que esta investigadora propone a la CPCT, en países latinoamericanos, es la necesidad de tener una mirada crítica a los problemas de exclusión social, reto que compartimos en la formulación y desarrollo de esta tesis. Porque, como bien señala Lozano, 
Si la respuesta a las preguntas fundamentales de la comunicación no toma en cuenta las condiciones puntuales del a población a la que se dirige en los países en desarrollo (indígenas, campesinos, grupos minoritarios, grupos urbano marginales, grupos rurales), se terminará haciendo programas que, en lugar de aportar a los problemas fundamentales, estén aportando y sin proponérselo, a mantener la distinción entre grupos excluidos y no excluidos. (Lozano, 2008: 12).

Por tanto, los objetivos, contenidos y estrategias de la CPCT no pueden formularse al margen de una discusión profunda de para qué se hacen y cuál es el objetivo que se persigue con sus estrategias. A más de ello, amerita una reflexión seria sobre cómo se estructura la actividad científica en el mundo, y particularmente en los países en desarrollo, y de cuál es el papel crítico que juegan los gestores de estos programas.

A partir de esta perspectiva, los proyectos y programas de comunicación de la ciencia deben dar respuesta a necesidades de los contextos en los que se desarrollan, a las formas de organización y de estructuración de la vida cotidiana, a los problemas reales y a la capacidad de respuesta de la comunidad. Por tal motivo, la investigación de un tema como el que se refiere en el Capítulo 6 de esta tesis resulta muy adecuada en el Ecuador y en más países de América Latina, porque está muy acorde con el contexto en el cual se desenvuelve la vida cotidiana de numerosas poblaciones indígenas en esa región. 


\section{CAPÍTULO 2}

\section{GENERALIDADES DE LA COMUNICACIÓN PÚBLICA DE LA CIENCIA}




\subsection{Definición}

Hay una gran variedad de términos relacionados con el hecho de transmitir socialmente los conocimientos científicos. De acuerdo con el país de procedencia o con el tipo de enfoque, se le llama vulgarización, popularización, divulgación científica, periodismo científico, comunicación científica pública, comunicación social de la ciencia o gestión de los conocimientos científicos (Isita, 1995). En México, se acostumbra analizar la difusión científica y la divulgación de la ciencia; en tanto que, en España, suele estudiarse el periodismo científico y la comunicación pública de la ciencia.

Difusión deriva del latín diffundere, que significa propagar o esparcir, y de fundere, que es derramar. Divulgar procede del latín divulgare y, a su vez, de vulgus: el vulgo. Así, en el ámbito científico, difundir es propagar o esparcir un conocimiento entre quienes integran una determinada comunidad científica, condición prima para —en el desarrollo de lo que Thomas Kuhn denominó revoluciones científicas (Kuhn, 1990)— extender tal conocimiento a los círculos más amplios de la población, donde se valida como producto social, mediante su divulgación. ${ }^{9}$ Por tanto, difundir es propagar el conocimiento científico entre especialistas, mientras que divulgar es presentar la ciencia al público en general. En Francia y en Estados Unidos usan popularizar, con la misma concepción que se atribuye al término divulgar.

Es claro que tanto la difusión como la divulgación son actividades de comunicación; aunque lo común es que los destinatarios se comporten de manera pasiva. Por lo tanto, cuando en la participación del conocimiento científico se busca el diálogo, esto es, el intercambio de saberes y de experiencias, se emplea el término comunicación (Estrada, 1992: 69-76).

\footnotetext{
${ }^{9}$ Esta opinión también la expuso Jorge Gastélum, al tratar sobre la actividad en los centros de ciencia (2000).
} 
Así lo expuso uno de los pioneros de la divulgación científica en México, Luis Estrada Martínez, quien dirigió la revista Naturaleza y fundó el Programa Experimental de Comunicación de la Ciencia de la UNAM, que luego se transformó en el Centro Universitario de Comunicación de la Ciencia, actual DGDC.

El periodismo es una actividad profesional que tiene por objeto la selección, el procesamiento y la transmisión periódica de informaciones de actualidad para un público masivo o para determinados sectores de ese público (Calvo, 1977, 1992, 1999). El periodismo científico es una especialización informativa que establece un puente entre productores del conocimiento científico y el público en general, a través de los medios de comunicación masiva (Calvo, 1988, 1992, 1999, 2001a, 2005; Fayard, 1990, 2004; Fernández Bayo, 1988).

Por Divulgación de la Ciencia se entiende la recreación del conocimiento científico, para hacerlo accesible al público general y fomentar una visión más crítica sobre la ciencia.

Comunicar es dialogar, es relacionar un hecho con la causa que lo produce y el efecto que genera. La Comunicación Científica Pública $(\mathrm{CCP})^{10}$ es el conjunto de actividades de comunicación que van desde las técnicas publicitarias hasta el espectáculo y las relaciones públicas, pasando por la divulgación tradicional, el periodismo, las exposiciones, los clubes de ciencia, la gestión de la opinión pública, entre otros.

\footnotetext{
${ }^{10} \mathrm{La}$ CCP es un concepto relacionado con el fenómeno de movilización social que provocan las innovaciones científicas y tecnológicas en la vida, en el trabajo o en el pensamiento.
} 
La CCP tiene contenidos científicos divulgados y destinados a un público no especialista. Está basada en los efectos sociales del progreso científico y se relacionada directamente con el periodismo científico. ${ }^{11}$

El término que se emplea en esta Tesis es Comunicación Pública de la Ciencia y la Tecnología (СРCT), porque éste permite involucrar no sólo a medios de comunicación (como supone el término "periodismo"), sino también a otros escenarios y actividades destinadas a la transmisión social e intercambio del conocimiento científico y tecnológico, entre diversos actores.

Comprende todo tipo de actividades de ampliación y de actualización del conocimiento científico, conforme a dos condiciones: que sean tareas hechas fuera de la enseñanza académica formal, y sin el objetivo de formar especialistas ni de perfeccionarlos en su propia especialidad. Estas condiciones las expuso F. Le Lionnais en el debate que la Asociación de Escritores Científicos de Francia (AESF) realizó el 26 de febrero de 1958.

La CPCT propicia el acercamiento de sujetos culturales a diversos aspectos de la práctica científica —que pueden ser históricos, sociológicos, de impacto cultural y político, epistemológicos o conceptuales-, con el fin de que estos aspectos promuevan la reflexión y la apropiación de conocimientos dentro de los marcos culturales de los destinatarios (Calvo, 1977). Asume el reto de propagar la ciencia en un lenguaje sencillo y comprensible hacia una amplia población, que incluye al público general o al mencionado hombre de la calle. ${ }^{12}$ Pero no ejerce una simple traducción del conocimiento científico, sino que lo recrea

\footnotetext{
11 Esta opinión también fue mencionada por la argentina Marisa Avogadro de Suárez, en su artículo “Comunicar la ciencia: un periodismo de proyección al 2000” (2000).

12 Término que utiliza Philippe Roqueplo en su libro que titula El reparto del saber (1983: 21).
} 
y lo contextualiza con creatividad, a partir de los conocimientos y de la propia imaginación del divulgador.

"Más que estudiarla [a la ciencia], la recrea o la reproduce, la parafrasea. La traduce en un sentido creativo (que es el único válido) de traducir. Es algo sobre el conocimiento científico en el sentido de paralelo a él. Es más un acto de mímesis creativa que de disección”, afirma de la divulgación científica Carlos López Beltrán, quien es historiador de la ciencia, divulgador y poeta mexicano (López Beltrán, 1983).

\subsection{Características}

La Comunicación Pública de la Ciencia y la Tecnología (СРСТ) puede realizarse desde la educación no formal; a través de los medios de comunicación, de la propaganda científica, del cine y la literatura, y en espacios abiertos para el intercambio de información científica y tecnológica.

Para esquematizar su estudio, el mexicano Eduardo Martínez elaboró “La pirámide de la popularización de la CYT”, en cuyos vértices inferiores contempló cuatro escenarios: 1) Centros y exhibiciones interactivos de CYT; 2) Programas multimedia de popularización de la CYT; 3) Medios de comunicación masiva, y 4) Educación formal: aprendizaje de las ciencias (Flores et al., 1997: 12).

El mexicano Francisco Serrano agregó un quinto vértice a la pirámide, para incluir en él las conferencias, pláticas, reuniones, encuentros, representaciones teatrales o de otro tipo y las exposiciones que permiten un acercamiento más directo entre los generadores del conocimiento científico y el público receptor (Serrano Figueroa, 2000: 16). Así quedó el esquema rediseñado por Serrano: 


\section{PIRÁMIDE DE LA COMUNICACIÓN PÚBLICA DE LA CIENCIA Y TECNOLOGÍA}

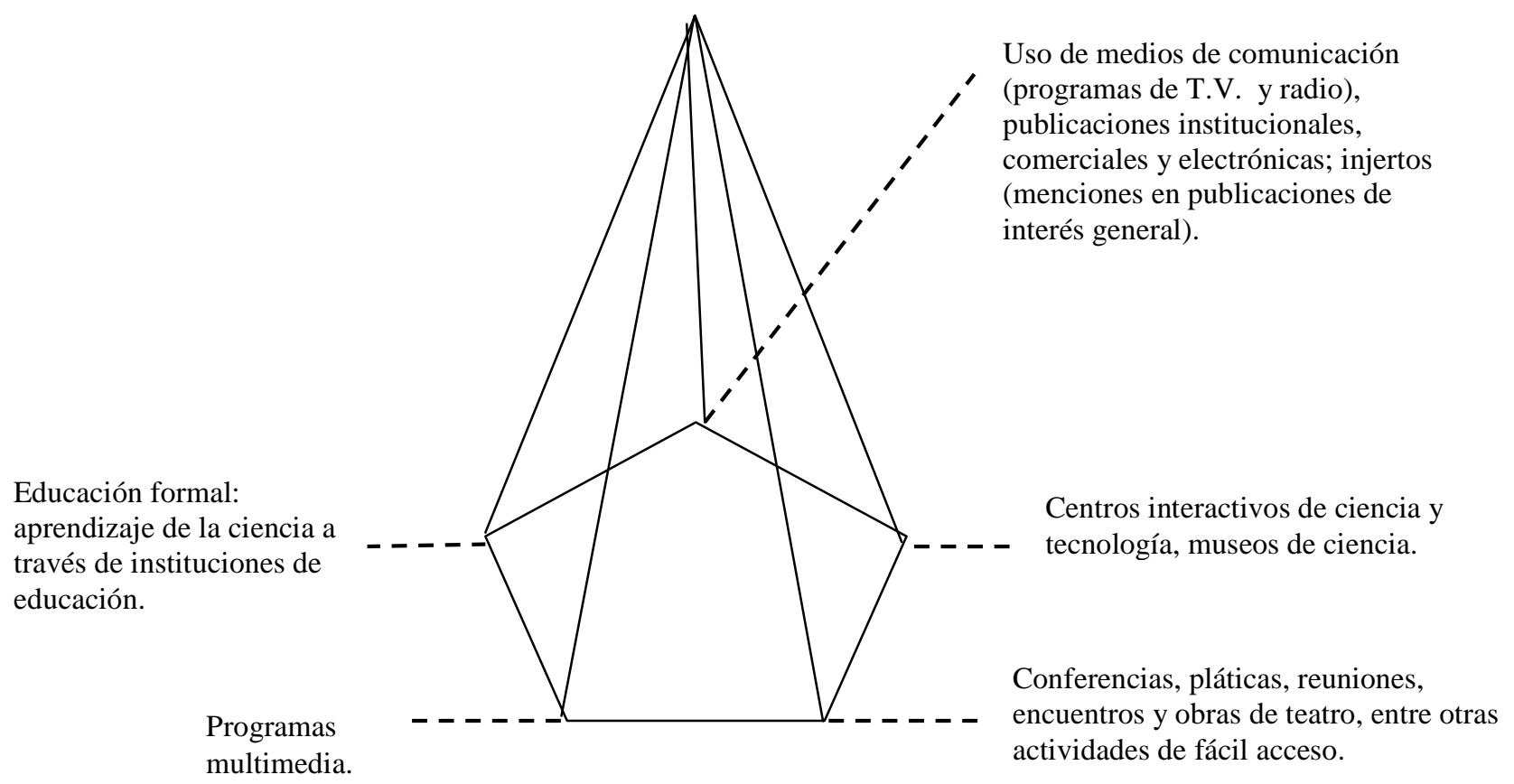

\subsection{Pirámide de la Comunicación Pública de la Ciencia y Tecnología}

La CPCT surge en el momento en que la comunicación de un hecho científico deja de estar reservada exclusivamente a los propios miembros de la comunidad investigadora o a las minorías que dominan el poder político, cultural o económico. ${ }^{13}$

Luis Estrada Martínez caracteriza la divulgación científica por incluir tres elementos: información clara y precisa sobre los resultados de la investigación científica; descripción de los métodos y de los procedimientos empleados por los científicos para obtener sus

\footnotetext{
${ }^{13}$ El español Manuel Calvo Hernando compartió esta opinión en la ponencia que intituló "Medios alternos y organizaciones para la divulgación de la ciencia” y que expuso en el Encuentro Nacional de Divulgación de la Ciencia, en México, el 22 de marzo del 2000: 7.
} 
resultados, y elementos necesarios para situar lo anterior en un contexto más amplio, de cultura general, preferentemente.

Por tanto, un buen artículo de divulgación no sólo debe referir los resultados de un proyecto científico, sino también el proceso seguido por esa investigación y los argumentos que permitan al público general comprender el cometido social de ese trabajo. La pregunta básica a la que debe responder es: ¿por qué los resultados de esta obra son tan importantes y por qué no se contestó antes a esta pregunta de la naturaleza? (Calvo, 1988).

Estas son algunas sugerencias que resultan fundamentales para escribir el artículo de divulgación científica: elaborar un guión, conocer al lector, identificar el canal por el que se divulgará, analizar la técnica que se empleará, estar actualizado, saber más de lo que se escribirá, seleccionar bien la información y ordenarla, usar datos confiables, interesar al lector, no rellenar, incluir novedades, usar frases y párrafos cortos, contextualizar y revisar bien el texto antes de publicarlo.

\subsection{Objetivos}

Los objetivos de la CPCT son múltiples; pueden ser clasificados de acuerdo con su carácter: intelectual, práctico o social. El decano del periodismo científico español, Manuel Calvo Hernando, presenta estos objetivos en el siguiente cuadro:

\begin{tabular}{|l|l|l|l|}
\hline \multicolumn{7}{|c|}{ Objetivos de la CPCT según su carácter } \\
\hline Intelectual & \multicolumn{1}{|c|}{ Práctico } & Social \\
\hline Proporcionar a la gente común la & Suministrar a los periodistas & Ayudar al individuo y a la \\
posibilidad de introducirse en el & o al divulgador información & sociedad a que entiendan los \\
conocimiento humano, de comprender & susceptible de ser entendida & riesgos del progreso científico y \\
el método científico, de buscar la & y utilizada, además de & las posibilidades de acabar con \\
verdad en la naturaleza, y de adquirir & ayudarles a comprender la & el hambre, la pobreza y la \\
\hline
\end{tabular}




\begin{tabular}{|l|l|l|}
\hline $\begin{array}{l}\text { instrumentos que le permitirán valorar } \\
\text { la belleza de las construcciones teóricas } \\
\text { de la ciencia moderna. }\end{array}$ & $\begin{array}{l}\text { importancia de los nuevos } \\
\text { descubrimientos científicos. }\end{array}$ & $\begin{array}{l}\text { enfermedad, es } \\
\text { concienciar sobre la importancia } \\
\text { de la ciencia. }\end{array}$ \\
\hline
\end{tabular}

Fuente: (Calvo, 1992: 29).

Calvo Hernando agrega dos objetivos que considera visibles y explícitos para la CPCT. El primero lo vincula al conocimiento: comunicar al público los avances de las grandes disciplinas de nuestro tiempo (astronomía, cosmología, origen de la vida, biología, conocimiento del Universo — micromundo y macromundo- y del propio ser humano); en otras palabras, ayudar a la gente a comprenderse a sí misma y a comprender su entorno, tanto el visible como el invisible.

El segundo objetivo lo concentra en la acción, tras el estudio de las consecuencias del progreso científico. Esta acción exigiría un plan que contemple las propuestas de centros de investigación, de universidades y de instituciones educativas en general, de museos de ciencia y, por supuesto, de periodistas, de escritores, de investigadores y de docentes.

La divulgación que se realiza a través de medios de comunicación se denomina periodismo científico. Sus objetivos son: poner a disposición del público los avances de la ciencia; dar a conocer las grandes corrientes del pensamiento científico moderno; informar sobre los descubrimientos; suscitar la curiosidad de la gente; reconciliar al humano con la ciencia y la técnica, así como hacerlas accesibles a la mayoría; advertir sobre las consecuencias sociales, económicas, políticas y ecológicas de los procesos de cambio derivados de la ciencia y la tecnología, movilizar a la opinión pública, y hasta reorganizar la economía del conocimiento (El Hadj et al., 1985).

Cabe diferenciar la transmisión informativa de temas científicos de su análisis crítico. Lo ideal es no sólo informar sobre conocimientos científicos, sino hacer que estos constituyan 
un componente fundamental en la cultura, en la conciencia social y en la inteligencia colectiva.

\subsection{Funciones}

La práctica de la CPCT tiene varias dimensiones, como bien lo reconoció la UNESCO en 1995.

Una de ellas es la política. La democracia requiere que todo ciudadano ilustrado pueda conocer el estado de los conocimientos y de los desconocimientos y, también, sus aspectos éticos. Pero tiene además una dimensión científica. Cuando aparecen constantemente nuevos campos de ignorancia, cuando la aplicación o no de un descubrimiento es cada vez más determinante para el futuro de la humanidad, es urgente y necesario abrir un diálogo entre las diferentes formas de saber y de preguntar. ${ }^{14}$

Una de las personas que escribió sobre la dimensión política de la divulgación fue Carl Sagan, el divulgador científico de mayor reconocimiento mundial en el siglo XX. "Cada vez que hacemos democracia, estamos también haciendo ciencia", afirmó en El mundo y sus demonios. En esta misma obra, expuso:

Los valores de la ciencia y los valores de la democracia son concordantes, en muchos casos indistinguibles. La ciencia y la democracia empezaron —en sus encarnaciones civilizadas—, en el mismo tiempo y lugar, en los siglos VII y VI a. C. en Grecia [...]. Lo que Jonia y la antigua Grecia proporcionaron no son tanto inventos, tecnología o ingeniería, como la idea de la interrogación sistemática, la idea de que las leyes de la naturaleza, y no unos dioses caprichosos, gobiernan al mundo (Sagan, 2001: 57, 343).

\footnotetext{
${ }^{14}$ Opinión expuesta en un documento oficial de la UNESCO, referente a las Reuniones Filosóficas que este organismo auspició en 1995.
} 
La función democrática de la divulgación ayudaría a evitar que el conocimiento científico genere un poder que esclavice a quienes carecen de él, como lo describió Michel Foucault en su libro Microfísica del poder. ${ }^{15}$

En relación con los científicos, la CPCT cumple una función que puede distinguirse por sus aspectos interno y externo. Hacia el interior, establece una comunicación especial entre ellos y, hacia el exterior, los relaciona con sus congéneres. Para el mexicano Luis Estrada Martínez son importantes ambas funciones, pero es de mayor urgencia la segunda en los países que están en vías de desarrollo.

\begin{abstract}
Con la divulgación de la ciencia podemos distribuir una riqueza cultural que, además de hacer justicia, llena una necesidad en estos tiempos. No seremos libres ni capaces de lograr una buena calidad de vida mientras permanezcamos al margen del conocimiento científico. Tampoco mejoraremos si el acercamiento a la ciencia es sólo de unos cuantos. He sostenido que la divulgación de la ciencia es una ayuda para distribuir el conocimiento científico, así como que esta actividad no es un remedio automático. Para lograr con ella tal ayuda es necesario realizarla en forma profunda y sistemática, pues en otro caso puede ser el disfraz de un peligro. Así como su versión genuina puede ayudar a la superación humana, la simulación de ella no será más que otro instrumento de enajenación, ya sea por entretenimiento o ya sea por manipulación (Estrada, 1992: 69-76).
\end{abstract}

Carlos López dice que la divulgación debe realizarse "entre dos fuegos": por un lado, debe extraer su sustancia, sus materiales, del cerrado ámbito científico, y por otro, debe alcanzar, interesar y, si es posible, hasta entusiasmar al público general con sus resultados. Concibe la divulgación como una forma especial de transmitir el conocimiento científico, que debe transformar la ciencia de la que parte. Aclara que los conceptos que se manejan en la divulgación no son los mismos, en un sentido estricto, que los de las ciencias. "No

\footnotetext{
${ }^{15}$ En esta obra, Michel Foucault afirmó que quienes concentran el conocimiento suelen ejercer poder sobre quienes lo ignoran. Su análisis lo hizo desde tres distintas circunstancias: el encierro, la locura y la sexualidad.
} 
pueden ser los mismos. Pero esto no es trágico. Al contrario, en eso consiste la autonomía de la divulgación" (López Beltrán, 1983).

Otro importante análisis sobre la función de la divulgación científica lo ofrece el mexicano René Anaya, al responder a la pregunta ¿para qué divulgar?:

\begin{abstract}
Se ha planteado que la divulgación científica debe cumplir, entre otras funciones, la de hacer partícipes a todos de los avances de la ciencia; estimular la vocación científica de los estudiantes; crear un ambiente favorable para las inversiones en la investigación; hacer comprender que la actividad científica y tecnológica influye en la mejora de las condiciones de vida de la población, y desterrar creencias falsas sobre los científicos, a quienes se les considera alejados de las preocupaciones cotidianas del común de la gente. Se podrían enunciar otras funciones más, todas válidas, pero la principal de la divulgación científica, en un país como el nuestro, es contribuir a formar un pensamiento científico que logre desterrar supersticiones y charlatanerías, y fomente el análisis de los grandes problemas nacionales, con sentido crítico (Anaya, 1998).
\end{abstract}

Pero la conformación de ese pensamiento científico no está reñida del todo con el pensamiento mágico que manifestamos en nuestra vida diaria, en la creación artística y hasta en el quehacer científico. "El reto actual es lograr la cohabitación de estos pensamientos, sin caer en el ultrarracionalismo ni en el misticismo paralizante", opina René Anaya.

\title{
2.6. Perfil del divulgador
}

¿Quién debe divulgar la ciencia? Ni en el mundo de la comunicación, ni en la comunicación científica, ni en la estructura educativa hay unanimidad sobre quiénes deben ejercer esta tarea. El periodista científico Manuel Calvo Hernando afirma que todos somos responsables: comunicadores, científicos, ingenieros, educadores, profesionales y todo 
aquel que sienta la necesidad y la vocación de promover la participación del público en el conocimiento científico (Calvo, 1999, 2001a, 2001b, 2005).

Ignacio Fernández Bayo cree que la solución es la simbiosis entre científicos y periodistas. (Fernández Bayo, 1988: 57-58). Compartimos ambos criterios, porque actualmente es imposible dominar todo el mundo de la ciencia. Por tanto, no es requisito imprescindible ser científico para ser divulgador de la ciencia, sino tener curiosidad e interés y, a la hora de divulgar, contrastar los datos con fuentes informativas fiables y/o buscar información de referencia.

Así como la música requiere de intérpretes para ser apreciada, la ciencia requiere de profesionales que interpreten ante el público las obras científicas. Hay excelentes divulgadores de la ciencia, aficionados o autodidactas, pero son muy pocos y no tienen una profesión específica. Ante la complejidad creciente del progreso científico y de la propia vida cotidiana, es necesario que cada profesional tenga algo de divulgador.

El mensaje es sencillo. Estamos científicos y legos (público general) en situación análoga. Eliminando matices, todos somos ignorantes. Necesitamos de muchos otros si aspiramos a construirnos siquiera un esbozo del mundo que nos tocó vivir. Ser experto y estudioso hoy día no da sino una buena imagen de un fragmento muy acotado de lo que (entre todos) sabemos. Nuestra condena es equivalente; la ignorancia individual se desboca conforme crece y se expande la red de preguntas, respuestas, dispositivos, dudas, imágenes, algoritmos. De ahí que la divulgación, el volcar lo que sabemos (y más aún lo que inquieta porque aún no se sabe) sobre el mercado común de la palabra compartida se haya vuelto tarea de sobrevivencia. No se trata nada más de repartir los bienes, de traer el evangelio científico a los legos y así contribuir a su libertad. Se trata más bien de crear las condiciones para que los espacios se vuelvan transitables, para que las aduanas se debiliten, para que recuperemos el libre tránsito. Que quienes viven aislados por sus murallas de expertez salgan a transitar entre los demás, y quienes se descubran acicateados por el deseo de participar, desde donde sea, en la conversación abigarrada que nuestra especie mantiene con su entorno, con su pasado, presente y futuro, lo pueden hacer (López Beltrán, 2001: 5). 
Quien opte por esta labor, debe expresarse con claridad y en un estilo que le resulte inteligible al receptor común; debe tener conciencia de que su objetivo básico es poner al alcance de la mayoría el patrimonio de la minoría. Para lograrlo, defenderá en sus escritos, en sus palabras y en sus imágenes, el derecho de todo ser humano a participar en la información y en el conocimiento, y a integrarse en la tercera cultura, que es humanística y tecnológica. ${ }^{16}$

Manuel Calvo Hernando concibe al divulgador como un profesional que sabe contar historias, que posee conocimiento científico y narrativo, y que reúne las siguientes cualidades:

1. Afán de comprensión.

2. Curiosidad universal, para satisfacerla personalmente y para suscitar, en sí mismo y en los demás, curiosidades y emociones nuevas.

3. Sed de conocimientos.

4. Capacidad de expresión.

5. Estado de duda, escepticismo y alerta permanente.

6. Amor al misterio.

7. Imaginación.

8. Preocupación por el rigor.

9. Capacidad de asombrarse y de maravillarse.

\footnotetext{
${ }^{16}$ Esta opinión la comparte Manuel Calvo Hernando en su artículo intitulado "Estilo para divulgadores científicos" (1998).
} 
10. Vocación pedagógica.

11. Gusto por comunicar.

12. Prudencia, en el sentido de respetar las zonas de incertidumbre y los límites de la validez de los conceptos, de evitar considerar como absoluto lo que no suele ser más que modelos transitorios.

13. Concentración en el trabajo.

14. Realismo.

15. Dotes de observación.

16. Perseverancia.

17. Interés por resultados prácticos.

El pionero del periodismo científico en Iberoamérica, Manuel Calvo Hernando, comparte con el mexicano Héctor Anaya cuando define al divulgador de la ciencia como un "narrador científico" y le atribuye la función de contar lo que otro ha hecho. "No sólo tiene que traducir o que recrear el proceso, también debe hacer de éste una creación verdadera" (Calvo, 1999).

Coherente con esta opinión, Calvo Hernando recuerda que uno de los objetivos del divulgador es descubrir las relaciones entre el quehacer científico y la vida cotidiana, entre el conocimiento nuevo y sus posibilidades en la vida de cada individuo o de cada grupo social. $^{17}$

${ }^{17}$ Este comentario de Manuel Calvo Hernando consta en la ponencia que presentó en el Encuentro Iberoamericano "El Periodismo Científico en el Siglo XxI", celebrado en Quito, Ecuador, del 28 al 30 de octubre de 1999. 
A este y a otros objetivos se refirió uno de los directores de esta Tesis Doctoral, Manuel Calvo Hernando, en el decálogo que escribió hace más de tres décadas y que, a pesar del tiempo, aún se mantiene vigente. A continuación se presenta la última versión de ese Decálogo.

\subsection{Decálogo del comunicador público de la ciencia y tecnología:}

1. Ante todo, tendrá conciencia de su altísima misión: poner al alcance de la mayoría el patrimonio científico de la minoría. Defenderá en sus escritos, sus palabras o sus imágenes el derecho de todo ser humano a participar en la sabiduría y a integrarse en la cultura y en la civilización, que les mantendrá unidos en un saber común.

2. El divulgador de la ciencia pondrá todo su esmero en difundir los descubrimientos y los hallazgos, situándolos en su propio marco, valorando su importancia para la humanidad, y estableciendo una posición de equilibrio entre lo que los descubrimientos tienen de sensacionales y su valor como fruto de una tarea permanente y colectiva.

3. En cuanto a la ciencia pura, subrayará el hecho de que sin ella no hay progreso ni ciencia aplicada, y expondrá la dignidad y la nobleza de este empuje de lo que hay de más sagrado en el hombre: la necesidad de saber y de orientarse. Sin olvidar nunca el doble aspecto de lo visible y lo invisible, lo inmanente y lo trascendente, en la relación del hombre con el mundo que le rodea y procurando, además, que su labor esté inspirada en la fe, en la unidad armoniosa de la vida humana.

4. Combatirá, con todos los medios a su alcance, la desconfianza de las personas hacia la ciencia, e insistirá en dos hechos evidentes: $1^{\circ}$ ) Los hombres de ciencia están obligados a ir siempre más arriba, más adelante y a profundizar en los secretos de la 
creación, y es la propia sociedad humana la que, después, hace mal uso, en ocasiones, de los descubrimientos científicos; y $2^{\circ}$ ) En el balance de las aportaciones de la ciencia al progreso y al desarrollo de la humanidad, es mínimo aquello que — incluso sin tener en cuenta el apartado anterior — podría considerarse como negativo.

5. Tratará de crear conciencia pública de la importancia de la investigación científica, de la necesidad de que participemos todos en esta nueva revolución universal, de la rentabilidad de la investigación científica y de la urgencia de una cooperación más eficaz por parte del estado, de los sectores productores y de los servicios, empresarios y financieros y, en suma, de la sociedad toda.

6. Insistirá, una y otra vez, en que la ciencia es cada día menos una aventura personal y, cada día más, una vasta empresa colectiva que necesita hombres, medios y un clima favorable.

7. Tratará de hacer ver al público el hecho de que, a pesar de lo que pueda parecer a los ojos del profano, la investigación científica no es algo misterioso, secreto ni terrorífico, sino una obra de sabiduría, de razón, de paciencia, de tenacidad y, sobre todo, de ilusión.

8. Denunciará la superchería de las falsas ciencias, que en muchas zonas de la humanidad siguen constituyendo obstáculos muy serios al desarrollo. Los curanderos están desacreditados, por lo menos en las sociedades occidentales; aunque los "shamanes" cobran día a día más importancia en varios países de América Latina. Pero hay que seguir combatiendo a sus equivalentes en otras ramas del conocimiento o de la actividad humana. 
9. Tratará a la ciencia con respeto; pero con familiaridad, poniendo el acento en la simpatía y en los aspectos humanos del científico. Frente a tanto temor y desconfianza parece necesario humanizar la ciencia al presentarla al público, y situarla entre nosotros de modo entrañable y cordial, sin restarle seriedad ni trascendencia.

10. $\mathrm{Y}$ todo esto, el divulgador lo presentará del modo más sugestivo posible, en su dimensión asombrosa y escalofriante, para llegar al mayor número de lectores, de oyentes o de espectadores, y utilizando la palabra, el sonido y la imagen de un modo periodístico; es decir, actual, interesante, directo y sencillo.

Otro decálogo, ${ }^{18}$ escrito por Miguel Ángel Garrido, ${ }^{19}$ resume claramente el panorama de СРCT que se describe en la presente investigación:

1. La información debe acudir de manera proporcionada a la creciente demanda social de conocimiento científico y técnico.

2. Junto a la adhesión al progreso, es preciso poner de relieve los riesgos que determinadas aplicaciones científicas pueden entrañar.

3. La demostración científica no tiene un valor absoluto, sino que ha de ser entendida, como cualquier otro discurso, dentro de un contexto y una situación.

4. Es preciso elaborar más y mejores elencos de vocabulario científico y técnico.

\footnotetext{
${ }^{18}$ Decálogo que incluyó Manuel Calvo Hernando en su artículo "Estrategias para comunicar el conocimiento (1)”. En: Autores científicos-técnicos y académicos, No 19, España, 2001.

${ }^{19}$ Profesor del Instituto de la Lengua Española del Consejo Superior de Investigaciones Científicas (CSIC), España.
} 
5. Hay que estimular a los científicos para que sean cada vez más los capaces de dominar tanto el lenguaje de la ciencia como el de la divulgación científica, que son discursos distintos.

6. Para el caso de aquellos científicos que no quieran o no sepan hacerlo, hay que propiciar la existencia de mediadores capaces de traducir de un discurso a otro.

7. El informador debe acercarse al campo de la ciencia como cualquier otro: con honradez, rigor y la máxima competencia posible. Para hablar sobre ciencia se posee el mismo instrumento que para hablar de cualquier otra cosa: la lengua común.

8. Se debe hacer propaganda de la ciencia: expande los límites del conocimiento humano y proporciona bienestar.

9. Hay que desmitificar la ciencia: no es una panacea para los problemas del ser humano, ni una religión. Como todo instrumento, se puede emplear.

10. Las ciencias y las humanidades forman parte de la cultura: no es aceptable una ciencia sin humanismo ni lo son unas humanidades al margen de la ciencia. 


\section{CAPÍTULO 3}

\section{PROBLEMAS DE LA COMUNICACIÓN PÚBLICA DE LA CIENCIA Y LA TECNOLOGÍA}

Hay tres colectivos que condicionan que la ciencia ocupe el espacio que le corresponde:

público, científicos y medios de comunicación.

(Ignacio Fernández Bayo) 
La Comunicación Pública de la Ciencia y la Tecnología (CPCT) afronta problemas que, generalmente, derivan de sus condiciones científica, informativa y divulgadora. Algunos surgen del temor generado por los repentinos avances científicos y tecnológicos, por el desconocimiento del lenguaje científico, por el insuficiente apoyo que se destina a la ciencia y a su comunicación, por las relaciones no tan gratas entre científicos y periodistas, por la escasa cultura científica que fomentan los planes de estudio, entre otros factores.

La clave para la superación de un problema es comprenderlo, en lugar de temerlo. Esta idea sustenta el desarrollo del presente capítulo, en donde se explica por qué la mayoría de problemas que afectan a la СРСТ provienen de la ciencia, la comunicación y la sociedad.

\section{La ciencia es como la Tierra: sólo}

puede poseerse una pequeña parte.

(Isaac Newton)

\subsection{Problemas de la ciencia}

El carácter evolutivo y el crecimiento acelerado de la ciencia ocasionan un gran problema a la СРCT, porque exigen la cobertura de un campo de estudio enorme, diverso y muy especializado. Por tal razón, Luis Estrada estima casi imposible saber lo que sucede en el mundo de la ciencia. Admite que hasta los científicos tienen problemas cuando intentan comprender especialidades distintas a la suya, y que es difícil comprobar si efectivamente es científica una aseveración que ostenta ese calificativo; ya que, para comprobarlo, "casi siempre es necesario establecer una cadena de aclaraciones cuyos eslabones se enlazan de manera deficiente y dan lugar a lo que de ordinario llamamos el teléfono descompuesto" (Estrada, 1992: 69-76). 
El problema surge porque el espectro de estudio que abarca la ciencia es demasiado amplio. Al declararse que su objetivo es la comprensión de la naturaleza, se advierte que la meta de la ciencia es explicar la realidad, someter todos los fenómenos que ocurren en ese vasto compartimiento de la naturaleza que incluye todo lo que existe "ahí afuera", todo lo que cabe dentro de nuestra capacidad de entendimiento, todo lo que es el mundo y lo que somos nosotros, a la racionalidad humana (Pérez Tamayo, 1998: 19).

El uso de la ciencia con carácter positivo o negativo depende de la información que se transmita y del análisis social que ésta genere. Para reflejar la repercusión positiva de la ciencia y tecnología en el mundo, la UNESCO citó los siguientes indicadores en su Primera Conferencia Mundial sobre la Ciencia: ${ }^{20}$

- Entre 1960 y 1994, el promedio de la esperanza de vida aumentó de 39.9 a 49.9 años. El porcentaje de la población que tiene acceso al agua potable se multiplicó por dos en los últimos 20 años; porque pasó de un 24 por ciento, en el sexenio 1975-1980, a un 42 por ciento, en el periodo 1990-1996. Todos estos promedios de crecimiento se refieren a los países menos desarrollados. (UNESCO, 1999).

- En los últimos 30 años, el desarrollo de la microinformática hizo posibles múltiples progresos espectaculares en el plano social y, en la actualidad, el potencial informático tiende a duplicarse cada 18 meses. Los teléfonos móviles y el abaratamiento de las computadoras logran que Internet penetre incluso en las zonas rurales de los países en desarrollo, con todas las implicaciones que esto conlleva en materia de aprendizaje a distancia y de democratización. Se puede considerar que los microprocesadores son la invención más revolucionaria de la segunda mitad del siglo

\footnotetext{
${ }^{20}$ Esta conferencia se celebró en Budapest, Hungría, del 26 de junio al 1 de julio de 1999.
} 
$\mathrm{XX}$, junto con la ingeniería genética y las biotecnologías. Estas invenciones abren paso a una serie de posibilidades que hacen que el vínculo entre ciencia y ética sea más estrecho que nunca.

- La mayor parte de conocimientos sobre diversos fenómenos naturales y sociales surgieron en el siglo XX, gracias a la profesionalización de la investigación científica y al apoyo económico que recibió esta actividad.

No todos los indicadores anteriores reflejan la experiencia de América Latina, debido a que la mayoría de países de esta región aportan débilmente al desarrollo de la CYT. Para su avance, la mayoría de países latinoamericanos invierten menos del 0.5 por ciento del Producto Interno Bruto (PIB) y, en ningún caso, más del 1 por ciento que recomienda la UNESCO. Apenas un 10 o un 15 por ciento de sus universidades tienen capacidad real y efectiva para realizar actividades de investigación científica.

A pesar de que esta región alberga al 8.4 por ciento de la población mundial, sólo contribuye con 3.6 por ciento al gasto total en investigación y desarrollo, y con un porcentaje similar a la producción científica global. ${ }^{21}$

Para superar estas limitaciones, el Comité Coordinador de Redes Científicas de América Latina (CCRCLA) promueve la realización de actividades que fortalezcan la colaboración regional en materia de ciencia y tecnología. Este comité lo integran: la Red Latinoamericana de Biología (RELAB), el Centro Latinoamericano de Física (CLAF), la Federación Latinoamericana de Sociedades de Física (FELASOFI), la Red Latinoamericana

\footnotetext{
${ }^{21}$ Estos datos constan en la Declaración que suscribieron miembros del CCRCLA (al término de la reunión celebrada en la Ciudad de México, del 2 al 4 de septiembre del 2001), y que la publicó el periódico Descubrir Latinoamericano, $\mathrm{N}^{\circ} 11$, México, noviembre del 2001.
} 
de Ciencias Químicas (RElACQ), la Red Latinoamericana de Ciencias de la Tierra

(RELACT), la Red Latinoamericana de Astronomía (RELAA) y la Unión Matemática de América Latina y el Caribe (UMALCA).

\subsubsection{Más de cien años de creatividad científica}

\begin{tabular}{|c|c|}
\hline 1900 & Max Planck descubre los cuantos de energía y formula su teoría cuántica. \\
\hline 1901 & $\begin{array}{l}\text { Guglielmo Marconi recibe en Newfoundland la primera señal telegráfica enviada desde Cornwall } \\
\text { (Gran Bretaña). }\end{array}$ \\
\hline 1903 & Los hermanos Wright logran efectuar un vuelo propulsado por motor. \\
\hline 1905 & Albert Einstein publica la teoría de la relatividad. \\
\hline 1909 & Paul Ehrlich encuentra el remedio para curar la sífilis. \\
\hline 1913 & Niels Bohr y Ernest Rutheford descubren la estructura del átomo. \\
\hline 1913 & Henry Ford inventa la cadena de montaje rápida para la producción masiva de automóviles. \\
\hline 1920 & Primera emisión de radio. \\
\hline Años 20 & $\begin{array}{l}\text { Primeros aparatos electrodomésticos (aspiradora, máquina de afeitar eléctrica, secadora centrífuga, } \\
\text { refrigerador, congelador de alimentos, radio). }\end{array}$ \\
\hline 1922 & Fredic Banting y Charles Best descubren la insulina. \\
\hline 1923 & Vladimir Zworykin inventa la cámara de televisión. \\
\hline 1924 & Edwin Hubble descubre la primera galaxia vecina de la nuestra. \\
\hline 1926 & John Logie Baird efectúa la primera emisión de televisión a través de ondas de radio. \\
\hline
\end{tabular}




\begin{tabular}{|c|c|}
\hline 1927 & Georges Lemaitre propone su teoría de la gran explosión para explicar el origen del Universo. \\
\hline 1928 & Alexander Fleming descubre la penicilina. \\
\hline 1929 & Edwin Hubble propone su teoría del Universo en expansión. \\
\hline 1930 & La British Broadcasting Corporation (BBC) inicia sus emisiones de televisión. \\
\hline 1931 & $\begin{array}{l}\text { Ernest Lawrence inventa el ciclotrón para estudiar el comportamiento de las partículas atómicas } \\
\text { aceleradas. }\end{array}$ \\
\hline 1932 & James Chadwick describe la composición del núcleo del átomo en protones y neutrones. \\
\hline 1935 & Invención del nailon y de los plásticos (fabricación de las primeras medias de nailon). \\
\hline 1942 & Enrico Fermi efectúa la demostración de la primera reacción nuclear controlada. \\
\hline 1945 & $\begin{array}{l}\text { Se hace estallar la primera bomba atómica en Nuevo México. Un mes después fueron lanzadas } \\
\text { bombas atómicas en las ciudades japonesas de Hiroshima y Nagasaki. }\end{array}$ \\
\hline 1945 & $\begin{array}{l}\text { Demostración de la primera computadora electrónica: el Analizador y el Ordenador Integrado } \\
\text { Numérico Electrónico (ENIAC). Utiliza tanta energía eléctrica que las luces casi se apagan. }\end{array}$ \\
\hline 1947 & Wiliam Shockley inventa el transistor. \\
\hline 1948 & Percy Julian sintetiza la cortisona. \\
\hline 1950 & Getrude Elion utiliza la quimioterapia para el tratamiento de la leucemia. \\
\hline 1952 & Jonas Salk produce una vacuna contra la poliomielitis. \\
\hline 1952 & $\begin{array}{l}\text { Henri Laborit descubre la cloropromazina y se sientan las bases de las terapéuticas químicas para } \\
\text { las enfermedades mentales. }\end{array}$ \\
\hline 1953 & James Watson y Francis Crick, con la contribución de Rosalind Franklin, descubren la doble \\
\hline
\end{tabular}




\begin{tabular}{|c|c|}
\hline & estructura helicoidal del ADN, el elemento de construcción de la vida. \\
\hline 1954 & Primer trasplante exitoso de un riñón. \\
\hline 1957 & La Unión Soviética lanza el satélite Sputnik. \\
\hline 1960 & Peter Medawar descubre el fundamento de la inmunosupresión. \\
\hline 1960 & Stephen Hawking publica su Gran Teoría Unificada del origen del Universo. \\
\hline Años 60 & $\begin{array}{l}\text { Descubrimiento de las enzimas de restricción (las "tijeras" utilizadas por la ingeniería genética } \\
\text { para unir los genes). }\end{array}$ \\
\hline 1961 & La Unión Soviética pone en órbita al primer astronauta en torno al planeta. \\
\hline 1964 & Murray Gell-Man pronostica la existencia de los quarks. \\
\hline 1967 & Christian Barnard lleva a cabo el primer trasplante de un corazón humano. \\
\hline 1967 & Jocelyn Bell identifica los púlsares (estrellas de neutrones). \\
\hline 1969 & Dorothy Hodgkin describe la estructura molecular de la insulina. \\
\hline 1969 & Los astronautas estadounidenses del Proyecto Apolo ponen el pie en la luna. \\
\hline Años 70 & Topografía informatizada (escáner CT) para examinar los tejidos blandos. \\
\hline Años 70 & Varias universidades norteamericanas se conectan mediante una red informatizada (ARPAnet). \\
\hline 1971 & Gilbert Hyatt e Intel producen el primer microprocesador comercial (ordenador o computadora). \\
\hline 1974 & $\begin{array}{l}\text { Bill Gates y Paul Allen conciben la programación del ordenador Altair y a continuación fundan } \\
\text { Microsoft, que en la actualidad es una de las empresas más rica del mundo. }\end{array}$ \\
\hline 1975 & Descubrimiento de las endorfinas (analgésicos naturales en el cerebro). \\
\hline 1975 & César Milstein y sus colaboradores crean los anticuerpos monoclónicos, las "balas m \\
\hline
\end{tabular}




\begin{tabular}{|c|c|}
\hline & pueden buscar antígenos específicos y, por consiguiente, organismos causantes de enfermedades. \\
\hline 1980 & $\begin{array}{l}\text { Tim Bernes-Lee, consultor del CERN, el laboratorio europeo de partículas físicas, concibe la } \\
\text { programación informática que conducirá a Internet. }\end{array}$ \\
\hline Años 80 & $\begin{array}{l}\text { Descubrimiento de los priones, agentes infecciosos de nuevo tipo, distintos de los virus. Uno de } \\
\text { ellos es el causante de la encefalopatía espongiforme bovina o "enfermedad de la vaca loca". }\end{array}$ \\
\hline 1983 & Luc Montagnier y Robert Gallo aíslan el VIH, virus causante del SIDA. \\
\hline 1989 & $\begin{array}{l}\text { Se crea un sistema normalizado y universal de tratamiento de datos que posibilita el nacimiento de } \\
\text { la Red de Redes Universal (www). }\end{array}$ \\
\hline 1990 & Lanzamiento del telescopio espacial Hubble. \\
\hline 1996 & Nace en Escocia la oveja "Dolly", producida mediante clonación de una sola célula mamaria. \\
\hline 1997 & $\begin{array}{l}\text { Los científicos predicen con exactitud el fenómeno climático El Niño en la zona tropical del } \\
\text { Pacífico, lo que permitió reducir considerablemente los efectos sociales y económicos de las } \\
\text { subsiguientes inundaciones y sequías en muchas partes del mundo. }\end{array}$ \\
\hline 1998 & $\begin{array}{l}\text { "El Universo acelera su expansión" fue galardonado como el descubrimiento más importante de } \\
\text { este año por Science, revista científica que publica la AAAS (siglas en inglés de la Asociación } \\
\text { Americana de Promoción de la Ciencia). }\end{array}$ \\
\hline 1999 & $\begin{array}{l}\text { La investigación en el campo de las células madre fue el principal avance científico de este año, } \\
\text { según la revista Science. En su edición del } 17 \text { de diciembre de } 1999 \text {, esta revista norteamericana } \\
\text { publicó la lista con lo más destacado del año, en la que no faltaron los progresos en genómica y la } \\
\text { consecución del mapa del ribosoma. }\end{array}$ \\
\hline 2000 & $\begin{array}{l}\text { El cáncer de pulmón es considerado uno de los problemas de salud más mortífero del mundo, pues } \\
\text { provoca más víctimas que los cánceres de mama, próstata y colon juntos. En el año } 2000 \text { se } \\
\text { diagnosticó cáncer de pulmón a más de 1'200.000 personas en todo el mundo, y más de un millón } \\
\text { murió ese año debido a esta enfermedad. El tipo de cáncer de pulmón más común es el no } \\
\text { microcítico, que representa el } 80 \text { por ciento de todos los casos. }\end{array}$ \\
\hline 2001 & Aumentan incidentes provocados por hackers: el gusano CodeRed es lanzado por la red Internet y \\
\hline
\end{tabular}




\begin{tabular}{|c|c|}
\hline & $\begin{array}{l}\text { se esparce rápidamente a direcciones electrónicas de todo el mundo; infecta cientos de miles de } \\
\text { computadoras en pocas horas. Microsoft presentó a Windows XP. }\end{array}$ \\
\hline 2002 & $\begin{array}{l}\text { La revista Science considera el hallazgo de la molécula que controla los genes como el } \\
\text { descubrimiento más importante de este año. }\end{array}$ \\
\hline 2003 & $\begin{array}{l}\text { El } 25 \text { de abril de } 2003 \text { se han cumplido } 50 \text { años del descubrimiento de la doble hélice de ADN por } \\
\text { Watson y Crick, publicado en Nature. Este ha sido considerado el descubrimiento más importante } \\
\text { de la Biología y de la Medicina en el s. XX y la revolución científica asociada al mismo persistirá } \\
\text { probablemente a lo largo de los s. XXI y XXII. }\end{array}$ \\
\hline 2004 & $\begin{array}{l}\text { La revista Science ha elegido como el avance científico más importante de este año los } \\
\text { descubrimientos de la misión en Marte del explorador de la NASA (MER), dirigida por un equipo de } \\
\text { investigación de la Universidad de Cornell. }\end{array}$ \\
\hline 2005 & $\begin{array}{l}\text { Muchos de los estudios que representaron grandes adelantos científicos en este año siguieron la } \\
\text { evolución al nivel de la genética. Estudios dedicados al seguimiento de la evolución en acción } \\
\text { fueron galardonados con el premio principal de “Adelanto de Investigación Científica más } \\
\text { Importante del Año", por la revista Science. La lista de los diez principales adelantos científicos } \\
\text { apareció en la edición del } 23 \text { de diciembre de } 2005 \text {, de Science. }\end{array}$ \\
\hline 2006 & $\begin{array}{l}\text { La vacuna contra el Virus del Papiloma Humano (VPH) ha sido considerado uno de los adelantos } \\
\text { científicos más importantes de los últimos } 50 \text { años. Estudios clínicos afirman que "GSK Cervarix" } \\
\text { es la primera vacuna que ha demostrado un } 90 \% \text { de efectividad al prevenir la infección de estos } \\
\text { dos peligrosos tipos de infección ( } 16 \text { y } 18 \text { ) de VPH, y las consecuentes lesiones precancerosas. }\end{array}$ \\
\hline
\end{tabular}

Fuente: Odisea del Espacio: 100 años de creatividad científica (http://www.pbs.org/wgbh/aso/thenandnow), más información publicada en las revistas Science \& Nature.

"Los valores de la ciencia y los valores de la democracia son concordantes, en muchos casos indistinguibles" (Sagan, 2001: 57). Carl Sagan pretendió resumir su idea de que la racionalidad, la búsqueda de las evidencias y la discusión de ideas, interpretaciones y conclusiones — por sobre las creencias, las opiniones o los prejuicios—, no sólo son la base de la ciencia, sino también de la democracia. 
Sólo la ciencia puede resolver los problemas del hambre y la pobreza, de la insalubridad y el analfabetismo, de la superstición y de los hábitos y tradiciones paralizantes, de los vastos recursos despilfarrados de un país rico habitado por gente que padece hambre... ¿Quién, en verdad, podría permitirse hoy menospreciar la ciencia? En cada ocasión tenemos que buscar su ayuda... El futuro pertenece a la ciencia y a los que se hacen amigos de la ciencia. ${ }^{22}$

Pero no se debe considerar a la ciencia una panacea, ni tampoco un mero almacén de hechos destinado a utilizarse de modo prosaico; sino uno de los grandes esfuerzos humanos que, junto con las artes y la religión, constituyen una guía y muestra de la intrépida búsqueda de la verdad por parte del hombre; como bien lo advirtió Gregory, (sir) Richard Arman (1846-1952).

La ciencia consiste más en el arte de hacer preguntas, que en el de responderlas. No obstante, su expansión y complejidad han motivado la utilización de técnicas y terminologías que provocan en el público "un rechazo generalizado a intentar entender todo lo que suene a ciencia y a la complejidad inherente a ella, lo que hace muy difícil que el método y el conocimiento de científicos penetren en la sociedad y sean verdaderamente reconocidos como elementos determinantes del progreso" (Tapia, 2000: 59).

\subsubsection{Aumento de términos científicos}

En 1993, los mexicanos Martín Bonfil Olivera y Martha Tappan Velásquez divulgaron un artículo en el cual analizaron los parámetros que rigen la creación de la terminología científica y cómo evoluciona ésta en el empleo que le dan sus diferentes usuarios: la

\footnotetext{
${ }^{22}$ Opinión expuesta por Jawaharlan Nehru, primer presidente de la India Independiente, y citada por Max F. Perutz (1990: 15).
} 
comunidad de investigación científica, los estudiantes y los iniciados en ciencia, y el gran público. Demostraron que la terminología de la ciencia ha surgido, tradicionalmente, de raíces griegas y latinas; aunque ahora también hay "cunas" que incluyen lenguas vivas (en especial el inglés), el lenguaje común, las metáforas, los nombres propios, los acrónimos ${ }^{23}$ y las invenciones gratuitas.

\begin{abstract}
Los términos provenientes de cada una de estas 'cunas' presentan problemas particulares en su comportamiento en sociedad, para los distintos niveles de público. Para los científicos, el problema principal quizá sea la pérdida de sistematización en la nomenclatura científica. Para los estudiantes, la función identificadora es la más importante y la que presenta mayores problemas. Para el público general, la terminología científica cumple sólo la función de identificar. Los distintos públicos influyen también en la forma en que los nuevos términos científicos son 'seleccionados', y sobreviven aquellos que cumplen su función en la comunicación (Bonfil et al., 1993: 253-267).
\end{abstract}

\title{
3.1.3. Límites de la enseñanza e inversión
}

El fomento de la cultura científica no es responsabilidad exclusiva de la educación formal. No lo permite el sistema educativo de la mayoría de países, debido a la falta de actualización de sus programas con relación al avance de la ciencia, y a la deficiente preparación de los profesores.

Los objetivos que caracterizan el contenido de la enseñanza básica de México, por ejemplo, sólo garantizan el dominio de la lectura y escritura, la formación matemática elemental y la destreza en la selección y en el uso de la información. En la secundaria, la enseñanza se concentra en materias de física, química y biología, con el propósito de

\footnotetext{
${ }^{23}$ Son iniciales que se usan para abreviar el uso de nombres muy extensos y descriptivos. Ejemplo: sida (Síndrome de Inmuno Deficiencia Adquirida), o láser (Light Amplification by Simulated Emission of Radiation).
} 
“establecer una vinculación continua entre las ciencias y los fenómenos del entorno natural que tienen una mayor importancia social y personal: la protección de los recursos naturales y del ambiente, la preservación de la salud y la comprensión de los procesos de cambio que caracterizan a la adolescencia”. ${ }^{24}$ Esta percepción también refleja la situación del sistema educativo ecuatoriano.

Tanto en México como en Ecuador, y en la mayoría de países latinoamericanos, la inversión del sector público y del privado a proyectos científicos se ubica en menos del uno por ciento del PIB. La parte más afectada suele ser la investigación básica, debido al poco valor que se le ofrece al compararla con la investigación aplicada. Al respecto, Carl Sagan alerta:

Cortar de cuajo la ciencia fundamental que tiene como guía la curiosidad es como comerse la semilla de maíz. Quizá nos quede un poco para comer el próximo invierno, pero ¿qué plantaremos para alimentarnos nosotros y nuestros hijos los inviernos siguientes? (Sagan, 2001: 431).

La falta de apoyo económico a proyectos de ciencia básica puede tener un impacto negativo en países de la región latinoamericana. Así lo reconocieron miembros del Comité Coordinador de Redes Científicas de América Latina:

La ciencia latinoamericana es una empresa frágil, que requiere aún de un impulso sostenido para su crecimiento y consolidación. En particular, las ciencias básicas son esenciales para reforzar nuestra capacidad de creación y utilización de conocimientos, tal y como fue reconocida por la Conferencia Mundial sobre la Ciencia, así como para lograr los objetivos que

\footnotetext{
${ }^{24}$ Tomado de "Perfiles de la educación en México"; publicación de la Secretaría de Educación Pública de México, enero de 2000. Versión online: http://www.sep.gob.mx/documentosof2/perfil/perfil.html.
} 
nuestros países se han planteado, de elevación y modernización de la enseñanza superior, de acuerdo con la Conferencia Mundial sobre la Educación Superior. ${ }^{25}$

\subsubsection{La ciencia que no se comunica, no existe}

El conocimiento científico puede llegar a ser un poder potencial o efectivo para clases, grupos, gobiernos o naciones; en términos de creación y uso de recursos y de riquezas, de prestigio e influencia, de capacidad política y diplomático-militar; dentro de cada país y en el sistema internacional. ${ }^{26}$ Reservar este conocimiento a las comunidades científica o política sería fomentar una microfísica de poder, el monopolio que cuestionó el filósofo Michel Foucault (Foucault, 1980).

"El conocimiento científico ha estado en poder de unos cuantos y es necesario que la nueva imagen del Universo que con ella se ha creado sea del dominio público" (Estrada, 1992). Para superar esta limitación, conviene apoyar la divulgación científica. No obstante, varios científicos tienen una actitud despectiva o indiferente hacia esta labor, porque no les representa aumento de puntos en su currículum, porque la consideran una pérdida de tiempo y de recursos.

Ya que la investigación científica es posible a partir de los impuestos pagados por el público, los científicos tienen la obligación ética de informar a sus promotores financieros sobre la manera en que gastan los fondos. "La ciencia debe ser objeto de crítica, control y

\footnotetext{
${ }^{25}$ Fragmento de la declaración suscrita por miembros del CCRCLA, al término de la reunión celebrada en la Ciudad de México, del 2 al 4 de septiembre del 2001. La declaración fue publicada en el periódico Descubrir Latinoamericano, $\mathrm{N}^{\circ} 11$, México, noviembre del 2001.

${ }^{26}$ Idea que expuso Marcos Kaplan en el II Congreso Mexicano para el Avance de la Ciencia y de la Tecnología (II COMACYT), que se realizó en la Ciudad de México a inicios de noviembre del 2000.
} 
denuncia”, aclara Ignacio Fernández Bayo, con el argumento de que los científicos también son ciudadanos y de que el público general tiene el derecho de opinar sobre la clase de ciencia que debe desarrollarse y sobre los programas que merecen prioridad (Fernández Bayo, 1988: 58).

Buen ejemplo de lo que puede lograr un científico como divulgador es el libro Los tres primeros minutos del universo. Su autor, el físico Steven Weinberg, atribuye su éxito editorial al hecho de haber escrito para un lector que está dispuesto a leer argumentaciones detalladas, pero que no está familiarizado con la matemática ni con la física.

\begin{abstract}
Aunque debo exponer algunas ideas científicas bastante complicadas, en el libro no se usa matemática alguna que vaya más allá de la aritmética ni se presupone conocimiento alguno de la física o la astronomía. He tratado de definir cuidadosamente los términos cuando se los usa por vez primera, y además he proporcionado un glosario de términos físicos y astronómicos. Cuando me ha sido posible, también he escrito números como 'cien millones' en lenguaje común, en lugar de usar la notación científica más conveniente: 10 elevado a 11 (Weinberg, 1978)
\end{abstract}

Desde su niñez, Carl Sagan descubrió en la ciencia el camino hacia la verdad y hacia la democracia, por eso la consideró una "luz en la oscuridad" y optó por divulgarla a través de Cosmos, de Un punto azul pálido, de Los dragones del Edén y de Miles de millones, entre otros libros de su autoría. En Miles de millones escribió sobre temas polémicos, como la abducción por extraterrestres, el trabajo de curanderos y las visiones sin pruebas.

También compartió su experiencia como investigador dentro del Proyecto SETI (búsqueda de inteligencia extraterrestre) y ofreció pistas que permiten distinguir entre visiones falsas y verdaderas. "Para mí, cada vez que ejercemos la autocrítica, cada vez que comprobamos nuestras ideas a la luz del mundo exterior, estamos haciendo ciencia. Cuando 
somos autoindulgentes y acríticos, cuando confundimos las esperanzas con los hechos, caemos en la seudociencia y la superstición”, expuso Sagan en esa obra.

Maurice Goldsmith comparte esta última idea, por eso considera de interés abordar la СРCT "con objeto de preservar su integridad ante las falsas creencias que sobre ella se tienen por gran parte del público: una ciencia ciega, auto-laudatoria y todopoderosa, y que es un problema que no puede discutirse únicamente por los científicos" (Goldsmith, 1999: 1 y 2).

La divulgación no es tarea exclusiva de científicos; son varios los responsables de su ejecución. Carlos López Beltrán ${ }^{27}$ lo percibe de la siguiente manera: "La fractura progresiva de un espacio, de un contexto común, ha convidado a los especialistas a regodearse en su aislamiento, $\mathrm{y}$ ha engendrado interminables (y a veces inútiles) disquisiciones sobre 'las dos culturas', 'la tercera cultura', 'la nueva barbarie'... El hiato, sin embargo, ha creado una nueva tribu nómada.

Los espacios abiertos entre los islotes alejados del archipiélago científico, entre los oasis rigurosamente vigilados, están desde hace décadas siendo recorridos por forajidos y aventureros que además han hecho de la relatoría de sus viajes una profesión. Marco Polos de la atomizada, distanciada tecnociencia, los divulgadores (como se les llama) han aprendido a entender los intrincados dialectos y costumbres de las islas y a generar escritos, imágenes, espacios en los que se aprenda y reconozca como propio lo que era en apariencia ajeno" (López Beltrán, 2001: 5).

\subsection{Problemas de la comunicación}

27 Mexicano, historiador de la ciencia, divulgador y poeta. Trabajó en el Centro Universitario de Comunicación de la Ciencia de la UNAM y en Naturaleza. Trabaja en el Instituto de Investigaciones Filosóficas de la UNAM. 
Otro gran problema de la CPCT es que carece de una teoría definida y de modelos de comunicación generados desde su experiencia. Porque, como cualquier otra actividad creativa, la СРCT requiere de un estudio sistemático y de una reflexión permanente sobre su propio quehacer.

La investigación en este campo puede separarse en dos grandes líneas: el estudio y análisis de las disciplinas científicas mismas, y de las formas y medios para comunicar la ciencia. En síntesis, la investigación en la divulgación de la ciencia es lo que permite crear modelos de comunicación del conocimiento científico, cuyos contenidos estén determinados tanto por su trascendencia intrínseca como por su interés cultural (Estrada, 1992).

Un aporte necesario de los comunicadores sociales puede ser el estudio del proceso de CPCT que conlleva a la comprensión pública de la ciencia, lo cual supone evaluar el nivel de percepción y de respuesta de sus destinatarios. Esta responsabilidad animó al comunicador Rolando Isita Tornell a proponer la aplicación del modelo denominado Propaganda científica $^{28}$ y a promover la investigación de nuevos modelos de СРCT.

Parte del proceso comunicativo es la circulación del mensaje, que tiene como uno de sus protagonistas a los medios de comunicación. La CPCT a través de estos medios garantiza una mejor comprensión pública de la ciencia y mayor exigencia informativa al periodismo.

"La ciencia necesita de la información para llegar al gran público y, por otra parte, la naturaleza de los sistemas de comunicación resulta vital para la ciencia [...]. No hay ciencia sin comunicación", advierte Manuel Calvo Hernando en su primer libro sobre periodismo científico.

El progreso científico y la explosión comunicativa trastornan y modifican conceptos y prácticas de estas dos fuerzas gigantescas de nuestro tiempo —el conocimiento y la información- y

\footnotetext{
${ }^{28}$ Este modelo se describe en el siguiente capítulo.
} 
obligan a los profesionales de la ciencia y del periodismo a una reflexión rigurosa e integradora (Calvo, 1999: 10).

Una limitación para la mayoría de periodistas que empiezan a divulgar la ciencia es su falta de adiestramiento en disciplinas científicas —como la física, la química o la biología—, porque en su carrera universitaria no les ofrecen materias referentes a esas áreas del conocimiento, ni con el fin de ampliar su cultura científica. Entre los escritos de un científico y de un periodista, son comunes las siguientes diferencias: (Fog, 1990; Prenafeta, 2002; Calvo, 1988, 1992, 1997).

1. El lenguaje: es preciso y especializado para el científico; general y reduccionista para el periodista.

2. El significado: el científico distingue muy bien entre el dato, la interpretación y la especulación; el periodista muchas veces confunde los tres.

3. Los errores: el científico suele rectificarlos inmediatamente; el periodista, sólo si hay escándalo. "La libertad de cometer errores y de admitirlo está dentro del quehacer del proceso científico", expuso Robert Pollack, decano de ciencias biológicas en el Columbia College.

4. Los lectores: suelen ser personas especializadas para un científico que publica; es más heterogéneo el grupo de lectores de un periodista.

Ante esta situación, ¿qué puede hacerse? Luego de analizar durante un año los reportajes y las actitudes de los medios de comunicación estadounidenses, en relación con la Ciencia y la Tecnología (CYT), el periodista científico Jim Hartz y el físico Rick Chappell comparten las siguientes recomendaciones (Hartz et al., 2001: 18) 
- Los investigadores y los periodistas deben entablar un diálogo para educarse los unos a los otros, sobre cómo satisfacer sus necesidades y las del público.

- La comunidad científica debería capacitar a los comunicadores para que sean voceros de las diferentes disciplinas científicas.

- Los periodistas deben incrementar su comprensión y su capacitación en ciencia.

- Los editores de revistas científicas deberían solicitar a sus autores que incluyan un resumen de sus trabajos —escritos en lenguaje llano- que muestre las perspectivas de sus resultados y que explique su relevancia e importancia.

- Los periodistas deberían poner más atención a los procesos de revisión por pares, con el fin de evitar darle importancia a trabajos que son potencialmente cuestionables.

- Todas las disciplinas científicas deben desarrollar sitios en la red operados por las principales asociaciones científicas para dar a conocer los trabajos, direcciones electrónicas y teléfonos de investigadores y voceros, así como otras informaciones de interés para el público y, en particular, para los medios.

- La Asociación Estadounidense para el Avance de la Ciencia (AAAS, por sus siglas en inglés) o la Academia Nacional de Ciencias (NAS, por sus siglas en inglés) deben mantener sitios maestros en la red que vinculen los sitios individuales.

- Los medios deberían utilizar los sitios de la red para enterarse de los acontecimientos científicos más relevantes, como una guía para sus noticias sobre tópicos de CYT.

\subsubsection{Del lenguaje científico al lenguaje cotidiano}


La complejidad del lenguaje científico es otro de los elementos atribuibles a una deficiente СРСТ. Comprenderlo es un paso necesario para lograr recrearlo sin deformaciones, con creatividad, de forma clara y sencilla.

Luis Estrada Martínez empezó a experimentar este obstáculo hace más de tres décadas, cuando fundó en México la revista Física y, posteriormente, Naturaleza. Dice que al plantearse la relación entre los lenguajes científico y común, lo que ordinariamente se busca es señalar la gran incomunicación que hay ente la comunidad científica y el resto de la humanidad (Estrada, 1988: 67-73). Y tiene razón Estrada, porque a medida que aumentan las disciplinas científicas, también crece el número de lenguajes especializados y, consecuentemente, se dificultan los intercambios entre la ciencia y el público. ${ }^{29}$ Con respecto al tema, Carlos López Beltrán opina lo siguiente:

La profesionalización y la estandarización de las maneras de actuar y de expresarse al seno de cada subtribu tecnocientífica trajeron la era babélica en la que estamos inmersos. Ahora es una gracia, una especie de monería encontrar un científico que escriba con estilo, que acierte a manejar con mínima destreza la lengua de todos para verter en ensayos o artículos no especializados sus cogitaciones, sus experiencias, aquello que crean necesario poner a circular por los aires comunes (López Beltrán, 2001)

\subsubsection{En español o en inglés}

El inglés se ha convertido en el idioma oficial de la ciencia. Lo hablan el ochenta por ciento de los investigadores; se lo usa para almacenar, en sistemas electrónicos, el noventa por ciento de la información científica; y dominarlo es un requisito fundamental para ser admitido en congresos o seminarios científicos internacionales.

\footnotetext{
${ }^{29}$ Esta afirmación la planteó en 1964 Ritchie Calder, uno de los primeros escritores que ejercieron la divulgación de la ciencia como hoy la conocemos (Calder, 1964).
} 
Estos datos los expuso la historiadora Bertha Gutiérrez en un debate que se efectuó en la ciudad alemana de Gotinga y que surgió de la premisa: el inglés es la lengua universal para transmitir conocimientos y revelaciones científicas.

Para que ahora un descubrimiento sea reconocido por la comunidad científica internacional, debe ser escrito en inglés. Esta prioridad también se refleja en conceptos acuñados por científicos de habla inglesa como acrónimos, y en expresiones onomatopéyicas que provienen de su idioma (como la famosa teoría del Big Bang o del Big Crunch, referente al origen o a la destrucción del Universo). Estos hechos confirman la idea de que los países que imponen su lengua en la formación de nuevas palabras científicas son los que encabezan la investigación.

En una intervención realizada en 1987, Pedro Fernández Blanco subrayó la complicación que supone el hecho de que:

\begin{abstract}
[...] el castellano es una lengua fundamentalmente literaria, de civilización, que no ha sabido crear el vocabulario científico o tecnológico necesario, debido a la hasta ahora escasa presencia de hispanohablantes en la investigación científica. La consecuencia lógica es la invasión de términos extranjeros, porque los traductores (y los divulgadores, podría añadirse) no son capaces de encontrar equivalencias idóneas. ${ }^{30}$
\end{abstract}

De ahí que Rolando Isita comente que, si el lenguaje de la ciencia se convierte a otro idioma, será porque los científicos de habla castellana, portuguesa, china o de otra, no sólo se habrán apropiado de la materia de su trabajo, porque estarán en la frontera de los

\footnotetext{
${ }^{30}$ Esta reflexión la expuso Pedro Fernández Blanco en "Considerations d'un traducteur indépendant sur la traduction technique en langue espagnole", publicado en Actas del XXIII Congreso de la Societé des hispanistes français, Caen, marzo 1987. (Lo citó Manuel Calvo, “Lenguaje científico y divulgación”, en Chasqui, № 57, Ecuador, 1997, p. 85).
} 
conocimientos, sino porque, además, su sociedad permeada culturalmente con el "éxito" de sus científicos, armada de "cultura científica" y con innovaciones tecnológicas en sus procesos nacionales de producción, habrán impactado culturalmente en el resto del mundo, como ya comienza a suceder con el idioma japonés a nivel de marcas y de tecnologías (Isita, 1995: 101).

\subsection{Problemas de la sociedad}

"Pues somos dos países a la vez: Uno en el papel y otro en la realidad. Aunque somos precursores de las ciencias en América, seguimos viendo a los científicos en su estado medieval de brujos herméticos, cuando ya quedan muy pocas cosas en la vida diaria que no sean un milagro de la ciencia”.

(Gabriel García Márquez)

Gerald Holton resumió la imagen pública de la ciencia y la tecnología en los siguientes términos (Holton, 1998):

1. La ciencia como una actividad con un doble beneficio: como puro pensamiento, ayuda a la mente a encontrar la verdad; $y$, como poder, proporciona herramientas para una acción efectiva.

2. Una segunda imagen de la ciencia es la del científico como iconoclasta. Suele ser atribuible a una falta de concepción de sus funciones. Por ejemplo, el historiador Arnold Toynbee acusó a la ciencia y a la tecnología de usurpar el lugar de la cristiandad como fuente principal de los nuevos símbolos culturales.

3. La tercera imagen de la ciencia es la de una fuerza que puede invadir, poseer, pervertir y destruir a una persona. Se debe al estereotipo actual del científico malvado o psicopático de la ciencia-ficción. Para Holton, el temor que hay detrás 
de esta actitud no se limita a la ciencia: está dirigido a todos los pensadores e innovadores.

4. Las dos últimas visiones sostenían que el hombre es intrínsecamente bueno y la ciencia, mala. La cuarta imagen está basada en la hipótesis opuesta: que al hombre no se le puede confiar el conocimiento científico y técnico. Hemos sobrevivido sólo porque carecíamos de armas suficientemente destructivas; ahora podemos inmolar a nuestro mundo.

5. La quinta imagen prevaleciente de la ciencia sostiene que mientras ni la ciencia ni el hombre pueden ser intrínsecamente malos, el surgimiento de la ciencia inició, como por accidente, un cambio en el equilibrio de las creencias e ideas que ahora corroen la única base concebible para una sociedad estable. Muchas aplicaciones de los conceptos científicos recientes fuera de la ciencia revelan simplemente una ignorancia de la ciencia. La imagen de la ciencia como un desastre ecológico puede ser sometida a una crítica severa.

6. Mientras que las últimas cuatro imágenes insinúan una repugnancia hacia la ciencia, el cientifismo puede describirse como una adicción a la ciencia. Se trata del hábito de dividir todo el pensamiento en dos categorías: conocimiento científico actualizado, en un lado, y absurdo, en el otro. Una fuente principal de esta actitud es el éxito convincente del trabajo técnico reciente. Otra reside en el hecho de que estamos atravesando un período de cambio fundamental. La ciencia se ha convertido en una operación a gran escala con un potencial para efectos rápidos y de alcance mundial. El resultado suele ser un avance espléndido en el conocimiento; pero con efectos colaterales que son análogos a los de la urbanización repentina. La sociedad se enfrentará con la insistencia seductora del 
cientifismo para adoptar lo que se considera — a menudo erróneamente— como la pauta de organización de la Gran Ciencia.

7. Finalmente, la magia. Pocos sospecharían un fraude si se anunciara repentinamente que se había sintetizado un elemento químico estable más ligero que el hidrógeno, o que una plataforma de observación tripulada se había posado en la superficie del Sol. Así pues, la séptima imagen representa a la ciencia como magia, y al científico como un brujo, un deus ex machina o un oráculo. La actitud hacia los científicos en este plano va desde el terror hasta el servilismo, dependiendo de qué motivos le atribuya a cada uno.

Holton cree que el predominio de estas siete impresiones es una fuente de alienación entre los elementos científico y no científico en nuestra cultura y, por tanto, un asunto importante. Porque "no sólo el hombre de la calle, sino casi todos nuestros líderes intelectuales y políticos, conocen muy poco sobre la ciencia. Y aquí llegamos al punto central que subyace a este análisis: la advertencia de que nuestros intelectuales están perdiendo su dominio de una cabal comprensión del mundo" (Holton, 1998).

Un ejemplo que confirma la anterior crítica es el hecho de que apenas un tercio de los británicos, y menos de la mitad de los norteamericanos, logra recordar la definición de año (tiempo que tarda la Tierra en dar una vuelta alrededor del Sol).

Es peligroso y temerario que el ciudadano medio mantenga su ignorancia sobre el calentamiento global, la reducción del ozono, la contaminación del aire, los residuos tóxicos y radiactivos, la lluvia ácida, la erosión del suelo, la deforestación tropical, el crecimiento exponencial de la población. Los trabajos y sueldos dependen de la CYT. Si nuestra nación no puede fabricar, a bajo precio y alta calidad, los productos que la gente quiere comprar, las 
industrias seguirán desplazándose para transferir un poco más de prosperidad a otras partes del mundo (Sagan, 2001).

El problema radica en que gran parte del público supone que la ciencia requiere de una educación especializada durante años, que su comprensión es responsabilidad exclusiva de los científicos; y no es así, porque a todos compete fomentar una cultura científica. "Cuando nos alejamos de ella -de la ciencia- porque parece demasiado difícil (o porque nos la han enseñado mal) abandonamos la posibilidad de responsabilizarnos de nuestro futuro. Se nos priva de un derecho. Se erosiona la confianza en nosotros mismos" (Sagan, 2001).

Quien se considere una persona culta, debería conocer de igual manera a Cervantes o a Shakespeare, que a Newton o a Einstein; aclara Manuel Calvo Hernando. Y su opinión es válida, debido a que la ciencia es parte de la cultura.31

Para que la CPCT apoye con mejores elementos la democratización científico-cultural, es conveniente saber qué percibe el público, cómo asimila la información científica, qué tanto aprende, qué tan fácil le es comprender el contenido, entre otros aspectos. ¿Pero quiénes son los destinatarios de la divulgación científica? Le Lionnais decía, hace treinta años, que esta labor debe destinarse a todo el mundo, "de la Escuela Maternal al Premio Nóbel", porque los problemas que aborda la ciencia afectan al conjunto de la población.

Martín Bonfil y Martha Tappan clasifican en niveles a los usuarios de la divulgación:

31 A esta conclusión han llegado varios críticos de la divulgación científica, como John Bernal, Ruy Pérez Tamayo, Amílcar Herrera, Manuel Calvo Hernando y quienes integran la DGDC-UNAM y la División de Divulgación Científica e Imagen Institucional del Instituto Politécnico Nacional (IPN) de México. 
1. El nivel de los investigadores, formado por científicos que trabajan en un área de estudio determinada.

2. El nivel educativo, que agrupa a científicos de otras áreas y a estudiantes de carreras científicas.

3. El nivel divulgativo, que integra al público en general y cuya relación con el lenguaje científico se establece, sobre todo, a través de los medios de comunicación.

\footnotetext{
Cada uno de estos públicos tiene una relación distinta con la ciencia y, por lo tanto, con el lenguaje científico. Como ocurre con las lenguas naturales, el lenguaje científico se halla sujeto a una 'selección lingüística', en donde las palabras que estorban la comunicación se van eliminando y son sustituidas por otras más funcionales. Desde esta perspectiva, puede hablarse de una 'evolución' de los términos científicos. La aceptación de los términos está determinada por las necesidades de cada público (Bonfil et al., 1993: 261).
}

Con respecto al público del nivel divulgativo, el objetivo es transmitir la información en forma comprensible e interesante. Para el efecto, Bonfil y Tappan sugieren no usar términos formales y evitar caer en malentendidos, como el que suele darse entre el término seropositivo y el tipo de sangre 0 positivo (en ocasiones se ha llegado a escribir que alguien es "cero positivo"). De ahí que ambos autores digan que el lenguaje científico está al libre albedrío del proceso de comunicación y que, por ello, adquiere transformaciones que no son controlables. De esta manera vemos cómo, al igual que con el lenguaje corriente, el uso del lenguaje científico se presta a incongruencias y a la violación de reglas; comportamiento que no es perjudicial, mientras no obstaculice el proceso de comunicación.

\subsubsection{Aporte de los M.C.M. a la comunicación de la ciencia}


Para la mayoría de la gente, la realidad de la ciencia es lo que leen de ella en la prensa y en otros medios de comunicación de masas (m.c.m.).

[...] porque como se dice en Periodismo, si una cosa no aparece en los medios, no existe; por lo que los m.c.m. van a ser el intermediario principal entre el mundo de la ciencia y la sociedad, el cual deberán utilizar para informarse de todos los acontecimientos diarios en CyТ y obtener una opinión crítica y concienciada de los mismos. ${ }^{32}$

Para sustentar esta opinión desde la experiencia de España, Alex Fernández Muerza brinda las siguientes pruebas:

a) Difusión de las revistas de divulgación científica en España, según datos de la Oficina de Justificación de Difusión (enero-diciembre 1999):

- $\quad$ Muy Interesante: 273470

- $\quad$ National Geographic: 268283

- Quo: 202200

- $\quad$ PC Actual: 92125

- $\quad$ Muy especial: 79674

- $\quad$ Newton: 67649

- $\quad$ La aventura de la Historia: 66534

- $\quad$ Geo: 63315

- $\quad$ Cuerpo Mente: 49927

- Integral: 34030

- $\quad$ Natural: 31298

\footnotetext{
${ }^{32}$ Comentario de Alex Fernández Muerza, “Divulgación de la ciencia. La comunicación de la ciencia, una necesidad social", en: http://www.recol. es/articulos2 asp?idCmdad=28\&nombCmdad=Ciencias\&home=1\&id=846\#marca2
} 
- Investigación y Ciencia: 24559

El director de Muy Interesante, José Pardina, atribuye el éxito de estas publicaciones al hecho de que en ellas los lectores hallan información que les interesa y que no ofrecen los demás medios de comunicación impresos o audiovisuales.

b) Informe de la Fundación BBVA "Ciencia, Tecnología y Sociedad", dirigido por Rafael Pardo, Conocimiento científico-tecnológico y legitimación de la CYT en España: "Entre las noticias que aparecen en los medios de comunicación, las noticias sobre CYT son las que más interés ofrecen, sin embargo, la gente se siente muy mal informada". c) Investigación de la Asociación de periodistas de Cataluña, el Llibre Blanc de la divulgación científica $i$ tecnológica a Catalunya: "Se observa que la mayoría de los productos divulgativos de los medios de comunicación, incluida la televisión, requieren conocimientos equivalentes a los estudios secundarios, de los que carece la mitad de la población. Por lo tanto, hacen falta programas asequibles".

d) Datos de la encuesta publicada en el libro Sciences aux quotidiens: l'information scientifique dans la presse quotidienne eurpéenne, del francés Pierre Fayard: “Contrariamente a lo que se creía, la cobertura de la actualidad de ciencia y tecnología es muy apreciada por los lectores de la prensa diaria europea, de su 'quality press', según la terminología anglosajona”.

e) Estudio del Centro de Investigaciones Sociológicas (CIS): "Los avances médicos, la ecología y los descubrimientos científicos generan en la ciudadanía los niveles de interés más elevados $(80,78$ y 63 por ciento, respectivamente), pero también son percibidos como insuficientemente tratados por los medios". 
f) Informe del "Observatori de la Comunicació Científica" de la Universidad Pompeu Fabra, La percepció de la ciència a la societat catalana: "Más del 80 por ciento de la población considera que la información científica es necesaria, útil y curiosa, pero el 40 por ciento la encuentra incomprensible".

Según un estudio de Manuel Calvo Hernando, las disciplinas científicas de mayor interés para el público son: astronomía, física y cosmología, biología y medicina, matemáticas, naturalistas, historia y paleontología (Calvo, 1996: 39-40).

En definitiva, ¿puede la ciencia llegar al público, popularizarse? ¿Es positivo que todos lleguen a entender la ciencia? ¿Es posible salvar la brecha entre cultura humanística y cultura científica? ¿Puede afrontarse el problema de la separación radical entre los científicos y la sociedad $?^{33}$ Si respondemos afirmativamente a estas preguntas, tenemos la responsabilidad de proponer alternativas que permitan desarrollar una buena CPCT. Esta es la idea que sustenta el desarrollo del siguiente capítulo.

\footnotetext{
${ }^{33}$ Estas interrogantes las formuló Roqueplo en El reparto del saber: ciencia, cultura y divulgación (1983).
} 


\section{CAPÍTULO 4}

\section{ALTERNATIVAS PARA UNA MEJOR CPCT}

Creo que efectivamente hay divulgadores natos y hasta geniales, pero esto no debe excluir al común de la gente que, como nosotros, ha tenido que aprender por ensayo y error, por tino y desatino, con criterios únicamente subjetivos porque no existe la enciclopedia de la divulgación, ni el método a seguir; no hay libros de texto ni recetas infalibles. Peor aún, no hay un sistema para evaluar el trabajo.

(Ana María Sánchez Mora)

¿Cómo se aprende a hacer divulgación?, preguntó cierto día un periodista mexicano a la maestra en física y en literatura, Ana María Sánchez Mora. Aunque no fue descabellada su 
inquietud, ni la selección de su fuente informativa,${ }^{34}$ obtuvo una contestación que lo desalentó.

¿¿Divulgación? ¿De cuál? [...] ¿Para niños, adolescentes o adultos? ¿Para primaria, secundaria o prepa? ${ }^{35}$ ¿Para científicos de otras especialidades? ¿Por escrito, en video o por radio? ¿Estilo literario o periodístico? ¿Cómo cuento, entrevista, ensayo o guión? ¿Modelo Gamow, Asimov, Sagan, Jay Gould o Dawkins?”. ${ }^{36}$ Con esta respuesta, Sánchez quiso mostrar al periodista la gama de posibilidades que existen dentro de la divulgación de la ciencia, no desanimarlo. Por eso aceptó ser nuevamente interpelada: ¿Cómo puede llegar alguien a ser divulgador?

\begin{abstract}
Aunque no lo parezca a primera vista —advirtió Sánchez—, esta pregunta es semejante a cuestionarse cómo aprende un pintor a pintar, un escritor a escribir y un compositor a componer. [...] En el caso de la divulgación no hay un método que se nos enseñe, no hay libros de texto ni exámenes. Los de mi generación y los que nos precedieron no tuvimos una escuela formal; hemos aprendido en la práctica, con suerte a la sombra de un divulgador ya formado y hasta reconocido. Como en cualquier actividad intelectual, con escuela o sin ella, algunos han trascendido al encontrar un estilo propio, una definición original, una manera muy personal de hacerla. Y si en suerte les tocó llegar a ser considerados divulgadores de primera línea, tal vez pudieron retribuir ese conocimiento empírico a otros jóvenes aprendices. Sólo a unos cuántos, pues fue una enseñanza individualizada (Sánchez Mora, A.M., 2000).
\end{abstract}

\footnotetext{
${ }^{34}$ A más de ser una divulgadora reconocida, Ana María Sánchez coordinó la creación del Diplomado en Divulgación de la Ciencia en la DGDC-UNAM.

35 El nivel Secundaria de México equivale, en Ecuador, a los tres primeros años del colegio; y el de Preparatoria, o "prepa", corresponde a los tres años siguientes.

${ }^{36}$ A esta experiencia se refirió Ana María Sánchez Mora en su texto titulado "Enseñanza y aprendizaje de la divulgación" $\left(2000_{\mathrm{b}}: 1\right)$.
} 
Este razonamiento despertó en Ana María Sánchez y en algunos de sus colegas el deseo de aportar al aprendizaje de la divulgación. Empezaron por compartir sus experiencias como divulgadores, mediante artículos y conferencias.

Luego organizaron un Diplomado en Divulgación de la Ciencia, con apoyo del Centro Universitario de Comunicación de la Ciencia de la UNAM (actual Dirección General de Divulgación de la Ciencia, DGDC-UNAM); y desde el 2003, participan en la programación del Postgrado en Filosofía de la Ciencia, que organiza el Instituto de Estudios Filosóficos y la Facultad de Filosofía y Letras de la UNAM.

La experiencia acumulada en seis ediciones del Diplomado de la DGDC ha permitido identificar varios obstáculos en la enseñanza de la divulgación. Los que destaca Ana María Sánchez Mora (Sánchez Mora, A.M., 2000b), son:

1. La divulgación no es una disciplina, de modo que no tiene un método que le sea inherente.

2. La ausencia casi total de reflexiones escritas sobre cómo hacer la divulgación. Esto incluye una antología mínima de los clásicos de la divulgación.

3. Se requiere también un conjunto de normas, extraídas de la práctica constante, sobre el mínimo de recursos que un divulgador debe conocer y saber utilizar para hacer su trabajo.

4. Hacen falta criterios sólidos para evaluar el trabajo.

5. Se precisa de una institución que respalde el proyecto de enseñanza, que le permita ser reproducible y que le otorgue garantía de calidad. 
Este Diplomado ha sido útil no sólo para analizar los problemas de la divulgación, sino también para intercambiar propuestas de mejoramiento y orientar en la búsqueda de soluciones. Gran parte de este trabajo se sustenta en esa experiencia académica, de la que rescato las siguientes alternativas para comunicar públicamente la ciencia: las estrategias de educación no formal; la literatura y la ciencia ficción como recursos narrativos, y el empleo adecuado de la propaganda científica y de la televisión.

\subsection{Estrategia de la educación no formal}

La CPCT no sustituye a la educación; ${ }^{37}$ pero puede llenar vacíos en la enseñanza moderna y ayudar al gran público a que adopte una determinada actitud ante la ciencia. Después de la educación formal, ${ }^{38}$ advierte el divulgador mexicano Juan Tonda:

[...] la única vía de acercarse a la ciencia y la técnica es a través de la divulgación de la ciencia, a menos que seamos autodidactas. Es por ello que la función educativa de la divulgación es una cualidad importante que no se debe soslayar. La responsabilidad del divulgador de la ciencia como maestro informal de sus lectores, videntes, escuchas o interlocutores significa la única fuente de conocimiento científico que posee una persona fuera del ámbito científico. (Tonda, 2000: 4).

\footnotetext{
${ }^{37}$ La educación -entendida como un proceso de transmisión de valores, creencias, conocimientos y sistemas simbólicos- cubre un amplio espectro que incluye: la educación informal (proceso que dura toda la vida y en el que las personas acumulan conocimientos, habilidades, actitudes y modos de discernimiento, mediante sus experiencias diarias y su relación con el medio ambiente), la educación formal o enseñanza escolarizada, la educación no formal y la divulgación. Así lo explican las hermanas Ana María y María del Carmen Sánchez Mora, en su artículo "Educación y divulgación” (2000).

38 Sistema educativo altamente institucionalizado, cronológicamente graduado y jerárquicamente estructurado, que se extiende desde la primaria hasta los últimos años de la universidad.
} 
La principal diferencia entre divulgación y enseñanza es, según Martín Bonfil, la ausencia de un "contrato educativo"; es decir, de un compromiso que obligue al público de la divulgación a demostrar lo aprendido, mediante una evaluación. "Debido a esta ausencia de compromiso, una de las prioridades del divulgador debe ser interesar al público. Para ello debe conocer tanto sus antecedentes como sus intereses, y adecuar el mensaje de divulgación para conseguir interesarlo" (Bonfil, 1993).

En México se aplican varias acciones en favor de la educación, a partir de la divulgación científica. Por ejemplo: los concursos que premian la reseña de un libro de la colección $L a$ ciencia para todos, las ferias del libro, los museos interactivos, la Semana Nacional de Ciencia y más actividades que integran el Programa de Ciencia y Tecnología del Consejo Nacional de Ciencia y Tecnología (CONACYT).

Debido al vertiginoso avance de la ciencia y de sus aplicaciones tecnológicas, es difícil que los programas de educación formal lleguen a ofrecer información actualizada y a cubrir todas las necesidades educativas de la sociedad. Ante esta limitación, surge una gran alternativa: la educación no formal. ${ }^{39}$

El término "no formal" apareció a principios de los años setenta, luego de la crisis mundial que sufrió la educación a finales de los años sesenta del siglo XX. Por educación no formal se entiende el conjunto de acciones sistematizadas que acontecen fuera del ámbito estrictamente escolar, aunque algunas pueden estar vinculadas con éste.

La divulgación de la ciencia contribuye en la educación de una manera no formal, lo cual no significa que quienes la realicen puedan hacer a un lado el compromiso educativo que tienen a

\footnotetext{
${ }^{39}$ Es toda actividad organizada, sistemática y educativa que se realiza fuera del marco del sistema oficial, para facilitar determinadas clases de aprendizaje a subgrupos particulares de la población.
} 
la hora de comunicarse [...]. El papel educativo que desempeña la divulgación de la ciencia es esencial para comprender el valor que posee dicha actividad dentro de las universidades. La divulgación puede contribuir a una educación no formal de la ciencia y la técnica, y con ello a una educación integral del individuo (Tonda, 2000: 1-7).

Una experiencia paradigmática de la educación no formal, que podría aplicarse en Ecuador y en más países Iberoamericanos, es la desarrollada por la Subdirección de Educación No Formal (SENF) de la DGDC-UNAM. Esta Subdirección organiza diplomados, cursos de capacitación académica, actividades lúdicas y experimentales, y elabora materiales didácticos que aportan a la propuesta de metodologías alternativas para la promoción de experiencias de aprendizaje en ciencias, de manera no escolarizada. Para el efecto, y debido a la diversidad de medios con los que cuenta, programa sus cursos y sus actividades de educación no formal e informal desde las siguientes áreas:

- Actualización.

- Medios didácticos.

- Área técnica.

\subsubsection{Actualización}

Entre las actividades efectuadas por la SENF, destacan la planeación y la organización de cursos de actualización y formación de profesionales de la divulgación. Estos cursos contemplan, como objetivos principales:

- Formar nuevos divulgadores de la ciencia y la técnica.

- Facilitar a maestros de disciplinas científicas, de secundaria y de bachillerato, el acceso a conocimientos y a métodos novedosos de enseñanza. 
- Capacitar en divulgación al personal de museos interactivos de ciencia, considerando la variedad de públicos que visitan esos museos y empleando herramientas didácticas.

- Presentar a diversos públicos opciones novedosas de educación no formal.

\subsubsection{Medios didácticos}

La enseñanza de las ciencias naturales y de las matemáticas, dentro de la educación básica, necesita cambios y adaptaciones que permitan fomentar la cultura científica de niños, jóvenes y adultos. Pero, mantener el interés de maestros y de alumnos en disciplinas intrínsecamente abstractas y con mayor grado de dificultad que otras de igual peso académico, obliga a una versátil búsqueda de alternativas pedagógicas.

Los paquetes didácticos que integran el proyecto de la SENF garantizan un acercamiento ameno y novedoso a la instrucción y evaluación de temas de ciencias naturales y de matemáticas para niños y jóvenes, desde tercero de preescolar hasta tercero de secundaria.

Concretamente, los paquetes denominados EXPERIMENTA, más que un conjunto de actividades representan un proyecto de enseñanza cuidadosamente planeado, con el fin de cubrir y enriquecer los programas oficiales correspondientes, $\mathrm{u}$ otros sistemas escolarizados. Son diseñados por maestros de amplia experiencia en el área, en colaboración estrecha con científicos y pedagogos de la UNAM y con la participación de divulgadores de la ciencia. Su diseño modular permite utilizarlos en distintos ambientes escolares.

\subsection{3. Área técnica}


El área técnica de la SENF comprende dos laboratorios -el Astrolab y el Fisilab- y un invernadero. En los laboratorios se estudian temas de física y de astronomía, mientras que en el invernadero se abordan aspectos biológicos y fisicoquímicos sobre el cultivo de plantas y árboles. En las tres secciones se desarrollan cursos y talleres, así como materiales didácticos para apoyar la divulgación y la enseñanza de temas científicos.

El Astrolab es un espacio destinado a fomentar el interés y la curiosidad de niños, jóvenes y adultos por la astronomía y la astronáutica. Está conformado por una sala de conferencias y un observatorio astronómico, en donde el visitante puede incursionar en el fascinante mundo de la astronomía, a través de charlas, conferencias, proyecciones, programas de cómputo, libros, revistas y videos.

El Fisilab está integrado por el teatro-laboratorio de experimentos didácticos, cuyo objetivo es despertar el interés de profesores y del público en general, en aspectos de física experimental. Está equipado con diversos aparatos e instrumentos que permiten realizar experimentos sobre electricidad, magnetismo, mecánica, acústica y radio comunicación. Cuenta con un pequeño auditorio y un escenario en donde se efectúan demostraciones y cursos participativos, ya que el público colabora con el montaje y la realización de los experimentos. En el Fisilab también se diseña y se elaboran equipos y montajes experimentales del tipo "hágalo usted mismo".

\subsubsection{Aprendizaje potencialmente significativo}

Dentro del marco teórico que sustenta la misión y objetivos de la Subdirección de Educación No Formal (SENF), es fundamental la Teoría del Aprendizaje Significativo, propuesta por David Ausubel. 
"Hay aprendizaje cuando el sujeto construye, en forma asimilativa, motivada y consciente, el significado de las experiencias, las cosas y los fenómenos, y ese significado es incluido en la estructura de conocimiento", expuso Carmen Sánchez en el módulo que ofreció dentro del VI Diplomado en Divulgación de la Ciencia de la UNAM, respaldada en su experiencia como titular de la SENF.

Para referirse al aprendizaje, conviene empezar por describir algunas tendencias que caracterizaron a la investigación epistemológica y práctica de este término. Hasta mediados del siglo XX, tuvo algunos seguidores la teoría asociacionista o conductista (behaviorista) del aprendizaje. Según esta teoría (Novack, 1988), el aprendizaje implicaba un proceso en el cual un estímulo (E) procedente del medio produce una respuesta (R) por parte del organismo, y que por repetición se formaba un enlace E-R, tal que un E determinado llevaba casi inevitablemente asociada una respuesta determinada, R. Pero gran parte de esta teoría se sustentaba en la experimentación de laboratorio con animales, y no alcanzó mucho éxito.

En un ensayo que tituló "Investigación y experiencias didácticas. Constructivismo humano: un consenso emergente", J.D. Novack (1988), de la Universidad de Cornell, reconoció que las ideas de la teoría asociacionista o conductista dominaron la psicología y la enseñanza, hasta los años setenta. Y que el fracaso de estas ideas para describir y predecir cómo producen conocimientos los escolares y cómo aprenden los humanos permitió que surgieran nuevas concepciones sobre el conocimiento. Una de estas concepciones epistemológicas fue la de esquemas conceptuales evolutivos, que Conant introdujo en su libro Sobre la Comprensión de la Ciencia (Conant, 1947). Novack considera esta concepción y el modelo cibernético del aprendizaje (Wiener, 1948), a fin de sustentar su investigación académica y de comprender los parámetros que influyen en la capacidad para resolver problemas. 
Según el modelo cibernético de aprendizaje, la mente es una unidad de procesado de información en la cual se realizan por separado el almacenamiento de conocimientos y el procesado de información (conocimientos). Al procesado de información lo considera un componente relativamente estable en el tiempo, pero no al almacenamiento de conocimientos, pues lo supedita a la aportación de nuevas informaciones y a la retroalimentación (Sánchez Mora, C., 2002; Moreira, 1993).

No obstante, la investigación de Novack y las que le siguieron empezaron a sugerir que tanto la capacidad de procesamiento como el ritmo de adquisición de nueva información dependían de los conocimientos relevantes que el aprendiz tenía almacenado en su estructura cognitiva, y del contexto del problema o de la tarea de aprendizaje. Y para el efecto, resultaba insuficiente el modelo cibernético.

Dos nuevos modelos en los que se resaltó la importancia de los conocimientos previos para el nuevo aprendizaje fueron: la teoría de la memoria F. C. Bartlett (Bartlett, 1932) y la psicología de los constructos personales de G. A. Kelly (Kelly, 1955). El primero afirmaba que los esquemas influyen en la percepción y recuerdo de la información, de una manera similar a como se concibe que operan los esquemas en las visiones contemporáneas de la ciencia cognoscitiva del aprendizaje y de la retención. Aunque el segundo, el de Kelly, también destacaba el papel del aprendizaje previo para el nuevo aprendizaje, no enfatizaba en los conceptos específicos ni en las estructuras proposicionales.

David Ausubel aportó la Teoría del Aprendizaje Significativo, ${ }^{40}$ (Ausubel, 1963), que resultó de gran utilidad para los estudios de Novack y los de siguientes generaciones. Esta teoría enfatiza el proceso de la cognición y ofrece una perspectiva constructivista a ese

\footnotetext{
${ }^{40}$ David Ausubel empezó a desarrollar esta teoría en su obra Psicología del aprendizaje verbal significativo, que fue publicada originalmente en inglés, en 1963.
} 
proceso. Su principal aporte, según Novack, fue destacar la importancia del aprendizaje significativo, en contraste con el aprendizaje por repetición, y la claridad con que describió el papel que juegan los conocimientos previos en la adquisición de nuevos conocimientos.

La esencia de esta teoría, y de sus posibles implicaciones, podría resumirse en la frase que Ausubel escribió para el epígrafe a las ediciones 1968 y 1978 de Psicología educativa: un punto de vista cognoscitivo en donde expuso:

Si tuviese que reducir toda la psicología educacional a un solo principio, diría lo siguiente: el factor aislado más importante que influencia el aprendizaje es aquello que el aprendiz ya sabe. Averígüese esto y enséñese de acuerdo a ello (Ausubel et als., 1978: IV).

- Con "aquello que ya sabe", Ausubel se refirió a la estructura cognitiva, al contenido total y a la organización de sus ideas en esa área particular de conocimientos.

- Con "averígüese esto", exhortó a que se revelara la estructura cognitiva preexistente, a que se haga el mapeamiento de esa estructura.

- "Enséñese de acuerdo" es fundamentar la instrucción en aquello que el aprendiz ya sepa.

En resumen: aprender de manera significativa es aprender de manera no arbitraria ni literal. Esto implica un proceso a través del cual nuevas informaciones adquieren significado por interacción (no asociación) con aspectos relevantes preexistentes en la estructura cognitiva, los cuales, a su vez, también son modificados durante ese proceso. "Para que el aprendizaje pueda ser significativo -aclara Marco Antonio Moreira-, el 
material debe ser potencialmente significativo y el aprendiz tiene que manifestar una disposición para aprender" (Moreira, 1993).

Esta advertencia supone el hecho de que el material tenga significado lógico y de que el aprendiz tenga disponibles, en su estructura cognitiva, subsumidores 41 específicos con los cuales el material sea relacionable.

Contrario al aprendizaje significativo es el aprendizaje mecánico (o automático) que, aunque no se procesa en un vacío cognitivo, no implica la interacción de conceptos relevantes existentes en la estructura cognitiva.

En su obra titulada An alternative to Piagetian psychology, Novak dice que el aprendizaje mecánico es siempre necesario cuando un individuo adquiere nuevas informaciones en un área de conocimiento que le es completamente nueva.

De su parte, Ausubel propone el uso de organizadores previos $^{42}$ que sirvan de anclaje para el nuevo conocimiento y el desenvolvimiento de conceptos subsumidores que faciliten el aprendizaje subsecuente. Con esta propuesta, Ausubel procura facilitar el aprendizaje significativo.

Según Ausubel, hay tres tipos de aprendizaje significativo: el representacional, el de conceptos y el proposicional. El más básico es el representacional; envuelve la atribución de significados a determinados símbolos (típicamente palabras). El aprendizaje de

41 La palabra subsumidor no existe en español, pero es una tentativa de traducir la palabra inglesa "subsumer". Representa un concepto, una idea, o una proposición que existe en la estructura cognitiva y que es capaz de anclar la nueva información. El aprendiz los adquiere de manera gradual e idiosincrática.

${ }^{42}$ Los organizadores previos son materiales introductorios que funcionan como "puentes cognitivos"; pueden ser textos escritos, discusiones, demostraciones, filmes o videos, entre otros. Su construcción depende de la naturaleza del material de aprendizaje, de la edad del aprendiz y del grado de familiaridad que tenga éste con el asunto que aprenderá. 
conceptos es, en cierta forma, representacional; porque también los conceptos son representados por símbolos particulares. Para ser significativo debe ser sustantiva y no arbitraria, al contrario de nominalista o meramente representacional. Ausubel dice que los conceptos son adquiridos a través de dos procesos: formación y asimilación. El aprendizaje proposicional, a diferencia del representacional, no tiene como tarea el aprender significativamente lo que representan palabras aisladas o combinadas, sino aprender el significado de ideas en forma de proposición. Por tanto, en este tipo de aprendizaje, la tarea es aprender el significado que está más allá de la suma de los significados de las palabras o conceptos que componen la proposición.

Aunque el aprendizaje significativo de las proposiciones es más complejo que los aprendizajes representacional y conceptual, es similar a éstos, en el sentido de que los significados emergen cuando la nueva proposición está relacionada e interactúa con proposiciones o conceptos relevantes (subsumidores), existentes en la estructura cognitiva.

Ausubel insiste en que el resultado de la interacción que ocurre en el aprendizaje significativo, entre el nuevo material a ser aprendido y la estructura cognitiva existente, es una asimilación de antiguos y nuevos significados que contribuyen para la diferenciación de esa estructura. De ahí que se refiera al principio de asimilación o a la teoría de asimilación, para aclarar el proceso de adquisición de significados en la estructura cognitiva.

El centro de la teoría de la asimilación está en la idea de que nuevos significados son adquiridos a través de la interacción del nuevo conocimiento con conceptos o proposiciones previamente aprendidos. La teoría del aprendizaje significativo enfatiza en el proceso de cognición con una perspectiva constructivista, la que impulsó Novack en su ensayo titulado "Constructivismo humano: un consenso emergente". En éste, expuso que el 
constructivismo humano "es un esfuerzo de integrar la psicología del aprendizaje humano y la epistemología de la construcción de conocimientos”. (Novack, 1988: 220).

\subsection{Divulgación de la ciencia como Literatura}

"Ninguna escuela literaria ha podido responder con precisión en qué estriba lo literario de una obra. Mi propuesta consiste en discutir por qué la buena divulgación sí podría considerarse literatura" (Sánchez Mora, A.M., 1995: 476-481). Esta propuesta es otra de las valiosas alternativas para una mejor divulgación de la ciencia; por eso se la incluye en el presente capítulo. La argumentó de manera contundente Ana María Sánchez Mora ${ }^{43}$ en su libro La divulgación de la ciencia como literatura, en varios artículos y en clases universitarias (Véase especialmente: Sánchez Mora, A.M., 2000a, 2000b, 1998 y 1996). Sus propios razonamientos ayudarán a comprender mejor esta segunda alternativa de divulgación científica.

\subsubsection{Ciencia y Literatura}

El interés en la relación entre ciencia y literatura puede rastrearse hasta Francis Bacon, siglos antes de que C.P. Snow esbozara las fronteras de las "dos culturas"; pero este interés ha cobrado intensidad en los últimos 10 años.

\footnotetext{
43 Ana María Sánchez estudió la licenciatura y maestría en física y la maestría en literatura comparada en la UNAM. Trabajó en el área de superconductividad del Instituto de Investigaciones en Materiales de la UNAM. Desde 1981 trabaja como divulgadora profesional en el Centro Universitario de Comunicación de la Ciencia, hoy DGDC-UNAM. Ha impartido varios cursos de divulgación escrita y ha coordinado el Diplomado en Divulgación de la Ciencia de la DGDC. Apoyó en la programación del Postgrado en Filosofía de la Ciencia de esa Universidad. Es socia titular de la Sociedad Mexicana de Divulgación de la Ciencia y la Técnica (SOMEDICyT). En sus ratos libres toca el violonchelo, escribe novelas y obras de teatro. Su novela La otra cara fue finalista del Premio Joaquín Mortiz para Primera Novela, 1996.
} 
Para analizar esta relación hay diferentes enfoques: el de los literatos, el de los científicos y el mixto. A los primeros pertenece el libro de Aldous Huxley, Literatura y ciencia (Huxley, 1979) que analiza la ciencia como posible fuente de inspiración para la literatura, en particular, para la poesía.

Este autor decía que si el siglo XX era eminentemente científico, sería de esperarse que la ciencia dejara huella en la literatura. Sin embargo, como la ciencia se ha convertido en un asunto de especialistas, al hombre de letras, incapaz de entender esas complejidades, no le queda más que ignorar por completo la ciencia contemporánea. Pero además del problema del lenguaje especializado de la ciencia, Huxley hace notar la gran diferencia entre ambas disciplinas. A la ciencia hay que acercarse de manera impersonal, mediante una observación desinteresada, una intuición y una experimentación carentes de prejuicios y una paciente racionalización de acuerdo con algún sistema de conceptos lógicamente relacionados.

En la vida real, dice Huxley, siempre hay conflictos entre razón y pasión, y la ciencia es intolerante frente a esta última. La literatura tolera un espectro mucho más amplio de actitudes humanas.

El enfoque mixto, o interdisciplinario como hoy se da en llamarlo, es el que rastrea desde los dos puntos de vista la influencia de la ciencia en la literatura. ${ }^{44}$ Pero aun cuando encontremos similitudes entre ciencia y literatura, saltan a la vista sus enormes diferencias: apasionamiento contra frialdad, objetividad contra subjetividad, interés por problemas humanos contra despersonalización.

\footnotetext{
${ }^{44}$ Un texto que ejemplifica este enfoque es el de Alan J. Friedman y Carol C. Donley, Einstein as Mit. And Muse, Cambridge, University Press, 1985. En esta obra, el tema de la relatividad se rastrea en obras de Durell, Nabokov, Wolf, Williams y MacLeish.
} 
Sumado lo anterior al problema del lenguaje especializado y a la falta de una cultura científica a todos los niveles, tendremos los ingredientes que actúan como repelentes para el público general. ¿Qué tiene que ver ese conocimiento abstracto e impersonal con sus problemas cotidianos, con sus pasiones y sentimientos?

Nadie, en su sano juicio, pretendería pedir "más objetividad” a la literatura o "más subjetividad" a la ciencia. Cada una desempeña un papel sui generis en el conglomerado que llamamos cultura. Pero de esas dos actividades creativas se ha logrado una intersección que conjuga ambos intereses: la divulgación de la ciencia.

\subsubsection{Lo literario}

El problema de lo literario ha sido abordado por innumerables autores. Ana María Sánchez Mora sostiene que el discurso literario aliena o enajena el lenguaje ordinario y que, paradójicamente, al hacerlo proporciona una posesión más completa, más íntima de la experiencia. Para sustentar esta idea refiere especialmente la introducción del libro de Terry Eagleton, Una introducción a la teoría literaria, de donde se desprende la siguiente cita:

Leemos una nota garrapateada por un amigo sin prestar mucha atención a su estructura narrativa, pero si un relato se interrumpe y después recomienza, si cambia constantemente de nivel narrativo y retarda el desenlace para mantenernos en suspenso nos damos al fin cuenta de como está construido y, al mismo tiempo, quizá también se haga más intensa nuestra participación. (Eagleton, 1988: 7)

Eagleton, a su vez, respalda sus ideas en el enfoque dado por "los formalistas" (sic.) a lo literario. Para ellos, lo literario consiste en una forma de escribir en la cual "se violenta organizadamente el lenguaje ordinario", y la obra literaria es un conjunto más o menos 
arbitrario de "recursos" relacionados entre sí o como "funciones" dentro de un sistema textual total.

Eagleton advirtió que los formalistas no se habían propuesto definir la "literatura", sino "lo literario"; es decir, los usos especiales del lenguaje que pueden encontrarse en textos literarios, pero también en otros diferentes. "No hay recurso 'literario' que no se emplee continuamente en el lenguaje diario" (Eagleton, 1988).

Ana María Sánchez Mora concuerda con esta opinión de Eagleton, pues le inquieta saber cómo puede reconocerse que una expresión o un recurso son literarios si el lenguaje en sí mismo carece de calidad o propiedades que permitan distinguirlo de cualquier otro tipo de discurso. Es el contexto el que nos revela su carácter literario: si la expresión proviene de una novela conocida, si el recurso forma parte de un texto que se ha leído como literario, si figura en el programa de lecturas de un curso universitario de literatura, si integra un texto que estaba en el estante etiquetado como novela en la librería o en la biblioteca. Lo anotado demuestra que la dependencia del contexto no hace una buena definición de lo literario; esta es una de las causas por las que el lector no acostumbra leer la divulgación como literatura.

\subsubsection{La tradición}

Muchas obras que se estudian como literatura en las instituciones académicas fueron construidas para ser leídas como literatura, pero también hay otras que no fueron construidas con ese propósito. Un escrito puede comenzar a vivir como historia, filosofía o ciencia y, posteriormente, ser clasificado como literatura; o bien puede empezar como literatura y acabar siendo apreciado por su valor arqueológico, histórico, etc. 
Algunos textos nacen literarios, dice Eagleton (Eagleton, 1988: 9); a otros se les impone el carácter literario y, al respecto, puede contar mucho más la educación que la cuna. Quizá lo importante no sea de dónde viene, sino cómo lo trata la gente. Si la gente decide que tal o cual escrito es literatura, parecería que de hecho lo es; independientemente de lo que se haya intentado al concebirlo. Si las obras de divulgación siempre se han clasificado como ciencia, al abordarlas las leeremos como ciencia; jamás nos percataremos de su valor como literatura, cuando lo tienen.

De lo anterior, se desprende que la literatura no puede considerarse tanto como una cualidad o conjunto de cualidades inherentes que quedan de manifiesto en cierto tipo de obras, sino como las diferentes formas en que la gente se relaciona con el escrito. Eagleton lo confirma al decir:

\footnotetext{
No es fácil separar, de todo lo que en una u otra forma se ha denominado literatura, un conjunto fijo de características intrínsecas (...). No hay absolutamente nada que constituya la esencia misma de la literatura. Cualquier texto puede leerse sin afán pragmático, suponiendo que en esto consista el leer algo como literatura; así mismo, cualquier texto puede ser leído poéticamente (Eagleton, 1988: 9).
}

¿Por qué entonces suele concebirse a las obras de divulgación científica como no literarias? Porque, según Ana María Sánchez Mora, no estamos posibilitados para decir con precisión por qué Shakespeare, Dostoyevski y Simon son literatura, ni tampoco por qué no lo podrían ser Einstein, Darwin o Jay Gould. Porque al momento de juzgar qué es literatura y qué no, a veces influyen los juicios de valor (Sánchez Mora, A.M., 1998: 112-113).

Entonces, ¿cómo explicar que ciertas obras literarias parecen conservar su valor a través de los siglos? Quizá la respuesta está en que asignamos valor a las obras literarias de acuerdo con lo que nos preocupa o interesa como seres humanos; a lo que nos conmueve, 
nos agita, nos hace mirarnos en un espejo. Pero esas inquietudes humanas que compartimos hoy con la obra literaria también han experimentado cambios y nada impide que la ciencia sea tratada en el contexto de tales inquietudes.

Luego de exponer los anteriores razonamientos, Ana María Sánchez Mora concluye:

Quedémonos, por ahora, con la noción de que una obra literaria es un texto bien escrito cuyo valor (variable) descansa en su capacidad de reflejar las preocupaciones humanas vigentes. Pero, resumiendo, ni el recurso de la invención ni el empleo característico de la lengua, ni el carácter de no pragmático son exclusivos de la literatura. El aprendizaje compartimentalizado, la rígida tradición de considerar estas características como exclusivas de la literatura, así como la imposición del carácter literario a ciertas obras, han dado lugar al destierro de las ciencias del reino de las bellas artes. Basada en que el concepto de literatura es cambiante y poco preciso, me atrevo a afirmar que el día en que las antologías literarias incluyan a Jay Gould y a Sagan, a Hoyle y a Dawkins, se habrá dado un gran paso en la cultura. Si se defiende el valor de estas y muchas otras obras de divulgación científica como literatura, independientemente de su tema, se habrá cimentado una tradición literaria más flexible y, por lo tanto, más completa" (Sánchez Mora, A.M., 2000b: 2).

La mexicana Ana María Sánchez predijo que los resultados de su análisis quizá no iban a ser aceptados por científicos ni por literatos, pero esperaba causar polémica entre los divulgadores de la ciencia, con su propuesta.

\subsubsection{Teoría de la Recepción}

Para sustentar teóricamente su propuesta, Ana María Sánchez Mora recurrió a la Teoría de la Recepción, que considera al lector como uno de los polos de la obra literaria, como el elemento que concreta el texto creado por el autor. Porque, "el texto solamente toma vida cuando es concretizado", dice Wolfgang Iser, uno de los estudiosos de esa teoría (Iser, 1972). 
Con esa frase, Iser quiso decir que el texto está modificado por la lectura, por cada lector; que el texto pierde su carácter virtual hasta que es leído (Sánchez Mora, A.M. 1995: 9-14). Por eso advirtió que, "a la hora de considerar una obra literaria, ha de tenerse en cuenta no sólo el texto en sí sino también, y en igual medida, los actos que lleva consigo el enfrentarse a dicho texto" (Iser, 1972). Esta postura es de suma importancia para la divulgación, afirma Sánchez, porque si ésta se olvida del receptor, puede perder su sentido primordial: comunicar.

Otra idea de Iser que conviene aplicar a la propuesta de divulgación como literatura, es: "Un texto literario debe concebirse de tal modo que comprometa la imaginación del lector". Porque, así como el texto literario "activa nuestras propias facultades, permitiéndonos recrear el mundo que presenta", el texto (y cualquier otro acto) de divulgación puede activar nuestros preconceptos equivocados y nuestro apego al pensamiento mágico infantil (Sánchez Mora, A.M., 1995: 9-14).

Aunque Ana María Sánchez advierte no estar totalmente de acuerdo con Iser, estima enriquecedora la aplicación de su Teoría de la Recepción al texto de divulgación científica. Aceptando que la divulgación de la ciencia es un asunto más literario que científico, ella concluye que es posible tomar prestadas de la literatura herramientas de análisis que pueden ser de gran utilidad para el divulgador.

\subsubsection{Ejemplos de divulgación de la ciencia como Literatura}

\section{Richard Dawkins, El gen egoísta, 1976.}

Imaginemos los días anteriores a la imprenta, cuando se copiaban a mano libros como los Evangelios. Todos los escribientes, no importan cuán cuidadosos, están expuestos a cometer errores, y algunos se sentirán inclinados a "mejorar" voluntariamente el original. Si todas las copias fuesen hechas a partir de un solo original, el significado no se falsearía demasiado. Pero si las copias se hacen 
a partir de otras copias que a su vez fueron hechas de otras copias, los errores empezarán a ser acumulativos y graves. Tendemos a considerar las copias erráticas como algo malo, y en el caso de los documentos humanos es difícil hallar ejemplos donde los errores puedan describirse como mejoras. Supongo que a los eruditos de la Versión de los Setenta se les podría atribuir el haber iniciado algo de enorme trascendencia cuando tradujeron equivocadamente la palabra hebrea "mujer joven" por la palabra griega “virgen”, resultando así la profecía:

"He aquí que una virgen concebirá y dará a luz a un hijo...". De cualquier modo, como veremos, el copiado errático de los replicadores biológicos puede, en un cierto sentido, dar lugar a mejoras, y para la evolución de la vida fue esencial que se cometieran algunos errores. No sabemos con qué precisión hacían sus copias las moléculas replicadoras originales. Sus descendientes modernas, las moléculas de ADN, son asombrosamente fieles comparadas con el proceso humano de copiado de más alta fidelidad, pero aun aquellas ocasionalmente cometen errores y en última instancia son esos errores los que hacen posible la evolución (Dawkins, 1976).

\section{Carl Sagan, Cosmos, 1980.}

El Cosmos fue descubierto apenas ayer. Durante millones de años todos tenían claro que no existían otros lugares fuera de la Tierra. Entonces, en la última décima de una centésima del lapso de vida de nuestra especie, en el instante entre Aristarco y nosotros, notamos con reticencia que no éramos el centro y el propósito del Universo, sino que vivíamos sobre un mundo diminuto y frágil perdido en la inmensidad y en la eternidad, navegando en un gran océano cósmico salpicado aquí y allá con millones de billones de galaxias y miles de millones de billones de estrellas. Con valentía hemos probado las aguas y hemos encontrado el océano a nuestro gusto, en resonancia con nuestra naturaleza. Algo en nosotros reconoce al Cosmos como el hogar. Estamos hechos de ceniza estelar. Nuestro origen y evolución han estado ligados a eventos cósmicos distantes. La exploración del Cosmos es un viaje de autodescubrimiento (Sagan, 1980).

\section{Alejandro Quevedo, "De fantasmas a fantasmas", en Naturaleza, México, 1983.}

Cuando el ministro Irma B. Otis tramitaba la compra de la propiedad de Canterville, todos le advirtieron que era una tontería — cuenta Wilde — pues el lugar estaba embrujado. El propio Lord Canterville le dijo "me temo que el fantasma existe".

Cuando Wolfgang Pauli concibió una partícula fantasmal que le permitía comprender ciertos aspectos misteriosos del decaimiento beta, y se lo dijo a sus amigos allá por 1930, a todos les pareció una idea insólita y a la vez digna de un teórico como él, pero nadie le aseguró que existiese. Hoy los físicos inventan media docena de partículas cada fin de semana, sin que ello cause asombro, ya que por lo regular, transcurridos un par de días durante los que se exponen y discuten esas ideas, ninguna subsiste. 
Pero el fantasma de Pauli nació bajo una buena estrella; no así el de Canterville que penó por más de 300 años. Fue Enrico Fermi quien bautizó la idea de Pauli llamándola "neutrino" (neutroncito) y a él se debe en gran medida la buenaventura que lo ha caracterizado desde entonces. El ministro tuvo sus motivos para adquirir la propiedad de Canterville, aunque incluyese, aparte del mobiliario y los jardines, a un fantasma. Pauli también tuvo sus razones; era mejor aventurar la hipótesis de una partícula como el neutrino que perder leyes tan firmes y útiles como las de la conservación de la energía y del ímpetu (Quevedo, 1983).

\section{Alan Lightman, Sonrisa, 1985.}

Los labios de la mujer están brillando a la luz del sol, reflejando luz de alta densidad en la parte posterior de la retina del hombre [...]. Después de unos 30 segundos —después de que varios cientos de billones de partículas de luz reflejada han entrado a los ojos del hombre y han sido procesadas_ la mujer dice hola. Inmediatamente, las moléculas de aire son comprimidas, partiendo de sus cuerdas vocales y viajando en un movimiento como de resorte hasta los oídos del hombre. El sonido hace el viaje desde ella hasta él (20 pies) en un cincuentavo de segundo.

Dentro de cada uno de sus oídos, el aire vibrante rápidamente cubre la distancia hasta el tímpano. El tímpano, una membrana oval de unas 0.3 pulgadas de diámetro inclinada 55 grados respecto al piso del canal auditivo, empieza a vibrar a su vez y transmite su movimiento a tres diminutos huesos. De allí, las vibraciones agitan el fluido en la cóclea, que se curva en espiral como un caracol de dos y media vueltas. Dentro de la cóclea, los tonos son descifrados. Aquí, una membrana muy delgada ondula en consonancia con el turbio fluido y a través de esta membrana basilar corren diminutos filamentos de diversos gruesos, como cuerdas de un arpa. La voz de la mujer, desde la distancia, está tocando esta arpa. Su hola empieza en los registros bajos y eleva su tono hacia el final. En respuesta precisa, los filamentos gruesos de la membrana basilar vibran primero, seguidos de los más delgados. Finalmente, decenas de miles de cilindros salientes de la membrana basilar conducen sus temblores particulares al nervio auditivo.

El mensaje del hola de la mujer, en forma eléctrica, corre por las neuronas del nervio auditivo y entra al cerebro del hombre a través del tálamo hasta una región especializada de la corteza cerebral, para ser procesado. Finalmente, una gran fracción de los billones de neuronas en el cerebro del hombre es implicada en el cómputo de los datos visuales y auditivos recién adquiridos. Los canales de sodio y potasio se abren y se cierran. Las corrientes eléctricas corren por las fibras neuronales. Las moléculas fluyen de una terminación nerviosa a la siguiente.

Todo esto se sabe. Lo que no se sabe es por qué, después de casi un minuto, el hombre se aproxima a la mujer y le sonríe (Lightman, 1985). 
Los anteriores ejemplos reúnen varias de las características que Ana María Sánchez Mora atribuye a los buenos textos de divulgación de la ciencia como literatura, porque:

- Se apoyan en la historia y la tradición.

- Usan la ironía y el humor.

- Logran entretejer arte y ciencia.

- Emplean analogías y metáforas.

- Recurren a lo cotidiano.

- Ceden espacio a la metafísica y a la religión.

- Se refieren a la cultura popular.

- Reconocen los errores humanos.

- Desacralizan la ciencia.

\subsection{Propaganda científica}

El mexicano Rolando Isita Tornell supuso que el problema principal de la transmisión social del conocimiento científico era la falta de un modelo de comunicación que interactuara y adecuara al sistema científico con los sistemas ideológico y social, sin entrar en conflicto con los valores, las creencias, los miedos, las fobias, las filias, las recetas, las costumbres y las tradiciones que caracterizan al público destinatario. Esta consideración lo animó a buscar un modelo que cumpliera con esas expectativas. Lo presentó en 1995, como tema central de su tesis doctoral, bajo el nombre de Propaganda científica (Isita, 1995). La premisa fundamental de su propuesta es que la ciencia no sólo es parte de la cultura, sino que en ocasiones la determina. 
Esta premisa la sustenta en los análisis escritos por John Bernal (1959) y Ruy Pérez Tamayo (1998). Es una idea que también la destacó Martín Bonfil Olivera en un artículo referente a la relación entre ciencia y cultura, (Bonfil, 2001), en donde empezó por atribuir varias definiciones al término cultura, como la denominada culta -que es elitista- y la que representa el conjunto de todos los productos de la actividad humana. En el segundo grupo contempló a la tecnología y a las culturas populares; pero también incluyó a la ciencia como parte de la cultura, con el argumento de que ésta surge de la creación humana.

Tanto la mente como la conciencia son fenómenos naturales porque, desde una perspectiva biológica, ambos son producto de la evolución. Sobre la base de esta premisa, Bonfil dijo que todas las ciencias destinadas al estudio de la mente humana (a las que denominó mundo 2, el filósofo Karl Popper), así como las que estudian la cultura (mundo 3, según Popper), forman parte del mundo biológico; el cual, a su vez, integra el universo físico (o mundo 1, en la obra de Popper). Para más información, véase Popper 1993: 20-30.

"Podría decirse, entonces, que no sólo la ciencia es parte de la cultura sino que la cultura es un fenómeno que surge a partir del mundo biológico, y por tanto queda dentro del amplio campo de estudio de la ciencia”, concluyó Bonfil en el citado artículo.

Isita concibe la cultura como un sistema global de culturas públicas ordenadas, pertenecientes a todas las actividades que se desarrollan dentro de la sociedad. Dentro de cultura identifica a los subsistemas ideológico, científico y social; cuya coherencia depende del análisis de los ocho propiospectos ${ }^{45}$ que caracterizan a los miembros de una sociedad.

Entendida la cultura como un sistema global; la ciencia, la ideología y lo social como los tres subsistemas fundamentales de la cultura, habremos de poner en relieve que la ciencia, de los

\footnotetext{
${ }^{45}$ Rolando Isita denomina propiospectos al grupo de creencias, valores, tradiciones, hábitos, fobias, filias, símbolos y conocimientos que caracterizan a una sociedad.
} 
tres subsistemas, es un sistema especial con sus propios valores y tradiciones legitimados por sus resultados; que su capital humano, en cambio, es producto de la sociedad en que la actividad científica se halla inmersa; que no hay manera de sustentar ninguna modernidad ni progreso económico si no existe en su base el desarrollo de la ciencia y su aplicación (Isita, 1995).

Isita sugiere divulgar la ciencia sin dejar de considerar la influencia de los tres subsistemas. Por tanto, un divulgador debe empezar por cuestionarse cuáles son los valores que priman en una sociedad, cuál es su imaginario colectivo y qué estrategias o políticas de Estado aplica ésta en el ámbito científico. "Pero si realiza su trabajo en un país con políticas de Estado incoherentes, debe esmerarse por lograr que su estrategia sea coherente con las necesidades de su entorno", aclaró Isita en una de las clases que impartió en la sexta edición del Diplomado en Divulgación de la Ciencia, de la Dirección General de Divulgación de la Ciencia de la UNAM. ${ }^{46}$

Entre los estudios que inspiraron este modelo están los realizados por Pierre Fayard; porque, a pesar de que este autor se abstuvo de usar el concepto propaganda, vislumbró en su análisis la interacción de la ciencia, la ideología y la sociedad, por medio de la seducción y la persuasión.

El estudio de Bernard Dixon (Dixon, 1986: 379-385) fue el primero que abordó la divulgación de la ciencia desde una perspectiva propagandística, según Isita. Pero no fue la propaganda en sí el objetivo del estudio, sino los libros y las películas como medios para hacer propaganda de la ciencia.

La propaganda puede clasificarse en eficaz o ineficaz. Resulta eficaz cuando, en lugar de ser elaborada empíricamente, se la ejecuta sobre la base de encuestas, de estudios de

\footnotetext{
${ }^{46}$ La autora de esta tesis cursó la sexta edición del Diplomado en Divulgación de la Ciencia, en la DGDCUNAM.
} 
mercado y de otras técnicas que permitan valorar la opinión del público meta. Ya que el conocimiento científico no es un producto determinado, difícilmente se podrá realizar un estudio de mercado referente a la ciencia; por eso, con mayor razón, el estudio debería priorizar los criterios provenientes de los receptores intencionales. El interés del divulgador no deberá ser cuántos recibieron su mensaje, sino quiénes lo recibieron y qué efecto les provocó.

Varios estudios sobre propaganda han demostrado que, con ella, se pueden inducir deliberadamente conductas, valores, creencias, fobias o filias; a favor o en contra de una idea, de una persona, de partidos políticos, de estados y de naciones. Que su ámbito de operación es el ideológico y el social, que se dirige a los sentimientos y no a la razón, aunque nada excluye que se pueda usar la razón dirigida a los sentimientos. Que, para ser eficaz, debe considerar la historia, las tradiciones, los valores, los símbolos y las creencias de los destinatarios de su acción. Que es más efectiva si está vinculada a programas de gobierno. Y que no debe circunscribirse sólo a medios de comunicación, sino que debe englobar todo hábito en donde tenga expresión la cultura, en cualquiera de sus manifestaciones (Isita, 1996: 66).

Una meta de la propaganda científica es la superación de los miedos que surgen de la naturaleza, del universo y del entorno social; pero, sin que ello implique suplir o imponer ante una creencia el conocimiento científico. Porque una de las características de este modelo es sustentarse en la creencia para ofrecer una explicación científica; dejar que convivan ambas ideas, pero logrando que la gente llegue a identificar sus diferencias y sus fundamentos. 


\subsubsection{Un ejemplo de propaganda científica: A golear con ciencia ${ }^{47}$}

\subsection{1.a) Justificación}

El avance científico y tecnológico en el área de las ciencias del deporte ayuda a disminuir los factores de riesgo en la salud, para superar problemas de obesidad, diabetes, hipertensión e infarto al miocardio. También contribuye a la detección y reclutamiento de talentos del deporte e, inclusive, al triunfo deportivo (Stokes, 1982).

El fútbol es el deporte que más impacto genera en los ámbitos nacional e internacional; el que a más público convoca sin resultar elitista ni discriminar por la edad o por el género (Nilo, 1983). Tanta es su relevancia, que incluso ha sido motivo de disputas a nivel social, político, económico y diplomático.

Un aficionado al fútbol, de nombre Albert Ruiz, recopiló en su página web las siguientes frases relacionadas con este deporte:

- "El fútbol no es una cuestión de vida o muerte, es mucho más que eso" (Bill Shankly).

- "Todo equipo que trata bien el balón, trata bien al espectador" (Jorge Valdano).

- "Siempre me gustó definir a la afición como un monstruo de mil cabezas. Sin embargo, existen unas que son más monstruosas que otras”(Jorge Valdano).

- "Hay dos tipos de espectadores: aquellos que aman el fútbol y aquellos que aman la moda o el fenómeno social. Estos últimos son los peligrosos" (Jorge Valdano).

\footnotetext{
${ }^{47}$ Este proyecto lo desarrolló la autora de esta tesis a mediados del año 2001, en México, para cumplir con la asignatura dirigida por el Dr. Rolando Isita Tornell, dentro del Diplomado en Divulgación de la Ciencia de la DGDC-UNAM. El proyecto fue aprobado.
} 
- "Si te agreden es porque eres bueno, porque te temen. Esa ilógica es la implacable lógica del enemigo y está registrada en el código de conducta más elemental del hincha de cualquier parte. Apunta al ánimo del adversario, pero sólo hace diana en los pobres de carácter" (Jorge Valdano).

Lo expuesto anteriormente confirma el gran impacto que tiene el fútbol en sus aficionados y en quienes lo aprovechan como escenario de poder, porque en muchos representa un factor de identidad nacional. Por tanto, su afición es masiva y gran parte está cautiva a través de los medios de comunicación que priorizan este deporte en su agenda noticiosa. Entre los periódicos mexicanos que cumplen con esta expectativa están los que pertenecen al grupo empresarial Reforma, concretamente los diarios Reforma y Metro, a cuyos lectores se escogió como público meta de este proyecto de propaganda científica, el cual fue diseñado por la autora de esta tesis a mediados del año 2001, en México, Distrito Federal.

A golear con ciencia es un proyecto que supone la presentación textual y gráfica de información referente a las ciencias del deporte; que pueden ser tan básicas como la fisiología y la bioquímica del ejercicio, la biomecánica y la nutrición del deporte, o tan complejas como son la kinesiología, la sociología, la psicología, la administración, la filosofía, la legislación y la tecnología del deporte.

Un principio que sustenta la formulación de este proyecto es que las adaptaciones fisiológicas a la actividad física regular disminuyen la morbi-mortalidad asociada con enfermedades cardiovasculares (Padilla, 2000; Gollnick Philip et. als., 1984). El objetivo es demostrar que en el cuerpo humano es posible detectar señales que reflejan el estado de salud de una persona - como la temperatura, el pulso, la frecuencia ventilatoria y la tensión 
arterial— y responder a preguntas frecuentes sobre el rendimiento y la fisiología del deporte. Entre estas preguntas consideradas para este proyecto, destacan las que se refieren a: recuperación con respecto al ejercicio, función muscular y entrenamiento con pesas, sistema de transporte de oxígeno, entrenamiento aerobio y anaerobio, composición del cuerpo, cambios de peso y nutrición, necesidades de agua y enfermedades provenientes del calor.

Para evitar problemas bioéticos relacionados con intensidad, duración y frecuencia del ejercicio, conviene realizarse previamente exámenes médicos y contar con la supervisión de personal calificado, como un técnico en fisiología del ejercicio, un profesor de educación física, un entrenador, un médico del deporte, un rehabilitador, o un investigador científico del deporte (Padilla, 2000). Pero el costo de esos exámenes hace que no todos puedan practicárselos. Esta carencia es la que me propuse cubrir con la ejecución de mi proyecto $A$ golear con ciencia, pues su contenido sustenté en información ofrecida por profesionales de las ciencias del deporte, en México.

\subsection{1.b) Propuesta}

Este proyecto, que la autora de esta Tesis diseñó a finales de 2001 en México, consistía en la publicación semanalmente de una página con información referente a la actividad futbolística, a partir de estudios promovidos por las ciencias del deporte. El nombre de esa página fue A golear con ciencia. Inicialmente se propuso publicarla en la sección deportiva del periódico, tras la realización de un estudio de mercado sobre el público meta de a sección. Luego de seis meses se ofreció evaluar la aplicación del proyecto y la percepción del público meta de esa sección periodística. 
La autora de este proyecto de propaganda científica se comprometió a desarrollarlo con creatividad, claridad y sencillez en el lenguaje; sin dejar de considerar la ciencia como parte de la cultura ni de contemplar los ocho propiospectos (creencias, valores, tradiciones, hábitos, fobias, filias, símbolos y conocimientos) que caracterizaban al público meta del proyecto.

\subsection{1.c) Género}

Estos son los géneros periodísticos que se consideró para la publicación de la página semanal A golear con ciencia:

- Reportaje.

- Entrevista.

- Columna de opinión.

- Reseñas de libros.

- Publicidad.

\subsection{1.d) Público objetivo}

Inicialmente, el proyecto estuvo destinado a los lectores de la sección deportiva del diario. Luego de seis meses se propuso aplicar este modelo de divulgación científica en otras secciones del diario.

Para desarrollar este proyecto de propaganda científica, hay que considerar las características del público al que va destinada la sección deportiva del diario donde se ejecute la propuesta $A$ golear con ciencia.

La pasión por el fútbol convoca en el estadio a gente de distinta condición social, tendencia política o edad. Y aunque mayoritariamente son hombres quienes asisten, va en 
aumento el número de mujeres aficionadas. Pero esta afición no siempre acude a los partidos, algunos prefieren enterarse a través de la radio o la televisión y complementar su información con la lectura del periódico. A estos hinchas o aficionados está destinado el actual proyecto.

Para conocer algunos rasgos característicos de estas personas, entrevisté al físico Enrique Buzo, secretario técnico de la Coordinación de Humanidades de la UNAM y experto en la aplicación de conocimientos de física al comportamiento del cuerpo humano. En su criterio, los hinchas del fútbol son personas que requieren de líderes y que pueden enlistarse en uno de los siguientes grupos:

- Fanático juvenil: Cuya edad oscila entre los 10 y 17 años de edad. Estas personas suelen dejarse llevar por las apariencias, porque "el problema de los jóvenes es que han perdido su capacidad de asombro”, lamenta el físico.

- Fanáticos maduros: Tienen entre 22 y 35 años de edad. Según Buzo, estos fanáticos desean mostrarse críticos ante el fútbol y actúan como si fueran técnicos o entrenadores de butaca. "De ellos hay que tener cuidado — advierte Buzo—, porque son los que entienden indebidamente los mensajes de la Medicina del deporte".

- Fanáticos dinosaurios: Son los que, después de los 35 años, desarrollan un gusto por el juego. "Ya no se identifican con un equipo en particular, sino que tienen la misma actitud acrítica que los fanáticos juveniles. Pero, si alguien pierde, buscan a un culpable. Si llegan a madurar en la fase de fanáticos maduros, podrían ser más críticos y convertirse en patriarcas o analistas del fútbol”, señala Buzo.

Con ironía y machismo, el físico mexicano Buzo dice que las mujeres fanáticas al fútbol son peores que los hombres. "Son más listas que ellos y algunas empezaron a serlo porque 
se dieron cuenta de que el fútbol es un medio para acercarse a los hombres. La mujer demostró su inteligencia desde que le dijo al hombre que ella era el sexo débil y que por eso él debía ir a trabajar", opina sonriente.

Sobre la base de estas apreciaciones, Buzo cree que el impacto de una propaganda científica sobre Medicina del deporte dependerá del grupo de fanáticos que la recepte. Para que resulte un buen ejercicio de divulgación, sugiere la ruptura del mito de que la Medicina del deporte es únicamente curativa, ya que también es preventiva. "El peligro surge por las falsas expectativas que puede generar la propaganda científica. Por eso, lo ideal es que ésta provoque el deseo de más información, en lugar de crear confusión o ideas erradas sobre lo que se deseaba divulgar. Es decir, que la propaganda debe despertar la curiosidad, pero no crear expectativas que sean como panacea ante un problema. La naturaleza del mensaje no debe ser fugaz, sino que debe estar relacionada con la vida cotidiana", ${ }^{48}$ aclara Buzo.

\subsection{1.e) Objetivos}

Principal: Promover en los lectores la predisposición para atender, valorar y asumir sugerencias médicas y fisiológicas relacionadas con la actividad fisicodeportiva y más acciones que conlleven a conservar una buena salud.

\section{Secundarios:}

- Fomentar la cultura científica en los aficionados al fútbol.

- Compartir información actualizada y contextualizada sobre los avances logrados en las ciencias del deporte.

\footnotetext{
${ }^{48}$ Fragmento de la entrevista realizada al físico Enrique Buzo, a mediados de julio del 2001.
} 
- Refutar con argumentos científicos los mitos que afectan a la práctica futbolística.

- Responder a las preguntas más comunes en torno al rendimiento y a la fisiología del ejercicio.

- Advertir sobre los posibles riesgos que plantea el consumo de productos alimenticios o vestimenta no apropiada para el desarrollo de actividades fisicodeportivas.

\subsection{1.f) Temario}

A continuación, expongo un listado de temas que podrían servir para publicar en la página A golear con ciencia:

- $\quad$ Causas de lesiones en deportistas jóvenes.

- $\quad$ Efectos provenientes del uso de anabólicos.

- $\quad$ Riesgos por el consumo excesivo de bebidas energetizantes (como Gatorade) o de bebidas alcohólicas; antes, durante y después del ejercicio.

- $\quad$ Tipo de calzado apropiado para cada disciplina deportiva.

- $\quad$ Adicciones que afectan el desempeño deportivo; relación entre tabaquismo y deporte.

- $\quad$ Lenguaje y jerga propia del ambiente futbolístico; su influencia en la literatura.

- Influencia de la altura en el rendimiento fisicodeportivo de los futbolistas.

- Liderazgo deportivo, político o empresarial que se ancla en la pasión por el fútbol. Análisis del estratega argentino Jorge Valdano, quien destacó como jugador en la Copa Mundial de Fútbol de México de 1986. 
- $\quad$ Antecedentes históricos del fútbol. En México, relación que existe con el antiguo juego de pelota de los mayas.

- $\quad$ Pros y contras de las dietas.

- $\quad$ El cuerpo y sus atributos.

- $\quad$ Características de la actividad físicodeportiva en la antigüedad.

- $\quad$ Apoyo universitario a las actividades deportivas y recreativas; especialmente al fútbol.

- $\quad$ Formas de recuperarse después del ejercicio.

- $\quad$ Relación entre la función muscular y el entrenamiento con pesas.

- $\quad$ Sistema de transporte de oxígeno.

- $\quad$ Entrenamiento aerobio y anaerobio.

- $\quad$ Cambios de peso y la nutrición.

- $\quad$ Importancia del agua para la actividad físicodeportiva.

- $\quad$ Enfermedades que afectan al deportista, por el calor.

- $\quad$ Sugerencias para estar más activo durante la vida cotidiana.

\subsection{Imaginario audiovisual de la ciencia, desde un enfoque sociocultural}

“Noticias e informaciones, ciencias y religiones, mitos y novelas, refranes y diálogo cotidiano, todos los contenidos de la cultura situada y virtual dirigen nuestra actividad y nuestro pensamiento. Nos dicen quiénes somos, qué es el mundo (social y natural), qué son las cosas, artefactos y operadores materiales y simbólicos de las tecnologías, saberes y lenguas creados por el hombre y, sobre todo, qué es la vida y a dónde vamos. De una u otra manera: en los curricula escolares o en la prensa, en la ciencia o en el teatro, en el templo o en las tertulias de televisión, en el bar o leyendo una novela”.

(Pablo del Río et als., 2004). 
El análisis sobre el rol de las narrativas en la argumentación sobre CYT demuestra que estos temas se tornan significativos cuando se los expone desde la narrativa (ejemplo: la producción de Carl Sagan o de Isaac Asimov). Porque, mientras las noticias y otros géneros informativos proporcionan mucha información y pocas estructuras de fondo, la ficción ofrece resultados más contextualizados. La ficción plantea un pasado y un futuro que permite dar forma al presente, para verlo como algo representado y para poder inscribirlo en una narrativa de mundo y de vida. Por eso las narrativas aportan a la construcción de la realidad desde lo imaginario.

Para comprobarlo, se realizó un análisis de contenido cualitativo y cuantitativo a una muestra representativa de los programas de televisión más vistos en España por el público infantil (cuyas edades oscilan entre 4 y 12 años), durante la semana comprendida entre el 3 y el 9 de noviembre del año 2003.

Esta muestra constituyó el corpus empírico de un proyecto de investigación estable que desarrolla la Universidad de Salamanca a través del Centro Tecnológico de Diseño Cultural (CTDC), en convenio con el Ministerio de Educación y Ciencia (MEC). Los canales de televisión considerados en la muestra, son: TVE, La 2, Antena 3, Tele Madrid, Telecinco y Canal Plus (+).

El objetivo de esta investigación fue identificar los imaginarios y las representaciones de CyT que generan esos programas de televisión. Para el efecto, fue necesario distinguir los niveles de estructuración que cumplen los géneros informativos en ese medio. La metodología empleada constituye un desarrollo propio y específico de esta investigación.

Esta fue una de las hipótesis planteadas: que las narrativas (cine, novela) cubren la función del paradigma, la macroestructura del imaginario; mientras que las noticias cubren una función más limitada (las microestructuras). Este análisis es un paso previo para 
justificar el diseño de un "currículum cultural y mediático" de las representaciones que generan los mensajes de televisión sobre temas de CYT.

La investigación se sustentó en el concepto científico de la naturaleza humana (la teoría histórico-cultural) de L.S. Vygotski (Del Río et als., 2004; Vygotski, 1973 y 1978), cuyo enfoque destaca la influencia de la mediación artística para la construcción psicológica y educativa del ser humano, porque considera que ciencia y arte son dos maneras de acercarse al conocimiento científico.

Con esta investigación no sólo se pretendió identificar hallazgos científicos, sino también las representaciones y la discusión sobre las implicaciones que genera el desarrollo científico-tecnológico en la sociedad; la evaluación de tecnologías, la participación pública en CYT y el desarrollo de políticas científico-tecnológicas. Para el efecto, se siguió la actual línea teórica de los estudios relacionados con la percepción pública de la CYT, y se enriqueció el análisis con el aporte que ofrece el enfoque histórico-cultural a la evaluación de las representaciones sociales y de los imaginarios generados por la televisión.

\subsubsection{Comunicar la ciencia al público desde un enfoque sociocultural: propuesta desde la perspectiva Genético Cultural}

La incapacidad de las escuelas para adecuarse a los cambios dinámicos que surgen en su entorno agudiza cada vez más la crisis que afrontan varias instituciones educativas en España y en más países de Iberoamérica. Por tanto, cabe preguntarse si los maestros están preparados para comprender y enfrentar las formas de transformación social tan radicales que generan los nuevos contextos de globalización.

Para comprender mejor este dilema, y para avanzar en la formulación de soluciones, conviene analizar la propuesta que ofrecen Pablo del Río, Amelia Álvarez y Miguel del Río 
en su obra Pigmalión: Informe sobre el impacto de la televisión en la infancia (2004). En esa obra se propone rediseñar la educación, con el fin de enfrentar los desafíos de un mundo en cambio acelerado, y de replantear el objetivo de la alfabetización como un programa para dominar las lectoescrituras y las multialfabetizaciones.

Por eso es necesario comprender a los niños como un "nuevo, renovado, diseño humano", para ayudarles a realizar su propia construcción personal de la mejor manera posible, salvaguardando lo mejor del pasado, ayudándoles a apropiarse de lo mejor del futuro, defendiéndoles en lo posible de los ataques de las mutaciones destructivas. (Del Río et als., 2004: 16)

$\mathrm{Su}$ análisis lo sustentan en la perspectiva histórico-cultural desarrollada por L.S. Vygotski (base fundamental del constructivismo) y por varios seguidores (como Bruner, Cole, Rogoff, Del Río). A partir de esta perspectiva, se ha logrado sustentar importantes alternativas metodológicas que ayudan a comprender y a aprovechar mejor los nuevos retos educativos. Uno de los grandes méritos de la teoría vygotskiana es su capacidad para ofrecer un modelo interdisciplinario de la mediación.

Para Vygotski, la escuela representaba un escenario cultural: un ámbito organizado socialmente para facilitar a los niños el uso y la apropiación de los instrumentos y de las actividades de la cultura. Por tanto, el aprendizaje humano supone una naturaleza social específica y un proceso mediante el cual los niños crecen dentro y hacia la vida intelectual de quienes les rodean. De ahí que el maestro asuma el rol de "facilitador" de esos conocimientos, instrumentos y habilidades culturales que el niño tiene que co-construir, en el marco de un contexto específico.

Este mismo análisis podría aplicarse a los medios de comunicación, pues uno de sus papeles fundamentales es in-formar; aunque no siempre anuncien al público que cumplen 
con esa función. La influencia de esos medios, sobre todo de la televisión, es cada vez más notoria en la formación de imaginarios y de representaciones sociales del público general. De ahí que convenga realizar investigaciones exhaustivas sobre el impacto cognitivo, cultural y social que está generando la televisión en el público infantil, como bien lo sugieren Pablo del Río, Amelia Álvarez y Miguel del Río en su Informe Pigmalión.

\footnotetext{
Como en las muñecas rusas, todas estas representaciones y remodificaciones de las herramientas del significado, todas estas mediaciones, llevan a una última y esencial herramienta del sentido que redefine realmente, en el fondo y no sólo en la forma, la aventura humana [...]. Los contenidos son los que, de hecho, sustituyen los instintos, emociones y objetos de la realidad animal por las narrativas, sentimientos y personajes de la realidad humana re-construida. La forma y la representación, las estructuras y los lenguajes son importantes, pero remiten en último término (deben remitir) a un contenido, a una nueva realidad propuesta por ellos. ¿Cuál sería el precio de olvidar que la escuela y la cultura de masas deben responder a esas grandes preguntas y que sus respuestas deben ser el territorio de esa nueva realidad y la brújula para orientarse en él? (Del Río et als., 2004: 16).
}

El precio de ese olvido ha sido la desorientación y el incumplimiento del cometido social que justificó la creación de la escuela y de los medios de comunicación. De ahí que el objetivo final de una pedagogía cultural de la alfabetización debería ser: analizar el modelo de mundo, de vida, de humanidad y de actividad que proponen los medios y la cultura actual, en su totalidad.

Desde las ciencias de la comunicación, el concepto de mediación y las teorías que éste propone se han constituido en el eje principal del actual pensamiento cultural. Los autores del Informe Pigmalión sugieren clasificar las entidades culturales o las mediaciones instrumentales en cinco grandes familias:

1. Los marcos o escenarios culturales o zonas sincréticas de representación (Del Río, 1990). 
2. Los artefactos culturales y medios de comunicación.

3. Los sistemas simbólicos, códigos y lenguajes.

4. Las estructuras formales de representación de carácter semántico (intermedias entre sistemas simbólicos y los contenidos); como conceptos, estructuras, géneros o formatos.

5. Los contenidos vitales vehiculados: mitos, modelos de mundo y de vida, ciencia, información, realidades o virtualidades representadas.

\subsubsection{Análisis sobre el imaginario audiovisual de la CYT}

Las familias 2 y 5 plantean aspectos que justificarían analizar la influencia de la televisión en la creación del imaginario audiovisual de ciencia y tecnología. Para sustentar este estudio con la propuesta desarrollada en el Informe Pigmalión, centré mi análisis de contenido en el impacto generado por la televisión en el público infantil.

A partir del análisis de contenido aplicado a una muestra representativa de los programas de televisión más vistos por el público infantil en España, se ha diagnosticado la influencia de este medio en la creación de imaginarios de ciencia y tecnología. Para el efecto, ha sido necesario distinguir los niveles de estructuración que cumplen los géneros informativos de la televisión. Los resultados de este análisis servirán para justificar el posterior diseño de un "currículum cultural y mediático" de las representaciones que generan los mensajes de televisión, en torno a temas científicos y tecnológicos.

La mayoría de proyectos diseñados para comunicar la ciencia al público siguen modelos de tipo asimétrico, limitado y unidireccional, como el de déficit o el de difusión. Por eso conviene proponer un modelo de comunicación más completo, desde una perspectiva 
sociocultural que contemple las articulaciones entre las formas de organización de la sociedad, las mediaciones y las prácticas discursivas de la ciencia y de su divulgación.

La "integración evolutiva" ha sido el gran aporte del enfoque interdisciplinario al desarrollo humano, que supone la constatación —desde las ciencias biológicas, la genética, las ciencias sociales y la psicología del desarrollo- de que los cambios en los niveles físicos, biológicos, sociales, culturales y psicológicos se integran, de manera dialéctica, en una reorganización sistémica que transforma todo el programa genético. ${ }^{49}$

Para analizar las culturas y proponer el diseño de un nuevo modelo de CPCT, conviene evaluar la relación entre el cambio cultural y el cambio humano. A este análisis puede contribuir la perspectiva genético cultural, que obliga a un diagnóstico del sistema cultural externo y social, a partir del supuesto de que cada cultura propone un sistema funcional de actividad y de conciencia acorde con su propia red cultural de mediadores. El objetivo de este tipo de diagnóstico consiste en analizar conjuntamente la cultura y la mente; propone comprender cada nueva generación como un Diseño Cultural del hecho humano.

Las investigaciones realizadas durante más de dos décadas por los españoles Pablo del Río y Amelia Álvarez demuestran que la buena aplicación del diagnóstico genético cultural ofrece un conjunto de conocimientos útiles para guiar las actuaciones humanas, a fin de optimizar los aspectos positivos del desarrollo y de evitar los nocivos; para intentar ver y valorar a tiempo las herencias culturales con valor funcional; para no dar lo humano por garantizado y evitar actuaciones masivas que destruyan su tejido cultural, o construcciones irreversibles excesivamente rápidas.

\footnotetext{
49 Reflexión expuesta por Pablo del Río y Amelia Álvarez en su artículo "Genética cultural y Diseño Cultural", publicado en Introducción a la selección de lecturas: Desarrollo, cultura y educación. La aproximación del Diseño Cultural.
} 


\subsection{Estudio de caso: proyecto Café Scientifique en Ecuador}

Los avances científicos o tecnológicos pueden tener efectos positivos o negativos en el ambiente, en la ecología, en el cuerpo humano, en el sector laboral, en la guerra y en la paz. Lo anterior implica, para países como Ecuador, la necesidad urgente de asignarle a la investigación científica y al desarrollo tecnológico un estatuto de política de Estado que permita derivar políticas públicas, como medio indispensable para acceder al crecimiento y al desarrollo justo del país. También obliga a ejercer mayor vigilancia civil y gubernamental sobre los posibles efectos negativos de la aplicación de la ciencia y la tecnología que se genera en el Ecuador o en otros países.

Para conseguir ambos propósitos, se requiere tomar en cuenta diversos factores, como son: la presión social o los problemas económicos, la inestabilidad política, la desnutrición, el desempleo y subempleo, el bajo promedio del nivel escolar nacional, la deficiente enseñanza y preparación en materias escolares de ciencias, los bajos índices nacionales de lectura, los medios de comunicación masiva ajenos a la ciencia nacional, los periodistas y comunicadores sin formación especializada en temas de ciencias, o la desvinculación estructural del sector productivo con el científico. Otro factor no menos relevante es la falta de espacios de diálogo constructivo y permanente entre los científicos y la sociedad; la consecuencia, es una sociedad distanciada de la cultura científica y tecnológica.

Superar estas limitaciones implica ejercer actividades de comunicación pública de la ciencia y la tecnología en diversos escenarios. Uno de los autores que inspiran esta propuesta es el francés Philippe Roqueplo, quien concluyó lo siguiente en su libro Le partage du savoir (en castellano: El reparto del saber, 1983): hay que "organizar 
conjuntamente un reparto de competencias para conectar saber y práctica". Roqueplo sugirió hacer esto en espacios cotidianos, como: talleres, en lo que concierne a la mecánica automotriz; consultorios médicos u hospitales, en lo que concierne a la salud. Al analizar la precitada conclusión de Roqueplo, el investigador francés Pierre Fayard escribió:

Esta recomendación increíblemente utópica va contra el fundamento de una sociedad tecnocrática, donde la posesión personalizada o institucionalizada de un saber es condición del ejercicio de una actividad económica. La manipulación verificadora y experimental, cuando fuera posible, permitiría la adquisición de un conocimiento operativo. La propuesta contiene los gérmenes de una verdadera apropiación del medio natural, corporal y tecnológico. Se asemeja en ello a las prácticas de ciertos médicos que informan a sus pacientes sobre el origen y mecanismo de sus trastornos, así como la forma de remediarlos. Pero el problema de la existencia previa de un nivel de conocimiento suficiente para dar sentido y organización a las informaciones transmitidas, permanece intacto. Por eso sigue siendo necesaria la divulgación que mitiga las insuficiencias culturales. Este planteamiento radical de Philippe Roqueplo debería cuestionar a todo mediador científico. ¿El objetivo de un producto de comunicación es o no el reparto de una habilidad efectiva? Al final de la operación, ¿el no especialista será más o menos dependiente del especialista? (Fayard, 2004: 39)

Promover encuentros más cercanos y permanentes entre la comunidad científica y la sociedad es el objetivo que se propuso cumplir el Instituto de Investigación para el Desarrollo (IRD) de Francia, el Programa Nacional de "Postgrado en Comunicación Pública de la Ciencia y Tecnología", la Alianza Francesa, la Embajada de Francia y varios organismos del Ecuador, al desarrollar el proyecto Café Scientifique (que inició como proyecto en el año 2006 y, al momento, tiene reconocimiento legal como Corporación).

Se trata de un proyecto de Comunicación Pública de la Ciencia y Tecnología, formulado a partir de un modelo de comunicación democrático y participativo. Con el fin de aportar al fomento de la cultura científica y tecnológica en el Ecuador, la autora de esta Tesis colaboró en el diseño y coordinación del proyecto Café Scientifique, versión Ecuador, 
desde octubre de 2006 hasta agosto de 2007. Desde septiembre de 2007, la coordinación de este proyecto se traspasó a otra persona, por el viaje que realizó a Holanda la autora de esta tesis. El proyecto siguió ejecutándose y, al momento, incluso tiene personería jurídica, con el nombre de Corporación Café Scientifique-Ecuador.

Este proyecto empezó a formularse en Quito, en octubre de 2006, con apoyo del Instituto de Investigación para el Desarrollo (IRD) de Francia. Posteriormente se incluyó la colaboración de varios científicos y organizaciones, como la Embajada Francesa, la Alianza Francesa, la empresa Telefónica, la Corporación Kimirina, la productora Mágika, la empresa de diseño Zur y el Cafelibro.

\subsubsection{Objetivos iniciales del proyecto}

- Promover el diálogo democrático e interdisciplinario entre miembros de la comunidad científica y el público en general, sobre temas de gran repercusión social.

- Aportar al fomento de la cultura científica y tecnológica en el Ecuador.

- Motivar la participación ciudadana en debates relacionados con el cometido social de la ciencia, la tecnología y la innovación.

\subsubsection{Metas del proyecto}

- Contribuir a la apropiación social del conocimiento científico y, consecuentemente, al fomento de la conciencia cívica en el Ecuador.

- Abrir nuevos espacios para el diálogo e intercambio de conocimientos y opiniones sobre el cometido social de la ciencia, la tecnología y la innovación. 


\subsubsection{Características del proyecto}

Desde su origen, los cafés científicos han permitido el diálogo sin tabúes sobre distintos temas de ciencia, tecnología e innovación; pero, especialmente, sobre el cometido social de estos conocimientos. Porque es deber de los científicos justificar la pertinencia de su trabajo para el conjunto de la sociedad, en términos accesibles. De esta voluntad de diálogo nacieron ediciones de cafés científicos en diferentes países; el primero se celebró en Francia, hace más de dos décadas, de ahí que en Ecuador este proyecto conserve el nombre de Café Scientifique.

Para su ejecución, este proyecto cuenta con el apoyo de una coordinación general, de un Comité Científico, de un Comité Organizador y de auspiciantes. En su origen, de la organización del Café Scientifique se encargaban: el Representante del IRD de Francia en Ecuador, Bernard Francou; el Director General de la Alianza Francesa, Marcel Zerr, representantes de la Embajada de Francia en Ecuador y la directora del "Postgrado en Comunicación Pública de la Ciencia y Tecnología” del Ecuador, María de los Ángeles Erazo, quien es autora de esta tesis doctoral. Posteriormente se involucró a más personas en esa coordinación, a través del Comité Científico y del Comité Organizador.

Este proyecto también cuenta con respaldo institucional del: Consejo Nacional de Educación Superior (CONESUP), Secretaría Nacional de Ciencia y Tecnología (SENACYT), Municipio Metropolitano de Quito, Cámara de Comercio de Quito, Museo Ecuatoriano de Ciencias Naturales, Facultad Latinoamericana de Ciencias Sociales (FLACSO), Universidad Central del Ecuador, Universidad San Francisco de Quito, Pontificia Universidad Católica del Ecuador, Escuela Politécnica Nacional(EPN), Escuela Superior Politécnica del Litoral, Organización de Estados Iberoamericanos (OEI), entre otros. 
La ejecución de este proyecto está abierta a todos quienes deseen participar en un diálogo interactivo, integrador y democrático, con la mediación de una persona que modera. La entrada a este acto ha sido gratuita desde el inicio.

\subsubsection{Conformación del Comité Científico}

La responsabilidad de cada miembro de este Comité es aportar en el análisis y selección de los temas correspondientes a cada edición del Café Scientifique, proponer el nombre de personas que pueden integrar el grupo de panelistas y garantizar el buen nivel de estos panelistas.

Con el fin de nombrar a los miembros de este Comité Científico, se convocó a una reunión el miércoles 13 de diciembre de 2006, en la Dirección de la Alianza Francesa de Quito. En esta reunión participaron las siguientes personas:

1. Dr. Bernard Francou, Director del IRD y promotor de la aplicación del proyecto de Café Scientifique en Ecuador.

2. Sr. Marcel Zerr, Director General de la Alianza Francesa.

3. Sra. Bénédicte Geneste, Directora Cultural de la Alianza Francesa.

4. Dr. Edmundo Estévez, médico e investigador en bioética y genoética de la Universidad Central del Ecuador.

5. Dr. César Paz y Miño, Ex Director del Laboratorio de Genética de la Pontificia Universidad Católica del Ecuador. Actualmente es decano del Instituto de Investigaciones Biomédicas de la Universidad de las Américas.

6. Mst. María de los Ángeles Erazo, Coordinadora del proyecto.

A esta lista se sumaron las siguientes personas, a partir de enero de 2007:

7. Dr. Washington Benítez, de la Universidad Central del Ecuador. 
8. Ing. Alexandra Alvarado, representante del Instituto Geofísico de la EPN.

9. Dr. Mauro Cerbino, Coordinador del Programa de Comunicación de la FLACsO.

10. Dr. Marco Antonio Altamirano, Museo Nacional de Ciencias Naturales.

11. Dr. Tarcisio Granizo, representante en Ecuador del organismo The Nature Conservancy.

12. María del Carmen Cevallos, en representación de la Corporación Kimirina.

\title{
4.5.5. Miembros del Comité Organizador
}

1. Sra. Bénédicte Geneste, Directora Cultural de la Alianza Francesa.

2. Sra. Cristina Carrión, Documentalista y representante del IRD.

3. Sra. Loly Espinoza, quien fuera representante de Prensa de la Alianza Francesa.

4. Sr. Nicolás Cimbaro, Agregado de Cooperación Técnica del Servicio de Cooperación y Acción Cultural, de la Embajada de Francia.

5. Sra. María Elena Machuca, Coordinadora de Actividades Culturales del Centro Cultural Metropolitano, Municipio Metropolitano de Quito.

6. Mst. María del Carmen Cevallos, en representación de la Corporación Kimirina.

7. Mst. María de los Ángeles Erazo, Coordinadora del proyecto.

\subsubsection{Patrocinadores económicos}

\author{
- IRD. \\ - $\quad$ Alianza Francesa. \\ - Embajada de Francia. \\ - Cafelibro. \\ - $\quad$ Corporación Kimirina.
}


- $\quad$ Movistar.

- Zur.

\subsubsection{Auspiciantes institucionales}

- $\quad$ Consejo Nacional de Educación Superior (CONESUP).

- $\quad$ Secretaría Nacional de Ciencia y Tecnología (SENACYT).

- Centro Cultural Metropolitano - Municipio Metropolitano de Quito.

- Cámara de Comercio de Quito.

- $\quad$ Museo Ecuatoriano de Ciencias Naturales.

- $\quad$ Facultad Latinoamericana de Ciencias Sociales (FLACSO).

- Universidad Central del Ecuador.

- $\quad$ Universidad San Francisco de Quito.

- $\quad$ Pontificia Universidad Católica del Ecuador.

- Universidad Politécnica Salesiana.

- $\quad$ Escuela Politécnica Nacional.

- $\quad$ Escuela Superior Politécnica del Litoral.

- $\quad$ Organización de Estados Iberoamericanos (OEI), entre otros.

\subsubsection{Público destinatario}

El diálogo que promueve el Café Scientifique está abierto a todos quienes deseen participar en un diálogo interactivo, integrador y democrático, con la mediación de una persona que participa como moderador/a del diálogo.

\subsubsection{Periodicidad e información adicional}


Desde el principio, y hasta la presente fecha, el proyecto Café Scientifique se ejecuta cada dos meses en la ciudad capital del Ecuador, Quito. El éxito alcanzado por este proyecto generó mucho interés en otras ciudades; de ahí que el Consejo Nacional de Educación Superior (CONESUP) propuso su apoyo para ejecutarlo en otras ciudades.

Hasta octubre de 2008 se han ejecutado 9 ediciones del Café Scientifique. Para acceder a más información e imágenes sobre el desarrollo y evolución de este proyecto, se creó la siguiente página web: http://www.cafe-scientifique.org.ec

\subsubsection{Características de las tres primeras ediciones del Café Scientifique}

\section{Características de la $1^{\mathrm{a}}$ edición del Café Scientifique}

Tema: “¡Nevados en peligro! Efecto del cambio climático”.

Lugar: CAFELIBRO, calle Leonidas Plaza N 23-56 entre Wilson y Veintimilla.

Fecha de 1ra. Edición: $\quad$ Martes 13 de marzo de 2007

Horario: $\quad$ De $18 \mathrm{HOO}$ a $20 \mathrm{H} 00$

Promotores del diálogo: $\quad *$ Dr. Luis Cáceres, Ministerio de Ambiente.

* Sr. Marco Cruz, guía de montaña.

* Dr. Eric Cadier, glaciólogo e hidrólogo, INAMHI/IRD

* Dr. Bernard Francou, representante IRD-Ecuador.

№ de asistentes: $\quad$ Más de 200 personas.

\footnotetext{
${ }^{50}$ La fundación del proyecto y la coordinación general de estas tres ediciones del Café Scientifique la llevó a cabo la autora de esta Tesis.
} 
El martes 13 de marzo de 2007, mientras grupos de poder promovían una lucha de intereses en Ecuador, en torno a la consulta popular y a la conformación del Congreso Nacional, también cobraba fuerza la voz de personas interesadas en aportar al fomento de la cultura científica y de la conciencia cívica. Por tal razón, esa noche, más de 200 personas se congregaron en el Cafelibro para participar en la primera edición del Café Scientifique, donde se analizó el tema: “¡Nevados en peligro! Efecto del cambio climático”.

Durante este encuentro se promovió un diálogo interactivo, abierto a todo público, a partir de evidencias científicas, experiencias y propuestas sobre la repercusión del calentamiento global en los nevados del Ecuador y del mundo.

En este diálogo, la principal conclusión fue apoyar en Ecuador la conservación de la Naturaleza y el mejoramiento de la calidad de vida del ser humano, lo cual conllevaría a disminuir los niveles del cambio climático y, consecuentemente, la desglaciación mundial.

Las inquietudes del público fueron respondidas o sustentadas con fundamentos de panelistas de reconocida trascendencia nacional e internacional, como son: Luis Cáceres, coordinador Nacional del Proyecto "Segunda Comunicación Nacional del Cambio Climático" (auspiciado por el Ministerio del Ambiente, por GEF y por el PNUD); Eric Cadier, investigador del INAMHI y del IRD; Marco Cruz, distinguido guía de montaña, y Bernard Francou, representante del IRD en Ecuador.

Pese a la torrencial lluvia y al agitado clima político que vivió el Ecuador el martes 13 de marzo, fue más importante el diálogo propuesto por el Café Scientifique para más de 200 científicos, educadores, investigadores, estudiantes, padres de familia y público en general, que se congregó esa noche en el local del Cafelibro.

\section{Características de la $2^{\mathrm{a}}$ edición del Café Scientifique}


Tema: "Viviendo con los volcanes: proceso eruptivo del Tungurahua".

Lugar: CAFELIBRO, calle Leonidas Plaza N 23-56 entre Wilson y Veintimilla.

Fecha de 3ra. Edición: $\quad$ Martes 15 de mayo de 2007

Horario:

De $18 \mathrm{H} 00$ a $20 \mathrm{HOO}$

Promotores del diálogo: * Hugo Yepes, Director del Instituto Geofísico de la Escuela

Politécnica Nacional.

* Edgardo Bartomioli, representante de la organización

Catholic Relief Services, en Ecuador.

* Rodolfo Azar, productor independiente.

$\mathrm{N}^{\mathrm{o}}$ de asistentes: $\quad$ Aproximadamente 160 personas.

El martes 15 de mayo, de 18 h00 a 20h00, se llevó a cabo la segunda edición del Café Scientifique en las instalaciones del Cafelibro. En esta edición se analizó el tema "Viviendo con los volcanes: proceso eruptivo del Tungurahua".

El principal objetivo de esta edición fue promover el diálogo en torno al modelo que actualmente permite comprender el funcionamiento del volcán Tungurahua, desde el punto de vista geocientífico. También se destacó el tema de las incertidumbres que ha generado el fenómeno eruptivo, cómo se las ha transmitido a la sociedad y cuáles han sido sus implicaciones en la gestión del riesgo volcánico.

A continuación, un resumen de las principales conclusiones de la segunda edición:

1. El riesgo volcánico es tarea de todos y que, por tanto, conviene promover en Ecuador el trabajo interinstitucional e interdisciplinario en la gestión del riesgo volcánico. 
2. Se debe evitar la teoría de la conspiración en la toma de decisiones políticas y sociales sobre el tema de gestión del riesgo volcánico.

3. Conviene promover más capacitación sobre la gestión del riesgo volcánico a través de los medios de comunicación y en los centros educativos.

4. Hay que apoyar la capacitación de los mediadores o comunicadores públicos de temas científicos y tecnológicos, como lo está haciendo el programa de "Postgrado en Comunicación Pública de la Ciencia y Tecnología", que se ejecuta actualmente en Quito, Guayaquil y Loja.

5. Se debe integrar a miembros de la comunidad como actores participativos en el proceso de capacitación y en la toma de decisiones sobre Gestión y Transformación del riesgo volcánico.

6. Conviene diferenciar claramente entre "mito" y "conocimiento científico" al hablar sobre gestión del riesgo volcánico, y aclarar estas diferencias a la sociedad.

7. Una de las principales vulnerabilidades es el desconocimiento de la gente. Por tanto, mientras ésta más conozca lo que significan las amenazas y su vulnerabilidad, estará en capacidad de tomar sus propias decisiones.

8. El problema del volcán Tungurahua debe analizarse más profundamente, para lo cual es necesario considerar los antecedentes en la toma de decisiones.

9. Uno de los principales problemas que involucran a los medios de comunicación, en el proceso de gestión y transformación del riesgo volcánico, es la falta de Comunicación Preventiva. Por tanto, conviene promover la cultura preventiva, en torno a esta temática. 
10. Se sugiere integrar el conocimiento ancestral con los avances técnicos y científicos, en la gestión y comunicación sobre el riesgo volcánico.

Preguntas fundamentales:

a. ¿Hasta el momento, qué conocemos sobre las características del proceso eruptivo del volcán Tungurahua, desde la óptica geocientífica?

b. ¿Cuáles son las incertidumbres propias de un proceso eruptivo?

c. ¿Cómo se deben transmitir esas incertidumbres en el marco del manejo social de un evento eruptivo?

\section{Características de la $3^{\text {a }}$ edición del Café Scientifique}

Tema: "Mitos y realidades sobre el VIH/SIDA".

Lugar: CAFELIBRO, calle Leonidas Plaza N 23-56 entre Wilson y Veintimilla

Fecha 3ra. Edición: $\quad$ Martes 10 de julio de 2007

Horario: De $18 \mathrm{H} 00$ a $20 \mathrm{H} 00$

Promotores del diálogo: * * Dra. Amira Herdoíza

Directora Ejecutiva, Corporación Kimirina.

* Lcdo. Rodolfo Muñoz,

Corresponsal de $\mathrm{CNN}$ en el Ecuador

* Dr. Edmundo Estévez

Director del Centro de Biomedicina, U. Central

* Guido Cisneros, Fundación Bhakty. 
El principal objetivo de esta edición fue dialogar en torno a los prejuicios, el conocimiento científico y experiencias que informan cómo prevenir el VIH/SIDA, para evitar que los números crezcan y que más personas resulten afectadas en el Ecuador. Porque hay varios mitos en torno al tema, lo cual está en directa relación con la información y educación de las personas, con los tabúes, el estigma y la discriminación que el tema conlleva.

Antes de la ejecución de este diálogo, varios ecuatorianos tuvieron oportunidad de participar en la presentación de una Obra de Teatro referente al tema de VIH/SIDA, en la Alianza Francesa. También pudieron receptar mensajes referentes a la convocatoria de esa edición del Café Scientifique, a través de diversos medios de comunicación.

Para iniciar la edición del Café Scientifique referente a "Mitos y realidades del VIH/SIDA", se proyectó un video sobre la actuación de "Las Zuquillo". Con su particular humor, las cuatro protagonistas de ese grupo de teatro dramatizaron un guión que abordaba mitos sobre VIH/SIDA, y promovieron algunos mensajes para apoyar la prevención; se refierieron a los grupos más vulnerables y exhortaron a la realización de la prueba, a fin de actuar con responsabilidad.

Durante el diálogo, a los asistentes también se les ofreció condones y materiales impresos relacionados con esta epidemia, muchos de los cuales fueron elaborados por la Corporación Kimirina.

A continuación, un resumen de las principales conclusiones de la tercera edición del Café Scientifique:

- Es fundamental la responsabilidad sexual en todas las personas.

- Es necesario promover más comunicación preventiva, a través de diversos espacios. Porque, desde la comunicación es posible plantear mecanismos de equidad. 
- Desde la bioética, se plantea cuatro principios aplicables al caso del VIH/SIDA: 1) La prueba del VIH/SIDA no debe imponerse o ser obligatoria. 2) Es necesario ampliar el acceso a los productos retrovirales. 3) No se debe fomentar la maleficencia (maldad). 4) Debe analizarse ese tema con justicia.

- La mejor vacuna contra el VIH/SIDA es la prevención.

- En el Ecuador se ha detectado como sectores más vulnerables a las mujeres, amas de casa, y a jóvenes. Por tanto, conviene ampliar las campañas de prevención en estos sectores.

- Debería impulsarse más educación en temas de sexualidad, desde la escuela.

- Son fundamentales los espacios de amplia participación, para superar los prejuicios en torno al VIH/SIDA. De ahí que convenga ampliar esta capacitación desde la familia, en el sector educativo o en el trabajo.

- Conviene integrar en esta capacitación o campañas de prevención a todas las organizaciones que están trabajando en torno al tema de VIH/SIDA (Estado, ONG's, universidades). Y debe reconocerse el buen trabajo realizado por las organizaciones que han desarrollado estrategias útiles para fomentar esta cultura de la prevención, como ha demostrado hacerlo la Corporación Kimirina.

\subsubsection{Evaluación de avances del proyecto Café Scientifique, Enero - Agosto 2007}

Durante el periodo de auspicio por parte de la Corporación Kimirina, al proyecto Café Scientifique, se logró convocar a más de 500 personas interesadas en participar en un diálogo interactivo e interdisciplinario sobre el cometido social de diversos temas científicos y tecnológicos. 
Para apoyar la promoción de las distintas ediciones del Café Scientifique y para dar continuidad al diálogo motivado por cada tema, se creó una página web. Su dirección anterior era: www.cafescientifique-ec.com $\mathrm{Su}$ actual página web es la siguiente: http://www.cafe-scientifique.org.ec

\subsubsection{1.a) Dificultades registradas en este periodo}

Durante la ejecución del proyecto Café Scientifique, una de las principales dificultades ha sido lograr que representantes de la comunidad científica expongan de forma adecuada, creativa y contextualizada sus mensajes, para lograr una mejor recepción por parte del público general.

Cada edición del Café Scientifique ha permitido mejorar y consolidar en Quito la fórmula del diálogo sencillo e integrador (o la aplicación del modelo democrático de comunicación pública de la ciencia y tecnología) para referirse al cometido social del conocimiento científico y tecnológico.

\subsubsection{1.b) Lecciones aprendidas}

Las personas que han participado en la organización, desarrollo y ejecución del proyecto Café Scientifique hemos aprendido a evaluar la ejecución de estrategias de comunicación pública de la ciencia y la tecnología. La experiencia de este proyecto nos ha confirmado cuán eficiente es recurrir a un modelo de comunicación democrático y sociocultural, en lugar de limitarnos al empleo del modelo del déficit, que es al que usualmente se recurre cuando se trata de transmitir socialmente conocimientos científicos.

El modelo de comunicación democrático promueve el diálogo interactivo, integrador e interdisciplinario entre representantes de la comunidad científica y el público en general. Y 
este ha sido el modelo de comunicación que hemos procurado aplicar en todas las ediciones del Café Scientifique.

Porque la meta principal de este proyecto es fomentar la cultura científica y preventiva, para motivar más participación ciudadana en la toma de decisiones sobre diversos temas científicos y tecnológicos.

\subsubsection{1.c) Solicitudes de asistencia técnica}

Es necesaria la asistencia técnica de una coordinadora, para apoyar en la organización y ejecución de cada edición del Café Scientifique; de una redactora, para elaborar un informe sobre la ejecución de cada edición del Café Scientifique; de técnicos encargados de la instalación de equipos de audio y de un equipo de producción, para cubrir de forma audiovisual el desarrollo de cada edición del Café Scientifique.

\subsubsection{1.d) Actividades realizadas}

1. Entrevistas y publicaciones para promocionar la $3^{\mathrm{a}}$ edición del Café Scientifique referente al Cambio Climático y, particularmente, al tema de nevados. La promoción se realizó a través de medios impresos, radio, televisión e Internet. Insumos y materiales entregados: material impreso elaborado por el IRD.

2. Ejecución de la $1^{\mathrm{a}}$ edición del Café Scientifique el martes 13 de marzo. Se abordó el tema: ‘Nevados en peligro! Efecto del cambio climático’.

$\mathrm{N}^{\mathrm{o}}$ de personas que asistieron a este diálogo: 220.

Insumos y materiales entregados: folletos y trípticos referentes al tema de esta edición. También se entregaron folletos, separadores, tarjetas y otros materiales de difusión de los organismos que auspician el Café Scientifique. 
3. Entrevistas y publicaciones para promocionar la $2^{\mathrm{a}}$ edición del Café Scientifique referente a la gestión del riesgo en volcanes. Esta promoción se realizó a través de medios impresos, de radio y de Internet.

4. Ejecución de la 2a edición del Café Scientifique, ejecutada el martes 15 de mayo. Se abordó el tema: 'Viviendo con los volcanes: proceso eruptivo del Tungurahua'. $\mathrm{N}^{\mathrm{o}}$ de personas que asistieron a este diálogo: 150 .

Insumos y materiales entregados folletos y trípticos referentes al tema de esta edición. También se entregaron folletos, separadores, tarjetas y otros materiales de difusión de los organismos que auspician el Café Scientifique.

5. Obra de Teatro ofrecida por el Grupo "Cuna de Brea", referente al tema del VIH/SIDA.

$\mathrm{N}^{\mathrm{o}}$ de personas alcanzadas: 100

Insumos y materiales entregados: condones y material impreso, elaborado por la Corporación Kimirina.

6. Entrevistas y publicaciones para promocionar la $3^{\mathrm{a}}$ edición del Café Scientifique referente a la epidemia del VIH/SIDA. Esta promoción se realizó a través de medios impresos, de radio, de televisión y de Internet.

Insumos y materiales entregados: material impreso y audiovisual, elaborado por la Corporación Kimirina.

7. Ejecución de la $3^{\mathrm{a}}$ edición del Café Scientifique, en la cual se abordó el tema: "Mitos y realidades del VIH/SIDA".

Esta edición se ejecutó el martes 10 de julio de 2007, de 18:00 a 20:00.

$\mathrm{N}^{\mathrm{o}}$ de personas que asistieron a este diálogo: Más de 100 . 
Insumos y materiales entregados: esferos con el logo de la Corporación Kimirina y del Café Scientifique; condones; folletos, separadores y trípticos referentes a la epidemia del VIH/SIDA, los cuales fueron elaborados por la Corporación Kimirina para esta edición. Actualmente, el proyecto continúa ejecutándose, bajo la coordinación de esta corporación y con el aval de los miembros del Comité Científico y Organizador.

\section{CAPÍtULOO 5}

\section{COMUNICACIÓN PÚBLICA DE LA CIENCIA Y LA TECNOLOGÍA DENTRO DE LA POLÍTICA CIENTÍFICA}


¿Cómo se podrá decidir la política de un país si sus ciudadanos no entienden los acontecimientos fundamentales (relacionados con el conocimiento científico y tecnológico)?

(Carl Sagan)

La ciencia, la tecnología y la innovación se han convertido en el principal soporte de las estructuras económica y productiva de la sociedad contemporánea; por eso conviene instituirlas al nivel de política de Estado. Pero si las políticas públicas en ciencia y tecnología no están orientadas a la solución de problemas nacionales fundamentales, éstas no contribuirán al desarrollo adecuado del país o a mejorar el bienestar de la población.

"El mundo actual no se concibe sin la ciencia y la tecnología, y resulta impensable el desarrollo de cualquier sociedad sin enfrentar, con políticas públicas adecuadas, que el impacto social de la ciencia y la tecnología mejore la vida del ciudadano. Pero el ciudadano no es un objeto, es un ente activo, punto de partida y destino de las Políticas Públicas". Así lo expresó Lina Domínguez, viceministra del Ministerio de Ciencia, Tecnología y Medio Ambiente de Cuba, en la inauguración del "Congreso Iberoamericano de Ciudadanía y Políticas Públicas en Ciencia y Tecnología”, celebrado en Madrid, España, del 5 al 8 de febrero de 2008 .

Para diseñar y construir políticas adecuadas a los contextos locales y regionales, que se integren a los escenarios nacionales y globales, se debe "disponer de diagnósticos e información que permitan la elaboración y el diseño de estrategias específicas eficientes para el mejor desarrollo de las potencialidades y capacidades, con el fin de promover la conformación de auténticas sociedades del conocimiento". Así lo sugirió la investigadora mexicana Martha Elena Márquez Villegas (2008), en el marco de ese mismo Congreso Iberoamericano, a partir de un análisis de la política científica que ha desarrollado en la Universidad Nacional Autónoma de México (UNAM). 
La mayoría de estudios relacionados con esta materia concluyen que el diseño y construcción de adecuadas políticas públicas en ciencia y tecnología requieren de participación ciudadana; y que, para lograrlo, conviene promover una relación más cercana y permanente entre la sociedad, los científicos y las autoridades encargadas de establecer políticas públicas. Este vínculo podrá lograrse con la ejecución de un Programa Nacional de Comunicación Pública de la Ciencia y la Tecnología; cuyo éxito dependerá, en gran medida, del modelo de comunicación que se aplique. Este trabajo propone adoptar un modelo de comunicación interdisciplinario, desde una perspectiva sociocultural.

\subsection{Razones para evaluar la Política Nacional de Ciencia, Tecnología e Innovación y para promover más participación ciudadana en esos temas}

La falta de una política científica orientada al estudio y a la solución de problemas nacionales, así como al fomento de una conciencia cívica, ha conllevado a varios países de Iberoamérica a un estado de extrema dependencia en los aspectos económico, industrial, político, científico y tecnológico.

Esta dependencia es confirmada por el español Jesús Sebastián, cuando analiza la evolución del desarrollo científico y tecnológico de América Latina (Sebastián, 2007: VII). A partir de su vasta experiencia en investigaciones referentes a esta región, relata que a principios del siglo Xx el desarrollo científico, especialmente en América del Sur, estuvo asociado al positivismo europeo y a esquemas de modernización basados, en buena medida, en la inmigración europea, la atracción de capitales y la adquisición de conocimiento externo. En este contexto, "las demandas por una investigación local son casi inexistentes, 
por lo que el incipiente desarrollo de las capacidades científicas se produce de manera autónoma" (Sebastián, 2007: VIII).

En esta obra, Sebastián recuerda que la generalización del modelo económico de sustitución de importaciones, impulsado por la CEPAL, contribuye al incremento de la industrialización enfocada a los mercados internos, mediante las correspondientes políticas arancelarias y crediticias, y la compra de tecnología incorporada. En su criterio, aunque esta etapa pudo suponer la del despegue del desarrollo científico y tecnológico, ésta no fue aprovechada suficientemente, a pesar de la generalización de centros tecnológicos en determinados sectores productivos.

El escaso dominio del cambio tecnológico y el desinterés por la tecnología no incorporada, con la consiguiente secuela sobre la escasa demanda por el desarrollo de tecnología endógena y por los procesos de adaptación y mejora tecnológica, impidieron una adecuada articulación entre investigación científica, desarrollo tecnológico y modelo económico. (Sebastián, 2007: IX)

Las notables diferencias en el desarrollo científico y tecnológico de los países de América Latina pueden corroborarse a través de los siguientes cuadros:

CuAdro 1. Distribución de los países de América Latina por indicadores de capacidades científicas:

\begin{tabular}{|c|c|c|c|c|c|}
\hline \multirow{2}{*}{$\begin{array}{l}\text { \% Investigadores } \\
\text { (personas físicas) por } 1.000 \\
\text { personas de la PEA }\end{array}$} & \multicolumn{5}{|c|}{$\%$ Gasto en I+D del PIB } \\
\hline & Menor de 0,1 & $0,1-0,3$ & $0,3-0,5$ & $0,5-0,7$ & $0,7-1,0$ \\
\hline Menor de 0,3 & $\begin{array}{l}\text { Ecuador } \\
\text { El Salvador } \\
\text { Honduras } \\
\text { Nicaragua }\end{array}$ & & & & \\
\hline $0,3-0,6$ & Paraguay & Bolivia & & & \\
\hline
\end{tabular}




\begin{tabular}{|l|l|l|l|l|l|}
\hline & & $\begin{array}{l}\text { Panamá } \\
\text { Perú } \\
\text { Venezuela* }\end{array}$ & & & \\
\hline $0,6-0,9$ & & Colombia & $\begin{array}{l}\text { Costa Rica } \\
\text { México* }\end{array}$ & & \\
\hline $0,9-1,5$ & & & Cuba & \\
\hline $1,5-3,0$ & & Uruguay & Argentina & Chile & Brasil \\
\hline
\end{tabular}

* El dato de Venezuela se refiere a Actividades Científico-Tecnológicas (ACT) y no solamente a I+D.

** El dato de México es de número de investigadores en Equivalente Jornada Completa (EJC).

Fuente: El Estado de la Ciencia. RICYT (2006) y elaboración de Jesús Sebastián (2007: XIX).

CUADRO 2. Evolución del \% gasto en I+D respecto al PIB.

\begin{tabular}{|c|c|c|}
\hline País & $\mathbf{1 9 9 3 - 1 9 9 5}$ & $\mathbf{2 0 0 1 - 2 0 0 3}$ \\
\hline Argentina & 0,41 & 0,41 \\
\hline Brasil & 0,90 & 1,01 \\
\hline Chile & 0,62 & 0,63 \\
\hline Colombia & 0,29 & $0,17 *$ \\
\hline Cuba & 0,60 & 0,63 \\
\hline México & 0,27 & 0,42 \\
\hline Venezuela** & 0,55 & 0,44 \\
\hline
\end{tabular}

* Datos de 2000-2001.

** Datos de ACT.

Fuente: RYCYT (2006) y elaboración de Jesús Sebastián (2007: XIX).

CuAdro 3. Número de patentes otorgadas a residentes por 1.000 investigadores (promedio de los últimos tres años)

\begin{tabular}{|c|c|c|c|c|c|}
\hline Menos de 2 & $\mathbf{2 - 4}$ & $\mathbf{4 - 6}$ & $\mathbf{6 - 8}$ & $\mathbf{8 - 1 0}$ & Más de 40 \\
\hline Bolivia & Argentina & & Chile & Cuba & Brasil \\
\hline Colombia & Costa Rica & & Uruguay & & \\
\hline & Ecuador & & Venezuela & & \\
\hline & México & & & & \\
\hline & Perú & & & & \\
\hline
\end{tabular}

Fuente: RYCYT (2006) y elaboración de Jesús Sebastián (2007: XIX). 
CUADRO 4. Balance entre la producción científica y tecnológica. Relación entre número de publicaciones científicas SCI y número de patentes otorgadas a residentes (promedio de los últimos tres años)

\begin{tabular}{|l|l|l|l|l|}
\hline \multicolumn{1}{|c|}{$\mathbf{3 - 5}$} & \multicolumn{1}{|c|}{$\mathbf{1 0 - 2 0}$} & \multicolumn{1}{c|}{$\mathbf{2 1 - 4 0}$} & \multicolumn{1}{c|}{$\mathbf{4 1 - 8 0}$} & \multicolumn{1}{|c|}{} \\
\hline Brasil & Cuba & Argentina & Chile & Bolivia \\
\hline & & Panamá & México & Colombia \\
\hline & & Perú & & Costa Rica \\
\hline & & Venezuela & & Ecuador \\
\hline
\end{tabular}

Fuente: RYCYT (2006) y elaboración de Jesús Sebastián (2007: XIX).

Al hacer un análisis comparativo con los datos que reflejan los cuadros antes citados, y las estadísticas que anualmente reporta el desarrollo científico y tecnológico de los países miembros de la Comunidad Europea (a través del denominado Eurobarómetro), podría concluirse que hay una gran brecha entre ambas regiones (Mac Culloch, 2005). Ello hace suponer que en la mayoría de países de América Latina la ciencia y la tecnología no están cumpliendo un cometido social, por no contribuir al desarrollo adecuado de los pueblos.

Este problema genera consecuencias lamentables para la población, es una de las principales razones que ha llevado a la masiva emigración de ecuatorianos hacia Estados Unidos y a diversos países de Europa, como España.

La búsqueda de soluciones anima a recordar el cometido social de la ciencia y la importancia de la comunicación para lograr que éste se cumpla. Porque, la ciencia que no se comunica no existe para el público general, a pesar de que la gestión de nuestras sociedades dependa cada vez más de los avances científicos y tecnológicos.

Para contextualizar este análisis, conviene resaltar la importancia de establecer una política científica adecuada. Un investigador mexicano que ha escrito sobre el tema es 
Marcos Kaplan, ${ }^{51}$ quien dice que todas las decisiones y actividades relacionadas con la ciencia tienen un carácter político; porque surgen y se desarrollan dentro de una estructura de poderes, sobre la cual se erige y actúa un arbitraje político. Según este investigador, toda política científica revela la coexistencia de tres conjuntos de variables, que presentan a la ciencia como elemento constitutivo, objeto y motivación de la acción política.

La política científica engloba el conjunto de intervenciones, decisiones y actividades de los poderes que coexisten en una sociedad y época dadas; está destinada a ignorar, obstaculizar, promover o estimular el progreso de la investigación científica y la aplicación de sus productos (Dedijer, 1969). En criterio de Kaplan, la política científica puede ser nacional o gubernamental: la nacional está constituida por el conjunto de políticas científicas correspondientes a los actores y unidades de los subsistemas político, social, productivo, cultural, educativo y científico; mientras que, la gubernamental, constituye el conjunto de medidas de intervención de poderes públicos destinadas a frenar o a estimular el avance de la ciencia.

Según Kaplan, siempre hay una política científica, que puede ser explícita o tácita, benéfica o perversa, por acción o por omisión; puede concretarse o no en planes, programas o proyectos; puede o no establecer una comunicación regular y más o menos armónica con otras políticas del Estado. Para evaluarla, este investigador sugiere considerar criterios e indicadores que agrupa de la siguiente manera:

1. Ideología de la política científica.

2. Grado de desarrollo de las organizaciones de investigación.

\footnotetext{
${ }^{51}$ Marcos Kaplan es politólogo, doctor en derecho y ciencias sociales e investigador nacional emérito del Sistema Nacional de Investigadores (SNI) del CONACYT. Ha publicado más de 30 libros y numerosos artículos sobre teoría y análisis del Estado, política científica y tecnológica, entre otros temas.
} 
3. Grado de desarrollo de los órganos centrales que intervienen en las políticas públicas de ciencia y tecnología, y de su integración en el sistema nacional que rige la toma de decisiones.

4. La política nacional de ciencia y tecnología como sistema de información.

El cuarto criterio permite justificar la propuesta de consolidar un Programa Nacional de CPCT, para fomentar la cultura científica, la participación ciudadana y la transparencia en la toma de decisiones sobre ciencia, tecnología e innovación.

\subsubsection{El reto es cerrar la brecha científica y pasar del análisis global a la acción local}

Al analizar la magnitud de la brecha que separa a la región de América Latina de otros continentes, Carlos Jarque, funcionario del Banco Interamericano de Desarrollo (BID), comenta lo siguiente:

Las brechas son significativas y son resultado tanto de los montos de inversión, como de la forma en que operan los Sistemas Nacionales de Innovación. Algunas cifras ilustran las brechas. Por ejemplo, los científicos holandeses o suecos, por separado, publican más que todos los hombres y mujeres de ciencia de América Latina y el Caribe. Muchos de nuestros investigadores están mal financiados, no están dedicados a las áreas críticas o estratégicas y, con frecuencia, tienen poca conexión con el sector productivo. En cuanto al número de personas en investigación y desarrollo, también hay grandes brechas. En Estados Unidos se estima que cerca de 1 millón de personas están dedicadas a investigación y desarrollo, en comparación con cifras menores a 30 mil en la mayoría de nuestros países. El número de sitios de Internet vinculados con CyT en Estados Unidos se mide en millones, en la mayoría de los países de América Latina es de menos de 300. Las diferencias también se reflejan, por ejemplo, en el número de patentes y en la cantidad de empresas con innovación continua. La capacidad de innovación parte desde los sistemas educativos. Cada vez hay una conexión más estrecha entre 
formación en ciencias básicas y tecnología. Sin embargo, la calidad de nuestros sistemas educativos requiere reforzarse, particularmente en estas áreas (Mac Culloch, 2005).

Para superar estas brechas, cada país debe fortalecer su Sistema Nacional de Ciencia, Tecnología e Innovación, y ofrecer soluciones a problemas tan importantes como son los relacionados con: educación, salud, nutrición, agricultura, calidad de la vivienda, explotación racional de los recursos naturales y energéticos, gestión del riesgo, entre otros. Al respecto, la experiencia de México aporta iniciativas alentadoras, como fue la creación del Programa Especial de Ciencia y Tecnología 2001-2006 (denominado PECYT), que estableció tres líneas estratégicas:
a) Disponer de una política de Estado en ciencia y tecnología.
b) Incrementar la capacidad científica y tecnológica del país.
c) Elevar la competitividad y la innovación de las empresas.

Uno de los grandes retos es valorar desde un contexto global las iniciativas que se propone en ciencia, tecnología e innovación; pero actuar localmente, con acciones destinadas a resolver las necesidades de cada país. Porque, como bien señala Carlos Jarque: "No sólo necesitamos invertir más, también tenemos que invertir mejor, en áreas críticas y estratégicas, de ventaja comparativa para cada país de la región" (Mac Culloch, 2005). Por eso Jarque estima necesario un nuevo paradigma, un enfoque más pragmático y un cambio sistémico profundo en el área de ciencia y tecnología:

Dado el gran dinamismo en CYT y la necesidad de esfuerzos persistentes, se tendrían grandes costos si caemos en acciones a corto plazo sin proyecto. Son costos en términos de crecimiento económico, pero también en pobreza y en pérdida del bienestar general. La región tiene grandes 
oportunidades en CYT, por sus recursos humanos y naturales, pero necesitamos incluir el tema en las prioridades nacionales, impulsar reformas estructurales y lograr más aliados y mejor coordinación de los sectores público, privado y académico. Debemos consolidar y fortalecer instituciones, articular mejor los sistemas de innovación y lograr, en particular, una mayor interacción con el sector productivo. Tenemos que reorientar recursos y acumular masas críticas, evitando dispersión y volatilidad en la inversión tecnológica. El reto es identificar las ventajas comparativas de cada país, así como de cada región, y concretar sus potencialidades, mostrar su rentabilidad económica y social, y elegircon criterio las áreas de mayor concentración. Se necesita un nuevo paradigma, un enfoque más pragmático y un cambio sistémico profundo en el área de Ciencia y Tecnología (Mac Culloch, 2005).

\section{2. "Ciencia y tecnología: patrimonio social de los ecuatorianos"}

En el año 2005 se registró un hecho histórico para el futuro de la investigación y la innovación en el Ecuador; porque, por primera vez, el Gobierno ecuatoriano consideró a la ciencia y a la tecnología como instrumentos clave para el desarrollo social y económico del país, por eso los ha instituido como una política de Estado.

Esta iniciativa fue acogida por el Congreso Nacional del Ecuador, con la aprobación de la Ley Orgánica de Responsabilidad, Estabilidad y Transparencia Fiscal, que destina el 5\% de recursos provenientes del excedente de la venta del petróleo para financiar proyectos de ciencia y tecnología. Se denominó "Fondos Cereps" a los ingresos provenientes de la cuenta especial "Reactivación Productiva y Social, del Desarrollo Científico-Tecnológico y de la Estabilización Fiscal"; estos recursos los destinó el Gobierno ecuatoriano para la implementación de Programas de Articulación, Consolidación y Fortalecimiento del Sistema Nacional de Ciencia, Tecnología e Innovación, desde finales del año 2005.

Esta decisión fue confirmada en el Reglamento General de la Ley de Reactivación Productiva y Social del Desarrollo Científico-Tecnológico y de Estabilización Fiscal, que 
se expidió a través del Decreto Ejecutivo No. 611, publicado en el Registro Oficial No. 131 del 24 de octubre del 2005.

Con este financiamiento, Ecuador podrá destinar más recursos para el desarrollo de estas actividades; pasó de invertir 0,06\% del Producto Interno Bruto (PIB), en el año 2004, a una inversión de 0,12\%, en el 2005, y a un mínimo de 0,22\%, en el 2006. Aunque estas cifras aún están muy distantes del promedio latinoamericano (0,60\% del PIB), sin duda empieza una época promisoria para la investigación científica y tecnológica en el Ecuador.

De 1994 a septiembre de 2006, la Secretaría Nacional de Ciencia y Tecnología (SENACYT) fue el organismo rector de la política científica y tecnológica en el Ecuador; mientras que la Fundación para la Ciencia y la Tecnología (FUNDACYT) ejercía las funciones ejecutivas y operativas.

De julio a diciembre de 2005, con el soporte técnico y administrativo de FUNDACYT, la SENACYT lideró un debate nacional, con el fin de diseñar la "Política Nacional de Ciencia, Tecnología e Innovación” del Ecuador, cuya vigencia regirá durante el quinquenio 20062010. Este trabajo supuso la activa participación de varios actores del Sistema Nacional de Ciencia, Tecnología e Innovación (SNCTI), como son representantes de universidades, escuelas politécnicas, cámaras empresariales, centros de investigación y secretarías de Estado. Entre todos, se pretendió poner en práctica el lema: "Ciencia y tecnología: patrimonio social de los ecuatorianos".

En septiembre de 2006, a través del Decreto Ejecutivo N 1829, se establece la creación del Consejo Nacional de Ciencia y Tecnología (CONACYT), para que asuma las responsabilidades que antes ejercía SENACYT; mientras que esta Secretaría pasó a ser el órgano ejecutivo y operativo del Sistema Nacional de Ciencia, Tecnología e Innovación. Tal decisión conllevó al término de las relaciones entre SENACYT y FUNDACYT. 


\subsubsection{Antecedentes legales de la transición de SENACYT y de FUNDACYT}

El Comité Ejecutivo CEREPS está integrado —según lo establecido en el Decreto Ejecutivo No. 965, promulgado en el Registro Oficial No. 175 de 28 de diciembre del 2005- por representantes de la Secretaría Nacional de Ciencia y Tecnología (SENACYT), del Instituto Nacional Autónomo de Investigaciones Agropecuarias (INIAP), de la Comisión Ecuatoriana de Energía Atómica (CEEA) y del Consejo Nacional de Educación Superior (CONESUP).

Este Comité aprobó proyectos de investigación y desarrollo tecnológico por un monto total de USD 8’117.701 y, mediante oficio SEN-PP-Q-CO6022 del 20 de diciembre del 2005, se solicitó financiamiento al Ministerio de Economía y Finanzas. Esta solicitud la expuso de conformidad con lo establecido en el Reglamento General de la Ley de Reactivación Productiva y Social del Desarrollo Científico-Tecnológico y de Estabilización FiscalCEREPS, expedido mediante el Decreto Ejecutivo No. 611, que se publicó en el Registro Oficial No. 131 del 24 de octubre del 2005.

Mediante Decreto Ejecutivo No. 991, del 22 de diciembre del 2005 (R.O. 185 del 11 de enero del 2006), se aprobó la asignación de USD 8'117.701 correspondiente a los fondos CEREPS del año 2005, para financiar los proyectos de investigación científica y desarrollo tecnológico, según los anexos 1, 2, 3 y 4 que forman parte del precitado Decreto.

El Decreto Ejecutivo No. 1829, promulgado el 7 de septiembre de 2006 en el suplemento del R.O. No. 351, "Expide las disposiciones normativas para reorganizar el Sistema Nacional de Ciencia y Tecnología, SNCT”, a más de eliminar el Decreto Ejecutivo No. 1603 del año 1994 (por el cual se aprobó la creación de SENACYT y de FUNDACYT). 
El Decreto Ejecutivo No. 1830, promulgado el 19 de septiembre de 2006 en el Registro Oficial No. 359, reforma el "Reglamento Operativo para el Funcionamiento con Recursos Estatales de Programas y/o Proyectos de Investigación y Desarrollo, Innovación y Capacitación de Recursos Humanos" (CEREPS), promulgado mediante Decreto Ejecutivo No. 965 en el Registro Oficial No. 175, de 28 de diciembre del 2005; y SENACYT asume la responsabilidad total de la gestión de esos recursos.

El Ing. Bernardo Creamer Guillén, quien fue designado Secretario Nacional de Ciencia y Tecnología mediante oficio SEN-Q-CO 017, del 29 de septiembre del 2006, comunicó a FUNDACYT la terminación del convenio Marco de Cooperación Interinstitucional SENACYTFUNDACYT, celebrado el 20 de diciembre del 2005, para la gestión de los proyectos financiados con recursos CEREPS.

Conforme a lo dispuesto en el Decreto Ejecutivo No. 1968, del 18 de octubre del 2006, FUNDACYT procedió a entregar a SENACYT la información técnica, económica y financiera de todos los proyectos financiados con recursos CEREPS.

\subsection{Principios que rigen la Política Nacional de CTI en el Ecuador}

En el marco de la transición de la SENACYT y la FUNDACYT, uno de los principales principios de la Política Nacional de Ciencia, Tecnología e Innovación del Ecuador fue "conformar un entorno integrador entre las organizaciones que conforman el SNCTI, mediante un adecuado marco legal, ágil y transparente". (Carpio, 2005: 7). Otros principios fundamentales eran:

- Garantizar la asignación de presupuesto estable para desarrollar CTI en Ecuador. 
- Desarrollar redes entre organizaciones académicas, grupos de investigación y el sector productivo para mejorar la sostenibilidad y eficiencia del SNCTI.

- Es prioritaria promocionar organizaciones de investigación, a fin de adaptarse a los continuos cambios en los objetivos de investigación que impone el ritmo del desarrollo económico nacional, inmerso en un proceso de globalización.

- Fortalecer los centros de investigación con líneas de investigación definidas.

- Propiciar el intercambio, transferencia y difusión científica y tecnológica, en el marco de los convenios y proyectos de integración subregional y regional.

- Lograr la sostenibilidad del SNCTI mediante el apoyo permanente del Estado.

El objetivo general de esta Política Nacional de Ciencia, Tecnología e Innovación era fortalecer la capacidad científica y tecnológica del Ecuador, mediante el impulso a la investigación básica y aplicada, que responda a las necesidades prioritarias de la población, para mejorar su calidad de vida, y fomentar la innovación y transferencia tecnológica que eleve la productividad y competitividad de la nación ecuatoriana.

\subsubsection{Líneas de acción de esta Política Nacional de Ciencia, Tecnología e Innovación}

I. Fortalecimiento de la investigación científica y tecnológica, dirigida prioritariamente a solucionar problemas socioeconómicos de la población, tales como: salud, nutrición, educación y vivienda.

II. Apoyo a la innovación, adaptación y transferencia tecnológica.

III. Articulación entre los sectores académico, gubernamental y productivo, mediante alianzas estratégicas con gobiernos locales. 
IV. Consolidación y fortalecimiento del Sistema Nacional de Ciencia, Tecnología e Innovación (SNCTI) del Ecuador.

\subsubsection{Surge el 'Sistema Nacional de Ciencia, Tecnología, Innovación y Saberes Ancestrales', en el Ecuador}

Desde el 28 de septiembre de 2008, a partir de la aprobación de la nueva Constitución del Ecuador (elaborada por una Asamblea Nacional Constituyente), entró en vigencia el desarrollo y ejecución del "Sistema Nacional de Ciencia, Tecnología, Innovación y Saberes Ancestrales”. Es decir que, a partir de esa fecha, se incluyó el aporte de los saberes ancestrales en el anterior Sistema Nacional de Ciencia, Tecnología e Innovación.

La nueva Constitución del Ecuador se refiere a este Sistema en su Art. 385, donde dice:

"El Sistema Nacional de Ciencia, Tecnología, Innovación y Saberes Ancestrales, en el marco del respeto al ambiente, la naturaleza, la vida, las culturas y la soberanía, tendrá como finalidad:

1. Generar, adaptar y difundir conocimientos científicos y tecnológicos.

2. Recuperar, fortalecer y potenciar los saberes ancestrales.

3. Desarrollar tecnologías e innovaciones que impulsen la producción nacional, eleven la eficiencia y productividad, mejoren la calidad de vida y contribuyan a la realización del buen vivir”.

Para normar la ejecución del precitado Sistema, la Secretaría Nacional de Ciencia y Tecnología (SENACYT) del Ecuador ha convocado esfuerzos tendientes a sustentar la elaboración de una nueva Política Nacional de Ciencia y Tecnología. 
Para analizar la viabilidad del "Sistema Nacional de Ciencia, Tecnología, Innovación y Saberes Ancestrales", la autora de esta tesis optó por investigar la relación entre los conocimientos y prácticas provenientes de la biomedicina y la medicina tradicional indígena, en el centro de salud Jambi Huasi de Otavalo, Ecuador, a partir de estudios de Comunicación Pública de la Ciencia y Tecnología (CPCT) y de Antropología Médica. El detalle de esta investigación consta en el siguiente capítulo.

\subsection{Resoluciones, Acuerdos y Mandatos sobre CTI aprobados por autoridades de Ciencia y Tecnología, en varios países ${ }^{52}$}

En el marco de la XV Reunión del Consejo Andino de Ciencia y Tecnología, CACyT (celebrada en Caracas, Venezuela, el 14 de diciembre de 2005), se solicitó a la Coordinación del Área de Ciencia y Tecnología del CAB y a la Coordinación del Programa de Desarrollo y Competitividad de la SGCAN compilar y presentar un documento con las resoluciones, acuerdos y mandatos de ciencia, tecnología e innovación (CTI) de los Jefes de Estado y de Gobierno y de los Ministros y Altas Autoridades de Ciencia y Tecnología.

Para cumplir con esta responsabilidad, el CAB analizó la documentación oficial que se había presentada en los siguientes actos:

1. Cumbres de Jefes de Estado y de Gobierno.

2. Consejo Presidencial Andino.

3. Conferencia General de la UnESCO.

4. Conferencias científicas del programa CYTED.

\footnotetext{
${ }^{52}$ La información que se ofrece a continuación fue obtenida de informes, de memorias referentes a seminarios o congresos y de entrevistas realizadas a representantes de la Comunidad Andina de Naciones (CAN) y del Convenio Andrés Bello.
} 
5. Encuentros de ministros y máximas autoridades de CyT de países del CAB.

\subsubsection{Principales temas de interés regional}

Luego de analizar varias resoluciones, acuerdos y mandatos de ciencia, tecnología e innovación (CTI) de los Jefes de Estado y de Gobierno, y de los Ministros y Altas Autoridades de Ciencia y Tecnología, el CAB comprobó que los temas principales que se había planteado a través de esos documentos eran los siguientes:

1. Políticas y legislación científica y tecnológica.

2. Cooperación e integración interagencial.

3. Financiamiento de la CTI.

4. Propiedad intelectual.

5. Las denominadas tecnologías de la información y del conocimiento (TICs).

6. Educación superior.

7. Desarrollo sostenible.

8. Espacio común del conocimiento.

9. Cambio climático.

10. Biodiversidad y medio ambiente.

11. Recurso agua.

12. Fomento de la cultura de la innovación para el desarrollo productivo y sostenible.

13. Apropiación social de la CyT.

14. Formación de talento humano para el desarrollo de la Cут.

15. Fortalecimiento de los SNCTI. 
Como puede notarse, los temas de interés descritos en los puntos 13 y 15 están directamente relacionados con los objetivos de una adecuada Comunicación Pública de la Ciencia y la Tecnología.

\subsubsection{Prioridades programáticas estratégicas}

El análisis realizado por el Área de Ciencia y Tecnología del CAB y por la Coordinación del Programa de Desarrollo y Competitividad de la SGCAN, también evidenció cuáles han sido las prioridades programáticas estratégicas para el desarrollo científico y tecnológico de América Latina y el Caribe, según ministros y altas autoridades de ciencia y tecnología de la región. A continuación, una enumeración de las precitadas prioridades:

1. Políticas y legislación científica y tecnológica.

2. Formación de talento humano de alto nivel para el desarrollo CTI.

3. Financiamiento de la ciencia y la tecnología.

4. Gestión de la CTI y cooperación e integración interagencial.

5. Estímulo y fomento de la interacción de los ONCYT.

6. Fomento y fortalecimiento de los SNCTI.

7. Prospectiva científica y tecnológica (PNCTI \& PRPCT).

8. Gestión e innovación tecnológica.

9. Formulación y evaluación de proyectos.

10. Fortalecimiento de centros de excelencia.

11. Investigación y extensión agropecuaria.

12. Biotecnología de los recursos naturales propios.

13. Biodiversidad, ecosistemas y desarrollo sostenible.

14. TIC's para el desarrollo. 


\section{Universidad - empresa.}

16. Transferencia de tecnologías apropiables.

17. Indicadores de la ciencia y la tecnología.

18. Movilización e intercambio de expertos.

19. Mecanismos de vinculación (interfaz) entre los sectores del conocimiento, sector productivo, sector financiero y sector tecnológico.

20. Fomento de la apropiación social y difusión de la CYT.

21. Alfabetización científica y tecnológica.

22. Innovaciones en la enseñanza de la CYT.

23. Propiedad intelectual e industrial asociadas a proyectos de I+D.

24. Patrimonio natural y cultural para el desarrollo sostenible.

25. Transferencia y socialización de mejores prácticas de CYT.

26. Redes para la integración científica y tecnológica.

27. Formación tecnológica y técnica para el trabajo productivo y competitivo.

Por tanto, las prioridades programáticas estratégicas para el desarrollo científico y tecnológico de América Latina y el Caribe también pueden fomentarse a través de una adecuada Comunicación Pública de la Ciencia y la Tecnología; especialmente, si se vincula al sector académico, empresarial, gubernamental (como se formula en el punto 15) y, por supuesto, más participación ciudadana. El impacto de esta actividad podrá reflejar cambios positivos al analizar los indicadores (punto 17) de percepción social de la ciencia y la cultura científica. 


\subsubsection{Primera Jornada Andina sobre Políticas de Ciencia, Tecnología e Innovación en los procesos de mundialización, integración y desarrollo sostenible}

En seguimiento a los acuerdos suscritos en el marco de la XV Reunión del CACYT, ${ }^{53}$ el 27 y 28 de marzo de 2006 se llevó a cabo la Primera Jornada de Reflexión sobre las Políticas de Ciencia, Tecnología e Innovación en los Procesos de Mundialización, Integración y Desarrollo Sostenible, en la ciudad de Cuenca, Ecuador. Participaron representantes de Bolivia, Ecuador, Perú y Venezuela; de la Secretaría General de la Comunidad Andina de Naciones (CAN) y del Convenio Andrés Bello (CAB).

El objetivo de este encuentro fue promover el trabajo conjunto de para la definición de un plan de acción andino, acorde a los retos que plantea el avance de los procesos de integración regional, como lo es el MERCOSUR y la CAN.

Estas jornadas estuvieron inscritas en el desafío planteado por la Declaración del Milenio (ONU, 2000) - la cual representa el mayor acuerdo de todos los gobiernos para conseguir en plazos definidos, los objetivos de Desarrollo del Milenio-, así como en los acuerdos alcanzados durante la Primera Reunión de Jefes de Estado de la Comunidad Sudamericana de Naciones, celebrada en Brasilia el 30 de septiembre de 2005, y en la Declaración Final de la Conferencia Internacional sobre Cultura Científica y Cultural Empresarial ante las Metas del Milenio, llevada a cabo en Salamanca, del 28 al 30 de septiembre de 2005 .

En estas Jornadas, la Secretaría General de la CAN propuso una Matriz Comparativa de las Políticas y Planes de Ciencia y Tecnología de los Países Andinos; junto con el CAB, también presentó los resultados de un estudio comparativo sobre las Resoluciones y

\footnotetext{
${ }^{53}$ Esta Reunión se celebró en cabo en Caracas, Venezuela, el 14 de diciembre de 2005.
} 
mandatos de los presidentes y altas autoridades de ciencia y tecnología de los países miembros de esos organismos.

También se reconoció la importancia de la ciencia, la tecnología y la innovación como elementos fundamentales para el desarrollo integral, solidario y equitativo de los pueblos, y para alcanzar la soberanía e independencia tecnológica, aunado a la necesidad de fortalecer las acciones conjuntas en el área andina como estrategia de integración y compromiso de cooperación para el logro de los objetivos comunes.

Al término de estas Jornadas, representantes de los países participantes de este encuentro, Bolivia, Ecuador, Perú y Venezuela, de la Secretaría General de la CAN y del $\mathrm{CAB}$, acordaron desarrollar un Plan de Acción a corto plazo que responda a las prioridades y se aproveche al máximo los recursos destinados a ciencia, tecnología e innovación, así como propiciar la voluntad política al interno de esos países para impulsar su desarrollo, proponen:

\subsection{3.a) Lineamientos de la Política Regional Andina}

- Conocimiento para el desarrollo local.

- Desarrollo de conocimientos propios de ciencia, tecnología e innovación, para la convivencia y la paz.

- La aplicación de la ciencia y la tecnología, para el mejoramiento de la calidad de vida de los pueblos.

- Promover la creación del Sistema Regional Andino de Ciencia, Tecnología e Innovación.

\subsection{3.b) Criterios Estratégicos}


- Apropiación social del conocimiento para propiciar la inclusión social y minimizar las brechas.

- Independencia científica - tecnológica para contribuir con la seguridad y soberanía de la región.

- Desarrollo de las capacidades científico-tecnológicas nacionales y regionales para garantizar el manejo soberano de los recursos naturales y la agregación de valor.

- Impulsar la incorporación de la ciencia, la tecnología y la innovación en todos los niveles educativos.

- Fomento a la cultura de la innovación y de la apropiación tecnológica para el desarrollo productivo y sostenible.

- Mejoramiento de la percepción publica de la ciencia, la tecnología y la innovación.

- Valorización de los conocimientos tradicionales y ancestrales.

\subsection{3.c) Programas Estratégicos}

- Energías y recursos naturales.

- Conservación, preservación y desarrollo de la biodiversidad.

- Soberanía y seguridad alimentaria.

- Salud.

- Calidad y equidad de la educación.

- Tecnologías de la información y la comunicación.

- Hábitat y Vivienda.

- Visibilidad y apropiación social del conocimiento.

- Estudios estratégicos e históricos de la región andina. 


\subsection{3.d) Tipos de acciones}

\section{Formación y capacitación:}

- Programa de becas para postgrados, preferiblemente doctorados, en las universidades de la región en las áreas temáticas de los programas estratégicos.

- Crear la beca "Simón Bolívar" para doctorados.

- Homologación y acreditación andina en educación superior.

- Crear y fortalecer programas de formación para el trabajo.

- Formación de gerentes tecnológicos.

\section{Lineas de proyectos de $I+D+i$ :}

- Acuicultura continental para la producción alimentaria:

- Amazonía: (Biodiversidad).

- Enfermedades endémicas.

- Recursos hídricos (calidad, gestión y prospectiva)

- Desarrollo rural y seguridad alimentaria.

\section{Difusión e intercambio de experiencias:}

- Encuentros andinos de inventores populares:

- Encuentro sobre Redes de Innovación Productivas (Venezuela) y de Unidades Productivas Agroindustriales Rurales.

- Innovación y Desarrollo Local (Municipio Innovado

- Red de Apropiación Social del Conocimiento: CAB. 


\section{Mecanismos de apoyo:}

- Plataforma tecnológica para generar una red de investigadores, inventores: Se propone la creación de una sola base de datos basada en la Plataforma CvLAC.

- Foro e-can sobre ciencia y tecnología.

- Apoyar plataforma Scielo y el índice Latindex.

- Utilizar referencia RICYT.

- Crear red de Centros de Innovación entre los distintos países.

Los participantes de esa Jornada también acordaron realizar las siguientes recomendaciones:

- Presentar los acuerdos alcanzados en este encuentro en la próximas reuniones de Jefes de Estado y Gobierno en el marco de la CAN, MERCOSUR y Comunidad Sudamericana de Naciones, y de las reuniones de altas autoridades de educación, cultura, ciencia y tecnología de los países del CAB, con miras a alcanzar la voluntad política y la sensibilización en el tema de ciencia y tecnología.

- Presentar las coincidencias programáticas entre la CAN y el CAB con el fin de viabilizar recursos financieros y alcanzar impactos cualitativos.

- Propiciar encuentros entre responsables de ciencia y tecnología de la CAN y MERCOSUR.

- Propiciar la creación de una oficina de la CAN ante la UE a objeto de gestionar proyectos conjuntos en materia de ciencia, tecnología e innovación.

- Impulsar la homogenización de los plazos en los planes de ciencia, tecnología e innovación cada uno de los países andinos. 
- Incorporación en los planes de ciencia, tecnología e innovación, en lo referente a las Metas del Milenio, como elementos concretos, sobre la base de los acuerdos políticos alcanzados por nuestros países.

- Propiciar los incentivos a la inversión en ciencia, tecnología e innovación.

- Destinar un porcentaje significativo del PIB de nuestros países a la inversión en ciencia, tecnología e Innovación.

- Aplicar los principios de Ética y Bioética que garanticen mayor transparencia en la toma de decisiones en ciencia, tecnología e Innovación.

- Explorar nuevos mecanismos y oportunidades de cooperación internacional con la UE y los países asiáticos.

- Hacerle seguimiento a los acuerdos CAN y MERCOSUR con la UE.

- Respaldar la creación del Instituto Andino de Biodiversidad por parte del Parlamento Andino y el Consejo Presidencial Andino y comprometer la activa participación de los organismos de ciencia y tecnología de los países de la CAN para la consolidación e inicio de las actividades del IAB.

Finalmente, se acordó informar en los diversos foros regionales y multilaterales la posición conjunta de los países de la CAN, en materia de ciencia, tecnología e innovación. Para dar constancia de su aprobación, en representación de los países y organismos participantes firmaron: Dr. Luis Marcano González, de la Presidencia del CACYT, Ministerio de Ciencia y Tecnología de Venezuela; Celso Ayala, director de Ciencia y Tecnología del CONACYT, Bolivia; Arturo Carpio Rodas, ex secretario Nacional de Ciencia y Tecnología del Ecuador; Jaime Ávalos, director Ejecutivo del CONCYTEC, 
Perú; Antonio Leone, Coordinador de Desarrollo y Competitividad de la CAN, y Henry Yesid Bernal, Coordinador Área Ciencia y Tecnología del CAB.

\subsection{3.e) Influencia de la cooperación regional y del BID}

La cooperación regional ha influido notoriamente en el desarrollo científico y tecnológico de países latinoamericanos; así como el financiamiento del Banco Interamericano de Desarrollo (BID). Este Banco no solamente ha contribuido con sus préstamos, sino que ha influido decisivamente en los enfoques de las políticas científicas y en el diseño de los instrumentos de fomento de la I+D, tanto en los países de mayor desarrollo, que han sido los principales beneficiarios de los préstamos, como en los de menor desarrollo, que se han incorporado tardíamente en las operaciones del Banco (Mayorga, 1996).

De acuerdo al análisis de Jesús Sebastián (2007), el BID ha priorizado el instrumento de los fondos competitivos para el estímulo directo de la demanda espontánea, en lugar de las acciones estratégicas integradas, disminuyendo, probablemente, la eficacia de los recursos financieros movilizados.

"Por otra parte, la equidad no ha estado presente en el diseño de las operaciones de crédito. Los préstamos estuvieron hasta 2000 concentrados en unos pocos países. Brasil, Argentina y México recibieron el 63\% de los recursos financieros y, sumando Colombia, Chile y Venezuela, el 92\%. De los 1.694 millones de dólares prestados por el BID hasta 2000, solamente 67 millones fueron concedidos a Ecuador, Costa Rica, Guatemala y Panamá”. (Sebastián, 2007: XIII)

No obstante, a pesar de los pocos recursos recibidos por países como Ecuador, esto supuso un alto porcentaje del gasto en I+D; de ahí que, inicialmente, el financiamiento del 
BID haya contribuido notoriamente en el desarrollo de sus políticas científicas nacionales. "Este aspecto puede suponer grandes condiciones en las estrategias nacionales, dada la tendencia del BID a aplicar patrones comunes descontextualizados de la situación y prioridades de cada país, a la vez de tomar ventaja de su mayor capacidad de negociación.

El aporte de la cooperación internacional en países de América Latina se ha reflejado especialmente en la formación de investigadores, en la creación de infraestructuras físicas, en la financiación y el desarrollo de actividades conjuntas de investigación (Sebastián, 2007: XIII-XIV). Algunas de las organizaciones que destacan por aportar en estas áreas son: el Programa Regional de Desarrollo Científico y Tecnológico de la Organización de Estados Americanos (OEA); ${ }^{54}$ el Programa Iberoamericano de Ciencia y Tecnología para el Desarrollo (CYTED), ${ }^{55}$ el BID, la Organización de Estados Iberoamericanos (OEI), el Convenio Andrés Bello (CAB), la Fundación Carolina, la UNESCO, además de otras organizaciones regionales y de Agencias de cooperación bilateral (Sebastián, 2002: 197229).

\subsection{Aporte desde la Comunicación Pública de la Ciencia y la Tecnología}

A más de fomentar la cultura científica, la Comunicación Pública de la Ciencia y la Tecnología (СРСТ) ofrece más transparencia al proceso de toma de decisiones sobre temas científicos y tecnológicos. El objetivo de la CPCT es contribuir a que se ejerza más

\footnotetext{
${ }^{54}$ Este programa fue creado en 1968 y generó un marco multilateral novedoso, que incidió en la génesis de una cultura de cooperación a nivel regional. Jesús Sebastián señala que el impulso de este programa no duró mucho, debido a que no se pudieron superar las dificultades que plantea la gestión de la multilateralidad, como consecuencia del efecto centrifugador de los intereses nacionales. (Sebastián, 2007: XIV)

${ }^{55}$ Este programa tuvo un notable desarrollo en los años noventa. Su principal contribución ha sido aumentar la cooperación multilateral intralatinoamericana,y de América Latina con España y Portugal.
} 
vigilancia civil y gubernamental sobre los efectos que genera la actividad científica y tecnológica. No en vano la Declaración de los Derechos Humanos señala, en su artículo 27: "Toda persona tiene derecho a tomar parte libremente en la vida cultural de la comunidad, a gozar de las artes y a participar en el progreso científico y en los beneficios que de él resulten".

La CPCT comprende la ejecución de varias actividades de ampliación y actualización del conocimiento científico y tecnológico. Éstas pueden realizarse desde la educación no formal, a través de medios de comunicación y en espacios abiertos para el diálogo sobre temas de ciencia y tecnología. No sustituye a la educación, pero ayuda a superar ciertos vacíos que deja el sistema de educación formal.

La mayoría de proyectos diseñados para comunicar la ciencia al público siguen modelos de tipo asimétrico, como el de déficit o el de difusión $;{ }^{56}$ pero éstos resultan limitados, porque analizan la comunicación como un proceso de recorrido unidireccional (que va desde el científico hacia el público), consideran neutra la información que transmiten e ignoran las diferencias culturales que caracterizan a los actores involucrados en el proceso de СРCT. Esta omisión es una de las principales razones que dificultan la comunicación entre los científicos y el público general. Porque, aunque la ciencia tenga una proyección internacional (global), para comunicar sus avances al público general hay que considerar las características culturales (valores, creencias, hábitos, fobias, filias, símbolos, tradiciones y conocimientos $)^{57}$ de los actores que intervienen en ese proceso de comunicación.

\footnotetext{
${ }^{56}$ Estos modelos los ha explicado ampliamente Lewenstein. Una de sus explicaciones puede extraerse desde: http://communityrisks.cornell.edu/BackgroundMaterials/Lewenstein2003.pdf

${ }^{57}$ El término “propiospectos" fue empleado por Rolando Isita Tornell en su tesis doctoral, que titula Ciencia y propaganda en España (1995: 66).
} 
Si aceptamos que el diálogo debe ser cultural, habrá que reformular el modelo tradicional unidireccional de comunicación y proponer uno más completo, interdisciplinario, desde una perspectiva sociocultural que contemple las relaciones entre las distintas formas de organización de la sociedad, las mediaciones socioeconómicas y las prácticas discursivas de la ciencia y de su divulgación. Este nuevo modelo debe considerar las siguientes categorías: institucionalización, mediaciones y agentes sociales que intervienen en el proceso de comunicación pública de la ciencia.

Varias son las obras que destacan la importancia de la CPCT para fortalecer la democracia en los países. Tenía razón el mexicano Marcos Kaplan cuando dijo que "la existencia, la madurez y la eficacia de la política científica era función directa del desarrollo del subsistema de información/comunicación; de su complejidad, flexibilidad y sensibilidad; de la cantidad y la claridad de la información que recibe, produce, trata y trasmite a través de la sociedad".

A más de cumplir un importante rol democrático, la СРCT puede ayudar a superar el denominado 'problema de las dos culturas' que anunció C.P. Snow. Este investigador expuso la tesis de que la cultura occidental estaba escindida en dos bandos que se ignoraban mutuamente: los humanistas y los científicos. Su propuesta era cerrar esta brecha y, para el efecto, sugirió “repensar la educación”. (Snow, 1956)

Por eso es importante destacar la función democrática que cumple la CPCT y el valioso aporte que podría ofrecer al Ecuador y a otros países de Iberoamérica, si se la institucionalizara, incluyéndola como tema prioritario dentro de la política científica de cada país. El Programa Nacional de CPCT que propongo debería fomentar el interés de la gente joven por participar en proyectos científicos y tecnológicos que den solución a los 
problemas nacionales. También debería destinar mejores salarios a los investigadores, para evitar la fuga de cerebros, y crear nuevas fuentes de trabajo.

Conviene apoyar actividades como el periodismo científico, porque esta labor "trata de poner lo más noble del espíritu humano, el conocimiento, al servicio del individuo y de la sociedad, para evitar que se repita la historia y que el progreso beneficie exclusivamente a las minorías. El Periodismo Científico tiene la obligación social de hacer lo posible y lo imposible por que la ciencia y la tecnología no sirvan sólo para el enriquecimiento cultural y el beneficio práctico de algunas naciones o ciertas sociedades privilegiadas. (Calvo, 2005)

En México, el denominado PECYT y la Ley de Ciencia y Tecnología otorgaron más apoyo a la comunicación pública de la ciencia. También adquirió más relevancia la CPCT en Europa, a raíz de la aplicación del VI Programa Marco de Investigación y Desarrollo de la Unión Europea $^{58}$ (6PM). Este Programa anuncia la promoción de relaciones entre ciencia y sociedad, en línea con lo expuesto en el 'Plan de Acción Ciencia y Sociedad' de la región. Este Plan incluye 38 acciones, que giran en torno a tres objetivos:

1. Promoción de la educación y de la cultura científica en Europa.

2. Elaboración de políticas científicas más cercanas a los ciudadanos.

3. Incorporación de una ciencia responsable en las distintas políticas.

En coherencia con el 'Plan de Acción sobre Ciencia y Sociedad' de la Unión Europea, el 6PM respaldaba actividades de educación y divulgación científica, promueve la igualdad de género y sitúa la práctica de una ciencia responsable en el centro de su política científica.

\footnotetext{
58 Con el "VI Programa Marco" (6PM) se pretendía contribuir a la creación del Espacio Europeo de Investigación y a la innovación (2002-2006). Se lo aprobó el 27 de junio de 2002. Futuras ediciones de ese Programa Marco confirman o fortalecen la anterior propuesta.
} 


\subsection{Programa Nacional de Comunicación Pública de la CyT}

Para contribuir al fortalecimiento y consolidación del Sistema Nacional de Ciencia y Tecnología, conviene promover una relación más cercana y permanente entre la sociedad, la comunidad científica y las autoridades encargadas de establecer las políticas públicas. Este reto puede lograrse con la ejecución de un Programa Nacional de Comunicación Pública de la Ciencia y la Tecnología.

Este Programa debe incluir varias acciones tendentes a compartir los conocimientos científicos con el público general; también deberá favorecer el diseño de nuevos medios y de metodologías que hagan más eficiente la CPCT en el Ecuador. Sensibilizar a dirigentes y a ciudadanos sobre la importancia de esta propuesta exigirá no sólo mayor equilibrio político y social, sino también más participación ciudadana en el saber común. Esta idea ha conllevado a que en varios países se asuma la CPCT como un tema de prioridad nacional.

¿Tiene sentido asociar política científica y participación ciudadana? Por supuesto que sí. Porque el fomento de la cultura científica a través de una adecuada Comunicación Pública de la Ciencia y Tecnología (CPCT) contribuye a potenciar la conciencia cívica y, consecuentemente, la participación ciudadana en la toma de decisiones sobre políticas públicas en ciencia y tecnología.

Es por esa razón que la "Declaración de la Conferencia Mundial sobre la Ciencia para el siglo XXI" destaca la necesidad de mejorar la participación ciudadana en la adopción de decisiones relativas a la aplicación de los conocimientos tecnocientíficos (http://www.unesco.org/science/wcs/esp/declaracion_s.htm). 
A esta idea contribuye la comunicación titulada "Política científica para la sostenibilidad y participación ciudadana”, que Amparo Vilches, Daniel Gil Pérez, Juan Carlos Toscano y Óscar Macias presentaron en el "Congreso Iberoamericano de Ciudadanía y Políticas Públicas en Ciencia y Tecnología", 59

Los autores de esta comunicación sostienen que la posesión de profundos conocimientos específicos, como los que tienen especialistas en un campo determinado, no garantiza la adopción de decisiones adecuadas; porque, para adoptarlas, se requiere también de enfoques que contemplen los problemas en una perspectiva más amplia, analizando las posibles repercusiones a medio y largo plazo, tanto en el campo considerado como en otros. Y este tipo de enfoques puede lograrse a través de la participación ciudadana, con apoyo de no especialistas, del público en general; a partir de perspectivas e intereses más amplios.

Es por ello que varios analistas del vínculo entre política científica y participación ciudadana (Aguilar, 2000; Bañón, 2003; Cardoso, 2006; Castañeda, 2007) consignan la posibilidad de implementar políticas públicas con un enfoque llamado "implementación desde abajo", el cual tiene como principal elemento distintivo las valoraciones de los sectores sociales involucrados en su implementación, con su conocimiento y experiencia de los contextos histórico-sociales en que operarán.

El impulso de la participación ciudadana en políticas públicas de ciencia y tecnología podrá lograrse a través del fomento de la cultura científica, con más personas interesadas en la repercusión social de los conocimientos científicos y tecnológicos. En este sentido, es fundamental el aporte de la CPCT.

\footnotetext{
${ }^{59}$ Este Congreso se llevó a cabo en Madrid, España, del 5 al 8 de febrero de 2008. Los autores de la citada comunicación participaron en representación de la Universidad de Valencia, España, y de la OEI.
} 


\subsubsection{Objetivos del Programa Nacional de CPCT}

- Fomentar más cultura científica y el aumento de la conciencia cívica.

- Sensibilizar a periodistas y a científicos sobre la necesidad de trabajar en equipo.

- Identificar cuáles son los problemas prioritarios del país, para orientar los recursos del Estado a la investigación y a la solución de esas necesidades.

- Contribuir a la eliminación del analfabetismo científico-tecnológico.

- Preparar a la población para que comprenda los avances de la ciencia y los alcances del cambio tecnológico, en los ámbitos nacional y mundial.

- Ayudar a las nuevas generaciones a que entienda mejor la evolución que ha experimentado el mundo en que viven; sus desafíos, sus riesgos y sus posibilidades.

- Aclarar la imagen social de la ciencia y de la tecnología, a partir de la evaluación de los temores, mitos y prejuicios que enturbian la percepción pública de esos temas.

- Establecer redes y convenios institucionales que permitan un diálogo permanente entre científicos y periodistas.

Este Programa deberá asignar funciones y tareas a tres comunidades: la educativa, la informativa y la científica.

\subsubsection{Compromisos desde el sector educativo}

Según Manuel Calvo Hernando, éstas son algunas de las acciones con las que puede contribuir el sistema educativo a la СРCT (Calvo, 1990): 
- Mejora efectiva de la enseñanza de las ciencias, como paso previo para iniciar una tarea de sensibilización ante la opinión pública.

- Formación de especialistas en la CPCT, procedentes tanto del periodismo como de la ciencia y de la docencia.

- La formación para periodistas debería ir precedida por la inclusión de la asignatura de Periodismo Científico en los planes de estudio de las facultades de Ciencias de la Información. Las universidades politécnicas deberán ofrecer a sus graduados e ingenieros cursos o seminarios de capacitación teórica y práctica, sobre la comunicación científica y tecnológica para el gran público.

- Desarrollo de programas de formación e información sobre biología, especialmente sobre genética y biotecnología, en todos los niveles educativos y en la mayoría de estudios universitarios.

- Apoyo a las actividades juveniles en ciencia y tecnología (clubes, ferias, congresos, concursos, olimpiadas, excursiones, campamentos científicos, aulas de la naturaleza) y a la creación de museos de ciencia, interactivos y móviles, para que puedan llegar tanto a las zonas urbanas como a las rurales.

- Establecimiento de programas de СРСТ y organización de cursos de postgrado sobre Periodismo Científico.

\subsubsection{Compromisos desde la comunicación}

No hay consenso sobre quién es la persona idónea para comunicar públicamente la ciencia. Una solución es el trabajo conjunto entre científicos y periodistas; pero este aporte será 
insuficiente sin la cooperación de otros profesionales, de educadores y de familiares.

Porque, así como la música requiere de intérpretes para ser apreciada, la ciencia necesita de profesionales que interpreten ante el público las obras científicas.

Maurice Goldsmith (1999) compara al comunicador público de la ciencia con el crítico de arte; le llama crítico científico y le sugiere lograr una formación multidisciplinaria, que integre cursos de ciencia general, historia y filosofía de la ciencia, arte y psicología de la comunicación, entre otras disciplinas.

Para una adecuada CPCT, Manuel Calvo Hernando sugiere considerar algunas reflexiones (Calvo, 2005):

1. La demostración científica no tiene un valor absoluto, ha de ser entendida como cualquier otro discurso, dentro de un contexto y de una situación.

2. Es necesario elaborar más y mejores elencos de vocabulario científico y técnico.

3. Hay que estimular a los científicos para que cada vez sean más capaces de proferir tanto el lenguaje de la ciencia como el de la divulgación científica.

4. Para científicos que no quieran o no sepan divulgar, conviene propiciar la participación de mediadores.

5. El informador debe acercarse al campo de la ciencia como a cualquier otro: con honradez, rigor y la máxima competencia posible.

6. Hay que desmitificar la ciencia: no es una panacea para los problemas del ser humano, ni una religión. Como todo instrumento, se puede emplear para el bien o para el mal.

7. Se debe hacer propaganda de la ciencia: expande los límites del conocimiento humano y proporciona bienestar. 
8. Las ciencias y las humanidades forman parte de la cultura: no es aceptable una ciencia sin humanismo, ni lo son unas humanidades al margen de la ciencia.

\subsubsection{Compromisos desde la comunidad científica}

El carácter evolutivo y el crecimiento acelerado de la ciencia ocasionan un gran problema a la CPCT; porque es demasiado amplio, diverso y especializado el campo de estudio que debe cubrir. De ahí que el periodista científico o comunicador público de la ciencia deba actualizarse de forma permanente.

$\mathrm{Al}$ analizar la inversión que en ciencia y tecnología han registrado los países de América Latina, Carlos Jarque, del BID, señala lo siguiente:

\footnotetext{
En general, en América Latina y el Caribe invertimos poco. La inversión en investigación y desarrollo está entre 0,1 y 0,6\% del PIB, en la mayoría de los países de la región, cifras que no han cambiado drásticamente en los últimos diez años. Nuestra inversión es baja en comparación con el 2 o el 3\% del PIB que invierten naciones de ingreso alto. Pero aún si nos comparamos con otros grupos de países vemos, por ejemplo, que la inversión anual de toda América Latina y el Caribe es casi la mitad de lo que invierte Corea del Sur. Son cifras acumuladas año tras año, que nos llevan a capacidades muy distintas (Mac Culloch, 2005).
}

Para que el Ecuador logre superar estas desigualdades, debe invertir mucho más en ciencia, tecnología e innovación, y ofrecer más apoyo a la formación de recursos humanos. De esta manera ofrecerá condiciones más propicias para crear nuevas fuentes de trabajo y, consecuentemente, mejorar la calidad de vida de sus habitantes; lo cual animaría a muchas personas a proyectarse un mejor futuro en su propio país. Al invertir más en la formación y en los salarios de los investigadores, también se evitará la fuga de cerebros; eso estimulará 
la participación de profesionales y de grupos científicos que estén social y científicamente comprometidos con el país.

El siguiente capítulo detalla las características de una investigación empírica que ofrece elementos importantes, para comprender las dificultades que afectan el proceso de ejecución y consolidación del "Sistema Nacional de Ciencia, Tecnología, Innovación y Saberes Ancestrales" del Ecuador, el cual fue aprobado en septiembre de 2008.

En la introducción del Capítulo 6 se incluye argumentos que justifican, de forma clara y coherente, por qué se ha desarrollado la mencionada investigación y cuál es su importancia, en el contexto de esta tesis. 


\section{CAPÍtULO 6}

\section{Análisis de la relación entre biomedicina y conocimientos}

locales, a partir de estudios de Antropología Médica y de CPCT

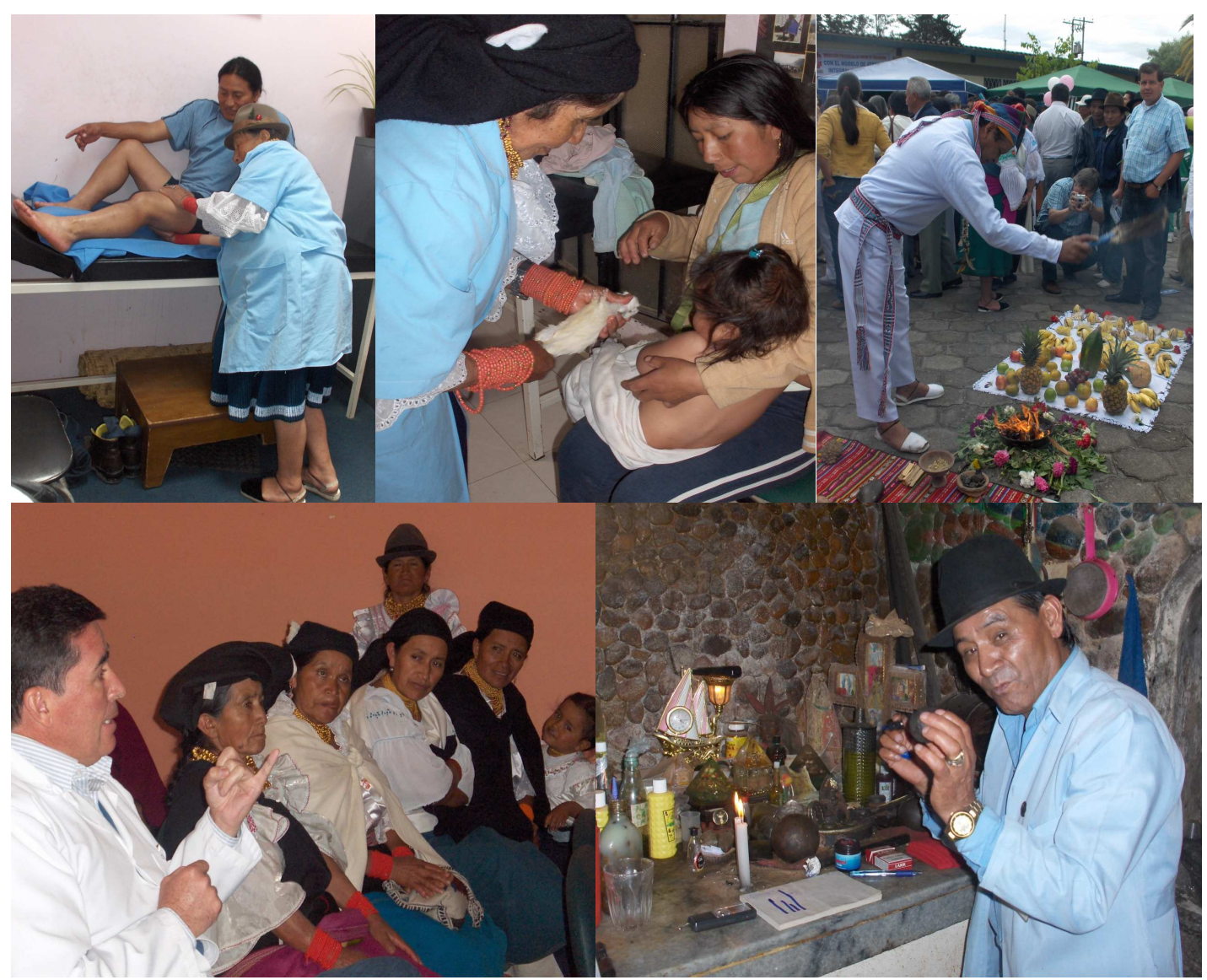

6.1. Introducción a la investigación empírica ${ }^{60}$

\footnotetext{
${ }^{60}$ Esta investigación empírica fue desarrollada por la autora de esta tesis, entre los meses de mayo y julio de 2008, para cumplir con el programa avanzado de "Master en Antropología Médica" de la Universidad de
} 
El desarrollo de la investigación que se detalla en el presente capítulo guarda coherencia con el título general de esta tesis, que es: "La comunicación pública de la ciencia en el centro de la política científica". Porque, aplicando estudios de Comunicación Pública de la Ciencia y Tecnología, y de Antropología Médica, los resultados de esta investigación ponen de manifiesto un gran problema que evita la eficiencia de la política científica y, por tanto, la consolidación del "Sistema Nacional de Ciencia, Tecnología, Innovación y Saberes Ancestrales"del Ecuador. ${ }^{61}$

Para analizar la viabilidad de este Sistema en el Ecuador, la autora de esta tesis optó por investigar la relación entre los conocimientos y prácticas provenientes de la biomedicina y la medicina tradicional indígena, en el centro de salud Jambi Huasi de Otavalo, Ecuador.

La presente investigación revela que, debido a razones culturales e históricas, ${ }^{62}$ y a problemas de comunicación, algunos indígenas evitan ir a hospitales, clínicas u otras unidades adscritas al sistema de salud formal, en busca de atención primaria.

Con el fin de satisfacer la demanda de esta población, la Federación Indígena y Campesina de Imbabura (FICI) creó el proyecto de salud Jambi Huasi, ${ }^{63}$ en Otavalo, hace más de 24 años.

Ámsterdam, en Holanda; y para considerarla en el contenido de la presente tesis doctoral, con el fin de solicitar la Mención de "Doctor Europeus".

${ }^{61}$ La aprobación oficial de este Sistema ocurrió el 28 de septiembre de 2008, en Ecuador. (Más detalles sobre las características de este Sistema, en la página 167.

${ }^{62}$ Al describir la historia de Jambi Huasi, se explica cómo el racismo institucional y la discriminación a personas indígenas ha limitado el acceso a los servicios de salud oficiales de la biomedicina, en el cantón Otavalo.

${ }^{63}$ El centro de salud Jambi Huasi (palabra Kichwa que significa "Casa de la Salud" en castellano) es coordinado y administrado por la Federación Indígena y Campesina de Imbabura (FICI). Este centro proporciona atención sanitaria a partir de la medicina tradicional indígena y de la biomedicina, tanto en 
El interés por saber las razones por las que los potenciales usuarios no van a los servicios de salud accesibles a sus comunidades, ha motivado estudios cualitativos en varios países, especialmente en las zonas donde habitan indígenas.

Según varias investigaciones en ciencias sociales (Ayora, 2002; Jacky, 2007; OPS, 2002; Conejo, 2006; Conejo et als., 2005; Conejo et als., 2004), los pueblos indígenas a menudo han sido marginados por su ubicación geográfica; por las diferencias culturales, el idioma, sus creencias y prácticas. De acuerdo a esos estudios se sabe que los principales problemas vinculados con esa marginación están relacionados con los siguientes aspectos: falta de atención oportuna o inconvenientes en las horas de atención; falta de profesionales y de personal de apoyo; maltrato por parte de proveedores de salud a pacientes indígenas; falta de participación directa de las comunidades indígenas en propuestas de salud; falta de participación de agentes locales en la salud de la población indígena (OPS, 2002: 38). El efecto práctico de este análisis, en torno al sistema de salud, debería analizarse en cada país.

A fin de superar este problema algunos países, como Ecuador, han firmado y ratificado declaraciones, acuerdos, resoluciones y tratados internacionales que proponen beneficios para la salud de los pueblos indígenas.

Varias organizaciones gubernamentales y no gubernamentales han tratado de integrar la medicina tradicional indígena en el sistema formal de salud (el cual se rige especialmente por la biomedicina).

Tal es el caso del centro de salud Jambi Huasi, que está ubicado en la ciudad de Otavalo, provincia de Imbabura, Ecuador. Este centro de salud fue elegido por la autora de esta tesis,

Kichwa (idioma nativo en la provincia de Imbabura) como en castellano. En enero de 1998 se Jambi Huasi reconoció el estatus jurídico de Jambi Huasi, bajo el nombre de "Fundación de Medicina Alternativa, ". Desde entonces, Jambi Huasi opera como un centro de salud en la ciudad de Otavalo. 
para desarrollar el trabajo de campo de la investigación empírica propuesta a la Universidad de Ámsterdam y a la Universidad de Salamanca; porque este centro ofrece servicios de atención primaria desde la biomedicina, así como desde la medicina tradicional indígena.

En esta investigación se explora en qué medida está presente la convencional distinción entre conocimientos y prácticas de la biomedicina y del conocimiento local, en el centro de salud Jambi Huasi.

Algunas personas entrevistadas creen que la interacción de las dos prácticas está debilitando la convencional distinción entre biomedicina y conocimiento local, según percepción de algunas personas entrevistadas. No obstante, aunque en Jambi Huasi se ha promovido vínculos entre conocimientos y prácticas de la biomedicina y de la medicina tradicional indígena, la relación entre ambos sistemas no siempre ha sido fácil en la práctica.

\subsubsection{Declaración del problema de investigación}

La precaria salud y las condiciones de vida de los pueblos indígenas generalmente están afectadas por un perfil epidemiológico que incluye enfermedades transmisibles, enfermedades crónico-degenerativas y problemas de salud vinculados con la urbanización. Estas deficiencias, según la Organización Panamericana de la Salud (OPS), justifican la necesidad urgente de repensar aspectos jurídicos, conceptuales, metodológicos y operativos, para garantizar el acceso equitativo de todas las personas a entornos saludables y calidad en la atención (OPS, 2002: 1).

Además, la hiper-especialización y la complejidad de la medicina sustentada en avances tecnológicos han generado un vocabulario técnico exclusivo, una terminología que resulta inaccesible para muchas personas. Esta situación ha creado una gran brecha en el proceso 
de comunicación entre representantes de la comunidad científica y el público en general (Erazo, 2007: 53-66). Pocos son los espacios que promueven una comunicación intercultural entre profesionales de la medicina y las personas que requieren atención sanitaria.

La incorporación de la perspectiva indígena, en el proceso de atención primaria de la salud, ha sido propuesta en varios países andinos, como Ecuador.

A pesar de que se han promovido vínculos entre los conocimientos y prácticas de la biomedicina y del conocimiento local, la relación entre estos sistemas de salud no siempre ha sido fácil.

Este problema será analizado en el contexto del centro de salud Jambi Huasi, con respecto a su atención primaria de la salud. Por lo tanto, en esta investigación empírica se propuso cumplir los siguientes objetivos.

\subsubsection{Objetivos}

\section{Objetivo general}

Analizar la relación de los conocimientos y prácticas provenientes de la biomedicina y de la medicina tradicional indígena, en el centro de salud Jambi Huasi de Otavalo, a partir de estudios de Antropología Médica y de Comunicación Pública de la Ciencia.

\section{Objetivos específicos}

Analizar:

1. Cómo la biomedicina y la medicina tradicional indígena están relacionadas en los servicios de salud que oferta el centro de salud Jambi Huasi, de Otavalo.

2. Si la distinción entre conocimientos y prácticas de la biomedicina y la medicina tradicional indígena ha desaparecido, o carece de relevancia en Jambi Huasi, o si la 
relación entre esas dos formas de conocimiento refleja conflicto en este centro de salud.

3. El rol de la comunicación en la relación de conocimientos y prácticas que caracterizan a la biomedicina y a la medicina tradicional indígena, en la experiencia del centro de salud Jambi Huasi.

\subsection{Contexto y metodología}

\subsubsection{Contexto nacional}

En el Ecuador coexisten varios modelos de atención primaria de la salud: el modelo de salud formal o institucional, que es esencialmente biomédico y que está apoyado por el Estado, y otros modelos de medicina alternativa. En esta investigación se analiza el caso de la denominada "medicina tradicional indígena", promovida por comunidades de origen Kichwa Otavalo. ${ }^{64}$

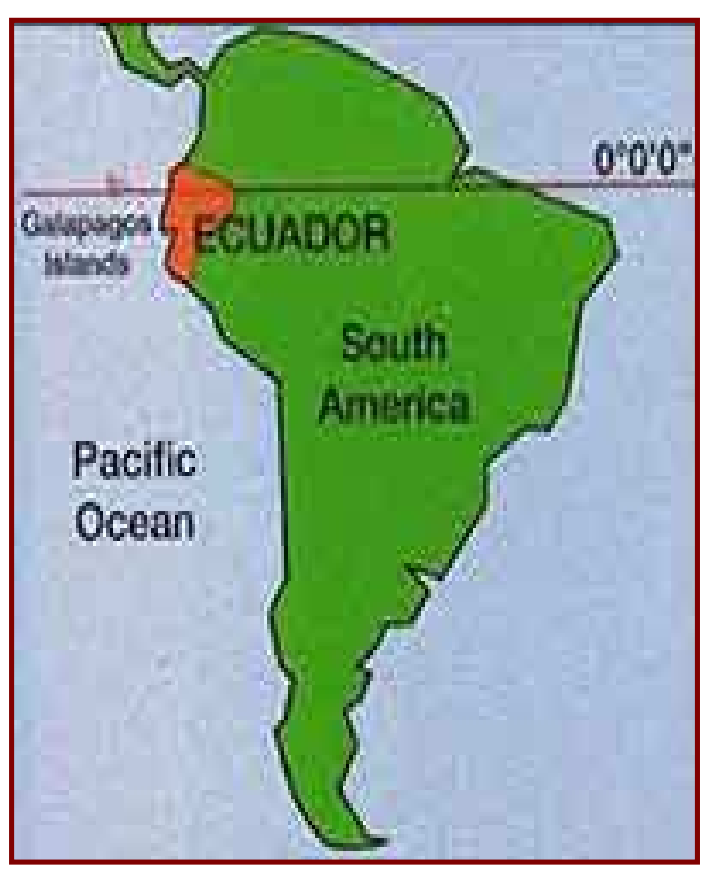

Sin embargo, esta práctica médica indígena fue influenciada por los Incas y sobrevivió a la Conquista Española del siglo XIV; que, sin duda, llegó a transformar esas prácticas. Actualmente, este tipo de medicina es utilizada por gran parte de la población rural ecuatoriana.

\footnotetext{
${ }^{64}$ En esta investigación se utiliza el término "medicina tradicional indígena" porque es el más utilizado por las personas entrevistadas durante el trabajo de campo.
} 
La gente que conoce y que provee atención de salud, a partir de la medicina tradicional indígena, se identifica con varios nombres, tales como: yachak, jakug, curandero, mamahua o partera, herbolario, fregador. ${ }^{65}$

Esta investigación emplea la palabra jambigkuna, ${ }^{66}$ de origen Kichwa, para referirse a las personas que proveen servicios de salud a partir de la medicina tradicional indígena.

Con el fin de beneficiar a la salud de los pueblos indígenas, varios países han firmado y ratificado declaraciones, acuerdos y resoluciones. Los mecanismos para destacar los derechos de la población indígena en el marco jurídico nacional difieren en cada país, así como el grado de aplicación.

Según la Constitución Política del Ecuador, aprobada el 5 de junio de 1998 por la Asamblea Nacional Constituyente, el desarrollo de las políticas estatales debe estar sustentado en un estado social de derechos, que reconocen al Ecuador como un Estado soberano, unitario, independiente, democrático, multiétnico, participativo y de administración descentralizada.

Los principales problemas políticos y sociales que afectan directamente a la salud en el Ecuador son: los altos niveles de pobreza, y su aumento significativo. Hasta hace un año, entre el $25 \%$ y el $30 \%$ de la población ecuatoriana no disponía de seguro médico (actualmente, toda la población ecuatoriana tiene derecho al seguro médico del Instituto de Seguridad Social). La ineficacia del Sistema Nacional de Salud, debido a la falta de liderazgo y de coordinación entre las instituciones, la fragmentación de los sectores y la

\footnotetext{
${ }^{65}$ La definición de estos términos se encuentra a lo largo de ese capítulo y en el primer Anexo.

${ }^{66}$ Esta palabra se utiliza en el centro de salud Jambi Huasi, con el fin de hacer referencia al: yachak, partera, jakug, herbolario y fregador.
} 
falta de presupuesto no ha permitido garantizar la adecuada distribución de los recursos sanitarios, en Ecuador (Municipio de Cotacachi, 2005: 1).

Las principales razones que limitan el acceso de las comunidades indígenas a los servicios de salud del Ministerio de Salud Pública en Ecuador son de carácter: geográfico, lingüístico y económico; además de la discriminación cultural y racial.

Para superar estos problemas, hace más de 10 años el Ministerio de Salud Pública de Ecuador, a través de la Dirección Nacional de Salud de los Pueblos Indígenas (DNSP), inició un programa de salud intercultural con el objetivo de construir redes entre las organizaciones indígenas, los departamentos gubernamentales de salud, los proveedores de atención sanitaria y las organizaciones no gubernamentales.

Adicionalmente, la Constitución de Ecuador que entró e vigencia en 1998 empezó a incluir aspectos referentes a la multiculturalidad y multietnicidad del Estado ecuatoriano, así como a los derechos colectivos de las comunidades indígenas y afro-ecuatorianos. Con respecto a estos grupos étnicos, en esa Constitución se consideró especialmente sus "sistemas, conocimientos y prácticas de la medicina tradicional, incluido el derecho a la protección de los rituales y lugares sagrados, plantas, animales, minerales y ecosistemas de interés vital, desde el punto de vista de esta medicina" (Artículo 84, apartado 12). Esa Constitución también reconoció la contribución de las culturas ancestrales a la atención sanitaria de la población ecuatoriana.

El texto de la nueva Constitución del Ecuador, la cual fue elaborada por una Asamblea Constituyente y aprobada por la población ecuatoriana el 28 de septiembre de 2008, también incluye artículos referentes a salud. Los artículos más relevantes son nueve y, entre ellos, se dice que el Estado ecuatoriano tiene la responsabilidad de fortalecer los servicios de salud de la población y garantizar la práctica de la medicina tradicional. 
La nueva Constitución confirma que los servicios de salud pueden ser prestados a través de agencias estatales, privadas, autónomas y en comunitarias, y que en estos lugares es posible ofrecer servicios de biomedicina, de medicina alternativa y complementaria.

Esta nueva Constitución también declara al español como lengua "oficial" en el Ecuador, mientras que el español, Kichwa y Shuar ${ }^{67}$ son los idiomas oficiales de relación intercultural. Otros idiomas ancestrales son de uso oficial de las nacionalidades indígenas en las zonas donde habitan esos grupos y en los términos determinados por la ley".

Un aspecto innovador de la nueva Constitución ecuatoriana es que destaca los derechos de pueblos indígenas, no sólo para confirmar la Declaración de Plurinacionalidad del Ecuador, sino en reconocimiento a la interculturalidad.

"Etimológicamente esto implica que, si la práctica de la educación y la salud intercultural es concebida como un derecho básico de la interculturalidad, será imposible alcanzar el reconocimiento jurídico, político y social de un país con diversidad de nacionalidades. Aunque, hasta ahora, muchas nacionalidades están vinculadas no sólo en términos de tolerancia, sino de sinergia”. Esta opinión la expresó Elizabeth Núñez, quien fuera directora de Comunicación del Ministerio de Salud Pública del Ecuador. En su opinión, la interculturalidad es un requisito fundamental para la declaración de Plurinacionalidad de un Estado Plurinacional.

Con respecto al estado de salud de los pueblos indígena, ${ }^{68}$ el equipo técnico del centro Jambi Huasi elaboró un informe hace cuatro años, en el cual expuso que las poblaciones

\footnotetext{
${ }^{67}$ Shuar es la lengua autóctona que caracteriza al grupo étnico del mismo nombre, el cual habita en la región amazónica del Ecuador y el Perú.

${ }^{68}$ Fuentes en Ecuador estiman que la población indígena de este país está entre 1 millón y 4 millones de personas; por lo tanto, las comunidades indígenas pueden representar entre el $10 \%$ y el $40 \%$ de la población ecuatoriana. Esta enorme diferencia en los datos se relaciona con la diferente concepción de "indígena" que
} 
indígenas ecuatorianas han desarrollado conocimientos especializados en varias áreas, tales como la medicina tradicional. "Sin embargo, este conocimiento no ha sido reconocido como tal y, para devaluarlo, algunas personas lo han definido sólo como saberes".

Por otra parte, la discriminación racial, el abuso social y económico y la explotación han influido en la crítica situación de la población indígena. (Conejo et als., 2004: 7). Una situación que se refleja en el estado de salud de los pueblos indígenas, ${ }^{69}$ que no ha mejorado significativamente, a pesar del hecho de que el Ministerio de Salud Pública del Ecuador ha impulsado varios esfuerzos y ha ampliado la cobertura de los servicios de salud.

A pesar de que muchas poblaciones indígenas han desarrollado y se han basado en la utilidad del sistema de salud de sus antepasados indígenas, este hecho no ha sido suficiente para resolver los problemas de salud causados por la inseguridad, la desnutrición, la contaminación del medio ambiente, y su situación socioeconómica.

Según la directora de Jambi Huasi, Myriam Conejo, los datos estadísticos han sido generalmente homogéneos y han ocultado algunos problemas de los pueblos indígenas "que aún persisten". (Conejo et als., 2004: 8)

tienen las personas; hay quienes plantean diferencias entre ser indígena puro, mestizo o campesino. Este problema es más grave que sólo la falta de confianza en el censo. El tamaño de la población indígena en Ecuador implica la estructura política y social del país.

${ }^{69}$ La mayoría de poblaciones indígenas del Ecuador están normalmente ubicadas en comunidades que están geográficamente lejos de ciudades o zonas urbanas; muchas no tienen acceso vial. Por estas razones, es difícil para algunos pueblos indígenas para asistir a los servicios de salud en casos de emergencia. Además, muchos hombres han emigrado para trabajar y muchas mujeres adultas sólo hablan Kichwa, por lo que esta, muchas de esas mujeres no suelen salir de sus comunidades. En el caso de las mujeres indígenas que realmente vaya a la ciudad, que debe encontrar a alguien que cuida de sus hijos, la casa y los animales, y también deben estar preparados para hacer frente a situaciones de abuso, la discriminación racial, las dificultades con un nuevo idioma, Y el temor de no poder regresar el mismo día a su casa. Por estas razones, muchos prefieren los pueblos indígenas a recibir la atención de la salud en sus propias comunidades. 


\subsubsection{Contexto Provincial}

En la provincia de Imbabura habitan grupos étnicos Kichwa, mestizo, ${ }^{70}$ afro-ecuatoriano. Su población total es de aproximadamente 329.755 habitantes $(48,2 \%$ son de origen mestizo; $40,1 \%$ son de origen indígena y $11,7 \%$ son de origen negro). Alrededor del $51,8 \%$ de la población vive en el área rural.

En el año 2000, la incidencia de la pobreza fue de 77,8\% según información registrada por el Municipio de Cotacachi (2005). La tasa de analfabetismo en 1990 fue de 16\%. Las necesidades básicas insatisfechas en 1994 afectaron al 40,3\% de la población y, seis años después, este índice ascendió a 57,5\%.

La esperanza de vida al nacer, durante el período comprendido entre 1995 y 2000, fue de 66,4 años (Municipio de Cotacachi 2005: 2).

En la siguiente sección consta una breve descripción del contexto local de Otavalo, entorno urbano que está experimentando cambios sociales.

\subsubsection{Configuración del estudio: Otavalo}

A una altitud de 2550 metros, en los Andes ecuatorianos, está ubicada la antigua ciudad de Otavalo, cuya población asciende a aproximadamente 31.000 habitantes. Su superficie es de 507 kilómetros cuadrados, el equivalente a una octava parte de la provincia de Imbabura. El cantón Otavalo está compuesto por la ciudad del mismo nombre y por 11 parroquias: dos urbanas y nueve rurales.

\footnotetext{
${ }^{70}$ El término "mestizo" se refiere a personas que tienen ascendencia indígena y española.
} 
La ciudad de Otavalo está ubicada 110 kilómetros al norte de la capital de Ecuador, Quito, y 25 kilómetros al sur de su capital provincial, Ibarra.

Aunque en Ecuador el idioma oficial es el español, en Otavalo muchas personas también hablan Runa Shimi o Kichwa. $^{71}$

La mayoría de las personas que viven en este cantón son

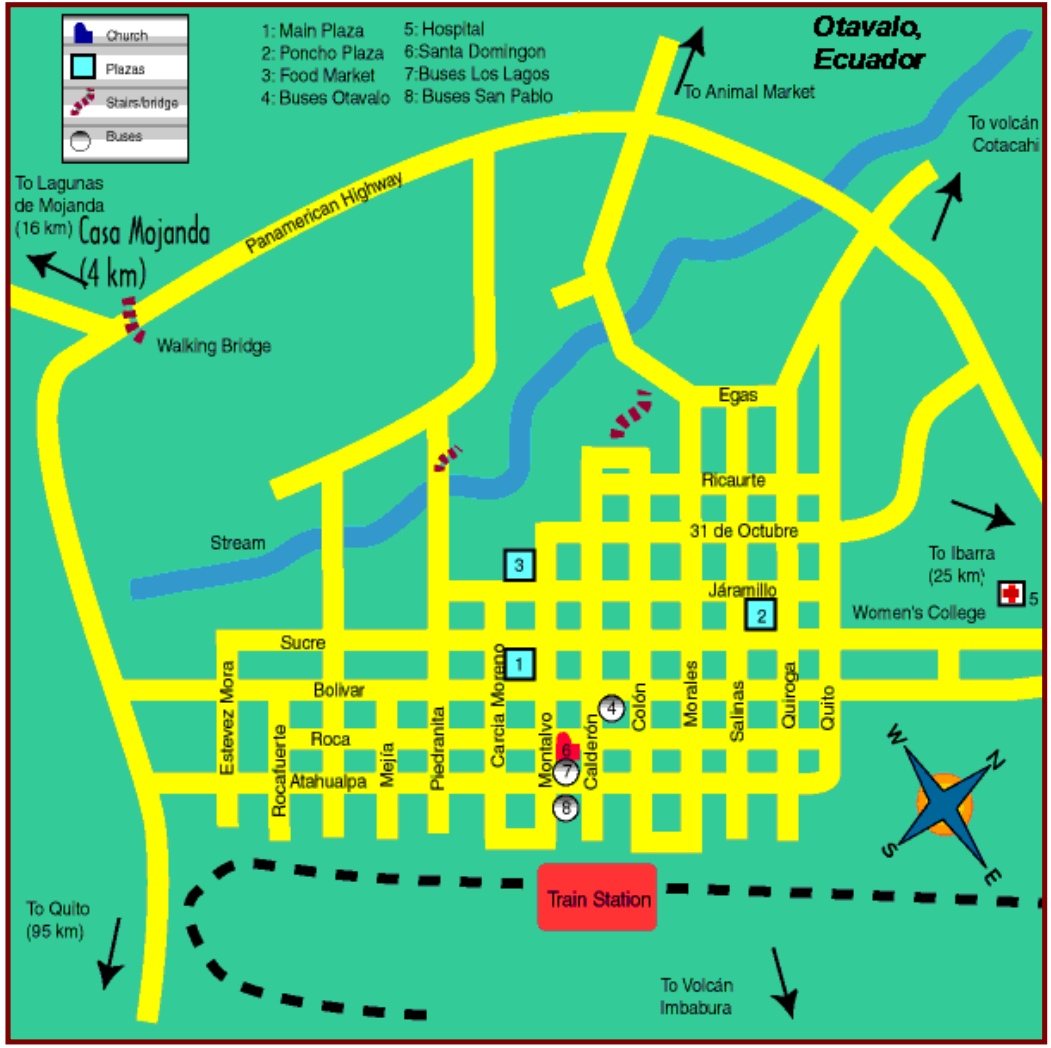
de origen Kichwa Otavalo, Kichwa Kayambi, y mestizo. "Esta es una sociedad en la cual, a pesar de la diversidad de la población, destaca la unidad basada en el respeto mutuo y en objetivos comunes; pero, fundamentalmente, donde los ciudadanos son responsables y no sólo están conscientes de sus derechos, sino también de sus obligaciones". Esta es la opinión del alcalde de Otavalo, Mario Conejo, ${ }^{72}$ quien es de origen indígena, formado en sociología y alcalde de este cantón durante ocho años (A mediados de 2009 él postulará por tercera vez su candidatura, con la aspiración de ser reelecto como alcalde).

\footnotetext{
${ }^{71}$ Este idioma es resultado de una fusión entre el Quechua (lengua que introdujeron a esta región los Incas, desde Perú), y otras lenguas anteriores al Kichwa.

$72 \mathrm{Su}$ hermana, la Dra. Myriam Conejo, es directora del centro de salud Jambi Huasi, lugar donde se desarrolló el trabajo de campo que permite sustenta la presente investigación.
} 
Debido a su ubicación, Otavalo es la más importante zona turística ubicada al norte del Ecuador (O’Neill et als., 2006: 34). Se trata del principal centro de producción y comercialización de textiles tradicionales en Ecuador.

En este lugar destacan, como actividad económica, la industria manufacturera y la venta de ropa y artesanías. Estos productos suelen ser comercializados, tanto en Ecuador como en otros países, a través por sus propios productores de origen indígena Kichwa. Un hecho cultural más reciente que destaca en el cantón Otavalo es la producción de música folclórica andina, la cual también se exporta a otros países (Kyle, 2002: 29-51).

La población indígena de Otavalo es uno de los grupos étnicos más reconocidos del Continente Americano, debido a sus fortalezas históricas y socio-culturales, lo cual les ha permitido mantener sus costumbres y tradiciones a través del tiempo.

Este grupo étnico es muy conocido a nivel internacional por su particular mercado de artesanías, por el talento musical que caracteriza a muchos integrantes, por sus tradicionales; así como por el estilo de su vestimenta y por la larga cabellera que suelen lucir tanto hombres como mujeres.

Una importante agrupación que radica en el cantón de Otavalo es la Asociación de Parteras Indígenas, fundada en el año 2002, con el fin de supervisar la certificación de parteras tradicionales en esa región. Son más de 64 las parteras quienes se han registrado en esa Asociación; sin embargo, son muchas más las que aún no están registradas y, por ende, no han recibido capacitación.

La falta de registro de parteras es un problema, según autoridades de la Dirección Provincial de Salud de Imbabura, "porque varios casos de muerte materno-infantil han sido atendidos por parteras no capacitadas", confirma Gonzalo Jaramillo, quien es titular en esa Dirección. 
A pesar de que esta Asociación es independiente de Jambi Huasi y de la FICI, también coordina algunas actividades de capacitación con ese centro de salud, a través de reuniones periódicas. La Dirección Municipal de Salud también apoya esos encuentros con el suministro de recursos para la formación, así con equipamiento.

Otro importante grupo es la Asociación de Yachaks de Ilumán, que está ubicada en una pequeña comunidad, cerca de Otavalo. Hasta el año 2005, esta Asociación había registrado a 47 miembros, incluidos algunos de las localidades circundantes (O'Neill et als., 2006: 34). Algunos de sus miembros han trabajado en el centro de salud Jambi Huasi.

La Federación Indígena y Campesina de Imbabura (INRUJTA, en Kichwa; FICI, en castellano), es la organización provincial que representa a comunidades indígenas. Esta Federación está ubicada en la ciudad de Otavalo.

Cambios en el estilo de vida de la población indígena Kichwa de Otavalo (como resultado de la emigración y por los problemas detectados en el acceso a los servicios de salud formal), influyeron para que la FICI proponga la búsqueda de estrategias que fortalezcan la identidad de los pueblos indígenas.

En este contexto, la reivindicación de la medicina tradicional indígena llegó a ser uno de sus objetivos fundamentales. Para lograr este objetivo, en 1983 la FICI creó el Proyecto de Salud Jambi Huasi, que en 1998 adquirió reconocimiento jurídico bajo el nombre de "Fundación de Medicina Alternativa, Jambi Huasi". 


\subsubsection{Caso de estudio: Centro de salud Jambi Huasi}

"Empezamos el proyecto Jambi Huasi con la idea de romper ciertos prejuicios, para recuperar los conocimientos sobre medicina tradicional indígena, con el fin de que ésta contribuya a la medicina occidental (o biomedicina). A través del proyecto Jambi Huasi queríamos demostrar que no somos gente ignorante”. Así lo expresó Myriam Conejo, directora del centro de salud Jambi Huasi ${ }^{73}$
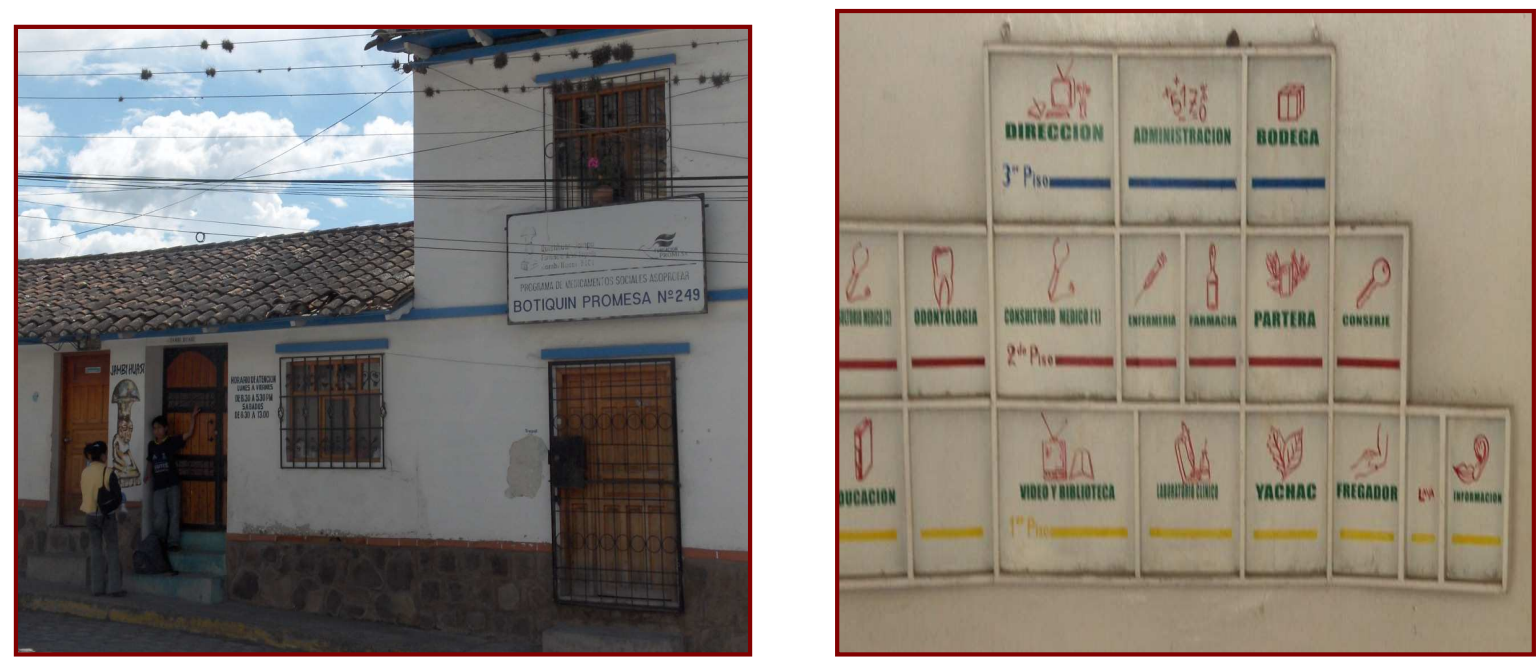

En una antigua casa de ambiente acogedor, ubicada en el área central de Otavalo, funciona actualmente el centro de salud Jambi Huasi. Este centro fue fundado en 1983, por parte de la Federación Indígena y Campesina de Imbabura (FICI). ${ }^{74}$ Desde 1994, este centro también provee servicios de salud sustentados en biomedicina, además de los servicios de medicina tradicional indígena. ${ }^{75}$

\footnotetext{
${ }^{73}$ Desde finales de 1994, Myriam Conejo es directora del centro de salud Jambi Huasi. Su ascendencia es indígena y, en el año 2006, ella recibió un premio internacional de las Naciones Unidas, a través del UNFPA, "por trabajar en favor de las mujeres indígenas de la provincia de Imbabura" desde Jambi Huasi. En octubre de 2004 este centro de salud también recibió el "Premio Cotama", del Municipio de Otavalo, en reconocimiento por su contribución a la comunidad.

${ }^{74}$ La FICI es una organización indígena apoyada por 160 comunidades de la provincia de Imbabura. También representa a esta región en la Confederación de Nacionalidades Indígenas del Ecuador (CONAIE).

${ }^{75}$ Más información sobre la historia del centro de salud Jambi Huasi podrá en la sección 6.4.
} 
En los servicios biomédicos trabajan médicos, un dentista y un profesional de laboratorio (quien realiza diversas pruebas médicas, como de Papanicolaou y del VIH/SIDA).

A partir del enfoque de la medicina tradicional indígena, en el centro Jambi Huasi también trabaja un yachak (curandero espiritual), un "fregador" (quien ofrece masajes), una jacub (quien realiza otro tipo de curaciones) y una mamahua (término Kichwa que significa "partera", en castellano; o "midwife" en inglés).

"La salud sólo puede entenderse en su contexto social y cultural, a partir del principio de solidaridad, reciprocidad e integralidad; tanto desde el aporte del laboratorio como de la medicina tradicional indígena, incluyendo el servicio de parteras tradicionales". (Conejo et. als., 2005)

A partir del supuesto de que las necesidades en salud es mejor abordarlas desde el contexto social y cultural de los pacientes, Jambi Huasi fomenta el derecho a recibir una atención de salud integral, en el respeto a las tradiciones culturales, en la solidaridad social y la reciprocidad.

Según los estatutos de la fundación de Jambi Huasi, la misión de este centro es "ofrecer servicios de calidad, con trato humanitario y oportuna, sin discriminación racial, social o la discriminación económica" (Conejo et als., 2005: 13). Parte de su misión es la de respetar la cosmovisión de sus pacientes, para proporcionar la atención de la salud, promover el compromiso político de los funcionarios con la comunidad, y para fomentar la coordinación interinstitucional con la plena participación de los pueblos indígenas. Con este fin, el centro promueve la coordinación de la medicina tradicional indígena y la biomedicina, así como la 
recuperación y revalorización de la medicina tradicional indígena y el papel de su Jambigkunas. $^{76}$

\subsubsection{Relación FICI - Jambi Huasi ${ }^{77}$}

La Federación Indígena y Campesina de Imbabura (FICI) ha sido la fuerza impulsora en la creación del centro de salud Jambi Huasi. En 1974, debido a la falta de beneficios que reportaba en salud la población indígena de Imbabura, la FICI planteó la necesidad de incluir entre sus líneas de acción la atención a ese problema; por ello, en 1983, apoyó la creación del área de salud Jambi Huasi. El objetivo de su fundación fue: “establecer un centro de medicina alternativa para vincular la medicina tradicional indígena con la medicina occidental (biomedicina), teniendo en cuenta la cosmovisión de los habitantes de la provincia de Imbabura”. (Conejo et als., 2004: 6)

Por lo tanto, la Fundación Jambi Huasi es como una respuesta de las organizaciones indígenas a la falta de atención a la salud de la población indígena (Conejo et als., 2005). “Jambi Huasi es un sueño (...). Es como una respuesta cultural”, opinó la dirigente indígena Blanca Chancoso, ${ }^{78}$ quien fue miembro de la administración de la FICI en la época de fundación de Jambi Huasi.

“Durante la primera fase de Jambi Huasi (de 1983 a 1992) este centro ofreció sus servicios de salud de forma gratuita, tanto a quienes provenían de sectores urbanos como de sectores rurales. Una particularidad de este período es que la actividad de Jambi Huasi

\footnotetext{
${ }^{76}$ En este estudio se utiliza la palabra Jambigkuna para referirse a todos quienes conocen y practican la medicina tradicional indígena, incluyendo el yachak.

${ }^{77}$ Más información sobre la historia del centro de salud Jambi Huasi podrá leerse en la sección 6.4.

${ }^{78}$ Este punto de vista se afirma a través de un vídeo institucional, producido por Jambi Huasi con el apoyo del UNFPA.
} 
estuvo vinculada con actividades de organización de la FICI. Sin embargo, ${ }^{79}$ dificultades administrativas dentro de la FICI y la falta de recursos económicos influyeron para que Jambi Huasi cerrara la atención al público en varias ocasiones. La última vez que este centro suspendió sus servicios de atención de salud fue en 1992.80

En 1994, Myriam Conejo y el equipo médico de Jambi Huasi presentaron un proyecto al Fondo de Población de las Naciones Unidas (UNFPA, por sus siglas en inglés), el cual les ofreció respaldo económico para que desarrollaran el proyecto titulado "Salud Integral para la Atención de la Mujer Indígena y Campesina de Imbabura” en Otavalo.

Desde ese año, hasta 2006, Jambi Huasi dio prioridad al desarrollo de un programa de salud sexual y reproductiva. Para llevar a cabo ese programa, los líderes de Jambi Huasi propusieron adoptar las mismas características del proyecto original: combinar la medicina tradicional indígena y la biomedicina en la prestación de servicios de salud destinados a diez comunidades del cantón Otavalo, así como a personas de otros sectores que visitan este centro de salud.

A diferencia de la etapa inicial y, a pesar de ser una entidad sin ánimo de lucro, durante la segunda fase (que comenzó en 1994) las autoridades de Jambi Huasi decidieron cobrar una tarifa mínima a los pacientes, por la prestación de los servicios de salud. "Nuestro interés ha sido trabajar en el desarrollo de una propuesta para la prestación de servicios de

\footnotetext{
${ }^{79}$ El primer equipo de salud de Jambi Huasi estuvo conformado por los médicos Mario Maldonado y Nancy Núñez; por el yachak Taita Churo y por Roberto Conejo. En esa época, la FICI fue administrada por dirigentes indígenas, como Fausto Jimbo y Blanca Chancoso.

${ }^{80}$ Más detalles sobre las razones que generaron la suspensión de servicios en Jambi Huasi pueden consultarse en los archivos históricos de este centro de salud, en la FICI y en el informe de una investigación realizada hace más de 10 años por Raúl Mideros y otros investigadores de la Universidad Andina Simón Bolívar, sede Ecuador.
} 
salud, cumplir con las características que exige una población diversa y generar propuestas de políticas de salud para la población indígena" (Conejo et als., 2004: 7).

Otro de los propósitos que motivó a la FICI crear Jambi Huasi fue apoyar el trabajo de profesionales indígenas capacitados en biomedicina. Myriam Conejo lamenta que, a pesar de que muchos indígenas se han capacitado profesionalmente en el ámbito biomédico, sean muy pocos los que trabajaban como médicos y que la mayoría hayan optado por trabajar en actividades artesanales; como empleados en el sector informal, doméstico o agrícola". (Conejo et als., 2004: 7)

Para las personas que trabajan en el centro Jambi Huasi la salud es un aspecto íntimo de la vida y las ideas referentes a las causas y al tratamiento de la enfermedad están a menudo situadas en un contexto cultural específico.

\subsubsection{Metodología}

Para el desarrollo de esta investigación se asumió un diseño exploratorio y se tomó en cuenta experiencias de representantes de la biomedicina, de la medicina tradicional indígena y de pacientes que asistieron al centro de salud Jambi Huasi durante el periodo de trabajo de campo.

Para el proceso de recopilación de datos se escogió la observación, la entrevista semiestructuradas y a profundidad, y el registro de material documentado. Las entrevistas y la observación fueron aplicadas especialmente en salas de consulta, en corredores y en más lugares del centro de salud Jambi Huasi. También se entrevistó a funcionarios de salud que laboran en Ibarra (capital de la provincia de Imbabura), así como en Quito. 
Con respecto a la muestra, se optó por entrevistar a 8 personas que trabajan como proveedores de salud en el centro Jambi Huasi; a 3 pacientes de este centro y a 10 representantes de diversas instituciones ( 3 investigadores académicos, 2 coordinadores del Ministerio de Salud Pública del Ecuador; 2 representantes de la Dirección Provincial de Salud de Imbabura; 1 director del Hospital San Luis de Otavalo, y 2 representantes del Municipio de Otavalo).

También se aplicó entrevistas en la ciudad de Cotacachi, capital de otro cantón en la provincia de Imbabura. En esa ciudad se entrevistó a dos representantes del programa de salud Jambi Mascaric y a dos representantes del Programa de Salud Cantonal Intercultural de Cotacachi. ${ }^{81}$

Por tanto, para sustentar el contenido de esta investigación empírica se entrevistó, en Ecuador, a 25 personas. Quince entrevistas fueron previamente estructuradas e incluyeron preguntas abiertas; en la mayoría de los casos se consideró relevante la historia personal del entrevistado/a.

El tiempo total de observación en el centro de salud Jambi Huasi fue de aproximadamente 40 horas, durante el trabajo de campo.

También se pudo acceder al reporte médico de consultas realizadas en el centro de salud Jambi Huasi, entre el 2 y el 27 de junio de 2008. Estos datos fueron proporcionados por personal de salud de Jambi Huasi, e incluyen tanto las consultas de profesionales biomédicos, como las que ofrecieron representantes de la medicina tradicional indígena. A

\footnotetext{
${ }^{81}$ Después de varias entrevistas y prácticas de observación, se notó que se iba a ser necesario más tiempo para ampliar el área de investigación a otras ciudades. Por ese motivo, se descartó la propuesta de aplicar el trabajo de campo en el centro Jambi Mascaric, de la ciudad de Cotacachi, y se concentró la investigación en el centro de salud Jambi Huasi, de Otavalo.
} 
partir de datos cuantitativos, fue posible elaborar gráficos que ilustran y/o confirman el análisis que se presenta en este capítulo. ${ }^{82}$

Esta investigación empírica exploró los siguientes aspectos:

4. ¿De qué manera están presentes la biomedicina y el conocimiento local (que es la denominada "medicina tradicional indígena" en esta investigación) en la práctica de la atención primaria de salud que ofrece el centro Jambi Huasi?

5. ¿La distinción entre los conocimiento y prácticas provenientes de la biomedicina y del conocimiento local ha perdido su pertinencia, o acaso estas dos formas de conocimiento están conflicto en la práctica de la atención primaria de salud, en el centro Jambi Huasi?

6. ¿Cuáles son las estrategias de comunicación que utiliza el centro Jambi Huasi, en la atención primaria de salud, y cómo éstas influyen en la relación existente entre biomedicina y conocimiento local?

Para responder al primer punto, se analizó la práctica de la biomedicina y de la medicina tradicional indígena en los servicios de atención primaria de salud, desde la perspectiva de los beneficiarios (pacientes) y proveedores de esa atención; a más de explorar el tipo de comunicación que se promueve entre estos grupos.

Para responder al segundo punto, durante el trabajo de campo se intentó observar si la clásica distinción entre biomedicina y medicina tradicional indígena se ha vuelto menos clara con el tiempo, y cómo las dos formas de conocimiento y la práctica influyen mutuamente.

\footnotetext{
${ }^{82}$ Esos gráficos constan en la sección 6.4.2. del presente capítulo.
} 
La respuesta al tercer punto se sustenta en entrevistas realizadas a pacientes y a proveedores de salud (tanto de la biomedicina como de la medicina tradicional indígena); así como en la observación de los procesos de comunicación que los caracteriza. Porque, en esta investigación, se dio especial énfasis a la influencia de las estrategias de comunicación utilizadas por representantes de la biomedicina, de la medicina tradicional indígena y por los pacientes que asisten al centro de salud Jambi Huasi.

Los objetivos de esta investigación fueron explicados claramente a todos los informantes, antes de entrevistarlos. El permiso para realizar el trabajo de observación y las entrevistas en Jambi Huasi fue concedido por la directora de este centro de salud, Myriam Conejo. A cada persona entrevistada se le solicitó previamente su autorización, para grabar la entrevista.

Para proteger el bienestar de los informantes, a todos se les consultó si preferían mantener su nombre en el anonimato; pero sólo tres de las 25 personas entrevistadas solicitaron ser identificados con un nombre ficticio en el contenido de la tesis.

Durante esta investigación se intentó respetar los valores culturales, creencias y normas locales de las fuentes de información.

\subsection{Enfoque teórico}

A fin de comprender las representaciones culturales sobre salud y enfermedad, en el ámbito de la biomedicina y de la medicina tradicional indígena, resulta útil el análisis sobre "pluralismo médico".

El grado de pluralismo en los sistemas de salud andinos se debe, en gran parte, al análisis de la enfermedad por parte agentes locales. El hecho de que haya mayor 
reconocimiento de la agencia entre participantes de los sistemas de salud es un tema clave que se refleja en recientes estudios de antropología médica desarrollados en los Andes; ${ }^{83}$ en estas relaciones, el papel de género, clase y poder es bien reconocido.

Las personas son atrapadas en redes de relaciones sociales que influyen en su experiencia y en sus opciones, y actúan desde diversos motivos, o por motivos que pueden cambiar con el tiempo. Al hacerlo, ellos construyen y reconstruyen sistemas de salud pluralista en los que participan. (Miles et als., 2003: 10)

Tal vez sea más exacto decir que los sistemas médicos nacionales en el mundo moderno o post-moderno tienden a ser "plurales", en lugar de ser "pluralistas", donde la biomedicina goza de una posición dominante sobre la condición de otras prácticas etno-médicas.

Como observa Charles Leslie: ${ }^{84}$ "Todas las civilizaciones con grandes sistemas médicos tradicionales han desarrollado una gama de profesionales, desde profesionales formados en medicina hasta individuos con poca o ninguna formación que practican una versión simplificada de la medicina tradicional. Otros curanderos han coexistido con estos practicantes, sus artes tienen categorías especiales tales como reguladores de huesos, cirujanos, parteras y chamanes”. (Leslie, 1974: 74)

A continuación se argumentará la forma en que el pluralismo médico ha sido desarrollado en la Cordillera de los Andes y su influencia en el centro de salud Jambi

\footnotetext{
${ }^{83}$ En el contexto de América Latina, el pluralismo médico ha sido bien documentado y debatido con frecuencia (Véase, por ejemplo: Crandon, 1986; Davidson, 1983; Finkler, 1991; Pederson et al., 1983; Young et al., 1994). A través de esta literatura se conoce que la biomedicina, la medicina popular (especialmente los remedios caseros), y la medicina tradicional (incluyendo la curación espiritual) han estado coexistiendo y han sido utilizados por individuos de forma alternativa o simultánea, en función de una amplia gama de variables y condiciones.

${ }^{84}$ Charles Leslie es antropólogo, ha desarrollado varias investigaciones sobre los sistemas médicos del Sur de Asia.
} 
Huasi. También se analizará cómo el concepto de "salud intercultural" permite entender la forma en que diferentes conocimientos y prácticas de biomedicina y medicina tradicional indígena están relacionados en Jambi Huasi, así como el contraste de puntos de vista y la interpretación de este concepto. Además, se considerará el uso del concepto de hibridación.

Esta sección se divide en tres secciones: 1) conocimiento indígena, 2) biomedicina y conocimiento local, y 3) construcción intercultural del conocimiento en salud.

Libbet Crandon Malamud planteó cuestiones interesantes sobre el pluralismo médico en la Cordillera de los Andes, a partir del análisis de algunas preguntas que los antropólogos han estado estudiando y que han tratado de responder durante décadas. Los argumentos esenciales de su análisis están detallados en el libro titulado Medical Pluralism in the Andes (Koss Chioino et al., 2003).

Para sustentar el análisis que se detalla en el presente capítulo, una contribución interesante de Crandon Malamud es el siguiente argumento: "Medicine is a critical domain to our sense of selves, infused with enormous power and riddled with different paths that access material and nonmaterial wealth" (En castellano: "La medicina es un dominio crítico al sentido de nosotros mismos, infundido con enorme poder y plagado de diferentes caminos de acceso a la riqueza material y no material”). (Crandon Malamud, 1991: 205)

En Otavalo, el resultado de la combinación de diversas alternativas médicas no sólo refleja la realidad de ese entorno, sino que también refuerza una de las principales conclusiones del trabajo desarrollado por Libbet Crandon Malamud: que la curación es sólo uno de los muchos objetivos o resultados de la elección médica. 
Los resultados de esta investigación están analizados desde la perspectiva de la Antropología Médica Crítica, ${ }^{85}$ porque entiende cuestiones de salud desde el contexto de las fuerzas políticas y económicas que influyen en las relaciones humanas; porque considera los comportamientos sociales, la condición de experiencias colectivas, el reordenamiento de ecologías locales y significados culturales situados, incluidas fuerzas de escala institucional, nacional y mundial. Por tanto, el surgimiento de la Antropología Médica Crítica refleja tanto el cambio hacia enfoques político-económicos en la antropología en general, así como un esfuerzo para participar y ampliar la economía política del enfoque en salud. (Baer et al., 1996: 21-40).

De acuerdo con la anterior revisión literaria, el enfoque de la Antropología Médica Crítica reconoce que las pautas del pluralismo médico tienden a reflejar las relaciones jerárquicas de la sociedad en general. Los patrones de jerarquía se rigen por criterios de clase, casta, raza, etnia, religión y distinciones de género.

Otro interesante aporte a esta investigación lo ofrece el análisis del concepto de "conocimiento situado". Este es un concepto útil, en el sentido de que reconoce diferentes lugares y los afirma como puntos de partida para la producción de conocimiento (Nazarea, 1999). Al analizar este concepto es posible reconocer que el conocimiento es subjetivo y que hay diferentes situaciones que pueden generar nuevo conocimiento.

\footnotetext{
${ }^{85} \mathrm{Si}$ bien la ecología y la adaptación dominaron anteriores perspectivas sobre salud, investigaciones realizadas en los años 1980 y 1990 adoptaron un marco más amplio, el cual reconoce el rol de factores macropolíticos y económicos en la estructuración de entornos locales y la importancia de las relaciones sociales en temas de salud. Este cambio caracterizó la evolución de la etnografía andina, estudios de biología y a la antropología médica crítica. "Estas nuevas perspectivas han dirigido antropólogos médicos andinos para ampliar sus anteriores definiciones sobre ambiente y adaptación, al reconocer las múltiples formas en que fuerzas sociales, económicas y políticas comparten la naturaleza de la vida andina". (Traducción personal de un fragmento escrito por: Miles et al., 2003: 10)
} 
Para analizar la forma cómo los profesionales biomédicos, los jambigkunas (quienes practican la medicina indígena) y los pacientes comprenden la relación entre biomedicina y medicina tradicional indígena en el centro Jambi Huasi, esta investigación también considera el concepto de "salud intercultural" y la categoría de Sistema Médico Complejo. Por tanto, esta investigación destaca la contribución de la antropología médica desde un enfoque holístico, teniendo en cuenta la dimensión socio-cultural de salud y la enfermedad.

\subsubsection{Anteriores perspectivas antropológicas sobre Pluralismo Médico}

Independientemente de su grado de complejidad, todos los sistemas médicos se basan en un doble núcleo conformado por curandero y paciente. En las sociedades complejas, el sistema médico - que es el conjunto de creencias médicas, prácticas y estructuras socialesconsiste en la totalidad de los subsistemas médicos que coexisten en una relación cooperativa o competitiva con los demás.

Muchas de las primeras investigaciones sobre Pluralismo Médico se centraron en la creación de tipologías que reconocen la existencia de este fenómeno en las sociedades complejas. En esta sección se presenta cuatro esquemas clasificatorios. Estos esquemas han sido divididos e identificados con los siguientes nombres: Frederick Dunn, Charles Leslie, Sistema Médico Americano y Sistema Médico Complejo (propuesto por un Grupo de Investigación de la Universidad del Estado de Río de Janeiro, Brasil).

\subsection{1. a) Frederick Dunn}

Sobre la base de su ubicación geográfica y cultural, el antropólogo Frederick Dunn delineó tres tipos de sistemas médicos: (1) sistemas médicos locales, (2) sistemas médicos regionales y (3) sistemas médicos cosmopolita. (Dunn, 1976: 133-58) 
Con el término "sistemas médicos locales", Dunn se refiere a los sistemas médicos "populares" o "indígenas" desarrollados en sociedades donde se promueve la agricultura, la horticultura o el pastoreo a pequeña escala; o en comunidades campesinas.

Los "sistemas médicos regionales" son sistemas distribuidos en un área relativamente grande. Ejemplos de este tipo de sistema son la Medicina Ayurveda y la Medicina Unani, desarrollada al sur de Asia, así como la Medicina Tradicional China.

La "medicina cosmopolita" se refiere al sistema médico mundial, o a lo que comúnmente se ha denominado "medicina científica", "medicina moderna", o "medicina occidental". (Baer, 2003: 43)

Las sociedades complejas generalmente abarcan estos tres sistemas médicos. La India, por ejemplo, tiene numerosos sistemas médicos locales asociados a sus grupos étnicos, al igual que Ecuador. En la ciudad de Otavalo también coexisten varios sistemas médicos. La biomedicina y la medicina tradicional indígena son los más conocidos.

\subsection{1. b) Charles Leslie}

El antropólogo Charles Leslie ha caracterizado el sistema médico de la India en cinco niveles: (1) la biomedicina, que lo ejercen médicos que han obtenido su grado de MSc o $\mathrm{PhD}$; (2) "los sistemas médicos indígenas", que integra a profesionales formados en colegios médicos especializados en la medicina Ayurveda, Unami o Siddha; (3) la homeopatía; (4) estudiosos de religión o aprendices de personas con inusuales capacidades de curación, y (5) curanderos populares locales, fregadores y parteras.

Para resumir el contradictorio rol que los sistemas médicos tradicionales desempeñan al sur de Asia, Leslie citó la siguiente opinión: "los médicos [tradicionales] a veces son dolorosamente conscientes de que la medicina cosmopolita [o biomedicina] domina el 
Sistema Médico de la India, pero existe un mercado substancial para la comercialización de productos de la medicina Ayurveda, así como para la realización de consultas con representantes de esa medicina". (Leslie et al., 1992: 2)

Este punto de vista podría servir para analizar la presencia de varios sistemas médicos en el Ecuador, especialmente en lugares con gran población indígena, como ocurre en Otavalo.

\subsection{1. c) Sistema Médico Americano}

El Sistema Médico Americano consta de varios niveles que tienden a reflejar la clase, raza/etnia, y relaciones de género de la sociedad en general.

En orden de prestigio, este sistema incluye: (1) biomedicina; (2) osteopatía, como sistema médico paralelo; (3) sistema médico heterodoxo profesionalizado (quiropráctica, naturopatía y acupuntura); (4) sistema médico heterodoxo parcialmente profesionalizado (ejemplo: homeopatía, herbolaria, reflexología, terapia de masaje); (5) sistemas de curación religioso anglo-Americano (ejemplo: espiritismo, adventismo del séptimo día), y (6 ) sistemas médicos populares (ejemplo: sistemas médicos del sur, como el "curanderismo", “espiritismo", "santería”, y los sistemas de curación de indígenas americanos).

Como resultado de la ayuda financiera (que provino inicialmente de fundaciones corporativas auspiciantes $\mathrm{y}$, posteriormente, del gobierno federal), destinada a sus actividades de investigación e instituciones educativas, la biomedicina ha adquirido superioridad científica y clara hegemonía frente a sistemas médicos alternativos.

\subsection{1.d) Sistemas Médicos Complejos}


El Grupo de Investigación de la Universidad del Estado de Río de Janeiro, Brasil, tiene gran reconocimiento en América Latina y está dirigido por Madel T. Luz. ${ }^{86}$ A partir del análisis de varios sistemas médicos, ella plantea cuestiones fundamentales como: ¿Estamos hablando de saberes, habilidades o de ciencia; de terapias o de prácticas?

Inspirada en estas inquietudes, Madel T. Luz analiza la categoría de "racionalidad médica", ${ }^{87}$ la cual ella utiliza para identificar el denominado Sistema Médico Complejo. Según esta investigadora, una racionalidad médica debe cumplir al menos cinco dimensiones para ser considerada sistema médico complejo: 1) morfología, 2) dinámica vital, 3) doctrina médica, 4) sistema de diagnóstico, y 5) sistema de intervención terapéutica (Luz 1996: 5).

A partir del análisis de estas características y de la categoría de la racionalidad médica, Luz identifica cuatro sistemas médicos complejos: 1) La medicina occidental contemporánea, o biomedicina, 2) la medicina homeopática, 3) la medicina tradicional china, y 4) la medicina Ayurveda. (Luz 1996: 3)

Desde la perspectiva cultural, estos cuatro sistemas médicos complejos están caracterizados por racionalidades médicas que proceden de sociedades complejas y altamente diferenciadas, según la investigadora Madel T. Luz.

\footnotetext{
${ }^{86}$ La Dra. Madel T. Luz es profesora del Instituto de Medicina Social en la Universidad del Estado de Río de Janeiro, Brasil.

87 "La racionalidad médica" es una de las principales categorías utilizadas por Madel T. Luz en sus investigaciones. Este concepto está doblemente inspirado en la obra de Max Weber: a partir de un punto de vista teórico, o nocional (es decir, por su contenido en términos significativos), y desde un punto de vista metodológico (es decir, de su construcción). Para obtener más información acerca de las características del término "racionalidad médica", se sugiere revisar la investigación teórico-comparativa que realizó Luz entre 1991-1994, como parte de su proyecto titulado "Racionalidad médica", en el Instituto de Medicina Social de la Universidad del Estado de Río de Janeiro.
} 
El investigador ecuatoriano Raúl Mideros ${ }^{88}$ y otros investigadores de la Universidad Andina Simón Bolívar, sede Ecuador, están analizando si la Medicina Andina Amazónica cumple con todas las condiciones necesarias para que sea valorada como sistema médico complejo. En este contexto, las diferentes técnicas de diagnóstico y tratamiento utilizadas por la medicina tradicional indígena en el centro Jambi Huasi podrían formar parte de la Medicina Andina Amazónica.

Con el fin de explicar por qué es difícil comparar los conocimientos y prácticas que provienen de la biomedicina y de la medicina tradicional indígena, Raúl Mideros plantea un paralelismo entre el sistema médico de la región andina y el sistema médico oriental.

"Es evidente que las cuestiones de salud en las comunidades andinas son similares a las cuestiones de salud de la medicina oriental, porque ambos no funcionan a partir de modelos mentales, como suelen hacer los europeos. Con sus modelos, los europeos tratan de construir la situación objetiva o la situación final y, a continuación, subordinan su acción a tal situación (...). Pero la medicina andina y la medicina oriental no trabajan con modelos mentales. Por ejemplo, un yachak o una mamahua (partera), a pesar de que tienen una experiencia que podría orientarles en su trabajo, no se sienten seguros sobre cuál será el punto de llegada en la solución de una enfermedad, ya que para ellos eso es incierto", expuso Mideros en una entrevista concedida para esta investigación.

\footnotetext{
${ }^{88}$ Raúl Mideros es Doctor en Medicina y Cirugía. Estudió una especialización en Investigación y Administración de la Salud, en la Escuela de Salud Pública de la Universidad Central del Ecuador. También estudió una Maestría en Antropología, en la Facultad Latinoamericana de Ciencias Sociales (FLACSO), en la ciudad de Quito, y un Ph.D. en Cultura y Sociedad en los Andes, en el Centro Bartolomé de las Casas, Cuzco, Perú. En la actualidad, es coordinador del programa de "Medicinas tradicionales y Sistemas de Salud noformal”, en la Universidad Andina Simón Bolívar.
} 
Sin embargo, Mideros llama la atención sobre las diferencias en la biomedicina, porque "en este contexto, los médicos suelen decir que ellos saben el punto de llegada". A partir de este análisis, Mideros cree que la propuesta de "salud intercultural" se asemeja a la forma de pensar y a las teorías de la biomedicina, ya que propone la creación de un modelo intercultural, en lugar de un enfoque coherente con la cosmovisión indígena de pueblos andinos.

A pesar de los diversos sistemas de clasificación ideados por antropólogos que reconocen la diversidad de los sistemas médicos en sociedades complejas, el estudio de estos fenómenos ha llegado a un callejón teórico sin salida. Brodwin afirmó: "Los intentos por clasificar los sistemas médicos plurales a menudo produjo tipologías funcionalistas rígidas o se rompió en una maremágnum de términos incomparable” (Brodwin, 1996: 1).

Es por ello que algunos antropólogos médicos han preferido estudiar otro tipo de problemas relacionados con la economía política de la salud, ${ }^{89}$ la hegemonía biomédica, sistemas médicos alternativos en sociedades occidentales; la reproducción, el cuerpo consciente y la dinámica social de encuentros clínicos.

\subsubsection{Conocimiento local: medicina tradicional indígena}

Los habitantes de pueblos y ciudades andinas ya no son vistos como pasivos, como víctimas sospechosas de aspectos sobrenaturales o de duras limitaciones medioambientales; ya que ellos son flexibles, persistentes y participan en el mantenimiento de su bienestar dentro de un complejo ajuste a través de varios medios.

\footnotetext{
${ }^{89}$ Varios antropólogos interesados en la economía política de la salud expusieron interés sobre la forma en que las relaciones de poder dieron forma a los sistemas médicos plurales.
} 
En los países andinos, como Bolivia y Ecuador, la reforma agraria y la eliminación del sistema de hacienda estimuló el crecimiento de mercados campesinos locales y la drástica reducción de la dependencia de pueblos indígenas a la clase mestiza. Estos cambios también destruyeron la base económica de la población rural mestiza, específicamente la extracción de recursos indígenas y la mano de obra (Carter, 1964; Dandler, 1969; Heath, 1969; Malloy, 1970).

Esta noción ha justificado la economía mestiza y el control de la población indígena. Por lo tanto, la destrucción del control político y económico mestizo sobre el Aymara local, en la década de 1950, eliminó un sentido mestizo de comunidad en el pueblo, ya que muchas personas salieron de los pueblos para vivir en la ciudad. Esta situación fue evidente en el Ecuador, por ejemplo, entre indígenas Kichwa de Otavalo y la gente mestiza que vivía allí.

Autoridades de Jambi Huasi afirmaron que en este centro de salud se evita la combinación de tratamientos. Esta sugerencia tiene por objeto prevenir ciertos problemas en los pacientes, como la auto-medicación o el exceso de medicación para cumplir con diferentes tratamientos.

La anterior preocupación puede estar vinculada con una de las principales preocupaciones que se expone en la literatura de antropología médica, sobre el uso farmacéutico: la cuestión de la auto-medicación o del auto-cuidado (Logan, 1983; Price, 1989; Van der Geest, 1987), puede estar vinculada a significados culturales sobre salud y enfermedad, como Blesdoe y Goubaud (1985) solían decir. Este problema fue confirmado en Ecuador a través de estudios desarrollados por Price (1989), quien sostuvo que en este país la práctica de la auto-medicación es coherente con la comprensión popular acerca de cómo la enfermedad debería ser gestionada (Finerman,1983). 
Según Van der Geest y Whyte, los medicamentos, definidos como "sustancias utilizadas en el tratamiento de la enfermedad", son "encantos" que actúan como vehículos importantes para impartir y comunicar mensajes sociales (1989:345).

Argumentando que en todo el mundo la popularidad de los medicamentos no se justifica únicamente por su eficacia, estos autores utilizan el concepto de fetichismo, el cual supone que los medicamentos son objetos que facilitan "procesos simbólicos" (Van der Geest et al., 1989: 345).

Los medicamentos están destinados a curar, a fin de que la transferencia de un medicamento de un lado a otro también implique la transferencia simbólica de poderes de curación también. Los productos farmacéuticos llevan consigo potentes asociaciones de una poderosa tradición de curación, que incluye médicos, laboratorios y ciencia; en otras palabras, "el poder y el potencial de la tecnología avanzada" (Van der Geest et al., 1989: 361; Whyte et al., 1988).

Los medicamentos basados en la medicina tradicional indígena son generalmente menos costosos que los productos farmacéuticos. Muchas personas tienen la creencia de que un paciente tiene poco que perder si inicia un tratamiento con medicinas naturales, sobre todo si el problema médico es menor. Sin embargo, como dijo Miles (1998): "la popularidad de la medicina natural va más allá de las cuestiones de costo y de la accesibilidad”. (Miles, 1998: 211)

\subsubsection{Biomedicina y conocimientos locales}

Actuales investigaciones de antropología médica andina reconocen a la biomedicina como una representación etno-médica de sistemas de conocimiento occidental; con una posición dominante y, a menudo, como una fuerza hegemónica. 
Además, la elección de una o más formas de curación en sistemas de salud pluralista no refleja grados de racionalidad, sino grados de negociación entre multitud de fuerzas sociales, incluyendo (o no) la eficacia percibida del tratamiento.

Los sistemas médicos en los Andes son pluralistas e incorporan una variedad de especialistas indígenas (incluyendo curanderos, fregadores, herbolarios y parteras), quienes practican en una población que también recurre a la práctica biomédica, que va desde la auto-medicación (con el uso de productos farmacéuticos), hasta la atención hospitalaria.

En efecto, el pluralismo médico es cada vez mayor en la Cordillera de los Andes. Nuevas prácticas se están introduciendo continuamente; a veces éstas son impulsadas por personas que buscan nuevas técnicas de curación y, a veces, más bien por consideraciones comerciales. Sin embargo, la cuestión de compatibilidad entre ideologías médicas y los sistemas u opciones de tratamiento, que alguna vez fue motivo de preocupación para los estudiosos, ya no parece ser una cuestión relevante para los antropólogos. (Koss Chioino et al., 2003: 9) Esta última idea se vincula con la propuesta del "Sistema Médico Complejo", propuesto por Madel T. Luz.

Acerca de la relación entre los practicantes biomédicos y locales, Pillsbury (1982) describió algunos de los primeros intentos de cooperación entre ellos, pero llegó a la conclusión de que resulta raro constatar cooperación genuina en algún grado significativo. El debate acerca de si la cooperación es deseable y factible, o no, todavía continúa. Algunos investigadores piensan que los conceptos teóricos son tan diferentes que la cooperación es prácticamente imposible.

Otros investigadores han tenido una opinión más pragmática y han apelado a la cooperación, debido a que ello supone mutuos beneficios. Otro punto de vista es que una relación más estrecha entre la medicina moderna y tradicional podría poner en peligro la 
existencia de esta última, ya que podría ser devorada por la medicina moderna. Una opinión más general, puesta de relieve por muchos antropólogos, es que los representantes de la medicina local y la biomedicina deberían promover más comprensión y respeto mutuo. (Hardon et als., 2001: 21).

Steffan Ayora promueve esta idea en su etnografía intitulada Globalización, conocimiento y poder: médicos locales y sus luchas por el reconocimiento en Chiapas (Ayora, 2002). En este libro, Ayora analiza la situación de algunos médicos locales que sienten la necesidad de buscar el reconocimiento de sus colegas de la medicina local, así como de representantes de la medicina cosmopolita. ${ }^{90}$

Por tanto, en su libro presenta una interpretación y análisis crítico de las estrategias utilizadas por médicos locales que trabajan en la región Alta de Chiapas (sobre todo en San Cristóbal de las Casas), México, para obtener el reconocimiento de la medicina cosmopolita.

Según Ayora, el estudio de los conocimientos y las prácticas médicas en el contexto de la globalización cultural exige una atención translocal y multisituada. Este tipo de enfoque permite a los investigadores estudiar los procesos de producción, distribución y consumo de conocimientos y prácticas médicas, como translocales; además de sugerir cómo están interviniendo los procesos de homogeneización y heterogeneización cultural que caracterizan a la globalización.

Ayora considera que el reconocimiento de estas intersecciones permitiría desenmascarar los diversos conocimientos médicos, el local y el cosmopolita, como productos híbridos

\footnotetext{
${ }^{90}$ Steffan Ayora (2002) considera "cosmopolita" a la forma dominante de conocimiento, o al conocimiento como ciencia establecida. En su estudio etnográfico Ayora se refirió al contraste entre las medicinas "local" y "cosmopolita".
} 
culturales (Ayora, 2002: 22). Desde la perspectiva de esta etnografía, partes de la diferencia y la hibridación son conceptos fundamentales.

En su opinión, el concepto de hibridación tiene una gran ambivalencia (Ayora, 1999a y 2002). En The Location of Culture, Homi Bhabha declaró que la ambivalencia del término hibridación es como un "tercer espacio" en el cual los discursos críticos pueden surgir. Según Bhabha, la desestabilización de oposiciones binarias entre "modernos" y "tradicionales", o "global" y "local", surgen del reconocimiento de la hibridación. (Bhabha,1994: 37)

Este argumento sugiere que lo híbrido no es la intersección de dos formas que fueron puras al comienzo; en contraste, reconociendo que híbrido significa reconocer que culturas diferentes confirman su pureza y autenticidad como estrategias de legitimación" (Ayora, 2002:57). Este autor propone entender el concepto de "híbrido cultural" como resultado de la combinación de conocimientos y prácticas locales/ regionales / cosmopolita. En su opinión, estos dos tipos de complejos conocimientos y prácticas ya son híbridos — desde su punto de partida - y cada uno trata de legitimar a través de una retórica basada en la autenticidad, la originalidad y pureza.

Es necesario admitir, dice Ayora, que las medicinas local y cosmopolita están atravesadas por una serie de imaginarios, que atribuyen a cada médico una compleja cadena de significados que contribuyen a fijar una diferente esencia.

Al considerar este análisis, el híbrido se concibe como un producto de las relaciones de poder que no desaparecen en la mezcla, sino que se mantienen y reproducen. En este contexto, la relación entre los conocimientos y prácticas de la biomedicina y la medicina local (como es el caso de la medicina tradicional indígena Kichwa) finalmente puede 
reproducir el poder de la biomedicina, si el marco de significado "moderno" se vuelve más importante que el local.

Esta tendencia ha sido confirmada en el actual estudio de caso, durante el trabajo de campo desarrollado en Jambi Huasi. En el contexto de este centro de salud, de Otavalo, el concepto de "híbridos culturales" está situado entre dos polos: la biomedicina y la medicina tradicional indígena.

El hecho de negar a estos dos polos crea la posibilidad de reclamar el conocimiento de las personas que se someten a la dominación de la sociedad cosmopolita y la cultura. Ayora también dice que el híbrido de diferentes sistemas médicos está expresado en la articulación y las mezclas de los imaginarios que definen cada forma de conocimiento y práctica médica. Por lo tanto, esto es exactamente lo que se puede observar en Jambi Huasi.

En la práctica, la relación entre la biomedicina y la medicina tradicional indígena en este centro de salud está mostrando hibridación, a través de la articulación y la mezcla de imaginarios que definen formas de conocimiento y prácticas de estos dos tipos de medicina.

El estudio de caso mexicano seleccionado por Steffan Ayora se sitúa en el contexto de la globalización cultural, en términos establecidos en la disciplina proveniente del trabajo desarrollado por Roland Robertson (1992, 1995), Arjun Appadurai (1996) y Jonathan Friedman (1994). En vista de ello, Ayora prefiere la distinción entre medicina local y cosmopolita. $^{91}$

Algunos analistas han criticado a Steffan Ayora por no haber empleado el sistema que desarrolló el antropólogo Eduardo Menéndez, el denominado Modelo Médico

\footnotetext{
${ }^{91}$ Esta distinción no es una dicotomía, sino que se refiere a la gama de formas de combinación posibles, que se derivan de la particularización de lo múltiple, que es universal, y de la universalización de lo particular (Ayora, 2002: 17).
} 
Hegemónico. $^{92}$ Pero en ambos casos, tanto en el análisis de Ayora como en el desarrollado por Menéndez, se reconoce la existencia de diferencias de poder entre las medicinas local y cosmopolita.

En su etnografía Ayora propuso una reflexión crítica que valide el concepto de translocalidad, lo que sugiere desplazar temporal y espacialmente los atributos que nos ayudan a superar los límites conceptuales impuestos por la dicotomía local-global. Esto también previene representaciones de la población local como estática e inmutable, como formas ancladas en un territorio definido.

Ayora sostiene que la noción de localidad, aunque indispensable en antropología, a menudo se inscribe e incluso enmarca la cultura en el tiempo y el espacio; lo cual contribuye a la institucionalización de la dicotomía global-local. En contraste, y como complemento, Ayora concibe a la translocalidad como un concepto que requiere el reconocimiento de formas de intercambio cultural, donde las relaciones entre grupos locales fomenta la producción de híbridos culturales y la trascendencia de dicotomías que destacan el aspecto local.

En su opinión, hay estrategias a través de las cuales las personas que practican la medicina local desean lograr el reconocimiento y el respeto como portadores de conocimientos útiles para los miembros de sus propios grupos sociales (Ayora, 2002: 29).

\footnotetext{
${ }^{92}$ Eduardo Menéndez define el modelo médico hegemónico para caracterizar la medicina vigente en la década de los años 60. Este modelo incluye el conjunto de prácticas, ideas y teorías generadas por el desarrollo de lo que se conoce como la medicina científica, que se identifica como la única manera de hacer frente a la enfermedad, legitimada tanto por criterios científicos, así como por el Estado. Él toma en cuenta la biomedicina dentro de este modelo (Menéndez, 1990).
} 
Como conclusión, Ayora sugirió que en las sociedades multiculturales (como en el caso del Ecuador) se trascienda el reconocimiento jurídico y formal para promover formas de reconocimiento que, en lugar de tolerar, promuevan el respeto cultural a conocimientos y prácticas locales.

En su investigación, Ayora explicó que la búsqueda de reconocimiento de los profesionales de la medicina local en Chiapas se sustenta en un marco ético construido a partir de la retórica del derecho a la igualdad y al respeto.

La experiencia del centro de salud Jambi Huasi ha sido un poco diferente a la descrita por Ayora. Porque, según la mayoría de entrevistados, el trabajo de los jambigkunas (personas que ofrecen servicios de salud a partir de la medicina tradicional indígena), ha sido apoyada por autoridades de ese centro en Otavalo; a diferencia de lo ocurrido en el caso de estudio que analizó Steffan Ayora en Chiapas, México.

Sin embargo, durante el trabajo de campo desarrollado en el centro de salud Jambi Huasi fue posible constatar una clara diferencia de opinión con respecto a la forma en que la medicina tradicional indígena y la biomedicina se relacionan. Algunas personas entrevistadas afirman que hay colaboración entre representantes de ambas medicinas, mientras que otros ven un proceso de subordinación o incorporación de la medicina tradicional indígena en el sistema hegemónico biomédico. Por esa razón, se propuso reformular la principal pregunta de investigación. ${ }^{93}$

Al iniciar el trabajo de campo, una de las principales preguntas de investigación fue analizar cómo la biomedicina y los conocimientos locales están presentes en la atención primaria de salud que proporciona el centro de salud Jambi Huasi. Sin embargo, a partir del

\footnotetext{
${ }^{93}$ Acerca de estos problemas, se ofrece un análisis más detallado en la mitad de este mismo capítulo.
} 
análisis de datos (provenientes del trabajo de campo y de la revisión literaria), se propuso una reformulación en la pregunta principal, de la siguiente manera: ¿De qué manera el concepto de "salud intercultural" permite comprender la forma en que diferentes conocimientos y prácticas de la biomedicina y de la medicina tradicional indígena se relacionan en el centro de salud Jambi Huasi? A partir del análisis que supone dar respuesta a esta pregunta, surge otra interrogante: ¿La relación entre biomedicina y medicina tradicional indígena ha generado acaso un híbrido, en la práctica de la atención de salud que proporciona el centro de salud Jambi Huasi?

\subsubsection{Construcción intercultural de la salud}

Con el fin de responder a la pregunta sobre cómo el concepto de "salud intercultural" permite comprender forma en que diferentes conocimientos y prácticas de la biomedicina y la medicina tradicional indígena se relacionan en el centro Jambi Huasi, se contrastó puntos de vista sobre ese concepto, a partir de la revisión literaria y de entrevistas realizadas durante el trabajo de campo.

Basado en el trabajo de campo de esta investigación, es necesario analizar la pertinencia del término "interculturalidad en salud" o "salud intercultural", ya que éste fue uno de los términos que más utilizaron los entrevistados. Por lo tanto, el análisis de este término permitiría tener un mejor entendimiento sobre el contexto cultural de Jambi Huasi.

Según Mirna Cunningham (2002), "la interculturalidad se suele confundir con el multiculturalismo, lo que implica el reconocimiento formal de la diversidad, pero dentro de un contexto de relaciones de poder vertical y de discriminación".

\footnotetext{
${ }^{94}$ Según ella, la interculturalidad implica ir más allá del reconocimiento de la existencia de diferentes culturas. Por tanto la interculturalidad, como concepto, hace referencia a la acción y la comunicación entre personas de
} 
El antropólogo mexicano Eduardo Menéndez explicó que la interculturalidad no se limita a relaciones entre miembros de agrupaciones amerindias y el personal biomédico; pues, tal relación, rebasa los límites de la identidad étnica. En su criterio, esa interacción asimétrica se produce en diversas situaciones, tales como la pobreza, la desigualdad y el estigma social.

Por lo tanto, para Menéndez el concepto de interculturalidad no debe ser analizado sólo en términos morales de respeto, tolerancia y cooperación. En su opinión, la “interculturalidad en los procesos de salud/ enfermedad /atención médica opera en un contexto desigual, en los siguientes aspectos: cultural, económico, social e incluso biológico (donde la esperanza de vida es mucho menor en las clases subalternas)".

A partir de entrevistas mantenidas con investigadores en ciencias sociales y de salud, (como Raúl Mideros y Jaime Breilh, profesores e investigadores de la Universidad Andina Simón Bolívar, en Quito), se optó por pasar del análisis teórico del concepto de interculturalidad al análisis referente a su repercusión práctica.

¿Hasta qué punto es viable el enfoque de la interculturalidad en el campo de la salud?

"A veces la interculturalidad en salud es sólo un membrete de la subordinación a determinadas estrategias de la biomedicina”, opinó Raúl Mideros.

"No creo que la interculturalidad en salud sea posible, si no hay un verdadero reconocimiento de la diversidad de conocimientos y prácticas en materia de salud [...]. Porque, para trabajar en salud, es necesario tanto el reconocimiento de la biomedicina como

diferentes culturas. No implica sólo a una persona, o a un grupo en particular, sino a toda la sociedad; con el fin de promocionar el conocimiento y la comprensión entre todos los sectores que componen la sociedad. Esta interacción implica la participación de todas las culturas, el respeto y la solidaridad. (Cunningham, 2002: 2) 
de la medicina tradicional indígena; porque, de lo contrario, sería como promover la evangelización de la biomedicina", agregó.

Por lo tanto, para trabajar en temas de salud Mideros sugiere descentralizar los esfuerzos, "de lo contrario corremos el riesgo de promover sólo la evangelización de la biomedicina”. Para explicar esa preocupación, recuerda el caso de algunas parteras que desaparecieron en Perú, "porque sus competencias fueron eliminadas o absorbidas por el sistema formal biomédico".

Jaime Breilh (quien es epidemiólogo y director del Área de la Salud en la Universidad Andina Simón Bolívar, Ecuador) considera que el debate sobre interculturalidad en salud se ha agotado, "porque muchas personas hablan de conocimientos ancestrales de salud limitándose únicamente al tema de terapias ancestrales; pero la interculturalidad en salud es mucho más que eso", afirmó Mideros.

\subsubsection{Conocimiento Indígena (CI)}

Resulta complejo definir el concepto de conocimiento indígena, debido a una multitud de factores históricos, socio-culturales, políticos y epistemológicos (Battiste, 2002; Agrawal, 2002). No obstante, el Banco Mundial define el conocimiento indígena (a menudo abreviado en "Cl" o en "IK", por sus siglas en inglés) en los siguientes términos: “exclusivo para una determinada cultura y sociedad, [...] la base local para la toma de decisiones en la agricultura, la salud, gestión de los recursos naturales y otras actividades. El IK está incrustado en las prácticas comunitarias, las instituciones, las relaciones y rituales" (Banco Mundial, 1998:1). 
No obstante lo dispuesto en la definición del Banco Mundial, muchos críticos argumentan que los esfuerzos por revitalizar y legitimar el conocimiento indígena podría servir para democratizar y empoderar la política educativa en las prácticas de varios países.

Investigadores en ciencias sociales (Agrawal, 1996; Fernando, 2003; Brown et als., 1998), que han analizado el concepto de conocimiento indígena, creen que la distinción entre conocimiento indígena y conocimiento científico/occidental puede presentar problemas para quienes creen en la importancia del "conocimiento indígena para el desarrollo" (Agrawal, 1996: 1).

Arun Agrawal considera potencialmente ridículo el intento de crear distinciones en términos de las comunidades indígenas y occidentales. En su criterio, es mucho más coherente hablar de múltiples dominios y tipos de conocimientos, con diferentes lógicas y epistemologías. Es algo contradictorio —aunque resulta inevitable - que el mismo conocimiento pueda ser clasificado de una manera u otra, en función de los intereses a los que sirve, de los fines para los que se aprovechan, o de la manera en que se genera. "Es sólo cuando nos alejamos de la estéril dicotomía entre conocimiento indígena y occidental, o entre conocimiento tradicional y científico, que es posible derivar un diálogo productivo centrado en salvaguardar los intereses de quienes están en desventaja” (Agrawal, 1996: 5).

Fernando (2003) y Brown et als. (1998) coinciden con el pensamiento de Agrawal. Según ellos, el denominado Conocimiento Indígena (CI) se ha convertido en un medio a través del cual la diversidad de los sistemas de conocimiento y, las culturas en las que éstos existen, están disciplinados y gestionados de acuerdo a la necesidad de capital para expandirse.

"El rol de colaboración desempeñado por organismos no gubernamentales (ONG) en este proceso está oscurecido por el uso de un lenguaje seductor sobre el empoderamiento de 
grupos sociales marginados. Hay la intervención de ONG's contrarias a los intereses del pueblo que dicen servir. El desafío es trabajar en pro de un entorno institucional alternativo que permita liberar que el uso de conocimientos indígenas esté determinado por la ideología y las instituciones del capitalismo” (Fernando, 2003: 1).

Brown y otros autores (1998) analizan este tema desde una evaluación escéptica de esquemas legales que controlan la apropiación cultural. Estos autores señalan que, aunque hay razones para ser escépticos sobre el derecho a la propiedad intelectual indígena, él apoya firmemente los esfuerzos para crear mecanismos básicos para la compensación de los pueblos indígenas por el uso comercial de sus conocimientos científicos, musicales, y sus creaciones artísticas.

En su opinión, es necesario tener directrices claras para el registro de datos etnográficos culturalmente sensibles y de material biológico humano potencialmente comercial, incluyendo las células madres.

"Me gustaría, también, que los antropólogos sigan el registro de objeciones a las patentes de medicamentos y plantas agrícolas descubiertas o domesticadas por las poblaciones indígenas y utilizadas por ellos durante siglos" (Brown et als., 1998: 204).

Debido a que el patrocinio internacional de Jambi Huasi ha provenido especialmente de sistemas de cooperación internacional de otros gobiernos, que de ONG’S, y debido a que su ayuda se ha enfocado más en programas específicos (como en la salud reproductiva) que en la atención primaria de salud, esta investigación no ha centrado su análisis en el tema del Conocimiento Indígena (CI). ${ }^{95}$ Sin embargo, ese aspecto sí fue considerado en las entrevistas referentes al centro Jambi Huasi. ${ }^{96}$

\footnotetext{
${ }^{95}$ La directora del centro Jambi Huasi, Myriam Conejo, informó que el financiamiento destinado por ONG's en este centro terminó hace aproximadamente dos años, y que ese respaldo estuvo focalizado en programas
} 
"El término "Conocimiento Indígena" es una de esas expresiones que se encuentran en la misma posición de dominación. Como el mundo cambia, como las culturas y los pueblos indígenas surgen en todo el mundo, entonces hay organizaciones que generan una réplica y una nueva terminología que les permita volver a reinstalarse en el poder", opinó Jaime Breilh en una entrevista.

Él criticó la labor de organizaciones que sólo utilizan la imagen de los pueblos indígenas para trabajar con una visión alineada a otros intereses. "Creo que no es sólo un problema ético, no es que haya gente que lo hace porque es éticamente incorrecta o mala, sino porque fueron formados en las universidades con paradigmas científicos que se prestan a ello". Breilh también critica el hecho de que el Banco Mundial haya contratado a personas para crear ciertas categorías, como el término 'conocimiento indígena', con el fin de adornar el camino.

\subsubsection{El rol de la Comunicación}

"La ignorancia con respecto a la visión indígena del mundo; el hecho de comunicarse en español con personas de habla Kichwa y la discriminación a los indígenas fueron obstáculos que evitaban un acercamiento respetuoso y un diálogo intercultural". (Conejo, 2006: 32)

La labor del centro de salud Jambi Huasi supone la comunicación de conceptos y de prácticas que se sustentan en la biomedicina y en la medicina tradicional indígena. En esta

específicos (como el de salud reproductiva). Ella también dijo que los patrocinadores de Jambi Huasi han provenido especialmente de los sistemas de cooperación internacional de otros gobiernos, que de ONG's.

96 Debido a la importancia e interés que genera el debate sobre el tema, la autora de esta tesis ofrece considerar este análisis en una futura investigación. 
investigación también se ha tomado en cuenta literatura referente a comunicación de la ciencia, en general, y de medicina, en particular.

La mayoría de proyectos diseñados para la comunicación de la ciencia, la tecnología o la medicina siguen modelos de un tipo asimétrico, como son los modelos de déficit o de difusión (Lewenstein, 2003: 3).

Estos modelos se limitan a estudiar la comunicación como un proceso unidireccional, pasando de los científicos al público, o de los médicos a los pacientes (en el caso de la medicina). Suponen que la información transmitida es neutral y no consideran las características culturales de los actores. Esta podría ser una de las principales razones que genera problemas en la comunicación entre médicos y pacientes (Wynne, 1996: 46).

Un aspecto que ha sido especialmente invisible en el reconocimiento de esta práctica ha sido la experiencia de quienes están mediando la comunicación de los conocimientos médicos, así como las implicaciones de esta mediación en el proceso de construcción de conocimiento. En este sentido, "los aspectos sobre la forma cómo diferente tipos de atención de la salud han generado subjetividades han sido poco explorado en relación con la dimensión comunicativa / educativa de la comunicación” (Pérez Bustos, 2008: 2).

Hablando de la relación médico-paciente, Rosa Gómez Esteban dijo que en esta relación, en el propio acto médico, las áreas del personal y la subjetiva son combinadas, tanto una parte como la otra. (Fernández Juárez, 2004: 70).

Si aceptamos la propuesta de que el diálogo debe ser cultural, entonces el tradicional modelo unidireccional de la comunicación de la medicina tendrá que ser reformulado a partir de una perspectiva socio-cultural, para convertirse en un modelo más completo. Este nuevo modelo de comunicación debe tomar en cuenta las conexiones entre las formas de 
organización de la sociedad (la política-cultural), las mediaciones socio-económico y las características culturales de los actores.

"La comunicación tiene un papel muy importante en el centro Jambi Huasi, porque promueve una buena relación entre las personas que aquí trabajamos y desde este centro hacia la sociedad", opinó en una entrevista Azalia Vásquez, psicóloga del centro Jambi Huasi.

Como estrategia de comunicación, Jambi Huasi transmite todos los lunes un programa de salud a través de Radio Ilumán, tanto en idioma español como en Kichwa. Jambi Huasi también ha colaborado en la elaboración de vídeos, folletos, informes para televisión y otros medios de comunicación. Además, su personal ha participado en diversas conferencias o seminarios nacionales e internacionales, para compartir con otros la experiencia de este centro de salud.

Aunque algunos médicos o profesionales biomédicos quieren lograr una proyección mundial, deben reconocer las culturas locales antes de comunicarse con el público en general. El francés Pierre Fayard resume este punto con la siguiente de opinión: "Si la ciencia es global, su medición, para ser eficaz, debe ser desarrollada a nivel local. Pensar globalmente, actuar localmente" (Fayard, 2002: 238).

Comunicar implica dialogar; es el hecho de referirse a la causa que la produce con el efecto que genera. En esta investigación el proceso de comunicación de la biomedicina y del conocimiento local ha sido entendido como una práctica socio-cultural que opera entre los profesionales de la biomedicina y los jambigkunas (personas que conocen y practican la medicina tradicional indígena), y entre ellos con pacientes de Jambi Huasi, en la atención primaria de la salud. 
En este sentido, los trabajadores de la salud que hablan el idioma y entienden las costumbres locales pueden ser cruciales para la prestación de una atención de calidad. Por esta razón, hace 8 años, Jambi Huasi empleó a tiempo completo el trabajo de la especialista en comunicación y educación, Mercedes Muenala, quien tiene el título de enfermera en medicina interna de la Universidad Central del Ecuador y, en la actualidad, se está coordinando el Área de Salud Intercultural, en la Dirección Provincial de Salud de Imbabura.

Cuando Muenala trabajaba en el centro Jambi Huasi, en la Sub Área de Educación y Comunicación, dedicó mucho tiempo para hablar con mujeres y hombres de las comunidades Kichwa, en un intento por aumentar la conciencia sobre cuestiones de salud reproductiva. Con su equipo de trabajo, ella ofreció talleres de formación a parteras, voluntarios de salud y adolescentes.

Según Jaime Breilh, la comunicación desempeña un papel fundamental en la promoción o tergiversación del proceso de salud intercultural. ${ }^{97}$

Recientemente se ha promovido algunas reflexiones sobre la necesidad de pensar en cómo el reconocimiento de nuevas u otras formas de producción de conocimiento en atención de la salud merece que se establezca y reconozca otras formas de comunicación (Barrio, 2008). En las nuevas formas, los pacientes se reconocen como actores que participan en estos acontecimientos y no sólo como usuarios finales o como meros consumidores de esos acontecimientos.

\footnotetext{
${ }^{97}$ Con el fin de confirmar su punto de vista sobre el tema de salud, Jaime Breilh entregó a la autora de esta tesis un artículo suyo que titula: "Latin American Critical ('Social') Epidemiology: New Settings for an Old Dream", y otro artículo escrito por el investigador Charles L. Briggs (de la Universidad de California, San Diego), con quien Breilh y la Universidad Andina Simón Bolívar tienen proyectos de cooperación académica y de investigación regional.
} 
A partir del análisis propuesto por Steffan Ayora, en torno al concepto de hibridación, se considera necesario cambiar la concepción sobre relaciones interculturales. Hasta ahora, la retórica sobre el multiculturalismo sigue dominado por la idea de tolerancia, lo que implica desigualdad, porque supone que una parte tiene la facultad de "tolerar" al otro.

En esta investigación se comparte la opinión de autores como Ayora (2002), Taylor (2004) y Honneth $\left(1995^{\text {a }}, 1995\right.$ b), quienes prefieren ir más allá de la tolerancia, cuando analizan la relación entre biomedicina y conocimiento local. En lugar de tolerancia, la propuesta es promover la aceptación y el respeto de cada forma cultural. Sólo a través de la aceptación, validez y el mutuo reconocimiento de los conocimientos médicos que produce cada forma cultural, será posible fomentar la "construcción intercultural de conocimientos".

\subsection{Presentación y análisis de los datos}

\subsubsection{Origen y desarrollo del centro de salud Jambi Huasi}

¿Cuáles fueron los aspectos políticos, sociales y culturales que influyeron históricamente en la aparición, permanencia y consolidación de iniciativas y proyectos sobre medicina alternativa en Imbabura, como en el caso de Jambi Huasi? ¿Cómo surgió la idea de creación del centro Jambi Huasi en Otavalo? En esta sección se intentará dar respuesta a estas interrogantes.

La Federación Indígena y Campesina de Imbabura (FICI) fue el motor que impulsó la creación de Jambi Huasi, como una respuesta de las organizaciones indígenas a la falta de atención al derecho de la salud de pueblos indígenas. (Conejo, 2006: 26).

¿Cómo se creó la FICI y cuáles fueron sus propuestas en torno al tema de la salud? Durante el pasado y el presente siglo, la población indígena Kichwa situada en la provincia 
de Imbabura ha tenido un importante rol político y social. Uno de los primeros intentos de organización fue la creación de la Federación Indígena Ecuatoriana, en $1926 .{ }^{98}$

Posteriormente, el Estado ecuatoriano formuló políticas destinadas a eliminar cualquier tipo de relación pre-capitalista, para fijar los salarios, para incorporar productivos técnicos más eficientes, para ampliar los campos de cultivo, para eliminar la finca o hacienda y para mejorar las condiciones de vida sociales y económicas del país.

Con el fin de promover el desarrollo de las comunidades indígenas, se aplicó un conjunto de programas de asistencia destinados a sectores rurales más vulnerables. Al principio, intervinieron los organismos de cooperación internacional; luego el Estado ecuatoriano asumió esa responsabilidad en las zonas de población indígena, especialmente en la región andina.

Fue gracias al apoyo de la organización "Misión Andina" que inició la aplicación de programas de capacitación médica destinados a miembros de la comunidad. (CONAIE, 1989) Sin embargo, la discriminación a indígenas — especialmente de la parte mestiza— ha sido una actitud muy generalizada en el Ecuador, lo cual también se expresa en centros de salud y hospitales. Esa es la razón por la cual muchos indígenas no se han sentido bien

\footnotetext{
98 Al inicio, la mayor preocupación de esta Federación fue resolver problemas relacionados con la legalización de tierras y la liquidación de salarios para los trabajadores que trabajaban en haciendas. Luego se incluyó el idioma Kichwa en la enseñanza de escuelas y colegios, hecho que dio inicio a un proceso político de reafirmación de la identidad indígena a nivel nacional. Con el fin de establecer relaciones con otras provincias, para conocer sus iniciativas de organización y su proyección, en 1972 se creó la ECUARUNARI en el Ecuador y, en 1973, se fundó el Comité Coordinador Provincial de Organizaciones Indígenas.
} 
atendidos, con respeto, cuando han requerido asistencia médica en hospitales o centros de salud del sistema formal. ${ }^{99}$

"En los hospitales los indígenas no han recibido una atención médica adecuada. En algunos casos, los pacientes no fueron registrados o atendidos. Su tratamiento nunca fue igual al que recibieron personas blancas o mestizas”. (Tamayo, 1996)

Otra referencia histórica la escribió Raúl Mideros, al decir que las relaciones entre pacientes y el personal médico se han caracterizado por lagunas culturales, pero principalmente por actitudes de intolerancia y etnocentrismo. (Mideros et als., 2000: 5)

"En el pasado, las personas indígenas han sido objeto de malos tratos. Se creía que los indígenas no cuentan y que sólo los mestizos tenían valor [...]. Se nos trató con desprecio. Lo mismo sucedió en los servicios de salud. Cuando íbamos al hospital como indígenas, no se nos ofrecía un trato respetuoso. Debido a todo esto empezamos a organizarnos nosotros mismos", opinó en una entrevista Sánchez Vidal, un indígena que trabajó como herbolario y fregador de huesos en Jambi Huasi.

Esa discriminación "motivó la acentuada separación entre los dos sistemas de salud, al parecer irreconciliables: la biomedicina no aceptó las prácticas de salud indígenas y estas prácticas se llevaron a cabo de manera clandestina, dentro de las comunidades. Algunas poblaciones indígenas no tenían acceso a otro servicio de salud”. (Mideros et. als., 2000: 5)

\footnotetext{
${ }^{99}$ Esta opinión la expusieron varias personas que fueron entrevistadas durante el trabajo de campo en Otavalo, Ecuador, tales como: Myriam Conejo, directora del centro Jambi Huasi, Javier Terán, director del Hospital San Luis de Otavalo; Olga Farinango, directora del Área de Salud del Municipio de Otavalo y el ex médico de Jambi Huasi; Mercedes Muenala, coordinadora del Área de Salud Intercultural en la Dirección Provincial de Salud de Imbabura; Sánchez Vidal, herbolario y ex trabajador de Jambi Huasi; Javier Perugachi, yachak de Jambi Huasi; Leandro Prieto, médico e investigador en la Universidad Andina Simón Bolívar, entre otros.
} 
Ciertas religiones trataron de intervenir en este tema, para "evangelizar a través de la salud". La religión católica afirmó que en la práctica de la medicina tradicional indígena había algunos signos de idolatría. Otras religiones misioneras protestantes y algunas sectas también pretendieron eliminar ese tipo de supersticiones indígenas.

En Otavalo, algunas comunidades indígenas recibieron de la religión evangélica el apoyo necesario para impulsar la alfabetización en Kichwa y, desde entonces, esos indígenas se volvieron seguidores del protestantismo, porque sintieron que esa religión les ayudó a reafirmar el valor de su idioma y cultura (Rohr, 1991: 99-100).

\subsection{1. a) La relación de la FICI con Jambi Huasi}

En 1960, el gobierno ecuatoriano dio importancia a la ejecución de políticas sociales, especialmente en el ámbito de la salud. En 1972, se estableció un año de servicio rural obligatorio para todos los médicos recién graduados, lo cual les permitió ofrecer sus servicios de salud a poblaciones rurales.

"Como consecuencia de ello, la estructura operativa del Ministerio de Salud Pública puso de manifiesto su crecimiento, principalmente en sus unidades de menor complejidad y, en consecuencia, dio aplicación al Plan Nacional de Salud Rural, con el enfoque de medicina comunitaria y, posteriormente, de Atención Primaria de la Salud”. (Suárez, 1987)

Sin embargo de ello, "la expansión de servicios sanitarios no pudo satisfacer las necesidades de atención médica $\mathrm{y}$, además, ese tipo de programas no fomentaron la participación comunitaria. Los viejos estereotipos de salud sobrevivieron a pesar de las buenas intenciones, la planificación vertical de acciones de salud siguió sin tener en cuenta las opiniones de la población Kichwa. 
La persecución a especialistas de medicina tradicional Kichwa, por parte de representantes del sistema de salud formal y biomédico, se intensificó; su lucha contra el sistema de salud cultural se convirtió en una tarea de civilización necesaria para "salir del atraso", según el criterio de autoridades biomédicas. Sin embargo, la medicalización de la salud en zonas rurales enfrentó gran resistencia en algunas comunidades por la fuerza de sus creencias locales. (Mideros et als., 2000: 10)

En este contexto, las primeras acciones promovidas por la Federación Indígena y Campesina de Imbabura (FICI) ${ }^{100}$ se dirigió a los procedimientos y demandas ante las instancias de salud estatales, con el fin de mejorar o ampliar sus servicios de salud para poner fin a la persecución de los especialistas de la medicina tradicional indígena.

La FICI había ganado una importante experiencia como resultado de sus acciones y relaciones con los programas estatales; pero, sobre todo, había adquirido la capacidad de contribuir al mejoramiento de las situaciones de vida de las comunidades indígenas y campesinas, enfrentándose a la ineficacia de ciertos programas de salud promovidos por el Ministerio de Salud Pública. Esos aspectos fueron beneficiados por la presencia de un médico indígena Kichwa que, desde 1983, apoyó las acciones de salud desarrolladas por la FICI. (Mideros et als., 2000:14) De esta manera, la FICI se convirtió en el motor que motivó la creación de Jambi Huasi.

Esta Federación propuso combinar los conocimientos y técnicas de la medicina tradicional indígena Kichwa con la biomedicina. Su discurso político, desde el decenio de 1980, destacó el "rescate" de la identidad indígena.

\footnotetext{
${ }^{100}$ Contribuir al mejoramiento de la salud de comunidades indígenas es una de las razones que motivaron la creación de organizaciones indígenas que nacieron antes, después o simultáneamente a la FICI.
} 
En noviembre de 1983, la FICI inició formalmente su accionar en materia de salud, con respaldo del financiamiento internacional ofrecido por el Fondo de Canadá —agencia especializada en la cooperación a poblaciones indígenas. Desde entonces, el área de salud de la FICI se identificó con el nombre Jambi Huasi, que significa Casa de la Salud.

Entre 1983 y 1984, los servicios de Jambi Huasi se sustentaron en dos actores: un especialista en medicina tradicional indígena (quien, en ocasiones, empleaba la medicina alopática) y el tayta yachak (quien usaba únicamente la medicina tradicional indígena Kichwa).

Cuando la FICI recibió el financiamiento de la "Organización Católica Canadiense para el Desarrollo y la Paz", Jambi Huasi amplió su oferta de servicios, pero su gestión y la dirección siguió controlada por la FICI.

En 1987, Jambi Huasi ofreció atención médica en los ámbitos de medicina general y pediatría, odontología y enfermería. También organizó actividades de capacitación para promotores de la salud en varias comunidades.

Posteriormente, Jambi Huasi propuso un sistema multifuncional, con servicios y actividades dirigidas a la atención primaria de salud de las comunidades; pero este sistema no logró estabilidad y permanencia, pues dependía de financiamiento.

"En nuestra realidad hay dos sistemas de salud: una es formal, occidental, estatal; ${ }^{101}$ mientras que el otro es no formal, Kichwa, tradicional. Ambos sistemas están en conflicto, uno por imponerse y el otro por sobrevivir. Sin embargo, en esta realidad de miseria y

\footnotetext{
${ }^{101}$ Esta opinión fue parte de un debate e integró el material presentado en el "Cuarto Congreso Provincial de la INRUJTA-FICI", celebrado del 13 al 16 de febrero de 1986 en la comunidad de Huaycopungo, en la provincia de Imbabura (Citado por: Mideros et als., 2000: 17)
} 
explotación, es posible rescatar los valores, los criterios y la mayoría de las experiencias positivas de cada uno de esos sistemas.

"No sólo médicos graduados estuvieron a cargo de la atención de salud en comunidades, sino también el Tayta yachak y el Tayta kakuk. Este tipo de actividades mixtas supuso una inquietud que aún no tiene respuesta: la institucionalización de la atención proporcionada por agentes de salud Kichwa" (Mideros et als., 2000: 17).

Por lo tanto, durante el primer año de operación de Jambi Huasi, su principal objetivo era atender los problemas de salud de las comunidades indígenas más alejadas. Sin embargo, todos los proyectos, actividades y decisiones seguían centralizadas en el Consejo de Gobierno de la FICI. La concentración de funciones en pocos dirigentes fue causa de la lentitud en la gestión de recursos para ejecutar proyectos de manera directa. Además, hubo falta de coordinación y dirección en la organización. (Mideros et als., 2000: 20)

Esta fue una de las principales causas que generaron problemas o distanciamiento entre los representantes del Área de Salud de la FICI y el resto de esta organización; este hecho provocó el debilitamiento de Jambi Huasi en 1987. A pesar de estos problemas, el personal de Jambi Huasi siguió trabajando hasta 1992; pero ese año optó por no ofrecer sus servicios al público, debido a la falta de recursos y a la crisis política y administrativa que afectaba a la FICI. Desde entonces, la autonomía administrativa ha sido uno de los requisitos de las personas que han estado a cargo de Jambi Huasi.

Inicialmente, la aspiración de autonomía administrativa fue causa de conflictos políticos al interior de la FICI; pero, en 1992, esta Federación autorizó dicha autonomía al equipo de Jambi Huasi. 
¿Cuáles fueron las lecciones aprendidas durante el primer período (1984-1992) de funcionamiento de Jambi Huasi? Según el equipo de Jambi Huasi, las principales lecciones aprendidas en este período fueron las siguientes:

- A pesar de su motivación inicial (1984-1992) para generar una propuesta de salud multicultural, donde la biomedicina y la medicina tradicional indígena puedan complementarse, en la práctica el contexto de discriminación llevó a Jambi Huasi a crear un servicio de personas indígenas para pueblos indígenas.

- Un modelo creado exclusivamente para la población indígena no facilitaba la promoción de un modelo multicultural eficiente que pueda ser luego incorporado en los servicios del Ministerio de Salud Pública. En esa etapa, no se logró aún el reconocimiento social de los jambigkunas (personas que ofrecen servicios de salud a partir de la medicina tradicional indígena Kichwa).

- La mayor parte de usuarios de Jambi Huasi es mujer; pero, en aquella ocasión, este centro de salud no ofrecía una respuesta a sus necesidades en materia de salud reproductiva.

- La gratuidad de sus servicios no garantizaba la sostenibilidad institucional; "en lugar de ser un factor de acercamiento con los usuarios, eso iba en contra del principio de reciprocidad. Este aspecto alentaba el paternalismo y el clientelismo político en la comunidad". (Conejo, 2006: 36).

- Para superar estos problemas, en 1992 la FICI confió las actividades de salud del proyecto Jambi Huasi a un equipo de profesionales, con el fin de que ofrezcan tanto servicios de medicina tradicional Kichwa, como de biomedicina. 
- Posteriormente, el equipo de Jambi Huasi elaboró propuestas de salud alternativa dirigidas a encontrar soluciones a partir del conocimiento y la realidad de los pueblos indígenas, especialmente de las mujeres indígenas. Para llevar a cabo estas propuestas, se solicitó respaldo financiero al Fondo de Población de las Naciones Unidas (UNFPA).

- El apoyo del UNFPA fue aprobado en octubre de 1994. Para cumplir el compromiso asumido con esta organización internacional, la nueva junta directiva de la FICI estableció los siguientes objetivos: adquirir una casa donde opere el centro de salud, con personal capacitado en la atención y el servicio; estudiar la conducta cultural en los procesos de embarazo, parto y planificación familiar, a través de talleres desarrollados por la FICI; fomentar la siembra de hierbas medicinales en las comunidades, e investigar sobre el uso de la medicina tradicional Kichwa y de hierbas”. (FICI, 1994)

- Una vez que el UNFPA pagó los recursos ofrecidos, la FICI confió la ejecución del proyecto Jambi Huasi a la "Fundación Utopía". ${ }^{102}$ Sin embargo, en enero de 1995, la nueva junta de la FICI reivindicó el derecho a administrar completamente el proyecto Jambi Huasi, pues consideraron que "la Fundación Utopía" no había puesto en práctica las directrices acordadas.

Luego del primer período, la FICI designó a la doctora Myriam Conejo como coordinadora del proyecto Jambi Huasi. Esta Federación también invitó a un yachak y a

\footnotetext{
${ }^{102}$ Posteriormente, el equipo de trabajo del centro Jambi Huasi lo integraron, principalmente, profesionales mestizos: dos médicos, un gerente, un educador, una partera, un auxiliar y un conserje.
} 
una enfermera para integrar el equipo técnico de Jambi Huasi. Posteriormente, a este equipo se integró la médica indígena Olga Farinango. ${ }^{103}$

Con respecto a esa época, Myriam Conejo recuerda: "La presencia de médicos formados en medicina occidental (o biomedicina), pero con una fuerte identidad y visión sobre el mundo indígena, fue un factor clave para debatir y definir el servicio, como un servicio multicultural. Paralelamente, se llevó a cabo un proceso de promoción de la salud, visitas comunitarias”. Según Conejo, el objetivo de estas visitas fue compartir experiencias, establecer un diálogo con la gente de las comunidades indígenas, para promover el reconocimiento y ejercicio de sus derechos individuales y sociales. "El objetivo fue promover el ejercicio de la ciudadanía en los espacios diarios”. (Conejo, 2006: 39)

En enero de 1998, Jambi Huasi adquirió su personería jurídica bajo el nombre de "Fundación de Medicina Alternativa, Jambi Huasi". 104

Con el propósito de integrar dos sistemas de salud diferentes, el personal de Jambi Huasi tuvo que enfrentar algunas tensiones y desacuerdos entre sí, así como en su relación con otros servicios de salud, especialmente con la biomedicina.

¿Qué lecciones aprendieron los miembros del centro de salud Jambi Huasi durante el segundo período (1994-2005) de funcionamiento? Según la directora y el personal de mayor antigüedad en ese centro de salud, las principales lecciones que han aprendido de ese periodo fueron:

\footnotetext{
${ }^{103}$ En esta nueva etapa, Jambi Huasi ofreció servicios basados en la biomedicina (a través de dos médicos indígenas graduados), y en la medicina tradicional indígena (a través de dos jambigkunas, una partera y un yachak); además de los servicios profesionales de una odontóloga, de un farmaceuta y de un herbolario.

${ }^{104}$ Esta denominación la conserva hasta la actualidad.
} 
- Que un servicio multicultural debe tener en cuenta poblaciones heterogéneas; con diferentes creencias, cultura y cosmovisión, lo cual hay que aceptar sin subestimar.

- La demanda de las poblaciones indígenas por acceder a servicios de salud no sólo exige ampliar la cobertura de salud, sino también mejorar la calidad de los servicios, ofrecer buen trato y respeto a su cultura. Para la población indígena el concepto de salud no sólo supone ausencia de dolor y enfermedad; sino que, para ellos, la salud significa estar en armonía, en equilibrio interno y familiar, así como con la comunidad y la naturaleza" (Conejo, 2006: 42). La comprensión y el respeto de esta visión es una de las principales características de la medicina tradicional indígena; según lo expresó Elizabeth Núñez, quien fuera directora del Departamento de Comunicación del Ministerio de Salud Pública del Ecuador, durante el periodo de trabajo de campo de esta investigación.

- Un servicio multicultural no sólo está preocupado por la adaptación de los servicios, sino que trata de superar los límites; muchos de los cuales se sustentan en prejuicios racistas, tales como: dificultades idiomáticas y un trato irrespetuoso a creencias indígenas o a personas indígenas, sólo por su origen étnico; y la falta de humanidad, el respeto y privacidad en la atención.

- El derecho a la calidad de la atención, teniendo en cuenta la identidad indígena y su cosmovisión, también se expresa en la forma cómo "los prestadores de servicios" y "los prestatarios de servicios" establecen sus relaciones diariamente [...]. Si la comunidad comprende que los servicios de salud son algo más que un espacio de curación, que también son espacios de encuentro, aprendizaje y motivación; entonces sería posible una nueva comprensión de la salud, teniendo en cuenta los derechos y responsabilidades de todos los actores". 
- A pesar de que el centro de salud Jambi Huasi se identifica como una organización sin fines de lucro, se estableció el cobro de una tasa mínima a los pacientes por su acceso a los servicios, lo cual permitió una gradual recuperación en los costos. El denominado Ranti Ranti (que significa dar y recibir en kichwa) es una práctica cotidiana en las comunidades indígenas. En Jambi Huasi, la relación entre personas que proveen servicios de medicina tradicional indígena y los pacientes todavía se rige al principio indígena Kamari, que significa reciprocidad en kichwa. (Conejo, 2006: $42-43)$

\subsection{1.b) Atención Integral a la Salud para las mujeres de Imbabura}

En 1995, con apoyo del UNFPA, el centro de salud Jambi Huasi aplicó un proyecto denominado "Atención Integral de la Salud para la Mujer Indígena y Campesina de Imbabura". Para lograr este objetivo, el personal de Jambi Huasi trató de complementar servicios provenientes de la biomedicina y de la medicina tradicional indígena, a través de la atención obstétrica.

Esta complementación fue un intento por rescatar la confianza a la labor de las parteras, teniendo en cuenta el papel que esas personas tienen en sus comunidades, además de garantizar un servicio institucional con la capacidad de respuesta técnica y con un sistema de referencia, en casos de complicaciones obstétricas.

Para ello "es necesario desarrollar un sistema de referencia interno entre los 'prestadores' de atención de salud de los dos sistemas", sugiere la directora de Jambi Huasi, Myriam Conejo, quien añade que este proceso debe ser personalizado y que los límites de ambos métodos deben ser claros, para garantizar la calidad de la atención y la credibilidad. (Conejo, 2006: 48) 


\subsection{1.c) La formación de docentes y adolescentes sobre educación sexual}

Durante su primer período de visitas a comunidades, de 1995 a 1999, el personal de Jambi Huasi también ofreció atención médica y servicios de odontología en las escuelas de 10 comunidades.

En el año 2000, un equipo de Jambi Huasi capacitó a 300 adolescentes sobre temas de educación sexual. Esta formación fue en español y en kichwa. Para garantizar la formación de adolescentes, Jambi Huasi también capacitó a los profesores y desarrolló materiales adecuados para la realidad étnica y cultural de adolescentes indígenas Kichwa. Sin embargo, debido a la falta de financiamiento, esas visitas fueron canceladas en el año 2005. Actualmente, Jambi Huasi sólo ofrece sus servicios en su establecimiento, que está ubicado en la ciudad de Otavalo.

\subsubsection{Características de los pacientes de Jambi Huasi}

El personal de Jambi Huasi informó que, durante los primeros años de servicio, los pacientes de la medicina tradicional indígena preferían llegar a este centro de salud en horarios nocturnos o muy tarde, para evitar ser vistos y criticados por otros; ya que muchos tenían la idea de que la medicina tradicional indígena (especialmente la labor del yachak) sirve para herir a otras personas.

El director del Hospital San Luis de Otavalo, Javier Terán, tuvo la siguiente impresión hace más de cinco años, cuando trabajaba como médico rural en Jambi Huasi: "Anteriormente las personas evitaban ser vistas en Jambi Huasi, pues temían ser criticadas; debido al hecho de que la medicina tradicional indígena aún no estaba reconocida o 
valorada. En vista de que Jambi Huasi ha logrado institucionalizar la medicina tradicional indígena, ahora la gente visita regularmente Jambi Huasi”.

Por lo tanto, al momento, la mayoría de pacientes prefieren llegar temprano a Jambi Huasi, sin temores, para conseguir un buen turno.

Horario de servicios del centro de salud Jambi Huasi

\begin{tabular}{|c|c|c|c|}
\hline Biomedicina & Horario & $\begin{array}{c}\text { Medicina } \\
\text { tradicional } \\
\text { indígena }^{\mathbf{1 0 5}}\end{array}$ & Horario \\
\hline Doctor general & $8 \mathrm{H} 30 /$ & Yachak & $8 \mathrm{H} 30 /$ \\
$17 \mathrm{H} 30$ & & $8 \mathrm{H} 30$ \\
\hline Psicóloga & Con cita previa & Jakug & $17 \mathrm{H} 30$ \\
\hline Dentista & $8 \mathrm{H} 30 /$ & Mamahua & $8 \mathrm{H} 30 /$ \\
& $12 \mathrm{H} 00$ & & $16 \mathrm{H} 30$ \\
\hline Farmacia & $8 \mathrm{H} 30 /$ & & \\
& $17 \mathrm{H} 30$ & & \\
\hline Laboratorio & $8 \mathrm{H} 00 /$ & & \\
clínico & $12 \mathrm{H} 00$ & & \\
& $14 \mathrm{~h} 30 /$ & & \\
& $16 \mathrm{H} 00$ & & \\
& & & \\
\end{tabular}

Durante mi trabajo de campo, tuve oportunidad de acceder a los reportes médicos de consultas que habían realizado varios pacientes en Jambi Huasi, entre el 2 y el 27 de junio

\footnotetext{
${ }^{105}$ Los días jueves, el yachak y la jakug trabajan sólo hasta las 13:00; los días sábados, hasta el mediodía. La partera trabaja de lunes a viernes. Ella tiene habilidades como "fregadora" y también realiza diagnósticos y limpieza con "cuy"; también cura el llamado "mal de aire" y el "espanto". La jakug también tiene experiencia como partera. Por tanto, los horarios que ha establecido Jambi Huasi garantizan a los pacientes que todos los servicios que oferta están cubiertos a lo largo de toda la semana.
} 
de 2008. De ese periodo se registró información correspondiente a 616 pacientes. Esos datos fueron reportados, en Jambi Huasi, por profesionales biomédicos y por jambigkunas (cuya atención la sustentan en la medicina tradicional indígena).

A partir de esos datos fue posible elaborar algunos gráficos que se exponen en esta sección y que ilustran, o confirman, el análisis presentado en este capítulo.

\section{Idioma de pacientes que visitaron Jambi Huasi en junio de 2008}

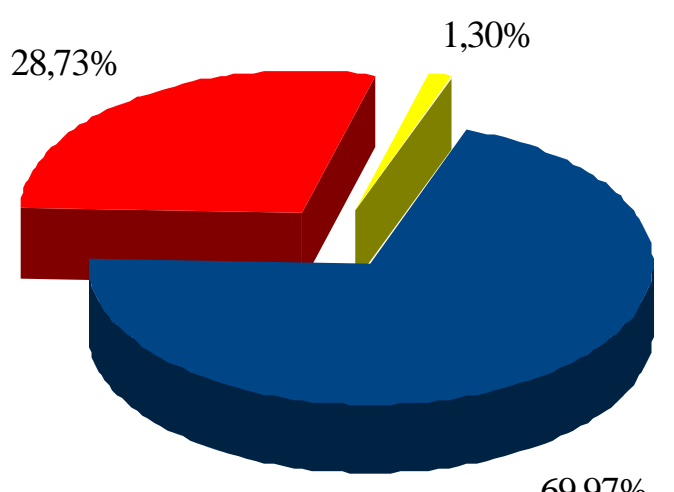

Español $\quad$ Bilingüe $\quad$ Kichwa

La mayoría de personas que viven en el cantón Otavalo son de origen Kichwa, Kichwa Kayambi y "mestizo". Aunque el idioma oficial en Otavalo es el español (o castellano), la mayoría de personas indígenas también hablan Kichwa. Algunas personas bilingües prefieren hablar en kichwa durante su consulta con el yachak, la jakug y la partera, porque es Kichwa el idioma original de estos proveedores de salud. La población indígena que habita en la provincia de Imbabura es numerosa, pues representa alrededor del $40 \%$ de la población total. (Conejo et als., 2004: 5-6). 
El idioma es de fundamental importancia para la salud de los indígenas, tanto en términos de su uso, como medio de transmisión de conocimientos dentro de las culturas y en la atención de la salud. (Montenegro et al., 2006: 1859).

En ese sentido, la médica Olga Farinango ${ }^{106}$ considera que el hecho de ser una mujer indígena bilingüe (que habla castellano y Kichwa) ha sido una ventaja que le ha facilitado establecer buenas relaciones con sus pacientes.

Datos de observación y reportes médicos informan que son más mujeres que hombres los pacientes de Jambi Huasi. Para confirmarlo, revisar el siguiente gráfico:

\section{Pacientes de Jambi Huasi en junio de 2008, según el género}

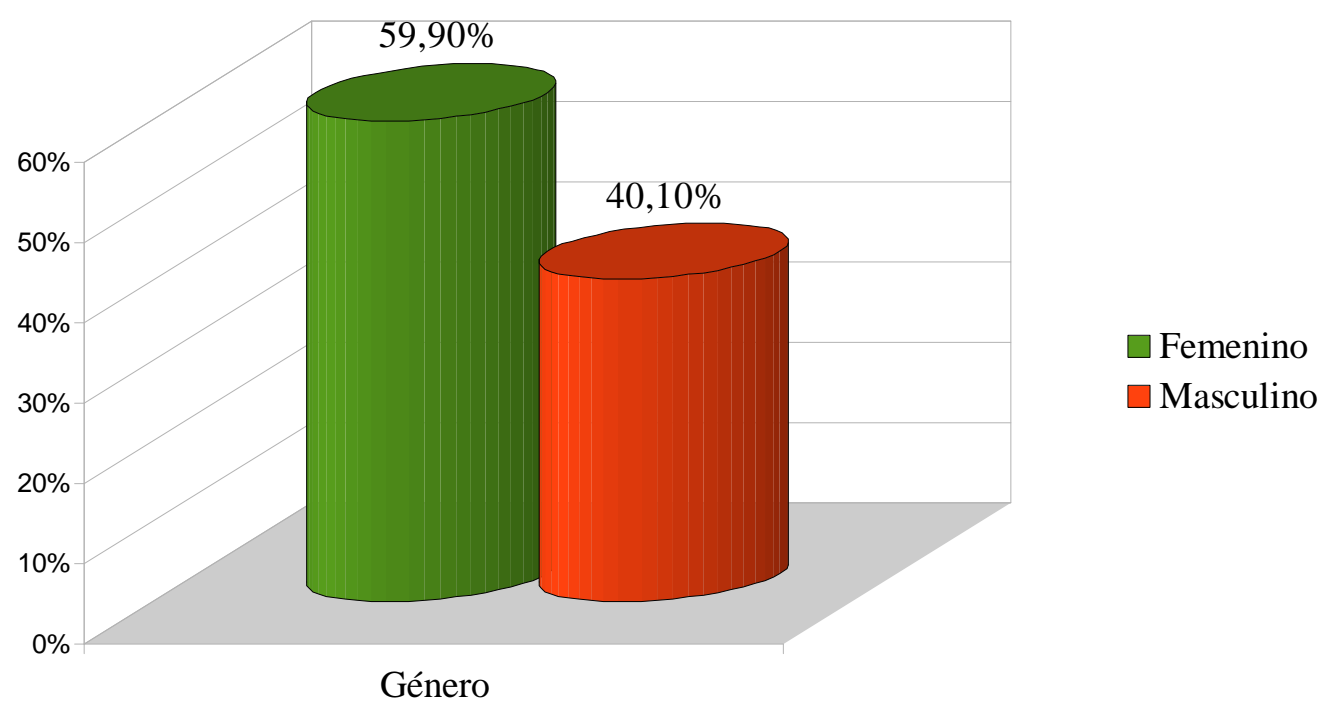

Según Hinrichsen (2000, 2006), el centro de salud Jambi Huasi es único porque proporciona servicios de biomedicina y tratamientos médicos locales, así como asesoramiento y servicios de planificación familiar. Esta combinación de servicios ha hecho

\footnotetext{
${ }^{106}$ Actualmente, Olga Farinango es directora del Área de Salud en el Municipio de Otavalo. En Jambi Huasi, ella trabajó como médico en el período 1995-2000. Estudió medicina en Cuba.
} 
de Jambi Huasi un centro de salud muy popular para personas de origen indígena o mestizo.

Es amplia la gama de servicios que ofrece Jambi Huasi. Tiene una sala de exámenes, un laboratorio, un consultorio dentista, una farmacia que dispensa productos de biomedicina y de la medicina tradicional indígena, un programa de información y educación, y servicios de extensión, que incluyen una ambulancia para casos de emergencia.

Durante el trabajo de campo se comprobó que la demanda de los pacientes fue mayor para los servicios que ofrecen los tres jambigkuna (partera, fregador, y yachak), que para los servicios biomédicos. Esta información puede confirmarse a través del siguiente gráfico:

Pacientes de Jambi Huasi en junio de 2008, de acuerdo al servicio recibido

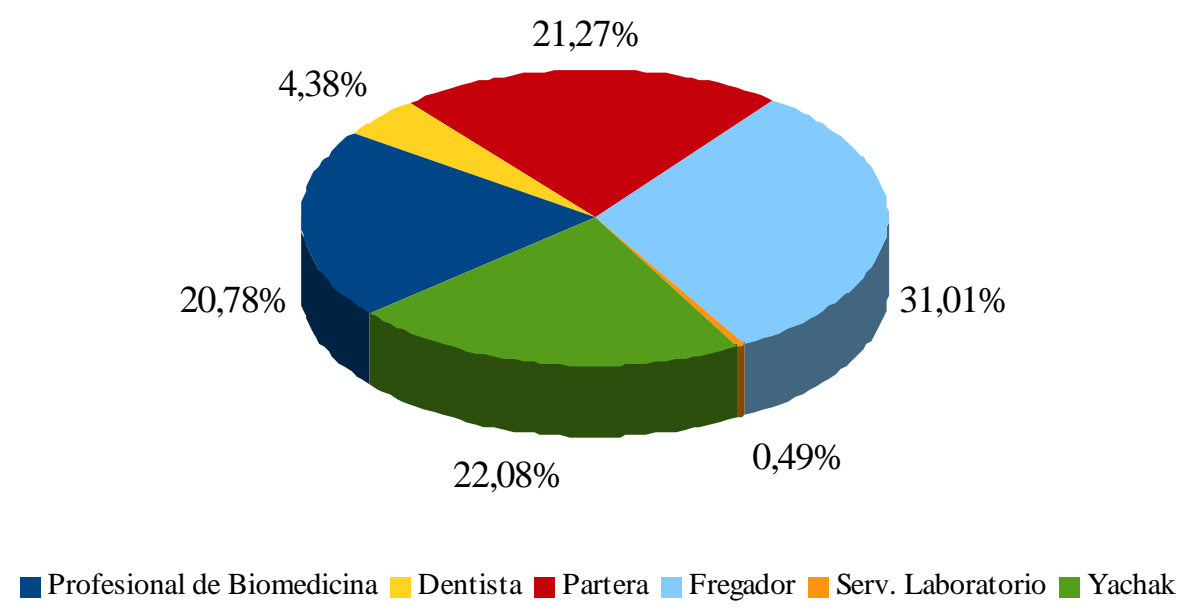

Por lo tanto, aproximadamente la mitad de pacientes de Jambi Huasi utilizaron los servicios provenientes de la medicina tradicional indígena, o medicina local. 
Según la mayoría de los pacientes entrevistados en Otavalo, el éxito de Jambi Huasi surge de su integración dentro de las tradiciones culturales y de su sistema de valores. Esta idea también fue destacada por Hinrichse, en las siguientes palabras: "Una característica importante de la demanda de Jambi Huasi se basa en la prestación de servicios de atención de salud de una manera que respeta los valores y creencias de los pacientes". (Hinrichsen, 2000: 3)

Pacientes de Jambi Huasi durante junio de 2008, según la clase de tratamiento practicado
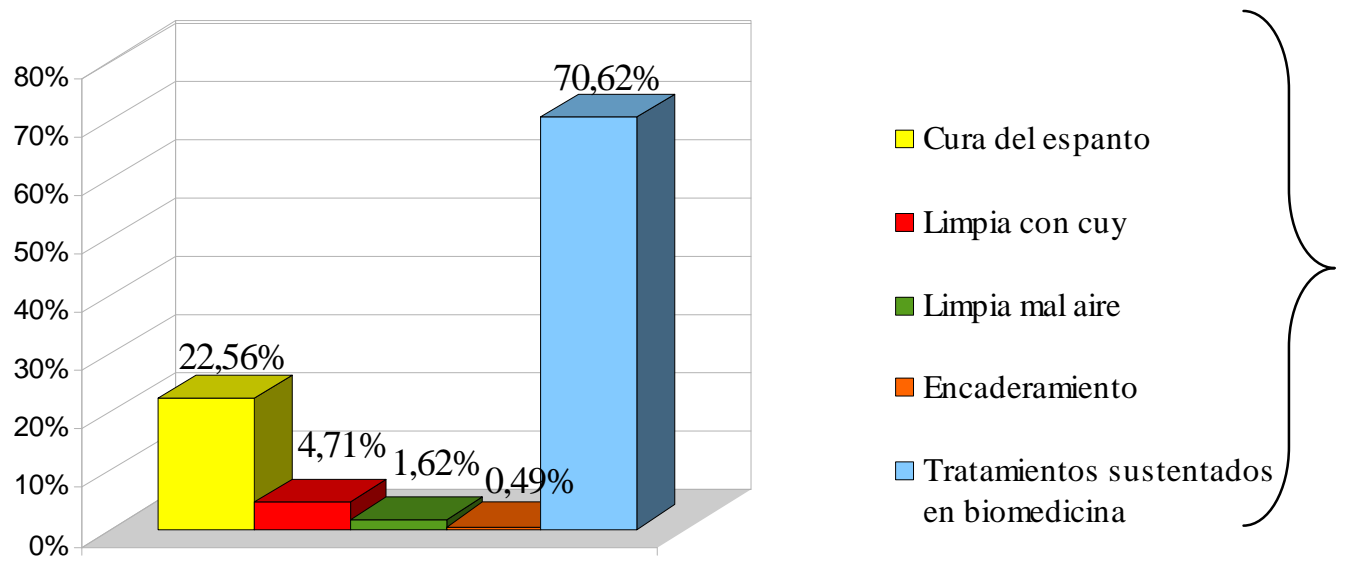

Tratamientos reportados de la medicina tradicional indígena.

Tipos de tratamientos

Los problemas de salud que atiende Jambi Huasi no sólo están centrados en los problemas que afectan a la población a través del tiempo; el personal médico de este centro ha identificado algunos inconvenientes relacionados con la coexistencia de sistemas de comprensión, sobre lo que es la salud y enfermedad, que son culturalmente distintos. 


\section{Servicios basados en Biomedicina}

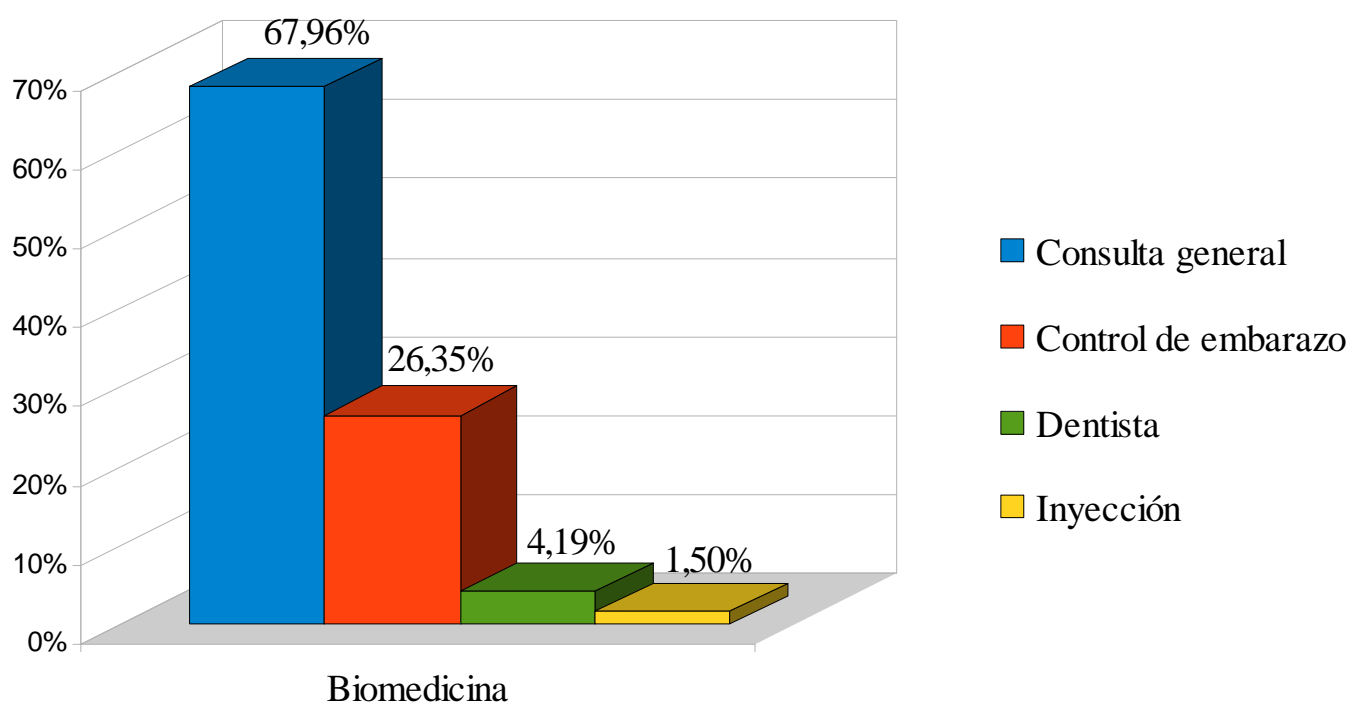

Durante el trabajo de campo destacó un hecho sorprendente. En el centro de salud Jambi

Huasi, la mayoría de pacientes indígenas llegan en busca de servicios provenientes de la biomedicina. En cambio, la mayoría de pacientes mestizos ${ }^{107}$ que llegan a Jambi Huasi prefieren recibir servicios de salud sustentados en la medicina tradicional indígena.

Este hecho se hizo evidente a través del trabajo de observación, de entrevistas mantenidas con profesionales biomédicos y con practicantes de la medicina tradicional indígenas que trabajan en Jambi Huasi. Esa tendencia también fue anunciada en las conclusiones a las que llegó un trabajo de investigación desarrollado por investigadores de la Universidad Andina Simón Bolívar durante el bienio 1998-1999. ${ }^{108}$

\footnotetext{
${ }^{107}$ La palabra "mestizo" se refiere a personas descendientes de españoles e indígenas.

${ }^{108} \mathrm{El}$ objetivo de esta investigación fue estudiar y analizar el perfil o características de la medicina tradicional indígena en el centro de salud Jambi Huasi. Los objetivos específicos fueron: sistematizar el proceso vivido en el centro Jambi Huasi, con énfasis en la trayectoria de actividades correspondientes al proyecto de salud de mujeres indígenas, y realizando un estudio comparativo entre los dos sistemas médicos que integran la prestación de servicios en Jambi Huasi.
} 
¿Por qué existen estas preferencias? Según el personal médico de Jambi Huasi, esa tendencia refleja que la mayoría de pacientes llegan a ese centro de salud luego de probar sus propias alternativas médicas.

El antropólogo mexicano Roberto Campos Navarro comparte ese punto de vista, pues escribió: "Una primera explicación es que los pacientes indígenas tienen sus curanderos en sus propios barrios y comunidades, por lo que ellos desean atención biomédica en un entorno intercultural adecuado; mientras que los 'mestizos' tienen (en Jambi Huasi) un área donde la medicina indígena es respaldada y socialmente legitimada por la propia institución sanitaria". (Campos, 2004: 144)

El médico Leandro Prieto también compartió sus experiencias como médico en Jambi Huasi: "Durante mi experiencia como médico rural en Jambi Huasi (hace más de cinco años) me di cuenta de que el vínculo entre la biomedicina y la medicina tradicional indígena es posible [...]. Yo también comprobé que en este centro hay más pacientes indígenas en busca de servicios biomédicos y más pacientes mestizos que desean ser asistidos por un especialista en medicina indígena".

Según el ecologista César Cotacachi, la principal razón por la que muchos indígenas prefieren la "medicina convencional" (o biomedicina) es la influencia de la religión. "La religión también ha influido en las creencias de los pueblos indígenas. Creo que en la actualidad, aproximadamente el 100\% de los indígenas Kichwa Otavalo son cristianos: católicos, evangélicos o mormones. Los evangélicos no creen en los servicios del yachak, por lo que muchos pacientes evangélicos no visitan al yachak en Otavalo; ellos prefieren recibir la atención de un 'médico occidental' (profesional biomédico) en Otavalo o en otras ciudades. La Iglesia Evangélica está presente en Ecuador desde el Gobierno de Eloy 
Alfaro $^{109}$ y ha influido en el cambio de actitudes y creencias de muchas personas indígenas de Otavalo". Esta es la opinión de Cesar Cotacachi.

Otra razón por la cual muchos pueblos indígenas optan por la medicina convencional (o biomedicina), es porque hay un número creciente de médicos de origen indígena en hospitales o centros de salud convencionales. Por ejemplo, el director del Hospital de San Luis de Otavalo es de origen indígena Kichwa-Otavalo.

"Generalmente, las personas indígenas temen la medicina occidental o convencional. Pero cuando son atendidos por otros indígenas, o por personas que pueden hablar su idioma (Kichwa) y que les tratan con respeto, entonces empiezan a confiar y luego prefieren el sistema de salud convencional (o biomédico)", así lo explicó César Cotacachi en una entrevista.

El yachak de Jambi Huasi confirmó que son más paciente mestizos, que indígenas, quienes prefieren su diagnóstico y tratamiento como yachak. ¿Por qué? "Debido a que la mayoría de mestizos suelen ser atendidos con pastillas, lo que les genera otro tipo de enfermedades; ellos llegan aquí buscando otro tipo de alternativa que les permita sanar, y eso yo les ofrezco con mis plantas medicinales. Por el contrario, la mayoría de indígenas prefieren buscar soluciones en la medicina occidental", comentó el yachak.

Acerca de este tema, es importante destacar el siguiente análisis propuesto por Libbet Crandon Malamud: "Medicine is a critical domain to our sense of selves, infused with

\footnotetext{
${ }^{109}$ Eloy Alfaro fue presidente del Ecuador de 1895 a 1901, y de 1906 a 1911 . Fue el líder de la Revolución Liberal Ecuatoriana.; luchó desde su juventud hasta 1895, cuando los liberales tomaron el poder. Impulsó la separación de la Iglesia del Estado y estableció la aplicación de muchos derechos políticos y civiles en el Ecuador, al igual que la libertad de expresión. Propuso la construcción del primer ferrocarril ecuatoriano, en la ruta Guayaquil-Quito; legalizó el divorcio, autorizó la construcción de escuelas públicas y el matrimonio civil.
} 
enormous power and riddled with different paths that access material and nonmaterial wealth" (En castellano: "La medicina es un dominio crítico al sentido de nosotros mismos, infundido con enorme poder y plagado de caminos diferentes que acceden a la riqueza material y no material”). (Crandon Malamud, 1991: 205)

Por lo tanto, evaluaciones mixtas de resultados o el recurso de varias alternativas médicas pueden reflejar la realidad; pero ello también podría reforzar la principal conclusión de Libbet Crandon Malamud, de que la cura es sólo uno de los muchos objetivos o resultados de la elección médica.

Es importante tener en cuenta que la población indígena de Otavalo es itinerante; suelen tener un intenso intercambio con otros pueblos y culturas. Debido a sus intereses comerciales, ellos suelen viajar a diferentes países. Otavalo es, de alguna manera, una de las ciudades más cosmopolitas del Ecuador; por esa razón, la percepción de la gente de Otavalo sobre la salud y la curación también es cosmopolita.

"En resumen, podríamos decir que la población de Otavalo es más difícil de engañar. Tienen buen olfato para los negocios. Por lo tanto, si los indígenas llegan a Jambi Huasi en busca de los servicios de la medicina occidental (o biomedicina), es porque ellos saben que dichos servicios puede ofrecerles mejores soluciones, con más posibilidades y recursos", opinó Mideros.

Comprender la relación entre el centro de salud Jambi Huasi y la cultura kichwa de Otavalo permitiría redefinir conceptos como "identidad cultural", o la concepción sobre lo que es “indígena”.

En la investigación que Mideros desarrolló hace más de 10 años destacó el hecho de que las personas que se identifican como indígenas son quienes viven en comunidades rurales. 
“Los otros no se sienten indígenas, sino que se consideran 'gente de Otavalo' y saben muy bien cómo moverse dentro de los círculos de poder", afirmó Mideros.

Durante el trabajo de campo referente a la investigación que sustenta el desarrollado de este capítulo, se constató que algunos indígenas provenientes de remotas comunidades rurales se sienten diferentes, con respecto a los indígenas que viven en zonas urbanas, sobre todo en la ciudad de Otavalo.

\subsubsection{Espacios de trabajo}

El tratamiento que ofrecen los jambigkunas (especialmente los yachak) incluye potentes mensajes simbólicos que están vinculados con tradiciones indígenas Kichwa y, a veces, con religión. Prueba de ello es la siguiente experiencia que tuvo lugar en el consultorio del yachak de Jambi Huasi, Javier Perugachi.

"Luego de haber visitado seis centros de salud en diferentes provincias del Ecuador, este yachak es la persona que más nos ha sorprendido positivamente, debido a su personalidad y a su buena actitud con los pacientes", afirmó la vocera de una delegación que visitó Jambi Huasi el 22 de mayo de 2008, en representación de la Dirección Provincial de Salud de Pastaza. El objetivo de la visita de esa delegación era conocer las características de Jambi Huasi y registrar enseñanzas que pudieran ser útiles para sus respectivos centros de salud en la provincia de Pastaza.

Madel T. Luz subrayó la importancia de la relación médico-paciente, cuando dijo que en cualquier sistema médico, independientemente de su racionalidad, gran parte de su eficacia está condicionada por el desempeño del terapeuta. "Esta eficiencia, a su vez, depende directamente de la relación entre el terapeuta y su paciente. El elemento simbólico se torna clave al determinar la eficacia de los sistemas médicos complejos". (Luz, 1996: 36) 
La sala de consulta del yachak de Jambi Huasi, Javier Perugachi, incluye un espacio ritual donde se exhibe "objetos sagrados", como él suele llamarlos; entre ellos hay objetos de origen natural, religioso y ancestral. También destaca un espacio destinado a la exhibición de plantas medicinales, piedras de distintos tamaños, imágenes de santos, frascos llenos de líquido, velas, entre otros.

La entrevista con el yachak tuvo lugar en ese consultorio, donde fue posible observar la estatua de una Virgen que parecía ahorcada por una cuerda que pende del techo. Cuando le pregunté por qué había colgado la imagen de esa Virgen en tal posición, él sonrió y dijo: Decidí colgarla así porque representa el sufrimiento de la Virgen María y el que tienen que afrontar muchas mujeres".

El yachak afirmó que cuando recibe a un paciente que padece una enfermedad grave le pide leer una oración que escribió él con ayuda de sus estudiantes de catecismo; pues él se declara católico e instructor de catequesis.

¿Es recomendable concentrar en el mismo lugar a personas que realizan diagnósticos y/o tratamientos procedentes de la biomedicina y de la medicina tradicional indígena? Myriam Conejo cree que sí, "para evitar los prejuicios que algunas personas tienen con respecto al trabajo de los Jambigkunas" y para ofrecer diferentes alternativas de atención en salud, en el mismo lugar.

Los archivos de Jambi Huasi registran visitas de representantes de las Naciones Unidas y de otras organizaciones que han llegado para compartir experiencias y/o para realizar pasantías. A este centro también han llegado misiones del Ministerio de Salud Pública de Chile, El Salvador y Bolivia; así como personas de diferentes provincias del Ecuador y dos ex ministros del Ministerio de Salud Pública: Asdrúbal de la Torre y Edgar Rodas. 
No todas las personas que fueron entrevistadas durante el trabajo de campo están de acuerdo con el hecho de que Jambi Huasi tenga su sede en la ciudad de Otavalo. Una de las personas que critican esta situación es el docente-investigador Raúl Mideros, quien desarrolló una investigación sobre Jambi Huasi hace más de 10 años. Recuerda que solía discrepar con la directora de Jambi Huasi, Myriam Conejo (cuando ella fue su estudiante) con preguntas como las siguientes: ¿Por qué ella permite que las pautas de gestión y división del trabajo en Jambi Huasi sean las mismas que rigen los sistemas de salud formal y los sistemas biomédicos? ¿Por qué Jambi Huasi tiene su sede en la ciudad de Otavalo, si las comunidades indígenas más necesitadas viven en zonas alejadas de esa ciudad?

Durante su administración como directora ejecutiva de Jambi Huasi, Myriam Conejo propuso trabajar en comunidades indígenas ubicadas en zonas rurales del cantón Otavalo. Este trabajo se desarrolló desde finales de la década de 1990. Pero, debido a limitaciones financieras, esas visitas se suspendieron desde el año 2005.

Matilde Farinango considera sagrado el lugar donde está la sede de Jambi Huasi. Dice que el espacio donde está el consultorio del yachak cumple con características necesarias para la curación y que "su ubicación es estratégica".

Ella también conoce a personas ancianas que no están de acuerdo con el hecho de que algunos yachak ofrezcan sus servicios en la ciudad, "porque muchos creen que hablar de interculturalidad impide la movilización del yachak o de las parteras a la ciudad”, comentó Farinango.

Teresa Jaramillo, ex directora del Hospital Asdrúbal de la Torre de Cotacachi, comparte la opinión de algunos ancianos indígenas al decir que las parteras deben trabajar en sus propias comunidades, mas no en hospitales. 
Algunas personas tienen otra opinión. "No podemos ignorar los conocimientos de la medicina tradicional indígena, la cual ha existido por miles de años. Pero no basta con respetar esos conocimientos, sino que hay que reconocer la labor de cada sistema y aunar esfuerzos para lograr un objetivo común: mejorar la salud de las personas para alcanzar el nivel de 'Sumak Kausay' (término Kichwa que significa 'Buen vivir'). Si las personas que conocen y practican la medicina tradicional indígena desean trabajar en un centro de salud u hospital de la ciudad, esa decisión deben tomarla de acuerdo a la realidad de cada comunidad. Pero si otros prefieren seguir trabajando en sus propias comunidades y, desde allí, contribuir al sistema de 'referencia y contra-referencia', yo apoyaría ambas propuestas", dice Matilde Farinango.

La investigación que Raúl Mideros desarrolló hace más de 10 años en Jambi Huasi destacó otras razones por las cuales el personal de este centro de salud no estaba muy satisfecho: "El hampik (o jambigkuna, quien recurre al conocimiento tradicional indígena para curar) compara sus espacios con los de un médico occidental y se siente en desventaja, ya sea por el tamaño de los espacios que se les ha asignado, como por la falta de interés en ofrecerles una mejor condición. Esto les hace sentir "menos", como que "no se les aprecia" y como si "estuvieran convirtiéndose en inútiles" dentro de Jambi Huasi. Sin embargo, "el equipo de trabajo es consciente de que la sostenibilidad financiera de ese centro de salud depende principalmente de los ingresos que ellos (los hampik) producen". (Mideros et als., 2000:33)

"En su discurso oficial, las autoridades de Jambi Huasi reconocen la relación entre los dos sistemas médicos. Los dirigentes de este centro afirman que entre los profesionales biomédicos y los hampik hay un diálogo, un aprendizaje permanente a través del intercambio de experiencias; dicen que "no se trata únicamente de poner un yachak en el 
centro, sino de lograr un mutuo desarrollo, con respeto y orientación; asesorándose y aprendiendo unos de otros, sin tratar de imponer' [...]. Sin embargo, la hampik han expresado su gran descontento hacia las circunstancias en las que trabajan. Ellos usan muchas comparaciones para describir su situación al interior y en relación con otros miembros del equipo. Ellos comparan sus consultorios y afirman que no tienen suficiente espacio para ofrecer todos sus servicios, ni para la conservación de medicamentos. Sin embargo, ellos creen que en el ámbito de la medicina occidental todo es hermoso, organizado [...]. Dicen que los tres (yachak, partera y fregador) son los últimos en ser atendidos". (Mideros et als., 2000:35-36)

"El hampik compara su situación con la de un trabajador agrícola, quizá porque tienen miedo de hablar con quienes dicen ser 'estudiados'; porque ellos (los profesionales de la biomedicina) hablan con palabras difíciles y sólo en español (no en Kichwa). El hampik percibe como injustas las normas de administración y las relaciones interpersonales en Jambi Huasi. Estas personas están bajo la mirada de los demás a quienes consideran sus superiores, en lugar de sus colegas. Las jerarquías se expresan también en el ámbito de los conocimientos y prácticas”. (Mideros et als., 2000: 36-37).

Por las razones anteriormente mencionadas, Sánchez Vidal y Mercedes Muenala (una enfermera indígena que ahora coordina el Departamento de Salud Intercultural, en la Dirección Provincial de Salud de Imbabura), decidieron renunciar al cargo que tenían en Jambi Huasi, hace más de 8 años.

La directora del centro de salud Jambi Huasi, Myriam Conejo, dijo que luego del informe de investigación elaborado por la Universidad Andina Simón Bolívar, hace más de 8 años, se ha puesto en marcha un plan de mejoras y cambios en Jambi Huasi; por ejemplo, 
en torno a la relación entre profesionales biomédicos y jambigkunas (representantes de la medicina tradicional indígena).

Esta percepción de cambio también fue compartida por miembros del personal de Jambi Huasi, durante el trabajo de campo correspondiente a esta investigación; pero, al final de una entrevista, el yachak compartió su insatisfacción por su espacio de trabajo y su salario.

El consultorio del yachak es de aproximadamente 10 metros cuadrados y está situado en el primer piso de la casa donde funciona Jambi Huasi. ¿Por qué no ha pedido el yachak un consultorio más grande? "Fue el yachak quien decidió que la ubicación de su consultorio sea en el primer piso, porque prefiere sentir un contacto más estrecho con la tierra", afirmó Myriam Conejo.

"No, esta no es mi casa. Aquí sólo soy un visitante y de aquí tendré que salir algún día", dijo el yachak Javier Perugachi. Luego, cuando se le consultó qué cambios sugeriría a las autoridades de Jambi Huasi, para mejorar su trabajo, él respondió seriamente: "Es inútil hablar sobre esos temas en reuniones, porque la situación no cambia [...]. Sugiero ampliar la casa donde funciona Jambi Huasi, para complementar las carencias de quienes trabajamos en este centro. También debe haber mejor comunicación entre quienes trabajamos en este centro, para evitar actitudes racistas [...]. Los profesionales que han estudiado biomedicina a veces han tenido actitudes racistas hacia mí, o subestiman mi trabajo. Es como si no dieran importancia a lo que tenemos que decir. Esa es la razón por la cual yo prefiero callar en las reuniones. Quizás por eso no me han pagado a tiempo".

\subsubsection{Sueldos / remuneraciones: ¿Cómo ha cambiado?}

Durante la primera fase de Jambi Huasi (1983-1992), la administración de los proyectos y recursos financieros los llevó a cabo la FICI, con la firma del Presidente, de un líder de la 
organización, de un administrador financiero y del director. Sin embargo, este proceso tuvo algunos inconvenientes porque, en varias ocasiones, el equipo de salud no pudo ponerse en contacto con dirigentes de la FICI (porque ellos estaban fuera de Otavalo).

Según la directora de Jambi Huasi, Myriam Conejo, era difícil hacerse cargo de este centro si éste dependía económicamente de la presencia de dirigentes de la FICI. En esas circunstancias, junto a técnicos que trabajaban en Jambi Huasi, ella propuso a la FICI que les delegue a ellos la administración del centro de salud Jambi Huasi, con la promesa de presentar un informe anual de actividades. Esta propuesta fue aceptada, lo cual condujo a la descentralización de la autonomía administrativa de Jambi Huasi, hasta la actualidad.

Luego de varios años de servicio, este centro de salud ha logrado mantener su autonomía financiera gracias al pago de consultas por parte de los pacientes y, en ocasiones, con apoyo de proyectos de salud financiados por organismos de cooperación internacional, tales como el UNFPA.

El principio de reciprocidad es una característica común en la práctica de la medicina tradicional indígena, por parte de las comunidades Kichwa de Otavalo. "Este principio se entiende como el hecho de proporcionar atención de salud de calidad y con honestidad a cambio de una tarifa mínima, en relación con los costos que exige pagar el sector privado por la oferta de sus servicios”, afirmó Conejo.

Durante su administración, el proceso de autofinanciamiento ha impedido establecer otro tipo de intercambios, tales como el trueque de especies; pero, en cambio, "hemos promovido la práctica de solidaridad con los pacientes, para ofrecer crédito o servicio gratuito a quienes no pueden pagar el costo de la consulta o los medicamentos", dijo Darwin Tamba, quien se encarga de recaudar el monto correspondiente al pago de consultas en Jambi Huasi. 
En su criterio, los principales problemas de este centro de salud han sido los siguientes: falta de apoyo y cambios en el consejo administrativo de la FICI (organización que impulsó la creación de Jambi Huasi); así como el permanente cambio de médicos rurales en Jambi Huasi. Hasta julio de 2008, al menos ocho médicos rurales ofrecieron sus servicios en este centro de salud. "Este es un gran problema, porque el cambio de un médico nos obliga a tener que empezar con el nuevo, hasta lograr integrarlo y que se solidarice con los pacientes. Debido a limitaciones presupuestarias, no hemos contratado a una persona de forma permanente".

Debido a esos problemas, Tamba cree que Jambi Huasi está en stand by. "Requerimos implementar nuevos servicios, tales como: 1) Sala de parto, 2) Quiromasajes, 3) Centro de Investigación, para contribuir a mejorar el trabajo de Jambi Huasi a partir de investigaciones académicas y sobre la base de estadísticas.

\subsection{4.a) La selección de personal en Jambi Huasi}

Entre junio y julio de 2008, el equipo de Jambi Huasi estuvo conformado por las siguientes nueve personas: (1) Myriam Conejo, directora ejecutiva, quien coordinó una investigación sobre tuberculosis en varias provincias del Ecuador, durante el año 2008; (2) José Farinango, administrador, quien fue director encargado de Jambi Huasi mientras la directora coordinaba el proyecto de tuberculosis; (3) Darwin Tamba, quien está a cargo del área de información y de cobros; (4) Janeth Cando, a cargo de la Farmacia; (5) María Carlosama, conserje; (6) Zoraida Narváez, contadora, y 3 Jambigkuna, o personas que conocen y practican la medicina tradicional indígena (constan un yachak, Javier Perugachi; una "partera", Concepción Brusil, y una jakug, Juana Perugachi). 
Desde 1997, el Ministerio de Salud Pública del Ecuador está financiando el programa de trabajo anual de un médico rural en Jambi Huasi; este cargo lo asume una persona diferente cada año. Desde 2001, este centro de salud también cuenta con el aporte de un profesional obstetra, a través de un acuerdo firmado entre Jambi Huasi y la Escuela de Obstetricia de la Facultad de Ciencias Médicas de la Universidad Central del Ecuador.

El Ministerio de Salud Pública del Ecuador financia el salario de los siguientes profesionales biomédicos que laboran en Jambi Huasi: 1 odontólogo, 2 médicos, 1 enfermera, 1 psicólogo. La Universidad Central del Ecuador apoya institucionalmente las prácticas que desarrolla una obstetra en Jambi Huasi.

Las autoridades de este centro de salud han dado prioridad a las siguientes características, para seleccionar a su equipo de trabajo: (1) Que sean bilingües (de español y kichwa). (2) Que respeten y valoren la contribución de la medicina tradicional indígena y de la biomedicina. (3) Que estén identificados, ideológicamente y prácticamente, con el trabajo social. (4) Que estén de acuerdo con la propuesta de atender a los pacientes desde un enfoque bio-psico-social. (5) Que estén comprometidos con el trabajo en equipo y que estén capacitados para cumplir con la actividad para la cual han sido elegidos.

En el caso de los profesionales biomédicos, las autoridades de Jambi Huasi prefieren elegir a estudiantes recién graduados de la Universidad, pues creen que los profesionales jóvenes responden de forma más adecuada a los parámetros que caracterizan a Jambi Huasi.

En el caso de la medicina tradicional indígena, el personal de salud de Jambi Huasi ha sido seleccionado con respaldo y apoyo de organizaciones indígenas locales y de la FICI.

El yachak Javier Perugachi, quien tiene 53 años de edad y ha trabajando en Jambi Huasi durante más de 12 años, trabajó antes con un famoso yachak, durante 26 años. 
La experiencia de la mamahua o partera y de la jakug, que trabajan en Jambi Huasi, proviene de la enseñanza que ellas recibieron de sus madres y abuelas durante su adolescencia y juventud. Ahora, la partera tiene 80 años de edad y, la jakug, alrededor de 70 años.

\subsection{4.b) Las diferencias en el pago}

Darwin Tamba, quien se encarga del área de información y de cobros, dijo que una forma de valorar equitativamente el trabajo de los representantes de ambas medicinas ha sido pagando el mismo sueldo al médico y al yachak. A la partera de Jambi Huasi, dijo que se la paga un monto equivalente al salario que percibe la obstetra.

Sin embargo, a través de entrevistas y de la técnica de observación, fue posible constatar la insatisfacción de algunos representantes de medicina tradicional indígena que trabajan o han trabajado de Jambi Huasi, debido a diferencias en los sueldos que ellos perciben, en relación al salario destinado para profesionales biomédicos.

Con respecto a los sueldos, Myriam Conejo explicó: debido a que no se tiene un punto de referencia que permita determinar la forma en que debe pagarse a los representantes de la medicina tradicional indígena, como política institucional hemos decidido que ellos deben recibir un monto equivalente al que reciben los profesionales del sistema occidental (biomedicina), según la jerarquía de sus colegas. "Por ejemplo, el yachak recibe un sueldo equivalente al sueldo de un médico de la biomedicina, mientras que la mamahua (partera) recibe un salario similar al de la obstetra, y la jakug recibe un salario similar al de un fisioterapeuta (quien trabaja en el sistema biomédico)" (Conejo et als., 2004: 18). 
Ella aclaró que el Ministerio de Salud Pública del Ecuador es responsable del pago de los sueldos de profesionales de la biomedicina, mientras que Jambi Huasi se responsabiliza del pago de los jambigkunas.

Raúl Mideros recuerda que, durante la investigación que él y otros investigadores desarrollaron en el centro de salud Jambi Huasi (en el período 1997-1998), se constató que la mayor parte de inversiones y de gastos realizados en este centro fueron destinados a la compra de medicamentos e insumos correspondientes a la medicina alopática o biomedicina. Este aspecto "refleja lo que era importante para las autoridades de Jambi Huasi, porque gastaron más dinero en lo que ellos creían que era una prioridad o la piedra angular de su proyecto", según Mideros. A él le sorprendió notar que hay mucha diferencia en la remuneración de las personas que trabajan en Jambi Huasi. Por ejemplo, recuerda que la remuneración de la partera, durante el periodo de su investigación, era muy inferior a la remuneración que recibían los profesionales biomédicos. Esa comparación le permitió darse cuenta de que, en la práctica, hay diferencias o desigualdad en el reconocimiento de las personas que trabajan en este centro de salud.

Esta opinión fue confirmada por el yachak de Jambi Huasi, Javier Perugachi, en una entrevista realizada a inicios de julio de 2008. Él afirmó que en Jambi Huasi recibe USD \$330 mensuales por su trabajo y que ganaba mucho más cuando trabajaba en el consultorio de su casa. "Es por mi amor al pueblo y por mi reconocimiento a esta organización que sigo trabajando en Jambi Huasi. He tenido que reducir mis ingresos para apoyar a este centro de salud".

Javier Perugachi aclaró que actualmente sólo atiende en el consultorio de Jambi Huasi, porque le obligan a no comprometerse laboralmente con otros lugares. Él estima que su trabaje en ese centro de salud genera una ganancia de alrededor de USD \$1800 mensuales 
por todos sus servicios (cobro de sus consultas, venta de productos naturales y de medicamentos que él prepara). No obstante, dice que su salario mensual es de USD \$ 330.

Mantener la infraestructura y los servicios de Jambi Huasi requiere de mucho financiamiento; el cual proviene, principalmente, del pago de consultas por parte de los pacientes.

“Se requiere alrededor de USD \$ 60.000 por año, sólo para pagar los sueldos de 11 personas", informó Myriam Conejo. Dijo que, a partir del pago de consultas, Jambi Huasi suele recoger alrededor de USD $\$ 45.000$ por año; por eso ella está buscando el apoyo de otras organizaciones o proyectos para alcanzar a financiar la cantidad restante.

Raúl Mideros reconoce el alto costo que implica mantener la infraestructura y el pago de salarios en Jambi Huasi. Para evitar problemas administrativos a futuro, cree que una buena solución sería que las autoridades de Jambi Huasi analicen bien sus prioridades.

\subsubsection{Reuniones y colaboración}

Esta sección destaca puntos de vista contrastantes sobre lo que está ocurriendo en los espacios del trabajo de Jambi Huasi. La idea que se tenía, antes de iniciar el trabajo de campo correspondiente a esta investigación, cambió un poco luego de aplicar la técnica de observación.

Se partió de la idea de que, en Jambi Huasi, los profesionales biomédicos y los representantes de la medicina tradicional indígena solían reunirse para intercambiar opiniones sobre sus respectivos diagnósticos. Sin embargo, durante el trabajo de campo se constató que, en la práctica, no se produce el intercambio de puntos de vista. Aunque el proceso de referencia y contra-referencia se lleva a cabo en ocasiones, especialmente en casos de mujeres embarazadas que muestran signos de riesgo. 
Javier Perugachi ha trabajado como yachak en Jambi Huasi durante más de 12 años. Durante la entrevista realizada para sustentar el presente trabajo de investigación, él escuchaba música alegre e instrumental, interpretada por un grupo de músicos indígenas. Su consultorio lucía como un espacio acogedor, donde destacaba la iluminación de dos velas.

Durante la entrevista, Perugachi habló español con voz muy pausada, como si se tratara de un consejero espiritual. Con dinamismo, él empezó a relatar su experiencia con las siguientes palabras: "Vine a Jambi Huasi no a practicar, sino a enseñar a la gente. Yo explico a mis pacientes las características y el estado real de la enfermedad que padecen así cómo los síntomas y los límites de mi curación. Les informo qué tipo de plantas pueden curar sus problemas de salud, porque esa es mi responsabilidad. Nunca dejo que los pacientes sigan consumiendo sedantes o tranquilizantes, sino que trato de ofrecerles tratamientos que curen de forma definitiva sus problemas de salud". ${ }^{110}$

Cuando se le preguntó sobre su relación con los demás miembros del personal de Jambi Huasi, incluidos los profesionales biomédicos, Perugachi respondió que él ha tenido una buena relación con todos, porque han tratado de comprenderse y de apoyarse mutuamente. Para ello, dijo que él ha tenido más comprensión que otros.

He tenido que ser más experto que nadie. Tengo que respetar a otros si quiero acercarme a ellos. Esa es la razón por la cual he aprendido a compartir otras alternativas de la salud con más personas. Esta es una de mis características, yo nunca estoy en contra de los médicos

\footnotetext{
${ }^{110}$ Javier Perugachi admitió que no siempre ha podido garantizar la curación de pacientes. "Por ejemplo, hoy acabo de recibir a un paciente que vino de Quito, quien tiene cáncer en etapa avanzada y ha estado en tratamiento durante 9 años, con productos biomédicos. En ese caso, yo no puedo ofrecerle una cura. Prefiero informar mi diagnóstico a un pariente. Si existen formas de curar, lo haría; pero hay casos en los que es imposible hacerlo [...]. Es mi responsabilidad decir eso a los familiares del pacientes", dijo el yachak.
} 
occidentales (profesionales de la biomedicina). He tenido la suerte o el privilegio de conocer a muy buenos médicos y científicos, y me he sentido feliz de compartir con ellos mi conocimiento sobre plantas medicinales. Yo siempre he dicho a mis pacientes: 'no deben estar en contra de la medicina occidental (biomedicina), ustedes deben acercarse a ella'. Si los médicos occidentales (biomédicos) prescriben medicamentos, jarabes, pastillas; yo también puedo prescribir esas cosas a través de plantas naturales y medicinales. Si combinamos los dos medicamentos, sería más fácil curar. (Javier Perugachi, yachak de Jambi Huasi).

Al final de la entrevista, Javier Perugachi comentó que su deseo es enseñar sus conocimientos y prácticas como yachak a su hija Marina (quien tiene alrededor de 18 años de edad),111 para que ella pueda considerar su experiencia cuando estudie Medicina en la universidad. $^{112}$

Según la directora de Jambi Huasi, Myriam Conejo, en este centro de salud se "ha tratado de impulsar el equilibrio de ambos sistemas. Esto significa que el personal no se sienta celoso por la provisión de insumos u otras necesidades, porque hemos tratado de ofrecer un trato justo a los representantes de ambos servicios".

No todas las personas entrevistadas comparten esa opinión, al analizar la relación que existe entre biomedicina y medicina tradicional indígena, en la experiencia de Jambi Huasi. Esos puntos de vista han permitido dar respuesta a las preguntas de investigación formuladas al inicio del presente capítulo. Esta sección muestra un análisis detallado sobre las distintas opiniones.

\footnotetext{
${ }^{111}$ Cuando se realizó esta entrevista, Marina cursaba estudios de $4^{\circ}$ año en el colegio. Su objetivo es estudiar Medicina y especializarse luego en cirugía, para vincular los conocimientos y prácticas de la biomedicina con los conocimientos y prácticas enseñadas por su padre.

${ }^{112}$ Para reforzar sus enseñanzas, Javier Perugachi desea heredar a su hija un cuaderno donde ha registrado información referente a consultas con sus pacientes, en el siguiente orden: fecha de consulta, nombres y apellidos del paciente, edad, lugar de origen, diagnóstico y tratamiento.
} 
Sánchez Vidal, quien se presentó a sí mismo como herbolario y fregador, ${ }^{113}$ trabajó en Jambi Huasi durante dos años y renunció hace ocho años porque, en esa época, "los líderes de Jambi Huasi no pudieron alcanzar los objetivos por los que se propuso la creación de este centro de salud; es decir, combinar la medicina occidental (biomedicina) y la medicina tradicional indígena (conocimiento local). Las autoridades preferían dar más apoyo a los profesionales de la medicina occidental (biomédicos) y yo no estaba de acuerdo con eso".

En su criterio, los dirigentes de Jambi Huasi no dieron facilidades a las personas que trabajaban en la medicina tradicional indígena. "Se nos consideraba de última prioridad, a pesar de que el mayor de los éxitos de este centro se debe a la oferta de servicios basados en los conocimientos de la medicina tradicional indígena. Siempre ha sido así, las personas indígenas hemos sido consideradas inferiores. Hemos sido más valorados por organismos internacionales, que por las autoridades locales”, comentó Sánchez Vidal.

Agregó que, cuando trabajó en Jambi Huasi, no contaba con los medicamentos o el apoyo necesario para cumplir con el programa de prevención en las comunidades. Además, “mi sueldo era mínimo. Por eso busqué otras opciones y ahora tengo mi propia sala de consultas en mi propio centro, cerca del lugar donde opera Jambi Huasi, y así me siento muy bien”, dijo sonriente Vidal Sánchez.

Acerca de la combinación de tratamientos, Darwin Tamba (quien trabaja en Jambi Huasi hace más de 8 años) dijo que en ese centro de salud los profesionales biomédicos y los representantes de la medicina tradicional indígena evitan combinar tratamientos al prescribir a sus pacientes. "Ellos pueden sugerir a los pacientes visitar a varios

\footnotetext{
${ }^{113}$ Además de trabajar como herbolario, Sánchez Vidal es bien conocido en Otavalo como un buen fregador (en la práctica, este trabajo es similar a la quiropráctica o al masaje con las manos).
} 
profesionales, pero les recomiendan iniciar y concluir un tratamiento, antes de comenzar otro", afirmó Tamba.

Con el fin de responder a la pregunta empírica: ¿De qué forma, en la práctica, el diálogo de conocimientos tiene lugar en el centro de salud Jambi Huasi? O para determinar si los prejuicios de cualquier tipo, en relación con la biomedicina o la medicina tradicional indígena, se interponen en el camino, conviene destacar la siguiente reflexión:

En la práctica, la relación entre la biomedicina y la medicina tradicional indígena existe en Jambi Huasi como una especie de juego, donde los pacientes tienen la opción de elegir entre diferentes alternativas de atención en salud. Pero, en la práctica, los profesionales biomédicos y los jambigkunas (personas que conocen y practican la medicina tradicional indígena) no están trabajando juntos para crear una nueva opción de atención en salud.

Haciendo una simple comparación: es como un centro que ofrece jugos de diferentes sabores: de naranja, manzana, pera o piña. Los clientes deciden qué tipo de jugo quieren, pero rara vez tienen la opción de elegir un jugo que incluya la combinación de todas las frutas.

"Y aunque reciban un jugo de diferentes frutas, en éste destacará el sabor de una, la cual prevalece entre las demás porque impone su características, su color o sabor. La misma situación ocurre con el intento de combinar la biomedicina con la medicina tradicional indígena”, comentó Raúl Mideros.

En el ámbito de la salud, él ha notado que la interculturalidad podría ser el espacio donde existe el intersticio entre cultura dominante y cultura subordinada. "La interculturalidad no se presenta como un estado o como algo estructurado, sino más bien como un juego, como un escenario en el que el paciente tiene la opción de elegir entre varias alternativas", dijo Mideros. 
Pero, ¿de qué manera la biomedicina y los conocimientos locales están presentes en la práctica de la atención primaria de salud, en el centro de salud Jambi Huasi?

En opinión de Cesar Cotacachi (indígena, ecologista, fotógrafo y guía de turismo en Otavalo), la atención primaria de salud es "el primer contacto del paciente con un hospital, clínica o centro de salud de la medicina convencional (biomedicina), o con un centro de medicina tradicional indígena, con el fin de recibir el primer diagnóstico sobre su estado de salud".

Sobre la base de esta interpretación, Cotacachi cree que la atención primaria de salud que proviene de la biomedicina sería equivalente al diagnóstico con "cuy" (también conocido como conejillo de indias) que realizan las jakug, o con el diagnóstico del yachak.

Según Myriam Conejo, directora de Jambi Huasi: “muchos indígenas usan el 'cuy’ con dos propósitos: 1) para formular diagnósticos y 2) como método terapéutico. Pero en el centro de salud Jambi Huasi el 'cuy' se utiliza únicamente para hacer diagnósticos sobre la base de la medicina tradicional indígena".

¿Por qué el "cuy" se utiliza en la medicina tradicional indígena, para hacer diagnósticos y terapias ${ }^{114}$

\footnotetext{
${ }^{114}$ El diagnóstico con "cuy" (conejillo de indias) es una técnica utilizada a veces por el yachak o por otros jambigkunas (representantes de la medicina tradicional indígena). El "cuy" es un animal que tiene un lugar reverente en la cultura andina. Se utiliza como alimento, así como instrumento para formular diagnósticos y procesos terapéuticos. El diagnóstico o la terapia con "cuy” se realiza con el animal vivo, al cual se lo pasa frotando por el cuerpo del paciente; de arriba hacia abajo por las piernas, los brazos, el pecho, los hombros y la parte superior de la cabeza del paciente. A continuación, el yachak o jambigkuna tiende a diseccionar el "cuy", con el fin de observar características que les permita diagnosticar el estado de salud del paciente. Algunos yachak y jambigkunas creen que el "cuy" es un animal que puede absorber las energías negativas de los pacientes. Por lo tanto, creen que al utilizar este animal en sus diagnósticos o tratamientos, las aflicciones de los pacientes son absorbidos por el cuerpo del "cuy".
} 
"Porque la distribución anatómica de este animal es muy similar al de un humano. El 'cuy' es similar a un ratón en su anatomía. Algunos investigadores usan ratones para probar medicamentos que, posteriormente, se prescribe a seres humanos. En Jambi Huasi, los jambigkunas también podrían utilizar ratones para diagnosticar los problemas de salud de sus pacientes; pero prefieren utilizar "cuyes" porque es más fácil encontrar estos animales en la casa de los pacientes, pues algunas personas crían este animal para su alimentación", explicó Myriam Conejo.

Javier Perugachi, el yachak de Jambi Huasi, prefiere utilizar otras técnicas para diagnosticar el estado de salud de sus pacientes. Él prefiere observar "muestras de orina” o la llama de la vela, tomar el pulso (como suelen hacerlo profesionales biomédicos) y analizar la respiración del paciente.

En la primera cita, y con el propósito de diagnosticar un paciente de la condición de salud, pidió una muestra de orina - han tomado en la mañana y en una taza, que se vende en las farmacias o en Jambi Huasi. A continuación, analiza la llama de la vela para diagnosticar el "lado espiritual del paciente".

Este yachak dice que la llama de la vela puede compararse con una pantalla de TV, en sus diagnósticos, porque a través de ésta puede observar el estado de salud del paciente. "Yo no pregunto a los pacientes dónde les duele o cuál es su problema. Este tipo de información le pueden dar a un médico occidental (biomédico), pero yo soy un hombre sabio y tengo que saber identificar el problema de mis pacientes".

En resumen, dentro de la medicina tradicional indígena, uno de los aspectos más importantes es que la persona que practica este conocimiento tiene el respeto y el reconocimiento de la comunidad. El diagnóstico puede hacerse de diferentes maneras: a través de la llama, utilizando el cuerpo de un "cuy" o un huevo, entre otras cosas. 
Estos diagnósticos, por lo general, están asociados con el proceso de curación, cuyos rituales exigen seguir varios pasos. Las personas que practican estas habilidades tienden a elegir el día, el lugar, e incluso la hora de la consulta, para realizar el diagnóstico y tratamiento a sus pacientes. "Estas personas utilizan diferentes herramientas de diagnóstico y, de hecho, sus resultados son exactos", dice Matilde Farinango, quien también destacó los esfuerzos de Jambi Huasi y de otras organizaciones, para lograr el reconocimiento institucional del trabajo de las parteras, especialmente en Otavalo.

La siguiente sección ofrece información detallada sobre el apoyo institucional y la capacitación ofrecida a parteras, así como sobre la práctica del sistema de referencia y contra-referencia entre profesionales biomédicos y jambigkunas (gente que sabe y práctica la medicina tradicional indígena).

\subsubsection{Referencias: casos de embarazo y parto}

\section{"Prefiero morir en mi casa que ir al hospital"}

"Hasta entonces, nunca había visto un parto vertical en vivo y en directo, sino sólo en teoría. Pero esa mujer me contó que todos sus hijos nacieron por medio de parto vertical. De repente, oí el sonido del 'agua de fuente' y vi cómo el bebé bajaba lentamente de su madre, entre sus piernas, como si estuviera en una resbaladera. ¡Se trataba de una bella imagen... Qué sabiduría tenía esa mujer!”. (Fragmento de la entrevista realizada a Matilde Farinango).

La primera iniciativa en el proceso de referencia y contra-referencia fue propuesta por el Ministerio de Salud Pública del Ecuador, hace muchos años. "Debido a la distancia entre las comunidades indígenas y las ciudades, el objetivo ha sido llevar a la práctica el proceso de referencia y contra-referencia”, explicó Matilde Farinango. ${ }^{115}$

\footnotetext{
115 Actualmente, Matilde Farinango es técnica de la Dirección Nacional de Salud de los Pueblos Indígenas, en el Ministerio de Salud Pública del Ecuador. Anteriormente, estudió enfermería en la Universidad Técnica del
} 
Para aclarar por qué valora tanto el trabajo de las parteras y la práctica del parto vertical, ella relató la siguiente experiencia que le ocurrió hace más de 10 años:

Recuerdo que era 24 de junio cuando, en mi comunidad indígena, una mujer embarazada y sus familiares buscaban desesperadamente a una partera para que les ayude con el parto. Mi madre les dijo que yo era enfermera y que podría ayudarles. Pero, en ese momento, yo no tenía el equipo necesario para atender a la parturienta. Ella me dijo que prefería morir en casa que ir a un hospital.

Yo sentía miedo porque, hasta entonces, nunca había atendido a un paciente fuera del hospital, o sin el apoyo de un médico. Así que llamé al hospital y pedí una ambulancia, con el fin de llevar a la mujer embarazada hacia el hospital; pero nadie respondió a mi llamada y, mientras tanto, esa mujer sentía más fuertes los dolores de parto. Luego marqué el número de emergencia '911' y alguien respondió a mi llamada. Sin embargo, cuando esa persona me pidió el nombre de las calles para enviar la ambulancia, yo no supe qué decir; porque, en mi comunidad, las calles no tienen nombres, nosotros ubicamos las casas de acuerdo a referencias. Por ese motivo, la ambulancia tardó mucho en llegar y, mientras tanto, la mujer embarazada tuvo contracciones de parto. Para mi sorpresa, sin la ayuda de nadie, la mujer embarazada se arrodilló y colocó su cuerpo en una posición que le permitió recibir a su bebé mediante parto vertical.

Hasta entonces, nunca había visto un parto vertical en vivo y en directo, sino sólo en teoría. Pero esa mujer me contó que todos sus hijos nacieron por medio de parto vertical. De repente, oí el sonido del 'agua de fuente' y vi cómo el bebé bajaba lentamente de su madre, entre sus piernas, como si estuviera en una resbaladera. ¡Se trataba de una bella imagen!

¡Qué sabiduría tenía esa mujer! Recuerdo que ella me dijo: “¡Por favor, no corte todavía el cordón umbilical, espere un momento!". Yo desinfecté el material con el que luego corté el cordón umbilical, mientras que los cuerpos de la madre y su bebé seguían unidos. Al final, fue la madre quien atendió su propio parto, ella misma, porque sabía cómo hacerlo". (Matilde Farinango)

Después de que el bebé nació, un grupo de paramédicos y la ambulancia del 911 llegaron a su casa. El rostro de Matilde Farinango se iluminó con una sonrisa mientras

Norte, en Ibarra, Ecuador. El título de su tesis de Licenciatura en Enfermería fue: "La medicina tradicional como una alternativa de curación", la cual defendió en 1993, antes de trabajar en el centro de salud Jambi Mascaric, de Cotacachi. 
relataba: "Recuerdo que fue una hermosa experiencia, creo que esa fue realmente una experiencia intercultural".

En su opinión, no es necesario que las mujeres embarazadas vayan al hospital para ser atendidas, sino que "los médicos también visiten las casas de mujeres embarazadas para atender ahí los partos".

Según Farinango, ese proceso podría considerarse intercultural, porque permite la interacción de médicos y pacientes desde sus diferentes puntos de vista y sus respectivos modelos de salud, durante el proceso de parto.

"Cuando los paramédicos ayudaron a la mujer parturienta a eliminar la placenta de su cuerpo, sus otros hijos sabían qué hacer con ese material: habían cavado un hoyo cerca de la chimenea de su casa, para enterrar dentro la placenta del bebé recién nacido. Este procedimiento es parte de la tradición indígena y parte de la idea de que, al enterrar la placenta cerca del fogón de la casa, se mantendrá el vínculo familiar y el calor de hogar con el bebé recién nacido, a más de evitar malos vicios en su futuro. Toda la familia puede ver y participar en el proceso del parto del bebé, en casa. Creo que estas costumbres o tradiciones han influido en la decisión de muchas mujeres indígenas, cuando han preferido el parto vertical en casa, en lugar de ir al hospital", opinó Matilde Farinango.

Mercedes Muenala, ${ }^{116}$ quien coordina el área de Salud Intercultural en la Dirección Provincial de Salud de Imbabura desde el año 2001, está interesada en promover los servicios de salud intercultural desde 1989, cuando cumplió con periodo de servicio rural en una comunidad indígena del cantón Riobamba, en el Centro de Salud Cacha.

\footnotetext{
${ }^{116}$ Ella estudió enfermería en la Universidad Técnica del Norte, en Ibarra, Ecuador.
} 
En esta comunidad Muenala atendió el parto de una mujer de 28 años, entonces pudo comprender por qué algunas mujeres indígenas no quieren recibir a sus bebés en un hospital, sino en su casa y con la ayuda de parteras".

"Yo había realizado estudios de medicina occidental (biomedicina), pero mi abuela fue partera y de ella aprendí conocimientos que me han permitido atender partos en posición vertical. A veces los indígenas quieren saber qué tipo de infusión pueden beber si ingieren ciertos fármacos", dijo Muenala.

\subsection{6.a) Descripción del trabajo de las parteras}

Durante el proceso parto, la atención de la partera implica varias acciones que dependen de las necesidades de la madre embarazada y del bebé. Con el fin de preparar a la mujer parturienta para el parto, la partera suele ofrecerle infusiones de varias plantas medicinales, como flor de alfalfa, raíz de ortiga o manzanilla.

Al momento del parto, es importante que el bebé esté colocado en posición vertical y con la cabeza hacia abajo; porque, de lo contrario, el parto podría complicarse. En tales casos, muchas parteras optan por referir a su paciente embarazada a un hospital.

Para la práctica del parto en posición vertical, la partera elige un lugar cálido y acogedor; a más de transmitir calor a la mujer embarazada mediante el uso de mantas, acercándolas a la chimenea u ofreciéndoles té o infusiones caliente.

Usualmente, para la práctica del parto vertical con parteras de Otavalo o de otros lugares del Ecuador, la mujer parturienta debe colocar su cuerpo en la siguiente posición: de rodillas o en cuclillas; debe apoyar sus brazos sobre algo que pueda sostener el peso de su cuerpo (puede ser una silla o una cuerda), y debe abrir sus piernas. En esa posición, la 
partera acaricia la cintura y el vientre de la mujer parturienta, mientras que el marido o pareja de ésta le apoya sosteniéndole sus brazos.

Cuando el bebé nace, la partera lo recibe mientras que la madre debe pujar con fuerza hasta expulsar la placenta de su cuerpo.

La atención que reciben las mujeres durante el parto vertical cumple, básicamente, una función ritual. El simbolismo que expresan esos ritos destaca la fuerza física y espiritual que tienen las mujeres en el proceso del parto, según algunas parteras entrevistadas. Por tanto, es importante destacar la función social que tienen las parteras y todos quienes participan en la medicina tradicional indígena.

\subsection{6.b) Razones para preferir la práctica del parto vertical ${ }^{117}$}

Durante un taller ofrecido en el Hospital Asdrúbal de la Torre de Cotacachi, el 28 de mayo de 2008, el médico español Leandro Prieto explicó algunas razones por las que es importante promover la práctica del parto vertical en el Ecuador.

“Según la OMS, las tasas de cesárea no deberían ser superiores al 10\% ó al 15\% de la cantidad total de trabajo. Sin embargo, en Ecuador la tasa de cesáreas es del $40 \%$ y, en los hospitales privados, incluso podría llegar al 60\%. Por lo tanto, Ecuador no está cumpliendo con las sugerencias de la OMS”, cuestionó Prieto.

En su criterio, las razones por la que es demasiado alta la tasa de cesáreas en el Ecuador son las siguientes: la desinformación de los pacientes y la impaciencia de muchos médicos que no quieren esperar para que los bebés nazcan por parto normal, sino que prefieren atender a más pacientes y ganar mucho más, a través del cobro por la práctica de cesáreas.

\footnotetext{
${ }^{117}$ Más información sobre las percepciones y argumentos de las mujeres indígenas, con respecto a su preferencia por la práctica del parto vertical en sus propias comunidades, pueden encontrarla en el Anexo 3.
} 
Prieto valora la práctica del parto vertical porque éste permite que el bebé nazca de forma más natural y porque se lo practica en un ambiente más acogedor, en relación a los hospitales; pues "éstos, generalmente, son lugares fríos y con iluminación inadecuada".

Este médico español critica el hecho de que en muchas clínicas y hospitales se prohíbe el acceso del padre o de otro familiar a la sala de parto; porque, en su criterio: "El parto debe realizarse en un entorno íntimo. Es un proceso en el que participan dos personas: la madre y el bebé. Por lo tanto, debemos respetar la forma en que las madres prefieren recibir a su bebé [...]. Debemos tratar de que el trabajo sea lo más natural posible y que sean menos las intervenciones médicas, en casos complejos".

Teniendo en cuenta la experiencia del Hospital San Luis de Otavalo, el Ministerio de Salud Pública del Ecuador está estudiando la posibilidad de aplicar esta práctica en otros hospitales, a nivel nacional. Esta propuesta se justifica por la idea de que "existe una alta tasa de mortalidad materno-infantil en el Ecuador, especialmente en las comunidades indígenas. Esa es la razón por la que debe buscarse estrategias que garanticen la salud de las personas [...]. El nacimiento no es una enfermedad", destacó el pediatra y director del Hospital San Luis de Otavalo, Javier Terán.

"Creo que es importante conquistar el espacio que originalmente se nos había negado [...]. Si somos un país pluricultural y multiétnico país, si tenemos conocimientos tan importantes, ¿por qué no aprovecharlos? ¿Por qué no aprovechar el conocimiento sobre la práctica del parto vertical en los hospitales?”, agregó Terán.

A partir de esta idea, Javier Terán decidió crear una "Sala de Parto Vertical" en el Hospital San Luis de Otavalo, con el apoyo del Ministerio de Salud Pública del Ecuador y del centro de salud Jambi Huasi. Esta sala fue inaugurada el 4 de abril de 2008. 


\subsection{6.c) El proceso de referencia y contra-referencia}

Matilde Farinango recuerda que cuando empezó a trabajar en el centro de salud Jambi Mascaric de Cotacachi, hace más de 10 años, el proceso de referencia y contra-referencia entre parteras y el hospital ya se estaba practicando. Sin embargo, las parteras consideraban inconveniente ese proceso para ellas, "porque tenían que ofrecer información sin recibir nada a cambio. Por eso hemos promovido también la contra-referencia de los profesionales de la biomedicina hacia los representantes de la medicina tradicional indígena”.

A partir de su experiencia laboral de cuatro años en la provincia de Pichincha, Matilde Farinango comentó que en esa provincia las parteras suelen entregar una especie de cupones de referencia a las pacientes parturientas, para que lo presenten en los hospitales con información sobre el control de su embarazo.

Para cumplir con el proceso de control y evaluación de las parteras, las autoridades del Ministerio de Salud Pública del Ecuador pidieron el apoyo de profesionales de la biomedicina, generalmente de enfermeras.

Pero a veces surgen problemas, según Farinango, cuando los pacientes no ubican en el hospital a una persona que acepte recibir los cupones de referencia, o cuando los profesionales biomédicos no aceptan referencias de otras personas. "Esto se debe a que hay algunos médicos occidentales (biomédicos) que no aceptan los diagnósticos realizados por personas que practican la medicina tradicional indígena; eso también ocurre con algunos yachak que afirman poder curar todo tipo de enfermedades, por lo que prefieren no referir sus pacientes a hospitales", comentó el médico Javier Terán. Él recuerda que mientras trabajó en Jambi Huasi (hace más de 4 años), tuvo una buena relación con los demás miembros del equipo y que, en varias ocasiones, practicó el proceso de referencia y contrareferencia con el herbolario Vidal Sánchez (quien dejó el centro de salud hace 8 años). 
Esta visión positiva del proceso de referencia y contra-referencia, en la práctica de Jambi Huasi, fue confirmada por la psicóloga Azalia Vásquez, ${ }^{118}$ quien dijo: "Los dos modelos de salud se complementan a menudo en Jambi Huasi. Creo que en ese centro no hay discordia entre los dos modelos de salud; porque, si un profesional de la medicina convencional (biomédico) se da cuenta de que un paciente necesita atención espiritual, él o ella recomiendan al paciente visitar a un representante de la medicina tradicional indígena".

Ella comenta que a veces los pacientes acuden con problemas físicos al centro de salud Jambi Huasi, pero "si el profesional biomédico nota que causas emocionales están afectando el estado físico del paciente, le sugiere al consultar al yachak, y viceversa".

Matilde Farinango tiene una opinión diferente: "sobre el proceso de referencia y contrareferencia se ha dicho demasiado. En la práctica, es muy raro que ocurra la contrareferencia (del profesional biomédico al representante de medicina tradicional indígena)". En su criterio, es más común la referencia de pacientes atendidos por representantes de la medicina tradicional indígena hacia la biomedicina, que de la biomedicina hacia la medicina tradicional indígena. Esta situación sólo podrá cambiar a partir de la confianza, el reconocimiento y la valoración de los diferentes tipos de conocimiento.

\subsubsection{Reconocimiento de los profesionales de la medicina tradicional indígena}

Matilde Farinango considera positivo el hecho de que, en Ecuador, varias instituciones estén respaldando el proceso de parto vertical. Con el apoyo de varios organismos, la Dirección Nacional de Salud de los Pueblos Indígenas (DNSPI) elaboró la "Guía Técnica para la atención del Parto culturalmente adecuado", publicada en agosto de 2008.

\footnotetext{
${ }^{118}$ Ella trabaja durante más de dos años en el centro de salud Jambi Huasi. Comenzó a trabajar como médico residente y ahora trabaja a tiempo parcial, con previa cita, cuando un paciente solicita ayuda psicológica.
} 
Para analizar el proceso de certificación de las parteras, y su incorporación en el sistema de salud formal del Ecuador, se llevó a cabo un taller en el Hospital San Luis de Otavalo, del 2 al 4 de julio de 2008. A esta reunión asistieron técnicos de la DNSPI (entre ellos, Matilde Farinango), del Consejo Nacional de Salud (CONASA), de la Dirección Provincial de Salud de Imbabura, entre otras organizaciones.

A finales de julio de 2008 se convocó a otra reunión para analizar el reconocimiento y respaldo de varias comunidades al trabajo de las parteras.

\subsection{7.a) Código de ética y análisis del trabajo de los yachak}

Según la directora de Jambi Huasi, Myriam Conejo, el Área de Salud Intercultural de la Dirección Provincial de Salud de Imbabura tiene una gran debilidad: "en esa área aún no se ha identificado ni se ha acreditado a los auténticos yachak".

En 1999, la Constitución del Ecuador aprobó el ejercicio de la medicina tradicional indígena. "Sin embargo, como paso previo, se debió haber hecho un registro y se debió acreditar a quienes son auténticos representantes de este conocimiento y lo practican. Como no hay registro, algunas personas que desconocen del tema están engañando a varios pacientes. Los falsos promotores de la medicina tradicional indígena han desacreditado a quienes realmente saben de esta práctica”, comentó Myriam Conejo.

En su opinión, a veces es contraproducente promover la medicina tradicional indígena, porque muchas personas que no saben del tema están tomando ventaja de la ingenuidad de algunos pacientes y turistas.

Matilde Farinango no comparte esa crítica, pues dice que el Ministerio de Salud Pública del Ecuador, a través de la Dirección Nacional de Salud de los Pueblos Indígenas, ha 
desarrollado actividades y proyectos para evaluar el trabajo de las parteras, yachak, fregadores, jakug y otros representantes de la medicina tradicional indígena.

"El problema no ha sido incluirlos, sino promover su participación como una contribución o complemento al sistema de salud formal. En algunas provincias del Ecuador no se acepta el aporte de los yachak dentro de los servicios de salud oficiales, pues lo consideran contrario a sus conocimientos", dice Matilde Farinango.

Ella confía en que se pueda superar esos obstáculos luego de que se apruebe el Código de Ética referente a la práctica de la medicina tradicional indígena. Para la elaboración de ese Código, la Dirección Nacional de Salud de los Pueblos Indígenas organizó talleres regionales en el Ecuador, con apoyo de otros organismos e instituciones de salud.

\subsubsection{Discusión sobre la investigación empírica}

Necesidades sociales insatisfechas, conflictos y aspiraciones diarias -pero, especialmente, las precarias condiciones de vida y el aumento de la pobreza- han sido factores clave para la movilización social y la organización de los indígenas Kichwa de Otavalo, en Ecuador. Esas también fueron causas que motivaron la fundación del centro de salud Jambi Huasi, por parte de la Federación Indígena y Campesina de Imbabura (FICI), en 1983.

En el contexto de los países andinos, el pluralismo médico ha sido un tema bien documentado y muy debatido en la literatura antropológica. A partir de esta literatura, en esta investigación se optó por el enfoque de la Antropología Médica Crítica, porque éste analiza los temas de salud en el contexto de las fuerzas políticas y económicas que influyen en las relaciones humanas, en las formas de comportamiento social, en las condiciones de 
experiencias colectivas, en el reordenamiento de ecologías locales y en significados culturalmente situados; incluidas las fuerzas a escala institucional, nacional y mundial.

La Antropología Médica Crítica reconoce que las pautas del pluralismo médico tienden a reflejar las relaciones jerárquicas de la sociedad en general.

Esta investigación también ha combinado una perspectiva de política económica con un enfoque simbólico; porque el significado de la medicina tradicional indígena no puede considerarse al margen de la relación socioeconómica y política de la vida cotidiana.

Hace más de 10 años, el Ministerio de Salud Pública del Ecuador inició un proceso para reconocer y promover la incorporación de las perspectivas, medicamentos y terapias indígenas en los programas nacionales de salud. Por tal razón, en 1999, este Ministerio creó la Dirección Nacional de Salud de los Pueblos Indígenas. También se ha incorporado los conocimientos y prácticas de la medicina tradicional indígena en las reformas del Código de la Salud; así como el enfoque intercultural, en los artículos de la ley del CONASA.

En la relación médico-paciente, la empatía que se desarrolla desde una profunda preocupación por las exigencias de la vida cotidiana ha caracterizado la eficiencia del encuentro de pacientes con practicantes de la medicina tradicional indígena, en Jambi Huasi. A partir de observaciones y de entrevistas realizadas en Jambi Huasi se constató que, en este centro de salud, la relación entre médico y paciente es generalmente amable y no discrimina a personas por su etnia o clase social. No obstante, un gran problema de la biomedicina en el Ecuador ha sido la actitud discriminatoria o de subestima con la que muchos profesionales biomédicos atienden a pacientes indígenas en hospitales, clínicas o centros de salud. 
La demanda de la población indígena, de tener más acceso a los servicios del sistema de salud formal, no sólo exige ampliar esa cobertura; sino también mejorar la calidad de esos servicios para ofrecer buen trato y respeto a la diversidad cultural.

Para la mayoría de indígenas entrevistados el concepto de salud no significa ausencia de dolor o enfermedad, sino que supone una buena relación del individuo con la familia, con la comunidad y con la naturaleza. En otras palabras, para la población indígena Kichwa de Otavalo, estar en buena salud significa experimentar el Sumak Kausay (palabra kichwa que significa "Buen vivir"). La comprensión y el respeto a esta visión es una de las principales características de la medicina tradicional indígena.

Para la mayoría de personas entrevistadas en Jambi Huasi, hablar de interculturalidad en salud supone la búsqueda del Sumak Kausay en los pacientes, con la contribución de dos sistemas de salud: de la biomedicina y de la medicina tradicional indígena.

Para analizar el tema de salud intercultural, en esta investigación se ha considerado la definición de A.M. Oyarce (2004). Ella entiende la interculturalidad en salud como la capacidad de moverse entre conocimientos, entre diferentes creencias y prácticas culturales relacionadas con salud y enfermedad, vida y muerte; el cuerpo biológico, social y relacional.

En países multiétnicos y multiculturales, como Ecuador, la medicina intercultural es un proceso continuo de transacciones, lo que genera gran cantidad de cambios, ajustes e intercambios a nivel técnico, teórico e ideológico.

La mayoría de personas entrevistadas durante el trabajo de campo utilizaron el concepto de salud intercultural para explicar la relación paralela, con la que se ofrecen los conocimientos y prácticas de la biomedicina y la medicina tradicional indígena, en el centro de salud Jambi Huasi. 
A partir del análisis de los datos provenientes del trabajo de campo y de la revisión bibliografía, se propuso reformular la pregunta principal de investigación, de la siguiente manera: ¿De qué manera el concepto de "salud intercultural” permite comprender la forma en que se relacionan diferentes conocimientos / prácticas de la biomedicina y la medicina tradicional indígena, en el centro de salud Jambi Huasi?

El análisis que inspira la respuesta a esta pregunta conduce a una nueva interrogante: ¿Se ha tornado híbrida la relación entre la biomedicina y la medicina tradicional indígena, en la práctica de la atención de la salud que proporciona el centro Jambi Huasi?

Para responder a estas preguntas es necesario revisar la sección 6.3. del presente capítulo, sobre todo la parte referente a la investigación realizada por el antropólogo mexicano Steffan Ayora, quien concibió el término "híbrido" como un producto de las relaciones de poder que no desaparecen con la mezcla, sino que se mantienen y reproducen.

En diferentes sistemas médicos lo "híbrido" se expresa en la articulación y en las mezclas de los imaginarios que definen cada forma de conocimiento y de práctica médica. Por lo tanto, el concepto de "híbridos culturales" se ubica entre dos polos; en cuanto a los servicios de Jambi Huasi, ese concepto alude a la relación que se mantiene entre la biomedicina y la medicina tradicional indígena.

Esta relación se constató al emplear la técnica de observación en la práctica de los servicios de atención primaria del centro de salud Jambi Huasi. En este centro, la relación entre biomedicina y conocimiento local (medicina tradicional indígena) está reproduciendo el poder de la biomedicina; porque, en la práctica, el marco de significado "moderno" o "biomédico" se ha vuelto más importante que el conocimiento local. 
El uso del término "hibridación" se sustenta en el análisis que desarrolló el antropólogo mexicano Steffan Ayora en su etnografía Globalización, conocimiento y poder: médicos locales y sus luchas por el reconocimiento en Chiapas (Ayora, 2002).

Con respecto al término "salud intercultural”, el epidemiólogo Jaime Breilh considera un gran problema si este concepto se limita para hablar únicamente sobre aspectos curativos de los sistemas médicos.

$\mathrm{Al}$ analizar la relación entre biomedicina y medicina tradicional indígena, Breilh aclara que él prefiere hablar de horizontalidad en las relaciones, por eso prefiere utilizar el término “construcción intercultural del conocimiento". Para el efecto, se sustenta en el análisis que promueve la unificación de dos enfoques: 1) el pensamiento crítico en las ciencias sociales —antropología, economía, sociología y ciencias sociales aplicadas a la salud- y 2) el pensamiento indígena crítico.

Según el investigador Raúl Mideros, "a veces el uso del término salud intercultural sigue siendo el membrete de la subordinación a prácticas o estrategias de la biomedicina". Por tanto, a menos que haya una real valoración de la diversidad de conocimientos y prácticas que caracterizan a la biomedicina y a la medicina tradicional indígena, él no cree posible la interculturalidad en salud.

En el ámbito de la salud, Mideros dice que la interculturalidad no debe ser interpretada como un modelo, sino como el intersticio donde la cultura dominante y la cultura subordinada están presentes. Porque, en su opinión, la interculturalidad no se presenta como algo estructurado, sino más bien como un juego, como un escenario donde el paciente tiene la opción de elegir entre varias alternativas. 
Esta opinión se aplica al caso de Jambi Huasi, porque el personal de este centro de salud no está trabajando para crear juntos, como equipo, una nueva opción de atención de la salud; sino para ofrecer diferentes alternativas de atención médica en un mismo lugar.

Todos los médicos y jambigkunas que fueron entrevistados durante el trabajo de campo, correspondiente a esta investigación, dijeron estar de acuerdo con la propuesta de salud intercultural. Sin embargo, algunos de ellos cuestionaron la presencia de representantes de la biomedicina y la medicina tradicional indígena en una misma área; por ejemplo, en hospitales o centros de salud, como es el caso de Jambi Huasi.

Para analizar la situación de Jambi Huasi, podría ser muy revelador considerar la dinámica de metropolización de la ciudad de Otavalo; porque ello puede servir de referencia para ilustrar cómo un servicio de atención en salud pone de manifiesto aspectos cruciales de la cultura Kichwa, donde se desconoce el límite entre el folklore y los aspectos ancestrales.

Por tanto, si analizamos la práctica de reproducción de aspectos ancestrales en la ciudad de Otavalo y, en particular, en el centro de salud Jambi Huasi, una interesante pregunta de investigación podría ser: ¿cuál es el límite entre la reproducción de aspectos ancestrales y el folclore que se reproduce con fines comerciales?

Para responder a esta pregunta, el investigador Raúl Mideros propone analizar a profundidad cómo, en la cultura kichwa de Otavalo, la producción de artesanías y el comercio permiten entender, de forma paralela, las características de producción y el comercio de símbolos y productos tangibles e intangibles. El centro Jambi Huasi es un lugar interesante para aplicar el estudio de caso sobre el tema.

Entender este contexto nos permitirá comprender las características de la relación entre biomedicina y conocimientos locales en Jambi Huasi, para entender qué tipo de proyecto se 
está desarrollando en este centro de salud, o para revelar cuál es el trasfondo de esas relaciones en la práctica.

Sería importante considerar ese análisis en futuras investigaciones o la redefinición del término "indígena", así como la influencia de varias organizaciones en el diseño y ejecución de proyectos de salud, lo que podría examinarse a través de un estudio sobre el denominado "conocimiento indígena". 


\section{CAPÍTULO 7}

\section{CONCLUSIONES}

La comunicación pública y masiva de la ciencia es una actividad relativamente nueva, que no tiene aún una estructura definida. Por ello, muchas veces se la malinterpreta o se la degrada, aunque también ello le otorga flexibilidad y dinamismo. La experiencia es todavía incipiente y puede decirse que está casi todo por hacerse. (Manuel Calvo Hernando)

La ciencia y la tecnología tienen un cometido social y, para cumplirlo, es necesario que el público general comprenda sus procedimientos, resultados y efectos; que asuma una conciencia cívica y que participe en la toma de decisiones con respecto a esos temas.

De esta manera se espera fomentar mayor cultura científica en el público general; este es uno los principales desafíos de la Comunicación Pública de la Ciencia y Tecnología (CPCT): aportar para que haya una visión más crítica, más participación ciudadana y más transparencia en la toma de decisiones sobre temas científicos y tecnológicos.

El principal objetivo de esta Tesis ha sido ofrecer información que contribuya a mejorar las políticas científicas del Ecuador y el fortalecimiento de su "Sistema Nacional de Ciencia, Tecnología, Innovación y Saberes Ancestrales", a partir de estudios de Comunicación Pública de la Ciencia y la Tecnología (СРCT) y de Antropología Médica. 
Para analizar la aplicabilidad del mencionado Sistema en el Ecuador, se optó por investigar la relación entre los conocimientos y prácticas provenientes de la biomedicina y la medicina tradicional indígena, en el centro de salud Jambi Huasi de Otavalo, Ecuador.

En el Capítulo 6 se detallan las características y resultados de esta investigación empírica, cuyo desarrollo guarda coherencia con el título general de esta tesis: "La comunicación pública de la ciencia en el centro de la política científica”. Porque, aplicando estudios de Comunicación Pública de la Ciencia y Tecnología, y de Antropología Médica, esta investigación ha puesto de manifiesto un gran problema que evita la eficiencia de la política científica y, por tanto, la consolidación del "Sistema Nacional de Ciencia, Tecnología, Innovación y Saberes Ancestrales” del Ecuador (el cual fue aprobado en septiembre de 2008).

A partir de esa investigación empírica se concluye que la falta de comunicación, o problemas de incomunicación, han impedido que haya buenas relaciones entre los profesionales biomédicos, los representantes de la medicina tradicional indígena y los pacientes del centro de salud Jambi Huasi, de Otavalo, Ecuador.

Problemas provenientes de la falta de comunicación en ciencia y tecnología motivaron el planteamiento inicial de esta tesis. Un reto de la denominada CPCT es eliminar la discordia entre los lenguajes científico y popular. Para lograrlo, se necesitan personas creativas, que estén en constante aprendizaje y capacitación; no solo para que expongan la ciencia en un lenguaje claro y sencillo, sin perder rigurosidad, sino también para que cumplan con su triple responsabilidad: informar, explicar y facilitar la comprensión de la ciencia.

Acierta Manuel Calvo Hernando al decir que uno de los mayores aportes de los comunicadores sociales es el estudio del proceso de comunicación de la ciencia; porque, en la práctica, es fundamental considerar la capacidad de recepción que tienen los diversos 
públicos a los que se destina esta actividad. Por tanto, conviene analizar los parámetros que rigen la creación de la terminología científica y la forma como evoluciona ésta, en el empleo que le dan sus diferentes usuarios: la comunidad científica, los estudiantes e iniciados en la ciencia, y el gran público.

A través de esta tesis se propone impulsar la aplicación de un Programa Nacional de Comunicación Pública de la Ciencia y la Tecnología, elaborado a partir de un enfoque sociocultural y con proyección de elevarlo al nivel de política de Estado.

En esta Tesis también se destaca el aporte de las narrativas al fomento de la cultura científica y tecnológica. Tuvo razón Carl $\operatorname{Sagan}^{119}$ al rechazar la idea de que la ciencia es secreta por naturaleza y al optar por divulgarla. Porque, con esta labor, se tiende a fortalecer la democracia, a suprimir la microfísica del poder, ${ }^{120}$ y a conquistar el ideal que Stephen Hawking describió de la siguiente manera:

Si descubriéramos una teoría completa del Universo, tendría que ser comprendida, con el tiempo, en sus principios básicos por todos; no solo por unos pocos científicos. Entonces todos: los filósofos, los científicos y la gente común, podríamos ser capaces de tomar parte en una discusión acerca de por qué existimos nosotros y el Universo. Si encontráramos la respuesta a eso, sería el triunfo final de la razón humana; porque, entonces, conoceríamos la mente de Dios. $^{121}$

\footnotetext{
${ }^{119}$ Carl Sagan fue el divulgador científico de mayor reconocimiento mundial en los últimos años. Descubrió en la ciencia el camino hacia la verdad y hacia la democracia, por eso la consideró "una luz en la oscuridad". Hasta el fin de sus días, persistió en el afán de compartir al mundo los aciertos y problemas de la ciencia. La idea que de él se cita consta en su obra más personal, que titula El mundo y sus demonios, 10a reimpresión, México, Editorial Planeta, 2001.

120 Término empleado por Michel Foucault, para referirse al poder que genera el monopolio del conocimiento.

${ }^{121}$ Fragmento del reportaje televisivo que transmitió el programa La Televisión en Ecuador, en agosto de 1993. El reportaje abordó la vida y el aporte científico del físico Stephen Hawking. (Título del reportaje en
} 
El vertiginoso avance de la ciencia dificulta la permanente actualización de los programas de estudio en el sistema de educación formal; además, no todos pueden costearse esta formación. Por eso es importante abrir espacios de educación no formal, con el fin de ampliar y de actualizar el aprendizaje sobre temas científicos. Para que la gente aprenda de manera no arbitraria ni lineal, se recomienda aplicar la Teoría del aprendizaje significativo de David P. Ausubel, que enfatiza el proceso de cognición con una perspectiva constructivista.

Es necesario que la enseñanza se adapte al incremento de conocimientos; pero sin que ello implique la segregación entre estudios científicos y literarios. De acuerdo con la propuesta de Ana María Sánchez Mora, la buena divulgación escrita tiene más nexos con la literatura que con la ciencia. De ahí que sugiera la ejercitación de los divulgadores en el uso de recursos literarios, y en la aplicación de la Teoría de la Recepción, para lograr textos más creativos, interesantes y entretenidos.

La mayoría de estudios que se han realizado sobre popularización, vulgarización, divulgación científica o CPCT reflejan la carencia de un método que comprenda la ciencia, las ideas y la sociedad en su conjunto. Superar esta limitación es lo que se propone Rolando Isita Tornell con su modelo denominado Propaganda científica.

Para comunicar públicamente la ciencia, las narrativas (cine, novela) cumplen un papel fundamental, porque cubren la función paradigmática, la macroestructura del imaginario; mientras que las noticias sólo cubren una función de relleno (microestructuras). Esta premisa se confirmó luego de realizar el análisis de contenido a una muestra representativa

inglés: A Brief History of Time, Inc., UK, 1991; Anglia Television Ltd. / Gordon Freeman Production, UK, 1992; Globus Comunicación, S.A., Madrid, 1993). 
de los programas de televisión vistos por el público infantil de España. El objetivo de esta investigación fue determinar el imaginario de CYT que han promovido esos programas de televisión, para sustentar el diseño de un mejor currículum cultural y mediático de ese medio de comunicación.

Coincido con los autores del Informe Pigmalión en que es necesario comprender a los niños como un nuevo y renovado diseño humano, para ayudarles a realizar su propia construcción personal de la mejor manera posible; salvaguardando lo mejor del pasado, ayudándoles a apropiarse de lo mejor del futuro, defendiéndoles en lo posible de los ataques de mutaciones destructivas.

El acceso del público general al conocimiento científico y tecnológico debe mejorarse tanto desde el sistema educativo formal como del no formal. Pero, en tanto se consiga incluir en el Sistema Nacional de Educación las reformas necesarias, conviene promover la creación de un modelo de CPCT que valore la diversidad cultural desde un enfoque sociocultural.

Tres conclusiones que expuso el mexicano Luis Estrada Martínez, y que amerita destacar, son: 1) La urgencia de consolidar lo logrado, a fin de contar con una base firme para que pueda continuar la divulgación de la ciencia. 2) Advertir que una causa importante de problemas en la divulgación de la ciencia es el escaso valor que se da a ésta en los medios académicos. En ellos casi no se le asigna valor curricular; por eso muchos científicos aseguran que divulgar es quitar un tiempo valioso a la investigación. 3) Reconocer que, por ahora, el futuro es incierto para quien quiera ser divulgador profesional. Porque la mayor parte de la divulgación se realiza de manera gratuita, por lo que muchos esperan que esta situación cambie. (Estrada, 1992: 69-76). 
La mayoría de proyectos diseñados para comunicar la ciencia al público siguen modelos de tipo asimétrico, como el de déficit o el de difusión (Lewenstein, 2003); pero éstos resultan limitados, pues analizan la comunicación como un proceso de recorrido unidireccional (que va desde el científico hacia el público), consideran neutra la información que transmiten e ignoran las características culturales de sus actores. Y esta omisión es una de las principales causas que dificultan la comunicación entre científicos y público general.

Si aceptamos que el diálogo deberá ser cultural, conviene reformular el modelo tradicional, unidireccional, de comunicación, y proponer uno más completo, desde una perspectiva sociocultural que contemple las articulaciones entre las formas de organización de la sociedad, las mediaciones socio-económicas y las prácticas discursivas de la ciencia y de su divulgación.

Por tanto, uno de los principales aportes de esta Tesis ha sido analizar y proponer la aplicación de un "modelo democrático" de Comunicación Pública de la Ciencia y la Tecnología, adecuado a la realidad de los países de Iberoamérica y sustentado desde un enfoque sociocultural.

Hay que recuperar el equilibrio entre el saber hacer científico-tecnológico y el saber qué hacer humano, de modo que este equilibrio guíe la toma de decisiones en materia de ciencia y tecnología.

Para que la ciencia y la tecnología aporten al fomento de la conciencia cívica -y cumplan, por tanto, con su cometido social-, hay que impulsar estudios de CPCT desde un enfoque sociocultural, que contemple en su análisis las siguientes categorías: institucionalización, mediaciones y agentes sociales que intervienen en ese proceso de comunicación. 
Conviene, por tanto: 1) superar la escisión entre ciencias y humanidades, 2) valorar y reforzar el aporte de las ciencias sociales al estudio de la СРCТ y 3) promover análisis interdisciplinarios en torno al tema. Porque, sólo el diálogo abierto permitirá superar los obstáculos que dificultan la comunicación entre científicos y público general

El análisis desarrollado en esta Tesis confirma la necesidad de reavivar el debate sobre los fines y los medios de la СРCT. Porque, la ausencia de este debate supone el riesgo de ver impuesto el modelo de comunicación más conocido: el del déficit. Lo ideal sería adoptar un modelo de comunicación interdisciplinario, que considere el aporte del enfoque sociocultural. Propongo que se adopte un modelo interdisciplinario, desde una perspectiva sociocultural, que impulse el fomento de la cultura científica, la participación ciudadana y la transparencia en la toma de decisiones sobre temas científicos y tecnológicos. Es necesario considerar las siguientes categorías: institucionalización, mediaciones y agentes sociales que interviene en el proceso de Comunicación Pública de la Ciencia y la Tecnología (CPCT).

También es necesario institucionalizar la CPCT para garantizar su adecuación al progreso científico y tecnológico, y para promover una relación más cercana y permanente entre la sociedad, la comunidad científica y las autoridades encargadas de establecer las políticas públicas. Este objetivo podría lograrse con la ejecución de un Programa Nacional de Comunicación Pública de la Ciencia y la Tecnología.

Concibo a este Programa como el conjunto de acciones tendentes a compartir los conocimientos científicos con el público general, para motivar su participación en las decisiones que se adopten sobre ciencia y tecnología, para avivar su conciencia cívica. Esta idea ha conllevado a que varios países (de la Comunidad Europea, Estados Unidos, Japón, México, entre otros) asuman la CPCT como un tema de prioridad nacional. 
Pocas son las investigaciones que aportan al estudio de la política científica y de la CPCT desde un enfoque sociocultural y, hasta ahora, ninguno ha hecho énfasis en la región de Iberoamérica. Este es el valor agregado que ofrece esta Tesis, a más de que expone estrategias de educación no formal, la propuesta de divulgar la ciencia como literatura, una buena aplicación del modelo de propaganda científica y la promoción de un mejor diseño cultural y mediático de la TV, que resulte útil para la enseñanza y difusión de temas científicos y tecnológicos. La aplicación de estas alternativas podría conllevar al mejoramiento de la CPCT en el Ecuador y en más países de Iberoamérica.

Para mermar la dificultad en la comprensión del lenguaje científico, su comunicación requiere de personas que estén en constante aprendizaje y capacitación; no sólo para que presenten la ciencia en un lenguaje menos denso, sino también para que cumplan con su triple responsabilidad de informar, explicar y fomentar la cultura científica.

También es necesario elaborar políticas públicas en ciencia y tecnología destinadas a fortalecer de forma económica, legal e institucionalmente el "Sistema Nacional de Ciencia, Tecnología, Innovación y Saberes Ancestrales"; para impulsar investigaciones que ayuden a solucionar los principales problemas que afectan al país. Esta propuesta cobró relevancia hace un año en el Ecuador, por eso soplan vientos de renovación y esperanza para la ciencia y la tecnología en este país.

Hay que ampliar el apoyo económico destinado a la investigación en ciencia y tecnología; porque, en la mayoría de países de la región esta inversión no supera el 1\% del PIB. También conviene superar la falta de capacitación y de formación de recursos humanos, en el ámbito científico y tecnológico. Para que estas iniciativas perduren con el tiempo, lo ideal es plantearlas al nivel de política de Estado; a este nivel conviene elevar también el Programa Nacional de CPCT propuesto en el presente trabajo. Este Programa 
debe impulsar actividades de CPCT con apoyo del sistema educativo, de la comunidad científica, de los medios de comunicación y de corporaciones culturales locales. Aunque en Ecuador se están cumpliendo varias de las actividades sugeridas, con auspicio de SENACYT, aún queda mucho trabajo por hacer en varias provincias ecuatorianas.

Por tanto, en el Ecuador, es necesario analizar y evaluar la evolución de las actividades de CPCT destinadas al fortalecimiento del "Sistema Nacional de Ciencia, Tecnología, Innovación y Saberes Ancestrales".

Con respecto a este tema, cabe recordar que los contratos sociales sobre la ciencia se hallan ligados a los modelos de producción del conocimiento, pero también a modelos de comunicación de la ciencia. Como bien lo señaló Mónica Lozano: "Mientras el viejo contrato social se desenvuelve en el contexto de un modelo lineal de producción de conocimiento, y con la preponderancia de un modelo de déficit en la comunicación; el nuevo contrato social se desenvuelve en un modelo complejo de producción de conocimiento y promovería la importancia de un modelo democrático en la comunicación" (Lozano, 2008:15). A lo largo de esta tesis se comparte la propuesta de implantar un modelo democrático de Comunicación Público de la Ciencia y Tecnología, en lugar de limitarse a reproducir las limitaciones que supone la aplicación del modelo de déficit en esa comunicación.

También conviene poner en práctica los cuatro retos que propuso Lozano (2008:1) a la CPCT en países latinoamericanos: (1) la necesidad de tener una mirada crítica a los problemas de exclusión social; (2) su participación en la definición de los problemas sociales y en la promoción de la participación pública en ciencia y tecnología; (3) la inclusión de una perspectiva desde las políticas públicas en ciencia y tecnología, y (4) la necesidad de una redefinición conceptual de la comunicación de la ciencia. 
El cumplimiento de estos retos permitirá consolidar la democracia y aportar al objetivo de la educación para toda la vida, en el contexto de los países de América Latina. En el caso del Ecuador, conviene considerar el análisis de temas que podrían resultar polémicos, o generar dilemas, en el marco del "Sistema Nacional de Ciencia, Tecnología, Innovación y Saberes Ancestrales". Uno de esos temas suele ser la relación existente entre diferentes modelos de salud y las percepciones de los pacientes, al momento de elegirlos. Por tal motivo se justifica la aplicación de estudios de CPCT y de Antropología Médica, para el análisis del tema escogido en la investigación empírica que se presenta en el Capítulo 6.

En la mencionada investigación, se comprobó que hay claras diferencias de opinión con respecto a la forma en que la biomedicina y la medicina tradicional indígena están relacionadas. Algunas personas entrevistadas el centro de salud Jambi Huasi creen que hay colaboración, mientras que otros perciben un proceso de subordinación o incorporación de la medicina tradicional indígena al sistema hegemónico biomédico. Con el fin de explicar estas opiniones, conviene contrastar puntos de vista sobre lo que está sucediendo en Jambi Huasi (en Otavalo, Ecuador).

En todas las entrevistas aplicadas en este centro de salud, del 21 de mayo al 8 de julio de 2008, destacó la idea de que en Jambi Huasi los conocimientos y prácticas de la biomedicina y la medicina tradicional indígena coexisten, y son utilizados de forma alternativa y simultánea por indígenas y mestizos.

Autoridades y empleados del centro de salud Jambi Huasi dicen que las diferencias entre la biomedicina y la medicina tradicional indígena deben ser superadas. Ellos confían en que la creación de este centro de salud está ayudando a superar los problemas de entendimiento entre médicos y jambigkunas (personas que saben y practican la medicina tradicional indígena). 
Pero, en la práctica, el diálogo de conocimientos y prácticas provenientes de la biomedicina y la medicina tradicional indígena ha sido muy limitado en Jambi Huasi. Esta idea fue confirmada por el investigador Raúl Mideros, quien dice que en Jambi Huasi los prejuicios han sido insuperables, cuando se trata de defender la validez de cada uno de los modelos de salud. En su opinión, en Jambi Huasi el camino está lleno de buenas intenciones y de muchos obstáculos, como la diferencia en el idioma.

Todos los médicos y jambigkunas (yachak, parteras o mamahuas, jakug y fregador), que fueron entrevistados durante el trabajo de campo están de acuerdo con la propuesta de salud intercultural. Sin embargo, muchos de ellos cuestionaron el hecho de que representantes de la biomedicina y la medicina tradicional indígena trabajen en un mismo lugar, como hospitales o centros de salud.

El proceso de "referencia y contra-referencia" es una de las prácticas que ha promovido el centro de salud Jambi Huasi, para consolidar la relación de diálogo, respeto mutuo y valoración entre profesionales biomédicos y jambigkunas (o representantes de la medicina tradicional indígena). En la práctica, este proceso ha sido más eficaz en la práctica del parto vertical, que ha sido muy respaldada en Otavalo.

El 4 de abril de 2008 fue inaugurada una "Sala de Parto Vertical" en el Hospital San Luis de Otavalo. A partir de esta experiencia, técnicos del Ministerio de Salud Pública del Ecuador, del Consejo Nacional de Salud (CONASA) y de otras organizaciones de salud trabajaron juntos para desarrollar la "Guía Técnica para la atención del Parto culturalmente adecuado”. La presentación oficial de esta Guía fue en agosto de 2008.

A pesar de esas propuestas, muchas personas entrevistadas cuestionaron la falta de criterios para evaluar y acreditar el trabajo de quienes conocen y practican la medicina 
tradicional indígena. Por la falta de criterios, varios charlatanes ofrecen sus servicios bajo el lema de "medicina tradicional indígena", lo cual contribuye a desacreditarla.

Para superar este problema, el Ministerio de Salud Pública del Ecuador está organizando talleres y reuniones para promover el desarrollo de un "Código de Ética", con el objetivo de analizar, evaluar y regular el trabajo de personas dedicadas a la medicina tradicional indígena. Estos talleres se están llevando a cabo en varias provincias del Ecuador, especialmente en Otavalo.

Aunque son varios los sistemas de clasificación que han ideado antropólogos, para reconocer la diversidad de sistemas médicos en sociedades complejas, la medicina tradicional indígena que se practica en el centro de salud Jambi Huasi aún no está reconocida como Sistema Médico Complejo (según los criterios propuestos por Madel T. Luz). Pero un grupo de investigadores de la Universidad Andina Simón Bolívar, sede Ecuador, junto a investigadores de otras instituciones América Latina, están analizando la posibilidad de reconocer a la Medicina Andina Amazónica como Sistema Médico Complejo. Diferentes técnicas de diagnóstico y tratamiento de la medicina tradicional indígena, que se practica en Jambi Huasi, podrían formar parte de la denominada Medicina Andina Amazónica.

Al igual que en otros países, en Ecuador la biomedicina ha tenido más prestigio que la medicina tradicional indígena, en el contexto de la gente blanca o mestiza; mientras que la medicina tradicional indígena ha sido especialmente preferida por poblaciones indígenas. Pero esta preferencia ha cambiado con el tiempo. Ahora, en el centro de salud Jambi Huasi, son cada vez más los pacientes indígenas que solicitan la atención de profesionales biomédicos y más los pacientes mestizos que solicitan los servicios provenientes de la medicina tradicional indígena. 
Otra razón por la cual la medicina tradicional indígena está ganando más adeptos en la población mestiza es por su menor costo; porque su diagnóstico y tratamiento cuesta menos que en lo correspondiente a la biomedicina. Además, el uso de la medicina tradicional indígena promueve más participación del paciente, que en la biomedicina, y de alguna manera encarna ideologías sobre la diversidad cultural del Ecuador.

Para comprender la causa de esta preferencia, es importante considerar que la selección de un particular sistema médico puede interpretarse como una crítica de dominio al sentido de nosotros mismos, infundido con enorme poder y plagado de diferentes caminos de acceso a la riqueza material y no material. Libbet Crandon Malamud analizó esta idea a partir de una investigación que desarrolló en Bolivia. En Otavalo, Ecuador, la selección de varias alternativas médicas muestra la aplicación de esa idea y también refuerza una de las principales conclusiones de Crandon Malamud: que la curación es sólo uno de los muchos objetivos o resultados de la elección médica.

En el centro de salud Jambi Huasi ha sido escasa la sistematización de experiencias, debido a que anualmente cambian algunos profesionales biomédicos, sobre todo quienes trabajan en medicina general, pues cumplen sólo un año de servicio rural en ese centro de salud. Por tanto, cada año Jambi Huasi debe vivir una experiencia nueva, al intentar implicar a los nuevos profesionales biomédicos en el esfuerzo por combinar sistemas médicos para lograr lo que el médico Javier Terán denominó “transferencia de conocimientos". Por ello, en Jambi Huasi la transmisión de conocimientos sigue siendo unidireccional.

Cuando la intervención del médico no se conecta con el discurso esperado por un paciente (porque ellos no se comunican en la misma lengua, o porque el médico tiene dificultades para explicar su diagnóstico o tratamiento); entonces pueden surgir conflictos o 
disonancias. Esta es una de las principales razones por las que, durante siglos, algunos indígenas han preferido buscar los servicios de la medicina tradicional indígena, con personas de su propia cultura.

Si se promueve la idea de que el diálogo entre personas de diferentes culturas llegue a ser intercultural, entonces conviene reformular el tradicional modelo de comunicación unidireccional de la biomedicina, desde perspectivas socio e interculturales, para convertirlo en un modelo más completo de comunicación. Por tanto, el nuevo modelo de comunicación debería considerar los vínculos entre las formas de organización de la sociedad, las mediaciones socio-económicas y las características culturales de los actores.

De esta investigación se desprende la necesidad de aplicar un modelo democrático de comunicación intercultural, para promover una mejor relación entre los conocimientos y prácticas de médicos y jambigkunas que trabajan en el centro de salud Jambi Huasi.

A partir del análisis de los conceptos de "hibridación" y "salud intercultural" conviene cambiar la concepción de relaciones interculturales.

Hasta ahora, la retórica sobre multiculturalismo sigue estando dominada por la idea de tolerancia, lo que implica desigualdad, porque se supone que una parte tiene la facultad de “tolerar" al otro. Esta investigación se propone ir más allá de la tolerancia, al analizar la relación entre biomedicina y conocimientos locales. En lugar de tolerancia, la propuesta es promover la aceptación y el respeto de cada forma cultural. Es sólo a través de esta aceptación, validación y el reconocimiento de las diversas culturas y modelos de salud, que será posible fomentar la "construcción intercultural de conocimientos".

En este contexto, compartimos una reflexión de Pierre Fayard con respecto al movimiento de cultura científica. Él señaló que, después de haber trabajado mucho sobre el presente, actualmente a este movimiento le hace falta operar en los itinerarios de 
apropiación del futuro, en los cuales la información es el ingrediente de base. "Fundamentalmente, la ciencia observa, se interroga, formula hipótesis, extrae coherencias y permite comprender y actuar sobre el mundo; ya no es concebible hoy en día, como tampoco en el pasado, que la cultura científica no se proponga una ambición similar como horizonte". (Fayard, 2004: 208-209).

La investigación que sustenta la elaboración de esta Tesis confirma que la Comunicación Pública de la Ciencia y Tecnología, así como la Antropología Médica, son líneas de investigación relativamente nuevas en Iberoamérica; de manera particular en Ecuador, donde conviene desarrollar más investigaciones y propuestas a partir de esos estudios.

Este desafío exige promover un trabajo interdisciplinario e interinstitucional, que demanda la participación de múltiples actores, tales como: representantes del Estado; de universidades y escuelas politécnicas; de centros de investigación; de medios de comunicación; de empresas vinculadas con temas de ciencia, tecnología e innovación, y, por supuesto, de la sociedad civil.

Con la activa participación de profesionales que dirigen y que cursan el Programa Nacional de "Postgrado en Comunicación Pública de la Ciencia y Tecnología" se espera incidir positivamente en la elaboración de políticas públicas, referentes a temas científicos y tecnológicos, y en el fortalecimiento del "Sistema Nacional de Ciencia, Tecnología, Innovación y Saberes Ancestrales" del Ecuador. 


\section{BIBLIOGRAFÍA}

Abad, L.

2004 Epílogo: reflexiones en voz alta acerca de las precisiones e imprecisiones de la llamada salud intercultural. En: Salud e interculturalidad en América Latina: perspectivas antropológicas. Quito: Edt. Abya-Yala, pp. 347- 350.

Agrawal, A.

1996 Indigenous and scientific knowledge: some critical comments. En: $I K$ Monitor 3(3). Versión electrónica de este artículo: http://www.nuffic.nl/ciran/ikdm/3-3/articles

Alderete, E.

2004 Salud y pueblos indígenas. Quito: Ediciones Abya-Yala.

Anaya, R.

1998 ¿Para qué divulgar? En: Columna Miradas, México: Diario El Financiero. Appadurai, A.

1996 Modernity at Large. Cultural Dimensions of Globalization. Minneapolis: University of Minnesota Press.

Asimov, I. 
1994 Cien preguntas básicas sobre ciencia, Madrid: Alianza Editorial / Ediciones del Prado (traducción de Miguel Paredes Larrueca. Título original: Please Explain, Hougton Mifflin Company, 1973).

Avogadro de Suárez, M.

2000 Comunicar la ciencia: un periodismo de proyección al 2000. En: Periodismo Científico. Madrid: Boletín de la Asociación Española de Periodismo Científico (AEPC).

Ayora, S.I.

2002 Globalización, médicos locales y sus luchas por el reconocimiento en Chiapas. México, D.F.: Universidad Autónoma de Yucatán y Editorial Plaza Valdes, S.A. de C.V.

Baer, $\mathrm{H}$.

2003 Contributions to a critical analysis of medical pluralism: An examination of the work of Libbet Crandon Malamud. En: Medical Pluralism in the Andes. (Koss Chioino J., Leatherman T, \& Greenway Ch.). Londres: Editorial Routledge.

Baer H. \& Singer M.

1996 Critical Medical Anthropology; Soheir Morsy. Political economy in medical Anthropology. En: Medical Anthropology: Contemporary Theory and Method. Carolyn F. Sargent and Thomas M. Johnson (eds.). Praeger

Barrio, C.

2008 La apropiación social de la ciencia: nuevas formas. En: Revista Iberoamericana de Ciencia, Tecnología y Sociedad. Vol. 4, num. 10, pp. 213-225.

Bartlett, F. C.

1932 Remembering, Cambridge: University Press. 
Battiste, M.

2000 Indigenous Knowledge and Pedagogy in First Nation Education: A Literature Review with Recommendations. Preparado por: National Working Group on Education and the Minister of Indian Affairs. Ottawa: Indian and Northern Affairs Canada.

Bernal, J.D.

1959 La ciencia en la historia. México, D.F.: UNAM / Editorial Nueva Imagen (Vol. I, $1^{a}$ edición en español).

1979 La ciencia en nuestro tiempo, México, D.F.: UNAM / Editorial Nueva Imagen (Vol. II. Título original: Science in History, C.A. Watts and Co. Ltd., London, 1954).

Bhabha, $\mathrm{H}$.

1994 The location of culture. Londres: Routledge.

Blesdoe, C. H. \& Goubaud, M. F.

1985 The Reinterpretation of Western Pharmaceuticals among the Mende of Sierra Leone. In: Social Science and Medicine 21(3):275-282.

Bonfil, M.

1993 El contrato educativo y la divulgación de la ciencia. En: La diversidad en la divulgación de la ciencia. México D.F.: SomediCYT (Memorias del II Congreso Nacional de Divulgación de la Ciencia, realizado en Veracruz, en 1992).

Bonfil, M. y Tappan, M.

1993 Los términos científicos: su nacimiento y comportamiento en sociedad. En: Ciencia, No 44, México D.F.: UNAM.

Borja, R. 
Manuscrito no publicado.

Brodwin P.

1996 Medicine and Morality in Haiti: The Contest for Healing Power. Cambridge University Press.

Brown, M., Barnes, J.A., Cleveland, D., Coombe, R., Descola, P., Hiatt, L.R., Jackson J., Karlsson, B.G., Posey, D.A., Powers, W.R., Rosen, L., Santos, F., Severi, C., Stephenson, D., Strathern M., Tuzin, D.

1998 Can Culture Be Copyrighted? En: Current Anthropology, Vol. 39, No. 2, pp. 193-222.

Calder, R.

1964 La science et le gran public. En: Impact. Science et Société, N 3. Vol. XIV. París: UNESCO.

Calvo, M.

2005 Ciencia y periodismo científico en Iberoamérica. Conferencia de apertura del II Congreso Iberoamericano de Comunicación Universitaria y I Reunión Iberoamericana de Radios Universitarias. Granada, 14 de marzo de 2005.

2001a El futuro alentador del periodismo científico. En: Infociencia. Salamanca: Universidad de Salamanca.

2001b Estrategias para comunicar el conocimiento (1). En: Autores científicostécnicos y académicos, № 19. Madrid.

2000 Hacia una teoría de la comunicación de la ciencia. En: Periodismo Científico, $\mathrm{N}^{\circ}$ 30, Madrid: publicación bimestral de la AEPC. 
1999 El Nuevo Periodismo de la Ciencia. Ecuador: Ediciones CIESPAL, Colección Intiyán, Vol. 40, $1^{\text {a }}$ edición.

1998 Estilo para divulgadores científicos. En Chasqui, N 62. Quito: Edt. CIESPAL.

1996 Corresponsales en el país de la ciencia. En Estratos. Madrid.

1992 Manual de Periodismo Científico. Madrid: Editorial Paraninfo.

1991 Ciencia y comunicación en una sociedad democrática. En Arbor, № 551-52, Madrid.

1990 Líneas Generales de un Programa Nacional de Difusión de la Ciencia al

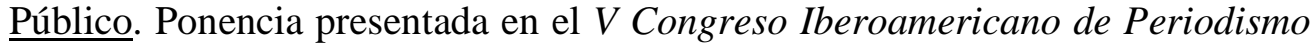
Científico. Valencia, noviembre 1990.

1988 Los nuevos desafíos del periodismo científico. En Arbor, Vol. 130, № 511-512, Madrid.

1982 Civilización Tecnológica e información. Barcelona: Editorial Mitre.

1977 Periodismo Científico. Madrid: Editorial Paraninfo.

Campos R.

2004 Experiencias sobre salud intercultural en América Latina. En: Salud e interculturalidad en América Latina. Fernández Juárez, G. Quito: EdicionesAbya Yala, pp. 129-151.

Carpio, A.

2005 Política Nacional de Ciencia, Tecnología e Innovación. Quito: SENACYT/FUNDACYT.

Carter, W. 
1964 Aymara Communities and the Bolivian Agrarian Reform. En: Social Sciences No. 24, University of Florida Monographs. Gainesville: University of Florida Press.

\section{CONACYT}

2002 Memorias de Congresos de Divulgación Científica organizados por el Consejo Nacional de Ciencia y Tecnología (CONACYT). México D.F.: Publicaciones de CONACYT.

\section{CONAIE}

1989 Las nacionalidades indígenas en el Ecuador. Quito: Tincui/CONAIE y Ediciones Abya Yala.

Conant, J.B.

1947 On Understanding Science. New Haven: Yale University Press.

Consejo Consultivo de Ciencias de la Presidencia de la República.

1994 Políticas de Ciencia y Tecnología en México. México: CONACYT (Responsable del estudio: Jorge Elizondo Alarcón).

Conejo M.

2006 Jambi Huasi Causai: Historia del Jambi Huasi, Sistematización de la experiencia de Jambi Huasi. Otavalo: INRUJTA-FICI, Jambi Huasi y UNFPA.

Conejo M., Álvarez M. \& Engel, D.

2006 Jambi Huasi Causai: todo bajo el Sol tiene un tiempo. (Video) Quito: UNFPA.

Conejo M., Farinango J., De la Torre J. \& Jimbo L.

2004 Salud e interculturalidad como práctica en el Jambi Huasi - FICI. Otavalo: Jambi Huasi. No publicado.

Crandon Malamud, L. 
1991 From the Fat of Our Soul: Social Change, Political Process, and Medical Pluralism in Bolivia. University of California Press.

1993 Why Susto? En: Ethnology, 22, pp. 153-67.

1986 Medical dialogue and the political economy of medical pluralism: a case from rural highland Bolivia. En: American Ethnologist. 13: 463-76.

Cunningham, $\mathrm{M}$.

2002 Ethnicity culture and health. [Título de una conferencia magistral]. Managua, Nicaragua.

Dandler, H.J.

1969 El sindicalismo campesino en Bolivia. En: Serie Antropología Social, No. 11. México, D.F.: Instituto Indigenista Interamericano.

Davidson, J.

1983 The Survival of Traditional Medicine in a Peruvian Barriada. En: Social Science and Medicine 17( 17): 1271-1280.

Dedijer, S.

1969 Politique de la Science, Genése et Evolution. En: Politique de la Science et Écart Technologique. Cahiers de l'ISEA, Genéve: Librairie Droz, tomo III, $\mathrm{N}^{\circ} 4$.

Del Río, P.; Álvarez, A. y Del Río, M.

2004 El impacto cultural en el desarrollo: Medios de comunicación, desarrollo humano y educación. En: Pigmalión. Informe sobre el impacto de la televisión en la infancia. Madrid: Edt. Fundación Infancia y Aprendizaje.

Dixon, B. 
1986 Books and Films: Powerful Media for Science Popularization. En: Impact of Science on Society, Francia.

Dunn F.

1976 Traditional Asian medicine and cosmopolitan medicine in adaptive systems. En: Asian Medical Systems: A Comparative Study. Charles Leslie (ed.), University of California Press: 133-58.

Eagleton, T.

1988 Una introducción a la teoría literaria, México, DF: Fondo de Cultura Económica.

Eco, U.

1990 Cómo se hace una tesis. Técnicas y procedimientos de investigación, estudio y escritura, México, D.F.: Editorial Gedisa.

El Hadj, S.A. y Bélisle, C.

1985 Vulgariser; un défi ou un mythe? En: Chronique Sociale. Lyon: La Chronique Sociale.

Erazo, M.A.

2007 Comunicación, Divulgación y Periodismo de la Ciencia. Quito: Editorial Ariel, Planeta.

Espeland, W. y Clemens, E.

1988 Buying Blood and Selling Truth: Organizational Theory and Cultural Analysis.

En: Comunicación presentada en la conferencia de la American Sociological Association, Estados Unidos (No publicada).

Estrada, L.

1992 La divulgación de la ciencia. En: Ciencias, N 27. México D.F.: UNAM. 
1988 Lenguaje científico y lenguaje común. En: Acerca de la edición de libros científicos, México D.F.: Coordinación de Humanidades, UNAM.

Evans Pritchard, E.

1976 Witchcraft, oracles and magic among the Azande. Oxford: Clarendon Press.

Fayard, P.

2004 La Comunicación Pública de la Ciencia: hacia la sociedad del conocimiento. México, D.F.: Dirección General de Divulgación de la Ciencia, UNAM.

2002 Los Centros para la Comunicación de la Ciencia de cara a la dimensión virtual: El impacto de la dimensión virtual en procesos de comunicación pública e ciencia y tecnología. En: Actas del Congreso Internacional la "La Ciencia al Público”. Salamanca: Universidad de Salamanca.

1990 Periodismo científico europeo. Comunicación presentada en el I Congreso Nacional de Periodismo Científico. Madrid: Consejo Superior de Investigaciones Científicas.

1989 La comunicación científica pública. Una respuesta a los abismos creados entre sociedad y técnica. En Telos, $\mathrm{N}^{\circ} 18$. Madrid.

Fernández Bayo, I.

1988 Periodismo científico: algo más que divulgar. En: Política Científica, $\mathrm{N}^{\circ}$ 15, Madrid.

Fernández del Moral, J. y Esteve Ramírez, F.

1993 Fundamentos de la información periodística especializada, Madrid: Editorial Síntesis.

Fernández Juárez, G. (Coordinator of publication) 
2004 Salud e interculturalidad en América Latina: perspectivas antropológicas.

Quito: Ediciones Abya-Yala.

Fernando, J.

2003 NGO's and Production of Indigenous Knowledge under the Condition of Post modernity. En: ANNALS, AAPSS, 590, November 2003. SAGE Publications. $\begin{array}{llll}\text { Versión electrónica } & \text { de }\end{array}$ http://ann.sagepub.com/cgi/content/abstract/590/1/54

FICI

1994 Solicitud de fondos al UNFPA (Informe). Versión del documento de aplicación firmado por el UNFPA. Otavalo: FICI.

Finerman, R.

1983 Experience and Expectation: Conflict and Change in Traditional Family Health Care among the Quichua of Saraguro. En: Social Science and Medicine 17(17): 1291-1298.

Finkler, K.

1991 Physicians at Work, Patients in Pain. Boulder, CO: Westview Press.

Flores, J. y Martínez, E. (compiladores).

1997 La Popularización de la Ciencia y la Tecnología: reflexiones básicas. México: Coedición de la UNESCO, del Fondo de Cultura Económica y de la Red de Popularización de la Ciencia y la Tecnología en América Latina y el Caribe (Sección de Obras de Ciencia y Tecnología).

Fog, L.

1990 Científicos y periodistas: tejiendo una historia. Ponencia expuesta en un Congreso de Periodismo Científico (No publicado). Bogotá: COLCIENCIAS. 
Foucault, M.

1980 Microfisica do poder (Versión original: Microphysics of power). $9^{\text {th }}$ Ed. Río de Janeiro: Graal.

Friedman, J.

1994 Cultural Identity and Global Process. Londres: Sage.

García, E.M.; González, J.C.; López Cerezo, J.A.; Luján, J.L.; Martín, M.; Osorio, C. y Valdés, C.

2001 Ciencia, Tecnología y Sociedad: una aproximación conceptual. Madrid:

Edt. OEI, Colección "Cuadernos de Iberoamérica”.

Gastélum, J.

2000 La actividad en los centros de ciencia. En: Lunes en la Ciencia, suplemento del diario La Jornada. México D.F.: Edt. Diario La Jornada (8 de mayo del 2000).

Goldsmith, M.

1999 El crítico científico. En: Todo por saber. Ensayos de cultura científica. México, D.F.: Edt. Dirección General de Divulgación de la Ciencia, UNAM. (Versión original: 1986. The science critic: a critical analysis of the popular presentation of science, Londres: Routledge \& Kegan Paul).

Good, B.J.

1994 Illness representation in medical anthropology: a reading of the field. En: Medicine, rationality and experience: an anthropological perspective, B.J. Good, pp. 25-64.

Green, J. \& Thorogood, N.

2004 Qualitative Methods for Health Research. Londres: Sage Publications. 
Hardon, A., Boonmongkon, P., Streefland, P., Tan, M.L., Hongvivatana, T., Van der Geest, S., Van Staa, A., Varkevisser, C., Acuin, C., Chowdhury, M., Bhuiya, A., Sringeryuang, L., Van Dongen, E., Gerrits, T.

2001 Applied Health Research. Anthropology of Health and Health Care. ( $3^{\text {rd }}$. revised edition). Amsterdam: Het Spinhuis Publishers.

Hartz, J. y Chappell, R.

2001 Mundos separados. México, D.F.: Ediciones DGDC-UnAM (Original en inglés: 1997. World Apart: How the Distance Between Science and Journalism Threatens America's Future. Estados Unidos: First Amendment Center).

Hawking, S.W.

1993 Una breve historia del tiempo. Madrid: Globus Comunicación, S.A. (Versión original en inglés: 1991. A Brief History of Time. UK: Inc.; 1992. UK: Anglia Television Ltd./ Gordon Freeman Production).

Heath, D.B.

1969 Bolivia: Peasant syndicates among the Aymara of the Yungas: a view from the grass roots. En: Latin American Peasant Movements, H. Landsbereger (ed.), Ithaca: Cornell University Press.

Hinrichsen, D.

2006 Working with Indigenous Communities in Ecuador: Jambi Huasi, a Model for Community Empowerment. Versión virtual de este artículo, en: http://www.unfpa.org/news/news.cfm?ID=742

2000 Taking health to the High Sierra. In: People \& the Planet.net. Versión virtual: http://www.peopleandplanet.net/doc.php?id=298\&section=4 
Holton, G.

1998 La rebelión contra la ciencia en el final del siglo XX. En: Einstein, historia y otras pasiones. Madrid: Edt. Taurus. (Texto citado en Periodismo Científico, boletín de la AEPC).

Honneth, A.

1995a The Fragmented World of the Social. Essays in Social and Political Philosophy.

Nueva York: Universidad Estatal de Nueva York.

1995b The Struggle for Recognition. The Moral Grammar of Social Conflicts. Cambrige: MIT Press.

Huxley, A.

1979 Literatura y ciencia. Buenos Aires: Editorial Sudamericana.

Iser, W.

1972 The Reading Process: A Phenomenological Approach. En: New Literacy History, $\mathrm{N}^{\circ} 3$.

Isita, R.

1995 Ciencia y propaganda en España. Tesis doctoral presentada en la Universidad Complutense de Madrid, España.

Jacky, C.H.

2007 Modern, Indigenous, Woman: Female Agriculturalists, Sustainability, and Development in the Highlands of Ecuador. Saint Paul: Project Macalester Geography Department.

Jacobi, D.; Schiele, B. \& Albertini J.M.

1988 Vulgariser la science. Le procès de l'ignorance. Mâcon: Champ Vallon.

Jacobi, D. 
1985 References iconiques et modeles analogiques dans des discours de vulgartisation scientifique. En: Information sur les Sciences Sociales, № 24. Ámsterdam.

Kaplan, M.

2000 Ciencia, Estado y Derecho en la Tercera Revolución. México, D.F.: UNAM.

1987 Ciencia, Sociedad y Desarrollo. México, D.F.: UNAM.

Kelly, G. A.

1955 The Psychology of Personal Constructs. Nueva York: Norton and Company.

Kerlinger, F.

1983 Investigación del Comportamiento. Técnicas y Metodología, México:

Ed. Interamericana (2a. Ed).

Koss Chioino J., Leatherman T, \& Greenway Ch.

2003 Medical Pluralism in the Andes. Londres: Edt. Routledge.

Kuhn, T.

1990 La estructura de las revoluciones científicas. México: Fondo de Cultura Económica, 14 impresión (original publicado en inglés, en 1962).

Kyle, D.

2002 Transnational peasants: migrations, networks, and ethnicity in Andean Ecuador. En: The Andean Exodus: Transnational Migration from Bolivia, Ecuador and Peru. Salman, T. \& Zoomers, A. (eds). Amsterdam: Centre for Latin American Research and Documentation (CEDLA).

Leslie, Ch. \& Young, A.

1992 Introduction. In: Paths to Asian Medical Knowledge. Leslie Ch. \& Young A. (eds.). University of California Press. 
Leslie Ch.

1974 The modernization of Asian medical Systems. En: Rethinking Modernization. John Poggie, Jr. \& Robert N. Lynch (eds.). Greenwood Press: 74.

Lewenstein, B.C.

2003 Models of Public Communication of Science and Technology. En: http://communityrisks.cornell.edu/BackgroundMaterials/Lewenstein2003.pdf

Logan, K.

1983 The Role of Pharmacists and Over the Counter Medications in the Health Care System of a Mexican City. En: Medical Anthropology 7:68-89.

López Beltrán C.

2001 Palabras comunes para la ciencia común. En: El muégano divulgador, $\mathrm{N}^{\circ}$ 14, México D.F.: DGDC-UNAM.

López Cerezo, J.A.

1997 Ciencia, Tecnología y Sociedad: El estado de la cuestión en Europa y Estados Unidos. En: Revista Iberoamericana de Educación. № 18: 41-68.

López Rupérez, F.

1985 Educación científica y enseñanza de las ciencias. En: Mundo Científico, Vol. 5, $\mathrm{N}^{\circ} 50$, Barcelona.

Lozano, M.

2008 El nuevo contrato social sobre la ciencia: retos para la Comunicación de la Ciencia en América Latina. En: Razón y Palabra (primera Revista Electrónica en América Latina especializada en Comunicación), Nº5. México, D.F.: Edt. Proyecto Internet del ITESM, Campus Estado de México.

Luz M.T. 
1995 Estudo Comparativo das Medicinas Occidental Contemporânea, Homeopática, Tradicional Chinesa e Ayurvédica em Programas Públicos de Saúde. En: Serie Studies in Collective Health, No. 140. Río de Janeiro: Instituto de Medicina Social de la Universidad del Estado de Río de Janeiro (Brasil).

Mac Culloch, C.

2005 ¿Cómo puede América Latina ponerse al día? En: BIDAmérica, revista del BID. Fragmento de una entrevista publicada el 27 de marzo de 2005. Dirección: http://www.iadb.org/idbamerica/index.cfm?thisid=3226

Malloy, J.M.

1970 Bolivia: The Uncompleted Revolution. Pittsburgh: University of Pittsburgh Press.

Meadows, J.

1986 The Growth of Science Popularization: a historical sketch. En: Impact of Science Society. France (Citado por Isita R.)

Medawar, P.B.

1984 Los límites de la ciencia. México: Breviarios del Fondo de Cultura Económica, $\mathrm{N}^{\circ} 469$.

Menéndez, E.

1990 Antropología Médica: orientaciones, desigualdades y transacciones. En: Cuadernos de la Casa Chata, México D.F.: Centro de Investigaciones y Estudios Superiores en Antropología Social.

Mideros R., Muyulema A., Lema M., \& Carlosama R. 
2000 Informe de Investigación del servicio médico pluricultural de la INRUJTA-

FICI, Jambi Huasi (no publicado). Quito: Universidad Andina Simón Bolívar.

Miles A.

1998 Science, Nature, and Tradition: The Mass-Marketing of Natural Medicine in Urban Ecuador. En: Medical Anthropology Quarterly 12(2)206-225. USA: American Anthropological Association.

Miles, A. \& Leatherman, T.

2003 Perspectives on medical anthropology in the Andes. In: Medical Pluralism in the Andes. Koss Chioino J., Leatherman T, \& Greenway Ch. Londres: Edt. Routledge.

Montenegro \& Stephens

2006 Indigenous health in Latin America and the Caribbean. En: The Lancet, Vol. 367: 1859.

Moragas, $\mathrm{M}$.

1981 Teorías de la comunicación. Barcelona: Gustavo Gili.

Moreira, M.A.

1993 La teoría del aprendizaje significativo de David Ausubel. En: Fascículo del $C I E F$, Serie Enseñanza-Aprendizaje, $\mathrm{N}^{\circ}$ 1. (Adaptado del capítulo 2 del libro Uma Abordagem Cognitivista ao Encino da Física, Porto Alegre, Editora da Universidade, 1983).

Muerza, A.F.

2000 Divulgación de la ciencia. La comunicación de la ciencia, una necesidad social. En:http://www.recol.es/articulos2.asp?idCmdad=28\&nombCmdad=Ciencia\&hom e1\&id=846\#marca2 
Municipalidad de Cotacachi

2001 Plan Cantonal de Salud de Cotacachi, un proyecto de vida y desarrollo humano "Mushuk Ali Kawsaimanta". Cotacachi: Municipio de Cotacachi, Asamblea de Unidad Cantonal de Cotacachi, Ministerio de Salud Pública del Ecuador.

Naciones Unidas

2007 Indigenous Women and the United Nations System: Good Practices and Lessons Learned. Nueva York: Publicación de Naciones Unidas. Online: http://www.un.org/esa/socdev/publications/Indigenous/indwomen07.htm

Nazarea, V.D.

1999 Ethnoecology: Situated Knowledge/Located Lives. Tucson: University of Arizona Press.

Nelkin, D.

1990 La ciencia en el escaparate. España, FUNDESCO.

Novack, J.D.

1988 Constructivismo humano: un consenso emergente. En: Enseñanza de las ciencias, $\mathrm{N}^{\circ}$ 6. (3), 213-223.

O’Neill, J., Bartlett, J., Mignone, J.

2006 Best Practices in Intercultural Health. Washington, DC: Publicación del Banco Interamericano de Desarrollo.

Ortega, D.

1991 Gran Sopena de Sinónimos y Asociación de Ideas. Diccionario Analógico de la Lengua Española. Barcelona: Edt. Ramón Sopena.

Ortiz, S. 
2003 El Proceso de Participación para el Desarrollo Local de Cotacachi 1996-2003. Informe de investigación. Quito: FLACSO.

Oyarce, A.M.

2004 Intercultural health policy in 1996: elements of a proposal. En: First National Meeting: Health and Indigenous Peoples. Saavedra: Araucanía.

Organización Panamericana de la Salud (OPS)

2008 Health of Indigenous Peoples of the Americas. Washington, D.C.: Pan American Health Organization

2002 Harmonization of Indigenous and Conventional Health System in the Americas: Strategies for Incorporating Indigenous Perspectives, Medicines, and Therapies into Primary Health Care. Washington, D.C.: OPS.

Pederson, D. \& Coloma C.

1983 Traditional Medicine in Ecuador: The Structure of the Non-Formal Health Systems. En: Social Science and Medicine 17(17): 1249-1255.

Pérez Bustos, T.

2008 Las Mujeres Colibrí: historias de una experiencia margen de la Popularización de Ciencia y Tecnología. Comunicación presentada en el Congreso ESOCITE 2008, Conferencia Latino Americana de Estudios Sociales de Ciencia y Tecnología. Río de Janeiro: Mayo, 2008.

Pérez Tamayo, R.

1998 Cómo acercarse a la Ciencia. México D.F.: Editorial Limusa (Colección: Cómo acercarse a).

Perutz, M.F.

1990 ¿Es necesaria la ciencia? Madrid: Espasa-Calpe, S.A. 
Piganiol, P.

1974 La gestión de los conocimientos. En: Europa en el año 2000. Fundación Cultural Europea. Madrid: Ediciones de la Revista de Occidente (Versión castellana de Ernestina de Champourcin).

Pillsbury, B.

1982 Policy and Evaluation Perspectives on Traditional Health Practitioners in National Health Systems. En: Social Science \& Medicine 16: 1825-1834.

Price, L.J.

1989 In the Shadow of Biomedicine: Self-Medication in Two Ecuadorian Pharmacies. En: Social Science and Medicine 28(3):905-915.

Ritchie C.

1964 La science et le gran public. En: Impact. Science et Société, № 3, París: Edt. UNESCO, Vol. XIV.

Rohr, E.

1991 In the Church: Ethnopsychoanalytic. Research in Ecuador. En: Group Analysis 26. (Sept. 1993): 295-306.

Robertson, R.

1992 Globalization. Social Theory and Global Culture. Londres: Sage.

1995 Globalization: Time-Space and Homogeneity-Heterogeneity. En: Global Modernities. Featherstone, M., Lash, S. \& Robertson R. (eds.), Londres: Sage.

Roqueplo, P.

1983 El reparto del saber: ciencia, cultura y divulgación. Buenos Aires: Editorial Gedisa, $1^{a}$ edición.

Sagan, C. 
2001 El mundo y sus demonios. México: Editorial Planeta (10ª reimpresión).

Sánchez Mora, A. M.

2000a La divulgación de la Ciencia como Literatura. México: DGDC-UNAM (Colección: Divulgación para divulgadores).

2000b Enseñanza y aprendizaje de la divulgación. México D.F.: $\quad$ DGDC-UNAM.

(No publicado. Texto ofrecido en el vi Diplomado en Divulgación de la Ciencia de la DGDC-UNAM).

1996 Relatos de ciencia. México: Consejo Nacional para la Cultura y las Artes, ADN Editores, $1^{\text {a }}$ edición (Colección Viaje al Centro de la Ciencia).

1995 Sobre la elaboración de artículos de divulgación de la ciencia. En Ciencia, $\mathrm{N}^{\circ}$ 46, México D.F.: CONACYT.

Sánchez Mora, A.M. y Sánchez Mora, C.

2000 Educación y divulgación. En: Ciencia, México, D.F.: DGDC-UNAM.

Sánchez Mora, C.

2002 Hacia la Alfabetización científica. México: Edt. Educación 2001 S.A. de C.V. Versión online: http://www.cneq.unam.mx/cursos_diplomados/diplomados/basico/abasico0920 04/material_didactico/articulos_cien_natu_Biologia/Educar_en_ciencias.pdf Sebastián, J. (Ed.)

2007 Claves del desarrollo científico y tecnológico de América Latina. Madrid: Fundación Carolina y Siglo XXI.

Serrano Figueroa, F.

2000 Los obstáculos pragmáticos para divulgar la ciencia. Tesis presentada en la Facultad de Ciencias Políticas y Sociales de la UNAM. México, D.F.: UNAM. 


\section{SOMEDICYT}

2002 Memorias de Congresos organizados por la Sociedad Mexicana para la Divulgación de la Ciencia y la Técnica (SOMEDICYT). México D.F.: Publicaciones de la DGDC-UNAM.

Snow, Ch. P.

1956 The Two Cultures and the Scientific Revolution. In: The Rede Lectures. Cambridge: Cambridge University Press.

Stavenhagen, R.

1992 Los derechos indígenas: algunos problemas conceptuales. En: Revista del Instituto Interamericano de Derechos Humanos. Revista IIDH. Ene-jun. 1992. (Vol.15) p. 123-143. San José de Costa Rica: Instituto Interamericano de Derechos Humanos.

Suárez, J.

1987 La situación de la salud en el Ecuador 1962-1985. Quito: Ministerio de Salud Pública del Ecuador.

Subdirección de Educación No Formal.

2001 Educación no formal. En: Página web de la DGDC-UnAM. México D.F. En URL: http://www.dgdc.unam.mx/vincu.html

Tapia, R.

2000 El saber científico en la sociedad del siglo XXI. En: Revista Universidad de México, № 588-589, México D.F.: Edt. Universidad de México.

Tappan, M. y Alboukrek, A.

1992 El discurso de la divulgación de la ciencia. En: Ciencia, № 43, México D.F.: Academia de la Investigación. 
Taylor, Ch.

1994 The Politics of Recognition. En: Multiculturalism, Amy Gutman (Ed.). Princeton: Princeton University Press, pp. 25-73.

Tamayo, E.

1996 Movimientos sociales: la riqueza de la diversidad. Quito: ALAI.

Tonda, J.

2000 La función educativa de la divulgación. México D.F.: DGDC-UnAm (No publicado. Texto ofrecido en el vi Diplomado en Divulgación de la Ciencia de la DGDC-UNAM).

Trigueros, $\mathrm{M}$.

1991 Un puente hacia la ciencia. Ponencia presentada en el Primer Congreso de la Sociedad Mexicana de Divulgación de la Ciencia y la Técnica (SOMEDICyT). México D.F. (No publicada).

\section{UNESCO}

1999 Informe mundial sobre la ciencia, Madrid: Editorial Santillana / Ediciones UNESCO.

Van der Geest, S.

1987 Self-Care and the Informal Sale of Drugs in South Cameroon. En: Social Science and Medicine 25(3):293-305.

Van der Geest, S., \& Whyte, S. R.

1989 The Charm of Medicines: Metaphors and Metonyms. En: Medical Anthropology Quarterly 3(4):345-367.

Weinberg, S.

1978 Los tres primeros minutos del universo. Madrid: Alianza Editorial. 
Whyte, S. R. \& Van der Geest, S.

1988 Medicines in Context: An Introduction. In: The Context of Medicines in Developing Countries. Sjaak van der Geest and Susan Reynolds Whyte, eds. Pp. 3-11. Dordrecht, The Netherlands: Kluwer Academic Publishers.

Wiener, N.

1948 Cybernetics. Nueva York: John Wiley \& Sons.

Wynne, B.

1996 May the sheep safely graze? A reflexive view of the expert-lay knowledge divide. En: Risk, Environment and Modernity: Towards a New Ecology, S. Lash, B. Szerszynski, and B. Wynne (eds.). Thousand Oaks, CA: Sage Publications.

World Bank

1998 World Development Report 1998/1999: Knowledge for Development. Washington, D.C.: World Bank.

Young, J. C., \& Garro L.

1994 [1981] Medical Choice in a Mexican Village. Prospect Heights, IL: Waveland Press. 


\section{ANEXOS}

\section{ANEXO 1 - GLOSARIO ${ }^{122}$}

\section{Conocimiento Local:}

En esta investigación, como conocimiento local se considera a la denominada medicina tradicional indígena, que supone un conocimiento transmitido de generación en generación, basado en la experiencia y en la observación de la naturaleza. En el Ecuador, especialmente en las comunidades indígenas Kichwa, se cree que el conocimiento indígena abarca una riqueza de conocimientos sobre plantas, animales y otros fenómenos naturales.

\section{Medicina tradicional indígena (MTI):}

En esta investigación se prefirió citar este término, porque es el más utilizado por las personas entrevistadas durante el trabajo de campo.

\section{Sumak Kausay:}

Los sistemas de salud indígenas de curación se basan en una concepción integral de la salud. Según este concepto, el bienestar se interpreta como la armonía entre los individuos, las comunidades y el universo que los rodea. En este contexto, la enfermedad es tanto un fenómeno del alma como del cuerpo. Desde esta perspectiva, la salud también depende de

\footnotetext{
${ }^{122}$ En esta tesis, las palabras escritas en Kichwa constan en letra cursiva.
} 
la adhesión a las normas sociales y del cumplimiento de las obligaciones morales. Cuando estas normas no se cumplen, puede surgir una enfermedad. (Alderete 2004: 71).

En las comunidades indígenas Kichwa de la provincia de Imbabura, y en otras comunidades indígenas del Ecuador, se denomina Sumak Kausay al concepto holístico de salud. El significado de este término Kichwa, en castellano, es "Buen vivir". Según el director del Área de Salud en la Universidad Andina Simón Bolívar, Jaime Breilh, el concepto de Sumak Kausay podría interpretarse como "estilo de vida saludable".

Desde la perspectiva de la medicina tradicional indígena, la interculturalidad en salud sugiere promover el Sumak Kausay en los pacientes, a través del empleo de diferentes alternativas médicas. En el caso del centro de salud Jambi Huasi, esta promoción se sustenta tanto en el aporte de la biomedicina, como de la medicina tradicional indígena.

\section{Construcción intercultural de conocimientos:}

Teniendo en cuenta el análisis referente a Sumak Kausay, Jaime Breilh propone la "construcción intercultural del conocimiento", para vincular el pensamiento crítico de las ciencias sociales con el pensamiento crítico formulado desde las comunidades indígenas, con el fin de analizar conjuntamente el sistema social existente.

Si se acepta la propuesta de construir interculturalmente el conocimiento, desde una relación horizontal (por ejemplo, entre la biomedicina y la medicina tradicional indígena), entonces resultará necesario saber cómo combinarlas, para analizar cualquier problema. Esto supone un gran desafío, según Jaime Breilh: “¿Cómo construir la interculturalidad a partir de la visión de todas las voces críticas, para que podamos discutir juntos cualquier fenómeno?" 


\section{Hibridación:}

En esta investigación, el término hibridación se entiende como un producto de las relaciones de poder que no desaparecen en la mezcla, sino que se mantienen y reproducen. Lo híbrido, en diferentes sistemas médicos, se expresa en la articulación y en las mezclas de los imaginarios que definen cada forma de conocimiento y la práctica médica. Así, según el antropólogo Steffan Ayora (2002:57), el concepto de "híbridos culturales" es el resultado de la combinación de los conocimientos y práctica local, regional y cosmopolita.

En su opinión, los diferentes tipos de conocimientos y prácticas complejas (como la biomedicina y la medicina tradicional indígena) son híbridos desde su punto de partida, y cada uno trata de legitimarse a través de una retórica basada en la autenticidad, originalidad y pureza.

Al considerar este análisis, la relación entre la biomedicina y la medicina tradicional indígena puede llegar a reproducir finalmente el poder de la biomedicina, en caso de que el significado de lo "moderno" y "global" se torne más importante que el significado de lo local. Esta tendencia se ha confirmado en el actual estudio de caso, durante el trabajo de campo en el centro de salud Jambi Huasi.

\section{Enfermedades y tratamientos procedentes de la medicina tradicional indígena}

1. Limpieza con huevo: Diagnóstico que se sustenta en la Medicina Tradicional Indígena, para determinar un tipo de enfermedad o sufrimiento. 
2. Limpieza con "cuy" o "conejillo de indias": Diagnóstico que se sustenta también en la Medicina Tradicional Indígena, para determinar un tipo de enfermedad o sufrimiento.

3. Encaderar: Acción que realizan las parteras después del parto, para volver el útero de la parturienta a su lugar inicial.

4. Susto o Espanto: De acuerdo a la explicación escrita por la investigadora CrandonMalamud (1983: 164), susto es una especie de padecimiento o sufrimiento que suele ser analizado desde el entorno sobrenatural y, por tanto, es atendido usualmente por curanderos, chamanes, u otros practicantes de la medicina tradicional..

Personas que ofrecen servicios de salud a partir de la Medicina Tradicional Indígena, en el centro de salud Jambi Huasi

1. Fregador: Persona que cura a partir del uso de hierbas y con masajes.

2. Jakug: Término Kichwa que se refiere a la persona que proporciona diagnósticos y tratamientos basados en la medicina tradicional indígena. Por lo general, la jakug que trabaja en el centro de salud Jambi Huasi ofrece diagnósticos a través del uso del "cuy" y también realiza la "limpia del mal de aire".

3. Jambigkuna: En el centro de salud Jambi Huasi, este es el nombre que se emplea para referirse a las personas que prestan servicios de salud basados en la medicina tradicional indígena. Por lo tanto, este nombre se refiere al: yachak, partera (o mamahua), jakug y fregador. 
4. Mamahua: Esta palabra se utiliza en el centro de salud Jambi Huasi para referirse a la partera.

5. Yachak: Puede ser hombre o mujer, pero es más usual encontrar hombres en ese desempeño. El yachak es el jambigkuna que recibe más pacientes por día en el centro de salud Jambi Huasi. Dentro de las comunidades indígenas Kichwa de la provincia de Imbabura, el yachak suele ser apreciado como sabio espiritual.

\section{Otras palabras de origen Kichwa:}

Kamari: Esta palabra significa "reciprocidad" en Kichwa.

Ranti ranti: Significa “dar y recibir", en Kichwa.

Runa Shimi or Kichwa: Esta lengua es resultado del sincretismo entre el idioma Quechua, proveniente de los incas del Perú, y de lenguas pre-Kichwas.

\section{Enfoque conceptual}

El enfoque conceptual que se presenta a continuación trata de comprender las dimensiones consideradas para referirse a la perspectiva holística de salud. Este análisis se sustenta en la literatura existente, así como en las experiencias que surgieron de la aplicación del programa "Salud de los Pueblos Indígenas de las Américas", impulsado por la Organización Panamericana de la Salud (OPS) y por los Estados Miembros de esta Organización (OPS 2008: 7-13, 160-165).

Otra publicación de la OPS (2002: 11-12) utiliza el término “armonización”, como sinónimo de conciliación, consenso, o mediación; y el término "incorporación", como sinónimo de asociación, inclusión, o acceso (Ortega-Cavero 1991). Sin embargo, es 
conocido el uso de otras palabras para representar la necesidad de la colaboración entre los sistemas de salud indígenas y el sistema de salud convencional (biomédico).

Es importante notar que algunos de estos términos pueden tener significados asociados a contextos socioculturales. Por ejemplo la palabra "integración”, como sinónimo y eufemismo de asimilación, está asociada con la década de 1940; especialmente con la tendencia hacia la aplicación de políticas que permitan mejorar las condiciones de vida de las poblaciones indígenas, principalmente, por la asimilación o integración de este grupo de personas en la denominada "sociedad nacional" (Stavenhagen 1992:8).

El siguiente cuadro presenta algunos de los términos utilizados en diferentes publicaciones, con respecto al tema en cuestión. También se incluye sinónimos.

\section{Términos utilizados}

\begin{tabular}{|l|l|}
\hline \multicolumn{1}{|c|}{ Término } & \multicolumn{1}{c|}{ Sinónimo } \\
\hline Incorporación & inclusión, acceso, entrada, aceptación, asociación. \\
\hline Integración & unión, unificación, reunión, combinación, igualdad. \\
\hline Colaboración & $\begin{array}{l}\text { contribución, participación, colaboración, apoyo, } \\
\text { reciprocidad, asistencia. }\end{array}$ \\
\hline Articulación & coyuntura, enlace, vínculo, acoplamiento, unión. \\
\hline Armonización & $\begin{array}{l}\text { enlace, conciliación, unión, mediación, creación de } \\
\text { consenso. }\end{array}$ \\
\hline Complementariedad $^{123}$ & Suplementario, aumentado, añadido, agregado. \\
\hline
\end{tabular}

Fuente: (Ortega-Cavero 1991)

En la investigación que se detalla en el Capítulo 6, se optó por utilizar y analizar el concepto de "hibridación".

\footnotetext{
${ }^{123}$ Según un informe de la OPS (2002), aunque la descripción del concepto de complementariedad tiene un sentido de subordinación, algunos investigadores hablan sobre el principio de complementariedad al describir la filosofía de los pueblos indígenas andinos. (Yánez del Pozo et al. 2002: 129).
} 


\section{ANEXO 2 - Personas entrevistadas en la investigación descrita en el Capítulo 6}

\begin{tabular}{|c|c|}
\hline PERSONAL DEL CENTRO DE SALUD JAMBI HUASI & $\begin{array}{c}\text { PERSONAL DEL CENTRO JAMBI } \\
\text { MASCARIC }\end{array}$ \\
\hline $\begin{array}{l}\text { 1. Dra. Myriam Conejo: directora del centro de salud } \\
\text { Jambi Huasi. Ella prefirió que se cite su propio } \\
\text { nombre en esta tesis. }\end{array}$ & $\begin{array}{l}\text { 1. Sra. Carmen Cumba: partera y coordinadora } \\
\text { del Área de Salud del centro Jambi } \\
\text { Mascaric, de Cotacachi. Ella prefirió que se } \\
\text { cite su propio nombre en esta tesis. }\end{array}$ \\
\hline $\begin{array}{l}\text { 2. Carlos: nombre ficticio de un médico que trabaja en } \\
\text { atención primaria de la salud y en medicina general. }\end{array}$ & $\begin{array}{l}\text { 2. Sra. Juana Morales: líder indígena y } \\
\text { directora del Área de Mujeres en el centro } \\
\text { Jambi Mascaric. Ella prefirió que se cite su } \\
\text { propio nombre en esta tesis. }\end{array}$ \\
\hline $\begin{array}{l}\text { 3. Dra. Azalia Vásquez: psicóloga. Prefirió que se cite } \\
\text { su nombre, Azalia, en el contenido de esta tesis. }\end{array}$ & \\
\hline $\begin{array}{l}\text { 4. Sra. Concepción Brusti: partera y frejadora. Ella } \\
\text { prefirió utilizar el nombre de "Mamá Conchita" en el } \\
\text { contenido de esta tesis. }\end{array}$ & \\
\hline $\begin{array}{l}\text { 5. Sr. Javier Perugachi: yachak de Jambi Huasi. Él } \\
\text { prefirió que se cite su propio nombre en esta tesis. }\end{array}$ & \\
\hline $\begin{array}{l}\text { 6. Srta. Matilde Perugachi: hija del yachak. Ella tiene } \\
17 \text { años y prefirió que se cite su nombre, Matilde, en } \\
\text { esta tesis. }\end{array}$ & \\
\hline $\begin{array}{l}\text { 7. Sr. Darwin Tamba: está a cargo del área de } \\
\text { información en el centro de salud Jambi Huasi. Él } \\
\text { prefirió que se cite su propio nombre en esta tesis. }\end{array}$ & \\
\hline $\begin{array}{l}\text { 8. Sr. Vidal Sánchez: practicante de la medicina } \\
\text { tradicional indígena, como hierbatero y frejador. Él } \\
\text { prefirió que se cite su propio nombre en esta tesis. }\end{array}$ & \\
\hline INSTITUCIONES & INSTITUCIONES \\
\hline $\begin{array}{l}\text { 1. Dr. Jaime Breilh: director del Área de Salud en la } \\
\text { Universidad Andina Simón Bolívar. Él prefirió que se } \\
\text { cite su propio nombre en esta tesis. }\end{array}$ & $\begin{array}{l}\text { 1. Dra. Teresa Jaramillo, ex directora del } \\
\text { Sistema Cantonal de Salud de Cotacachi } \\
\text { (hasta abril de 2008). Ella prefirió que se } \\
\text { cite su propio nombre en esta tesis. }\end{array}$ \\
\hline $\begin{array}{l}\text { 2. Dr. Raúl Mideros: investigador y profesor en el Área de } \\
\text { Salud de la Universidad Andina Simón Bolívar. Él } \\
\text { prefirió que se cite su propio nombre en esta tesis. }\end{array}$ & $\begin{array}{l}\text { 2. Sr. Marcelo Pinto, coordinador del Comité } \\
\text { Intersectorial de Salud de Cotacachi. Él } \\
\text { prefirió que se cite su propio nombre en } \\
\text { esta tesis. }\end{array}$ \\
\hline $\begin{array}{l}\text { 3. Dr. Leandro Prieto: investigador y estudiante en el Área } \\
\text { de Salud de la Universidad Andina Simón Bolívar. Él } \\
\text { prefirió que se cite su propio nombre en esta tesis. }\end{array}$ & \\
\hline $\begin{array}{l}\text { 4. Mario Conejo: alcalde de Otavalo. Él prefirió que se } \\
\text { cite su propio nombre en esta tesis. }\end{array}$ & \\
\hline $\begin{array}{l}\text { 5. Olga Farinango: directora del Área de Salud en el } \\
\text { Municipio de Otavalo y el ex médica de Jambi Huasi. }\end{array}$ & \\
\hline $\begin{array}{l}\text { 6. Dr. José Javier Terán: director del Hospital San Luis de } \\
\text { Otavalo. Él prefirió que se cite su propio nombre en }\end{array}$ & \\
\hline
\end{tabular}


esta tesis

7. Dr. Gonzalo Jaramillo: director Provincial de Salud de Imbabura. Él prefirió que se cite su propio nombre en esta tesis.

8. Elizabeth Núñez: ex directora de Comunicación del Ministerio de Salud Pública. Ella prefirió que se cite su propio nombre en esta tesis.

9. Matilde Farinango: técnica de la Dirección Nacional de la Salud de los Pueblos Indígenas (DNSPI), en el Ministerio de Salud Pública del Ecuador. Ella prefirió que se cite su propio nombre en esta tesis.

10. Mercedes Muenala: coordinadora del Área de Salud Intercultural, en la Dirección Provincial de Salud de Imbabura. Ella prefirió que se cite su propio nombre en esta tesis.

\begin{tabular}{|c|}
\hline PACIENTES \\
\hline 1. Sr. José Perugachi: nombre ficticio de un paciente de la
\end{tabular} fregadora, Concepción Brusti. Él prefirió usar un seudónimo.

2. Sr. José: nombre ficticio de un paciente del yachak.

3. Sr. César Cotacachi: hijo de un paciente del yachak de Jambi Huasi. Prefirió que se cite su propio nombre en esta tesis. 


\section{ANEXO 3. Parto tradicional en posición vertical}

\section{Estado previo}

En el año 2002, después de una reunión entre parteras y otras mujeres de organizaciones indígenas con técnicos de la Dirección Provincial de Salud de Imbabura, surgió la iniciativa de implementar el parto normal en posición vertical (lo que se conoce como "parto tradicional", en las comunidades indígenas del Ecuador).

La principal razón que animó a tomar esta decisión fue el rechazo de muchas mujeres indígenas a la posibilidad de realizar sus partos en hospitales o centros de salud del sistema oficial. Para justificar su rechazo, algunas de las mujeres indígenas expusieron los siguientes argumentos:

1. Las mujeres indígenas, por lo general, no reciben un buen trato por parte de los profesionales biomédicos en hospitales, clínicas o centros de salud oficiales.

2. A ellas no les gusta que el médico prohíba el acceso de sus familiares, durante el proceso del parto.

3. A la mayoría de mujeres indígenas no les gusta que otras personas afeiten sus partes íntimas, antes del parto (hecho que ocurre en algunos hospitales).

4. Ellas creen que son ambientes muy fríos las salas de parto de clínicas y hospitales, para llevar a cabo un parto. Porque, desde su cosmovisión, el parto debe realizarse en ambientes cálidos. 
5. Ellas no quieren correr el riesgo de una cesárea, práctica demasiado común en la mayoría de clínicas y hospitales del Ecuador.

6. A la mayoría de mujeres indígenas de la provincia de Imbabura no les agrada el color blanco de la vestimenta de médico y enfermeras, así como de la mayoría de sábanas y paredes de clínicas y hospitales. Porque, en varias etnias indígenas del Ecuador, se asocia el color blanco con la muerte.

7. Algunas mujeres indígenas desean llevar a cabo rituales antes del parto. Por ejemplo, desean una limpia (curación) para el denominado "mal de aire", o tomar alguna infusión antes del parto.

8. A muchas mujeres indígenas les molesta el hecho de que un médico inserte sus dedos en la vagina de ellas.

9. En las comunidades indígenas, generalmente las personas no pagan con dinero el trabajo realizado por las parteras, sino que les ofrecen otro tipo de productos (usualmente víveres) para expresarles su respeto y reciprocidad, por el apoyo recibido en el parto. Por lo tanto, por falta de costumbre, a muchas mujeres indígenas no les agrada pagar con dinero los servicios que reciben en clínicas u hospitales privados.

10. A muchas mujeres indígenas no les agrada la práctica del parto en posición horizontal (como es habitual en la práctica biomédica), sino que prefieren hacerlo en posición vertical.

11. En muchas comunidades indígenas, un importante ritual es enterrar la placenta de los bebés recién nacidos cerca del fogón o chimenea de la casa donde nacen, con el 
anhelo de mantener así el vínculo familiar a través de los años. ${ }^{124}$ Pero en hospitales, clínicas y centros de salud no es usual entregar la placenta de un bebé recién nacido a su madre, lo cual molesta a las mujeres indígenas porque eso les impide cumplir con el precitado ritual.

12. Algunas mujeres indígenas tienen dificultades para comunicarse en castellano y, usualmente, los médicos o enfermeras de formación biomédica no saben comunicarse en lengua Kichwa o en otra lengua indígena.

Las opiniones antes citadas fueron expuestas por mujeres indígenas hace más de 6 años, en una reunión organizada por representantes de la Red de Salud del Cantón de Otavalo, del Hospital San Luis de Otavalo, del Municipio de Otavalo, del centro de salud Jambi Huasi y del UNFPA. En la actualidad, esas instituciones apoyan la propuesta de tomar en cuenta los conocimientos y la práctica del parto vertical en el sistema de salud formal del Ecuador.

A partir del año 2003, la Dirección Provincial de Salud de Imbabura empezó a ofrecer talleres de formación sobre interculturalidad en salud, con énfasis en el parto vertical tradicional. ${ }^{125}$

Estos talleres se celebraron en varios cantones de la provincia de Imbabura, pero especialmente en Otavalo; porque, según informes de la Dirección Provincial de Salud, el 53\% de la población es indígena en ese cantón.

Mercedes Muenala, coordinadora del Área de Salud de los Pueblos Indígenas en la Dirección Provincial de Salud de Imbabura, recuerda que las autoridades del cantón

\footnotetext{
${ }^{124}$ Esta práctica simboliza el deseo de que el recién nacido, cuando sea adulto, pueda recordar su origen, el calor de hogar y el afecto que por él/ella sienten su familia.

${ }^{125}$ En estos talleres, Raúl Mideros y Fernando Calderón han trabajado como instructores, así como otras personas que tienen estudios sobre salud intercultural.
} 
Cotacachi aceptaron inicialmente la propuesta de incluir la práctica del parto vertical en el Hospital Asdrúbal de la Torre de ese cantón; "pero esa propuesta no se cumplió; porque, al final, ésta no fue apoyada por la organización indígena Jambi Mascaric, de la UNORCAC".

En cambio, en el cantón Otavalo hay avances con respecto a la aplicación de esa propuesta. El 19 de octubre de 2005 la organización Care International, luego de un acuerdo firmado con el Municipio de Otavalo, respaldó este proceso al apoyar con provisiones a las parteras, especialmente con materiales destinados a la atención del parto y con folletos informativos.

Algunos puntos clave en la ejecución de esta propuesta han sido:

- Socialización del parto vertical en 4 cantones de la provincia de Imbabura.

- Registro y formación de otras parteras en la provincia de Imbabura.

- Preparación de informes sobre la atención del embarazo, parto, post-parte y sobre atención al recién nacido, por parte del grupo de parteras capacitadas.

- Búsqueda de compromisos con el Rector de la Universidad Central del Ecuador, para que se incluya el tema del parto vertical en el programa académico de la Facultad de Medicina de esa Universidad.

- Elaboración de una guía sobre el parto vertical.

- Acercamiento entre parteras y personal sanitario de los hospitales de la provincia, con el fin de intercambiar conocimientos. ${ }^{126}$

\footnotetext{
${ }^{126}$ Tuve oportunidad de participar en un taller celebrado en el Hospital "Asdrúbal de la Torre”, en el cantón Cotacachi, de la provincia de Imbabura (a pocos kilómetros de Otavalo).
} 
- Creación de la "Sala de Parto Vertical" en el Hospital San Luis de Otavalo, junto al Área de Emergencia de ese hospital (para asistir a pacientes que requieran ese tipo de atención).

- Intercambio de experiencias sobre el parto vertical con las parteras del Perú.

Para la implementación de la práctica del parto vertical en el sistema de salud de la provincia de Imbabura, el centro Jambi Huasi recibió el apoyo de las siguientes organizaciones: Dirección Provincial de Salud de Imbabura, UNFPA, Municipio de Otavalo, Hospital San Luis de Otavalo, Dirección Nacional de Salud de los Pueblos Indígenas del Ministerio de Salud Pública del Ecuador, ECUARUNARI y UNICEF.

Según Mercedes Muenala, algunos factores limitantes en este proceso han sido:

- Falta de presupuesto para apoyar la formación y la práctica del parto en posición vertical.

- Escaso conocimiento sobre la medicina tradicional indígena, por parte del personal del Ministerio de Salud Pública del Ecuador.

- Escasez de publicaciones referentes al parto vertical tradicional en el Ecuador.

- Desconfianza en la atención del parto vertical y en la atención de las parteras, en el Hospital San Luis de Otavalo.

- Constante cambio de autoridades de salud a nivel local, provincial y nacional.

- Algunas parteras no aceptan la formación impartida por los médicos rurales y por estudiantes de las escuelas de obstetricia.

- Comunicación limitada entre los profesionales que trabajan en el Hospital San Luis de Otavalo. 
Anexo 4 - Fotos de informantes

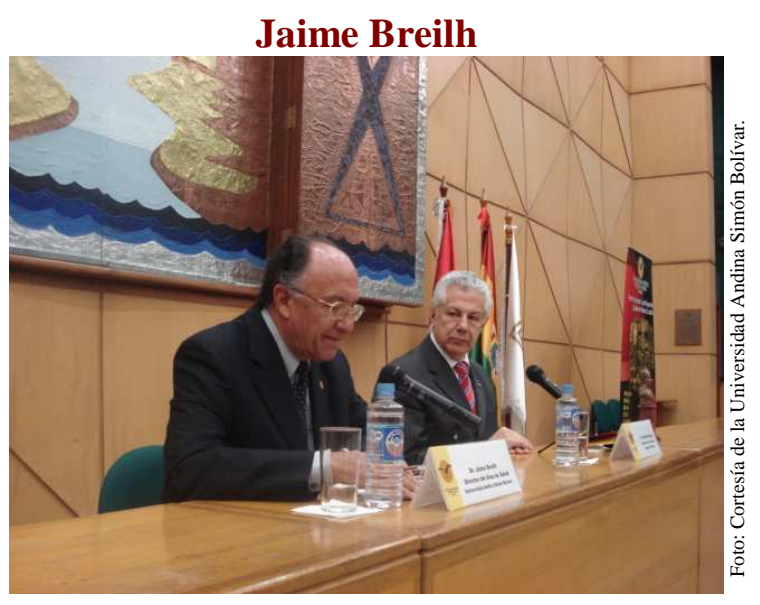

Raúl Mideros
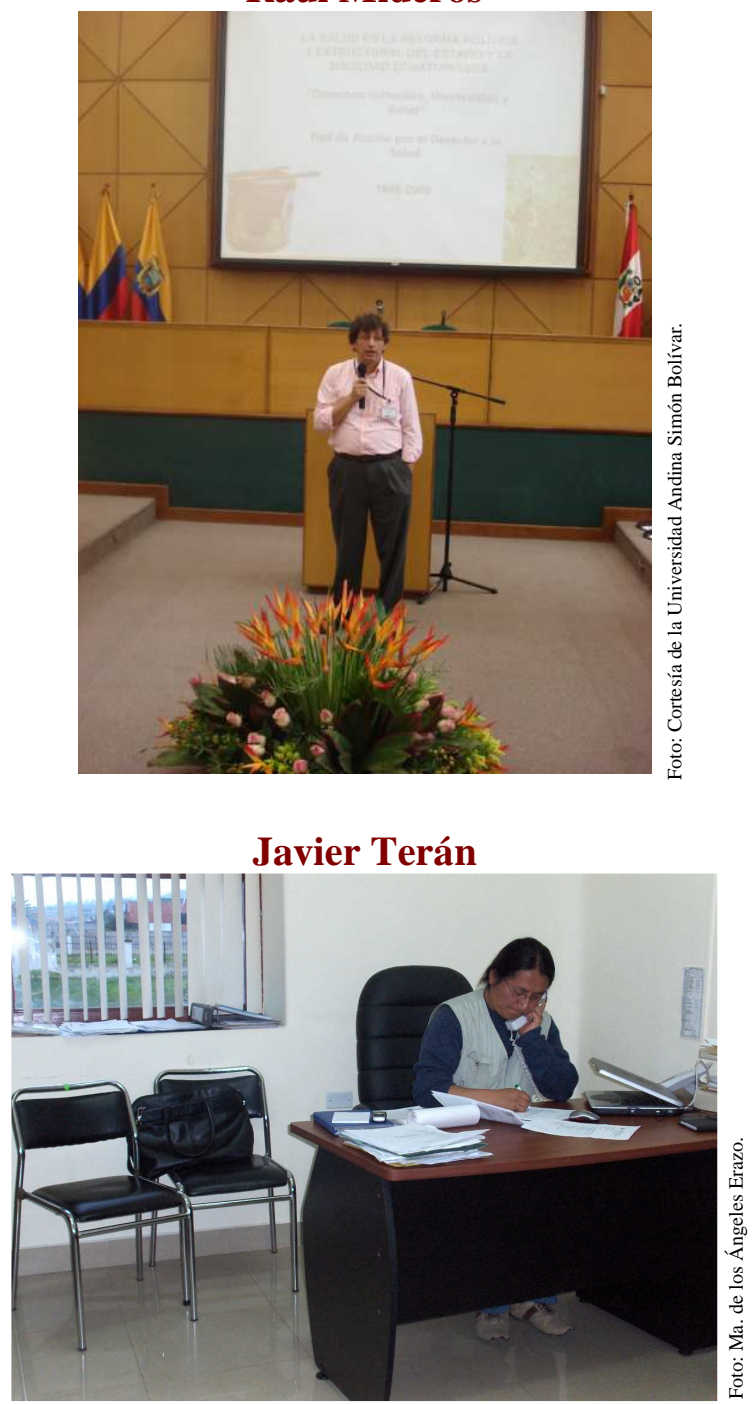
Concepción Brusti: mamahua o partera y fregadora de Jambi Huasi
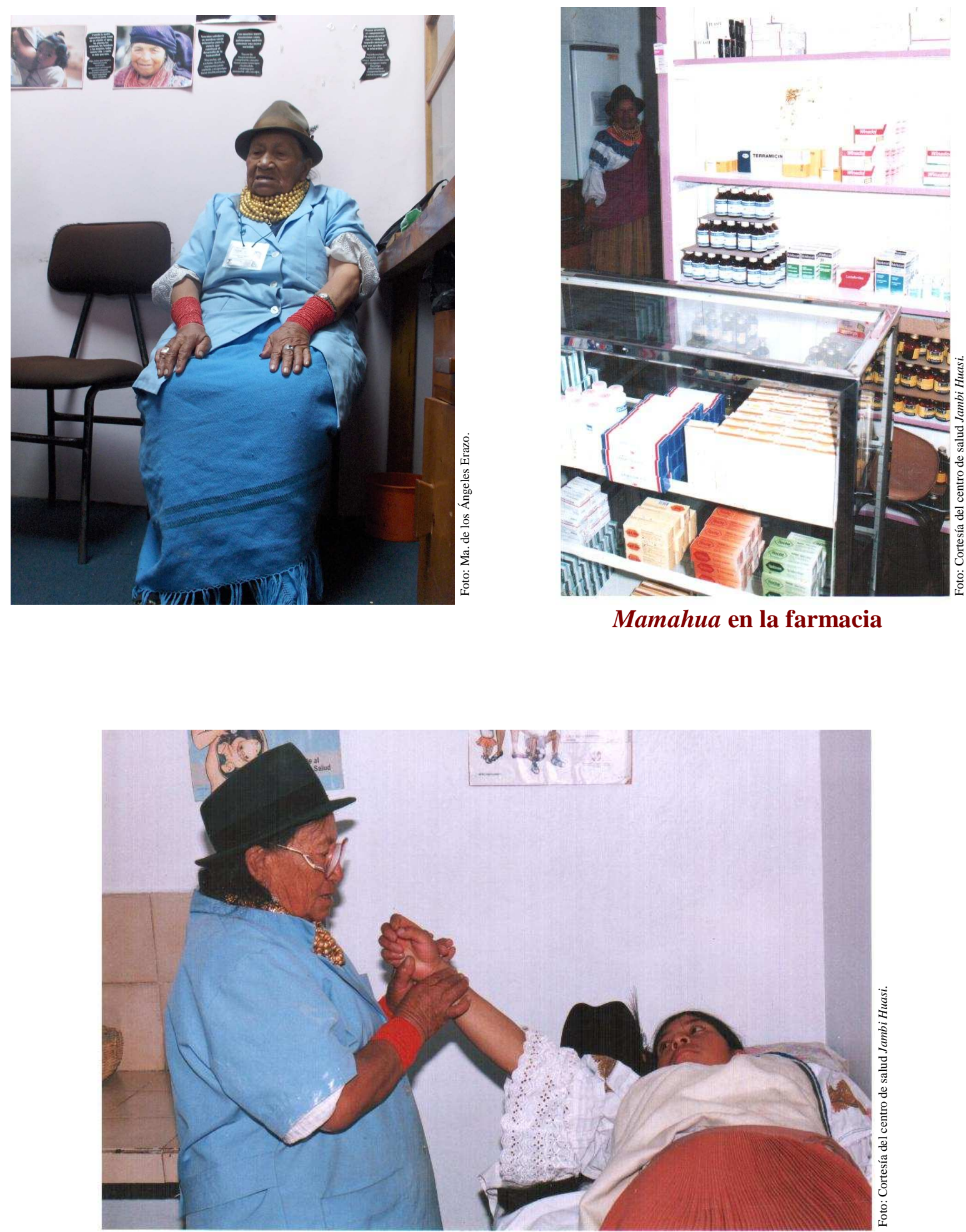
Juana Perugachi, jakug del centro de salud Jambi Huasi
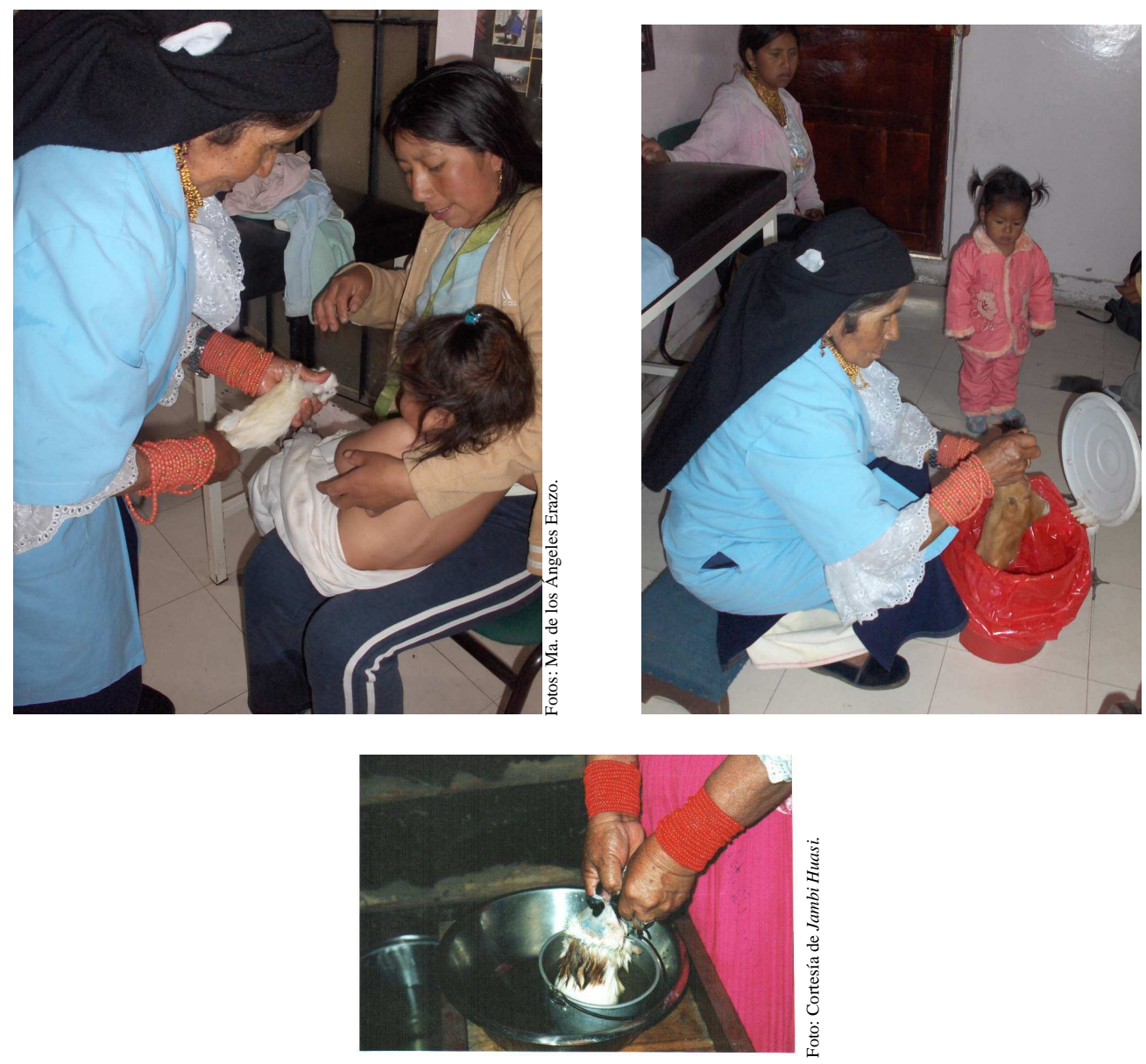

Jakug in a "limpia con cuy"
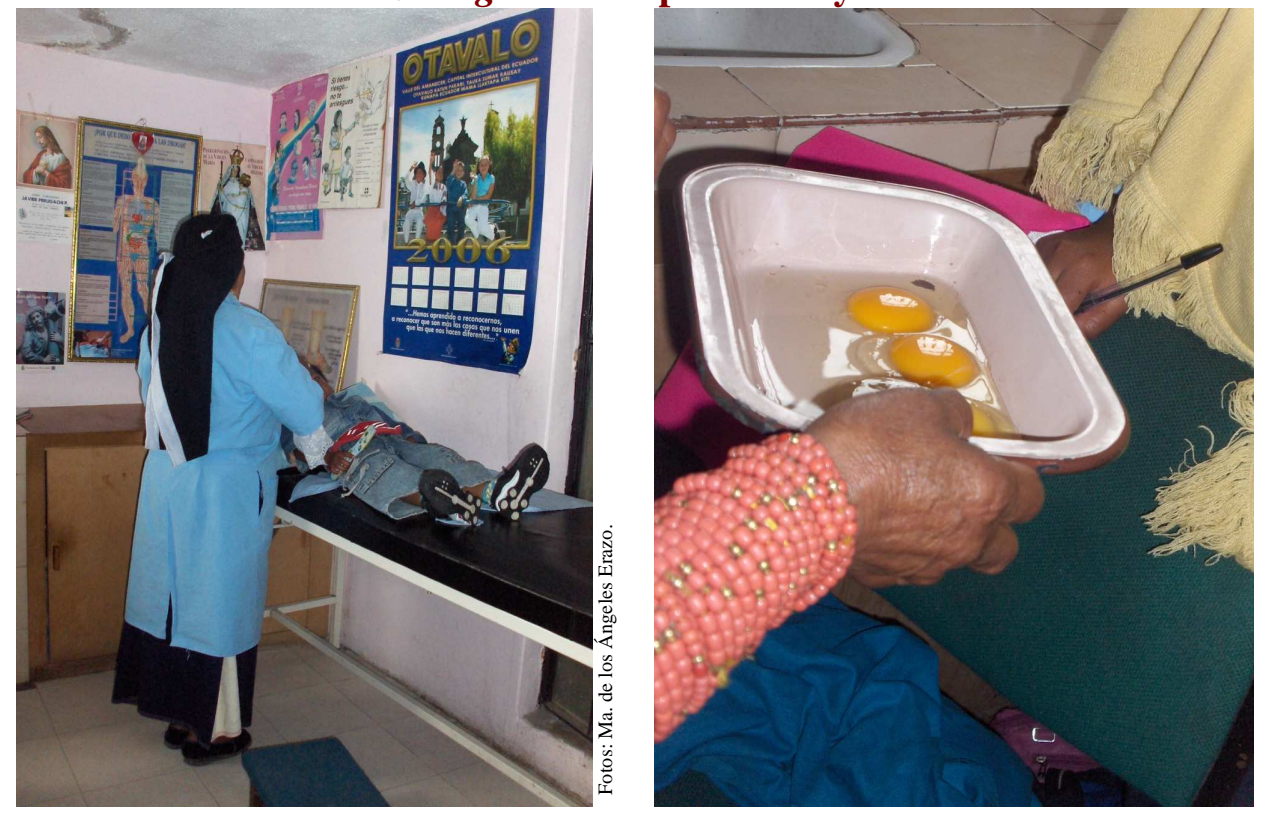
Javier Perugachi, yachak del centro de salud Jambi Huasi
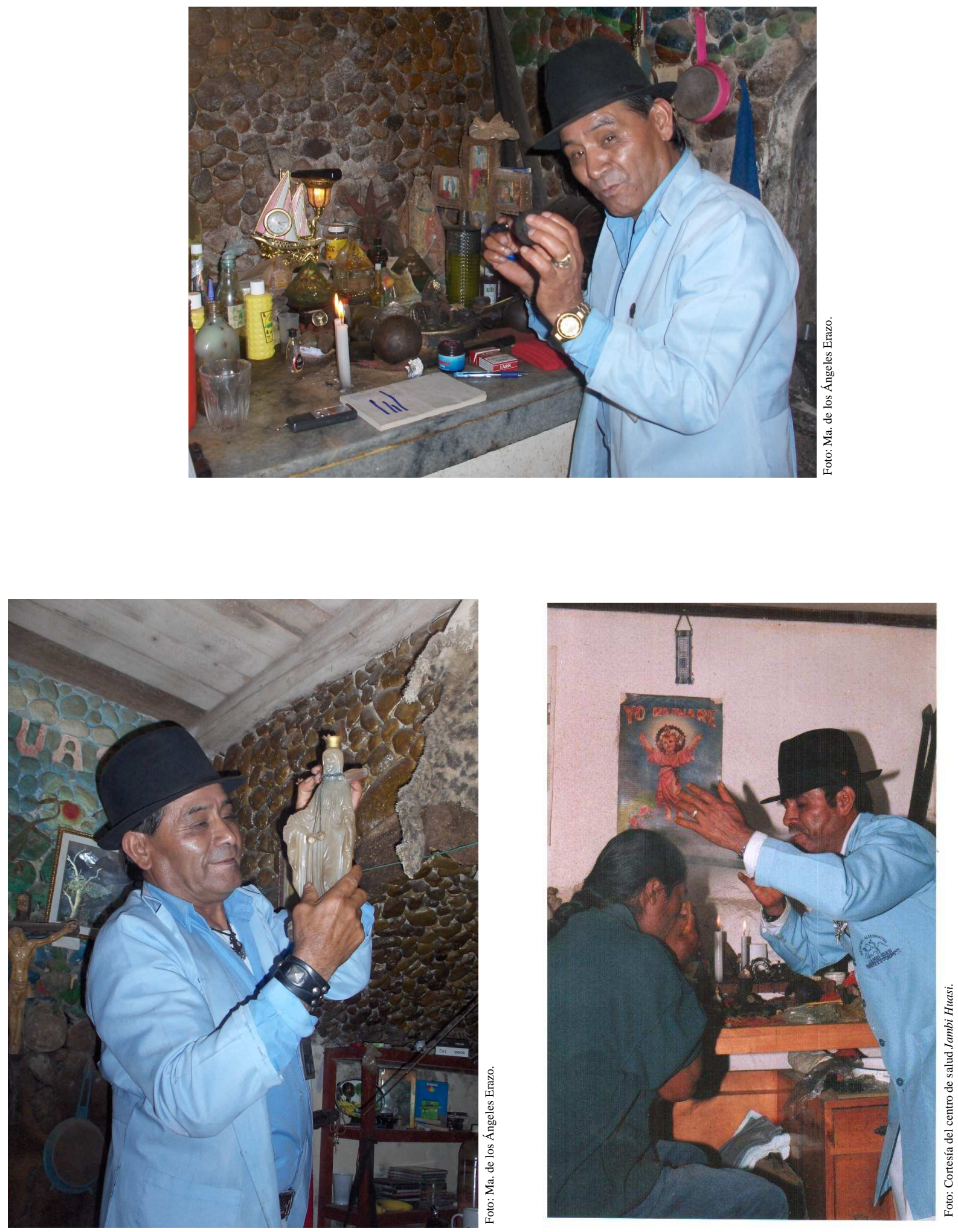


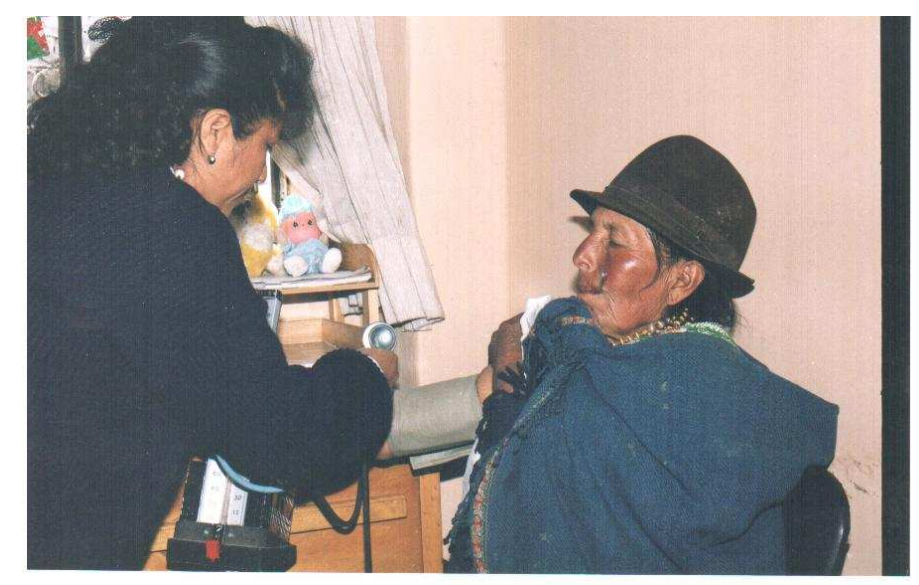

Enfermera y paciente, en el centro de salud Jambi Huasi

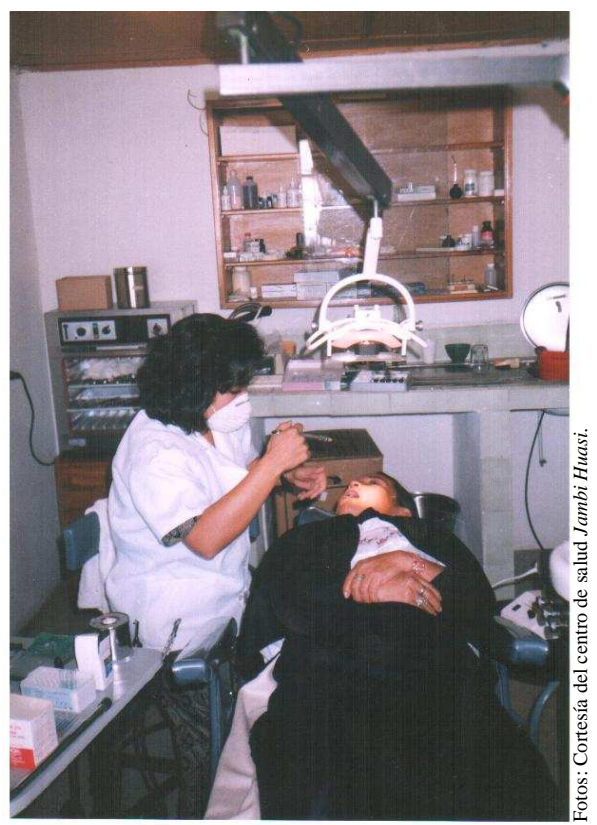

Dentista en Jambi Huasi

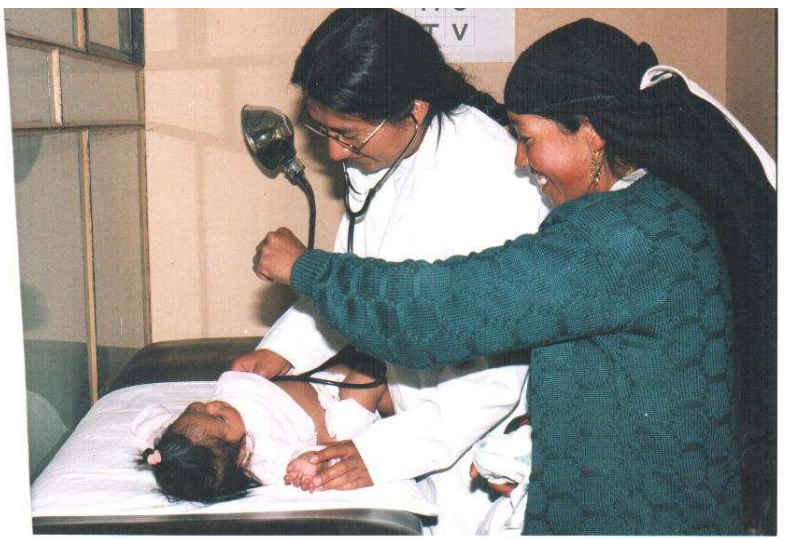

Pediatra Javier Terán, en Jambi Huasi 


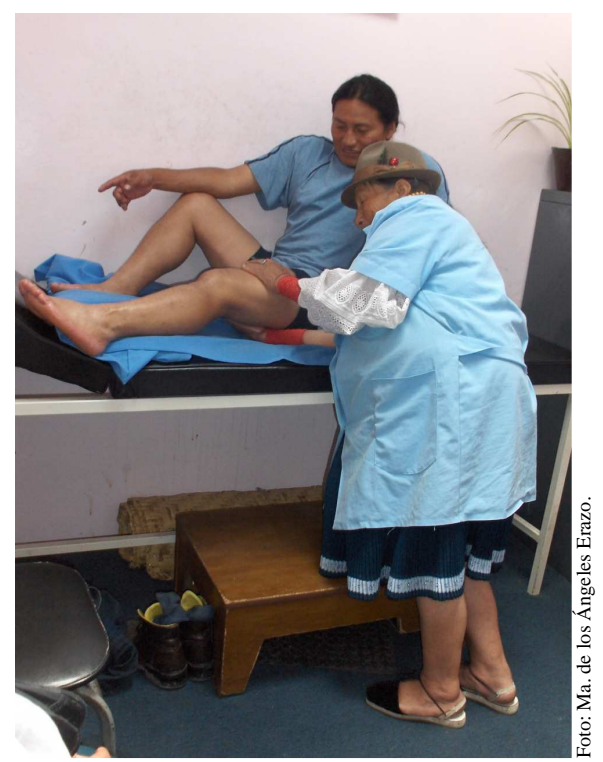

Concepción Brusti como fregadora, con un paciente

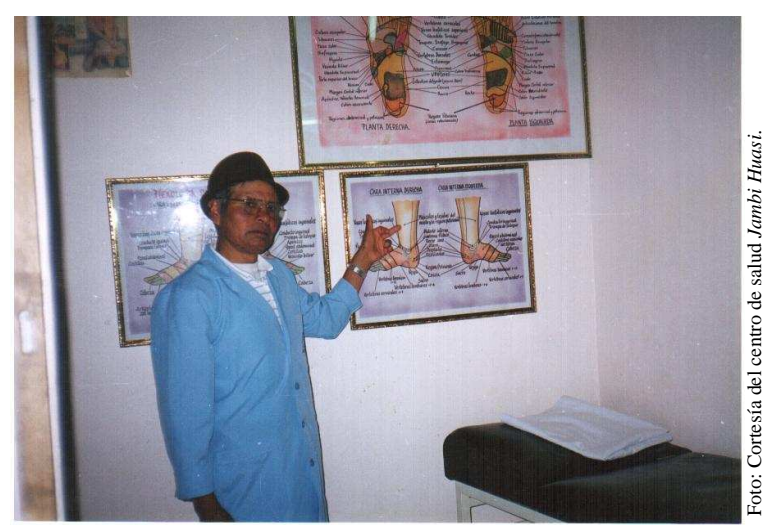

Vidal Sánchez como fregador in Jambi Huasi, hace 8 años

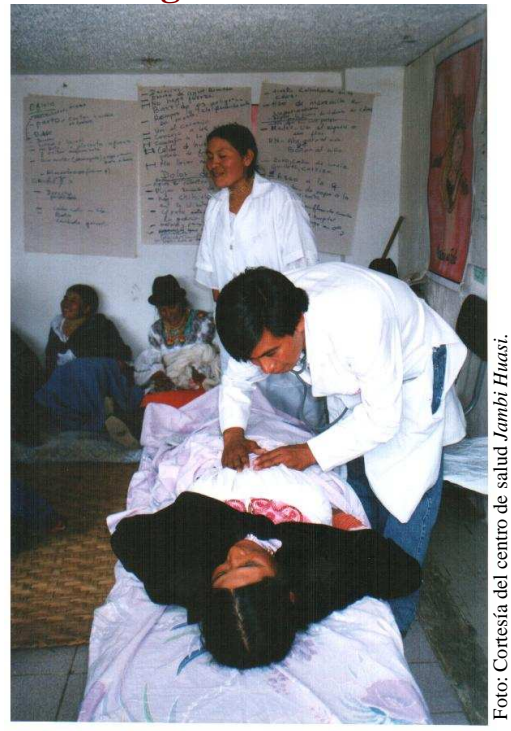

Médico y parteras en un taller 
Ritual y taller con doctores y parteras, en Cotacachi
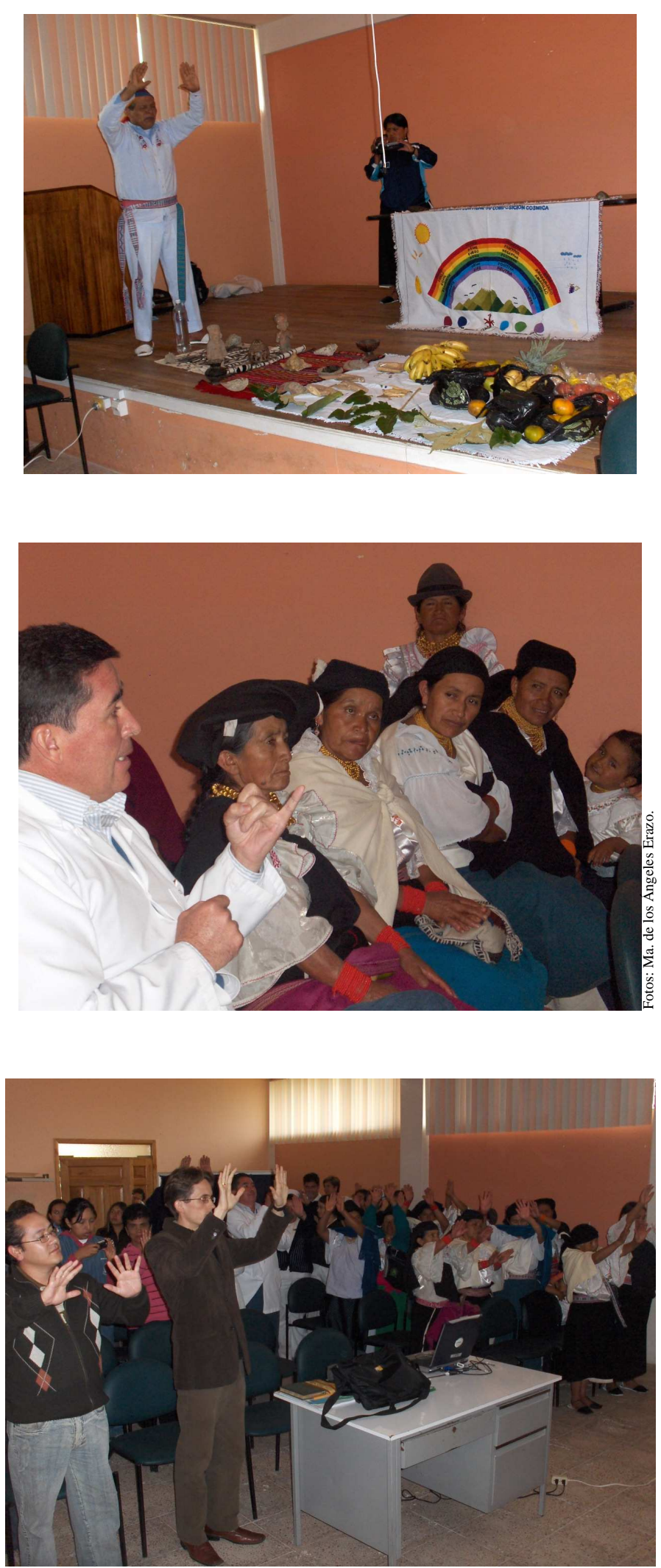
Sala de Parto Vertical, en el Hospital San Luis de Otavalo
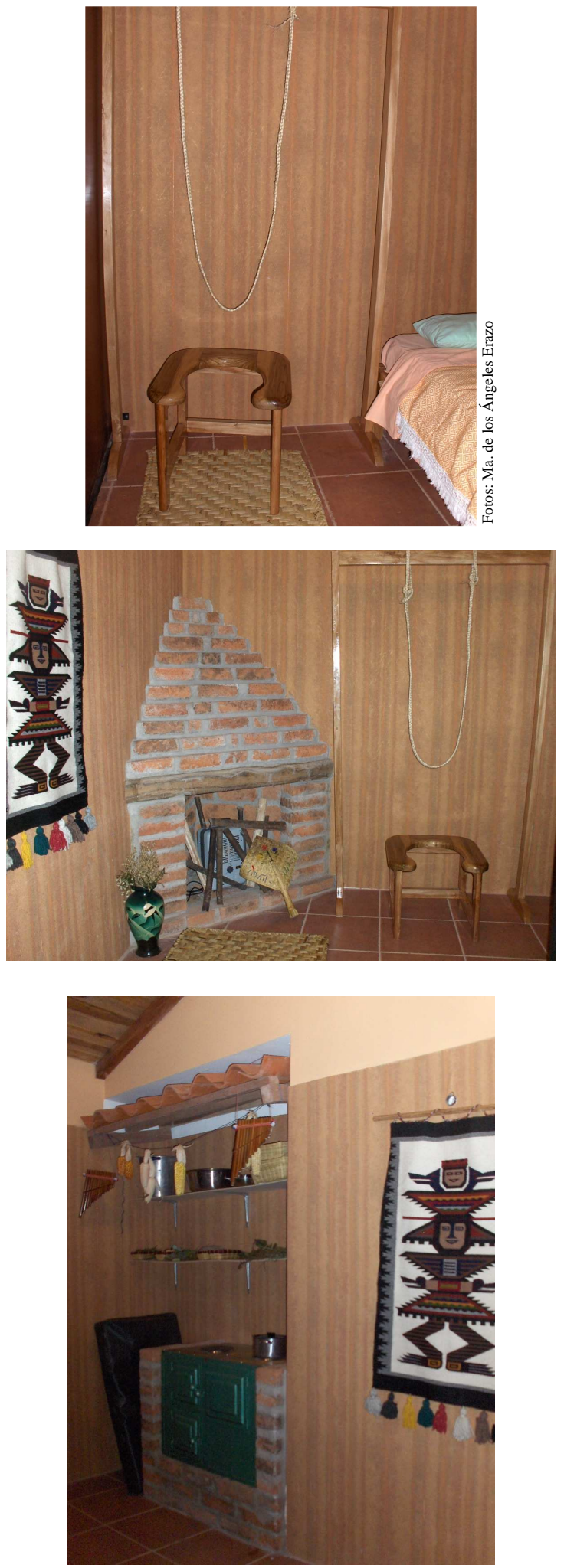
Demostración de las posiciones para la práctica del Parto Vertical
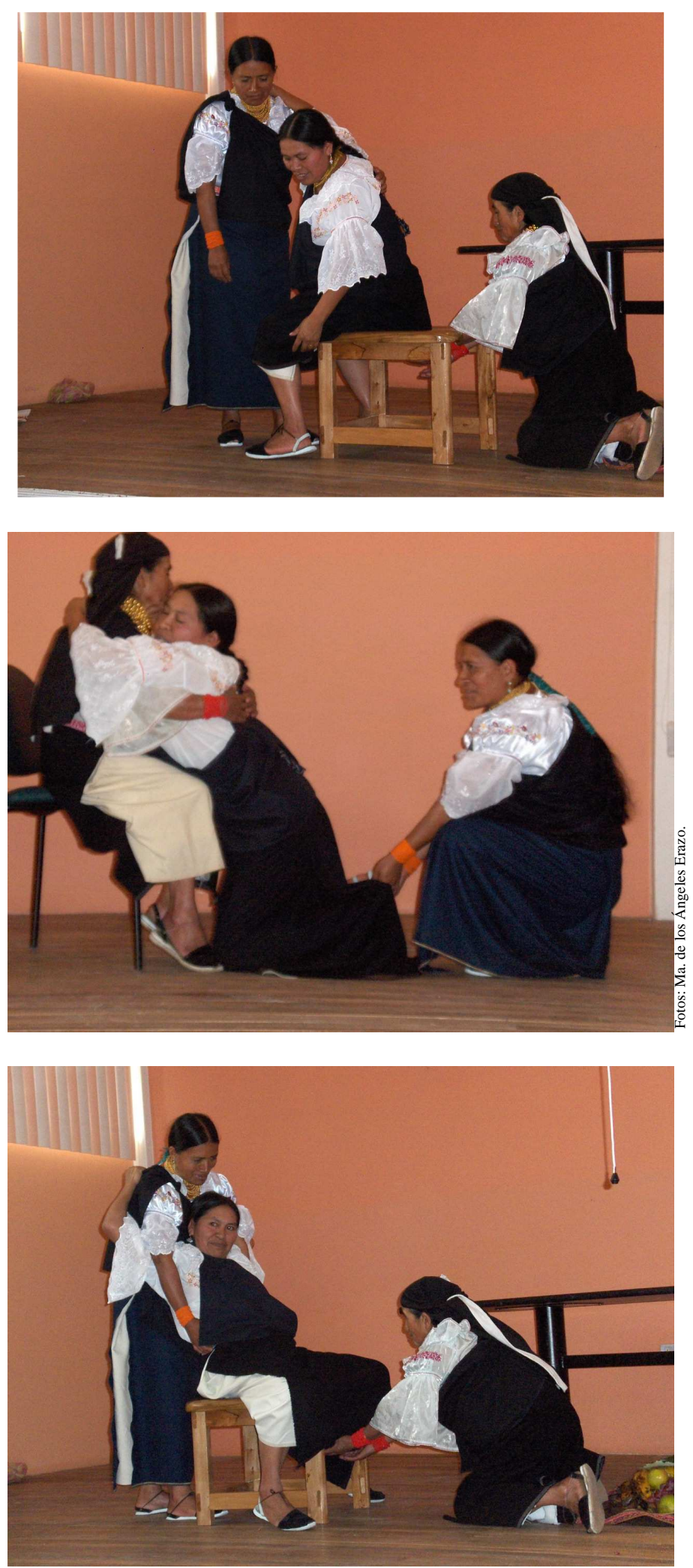


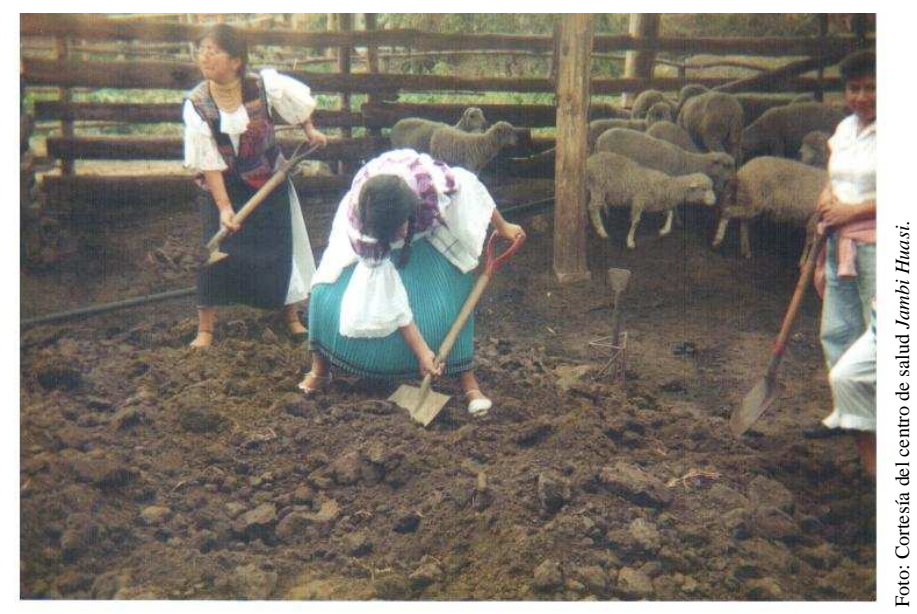

Myriam Conejo, directora de Jambi Huasi, en una comunidad indígena

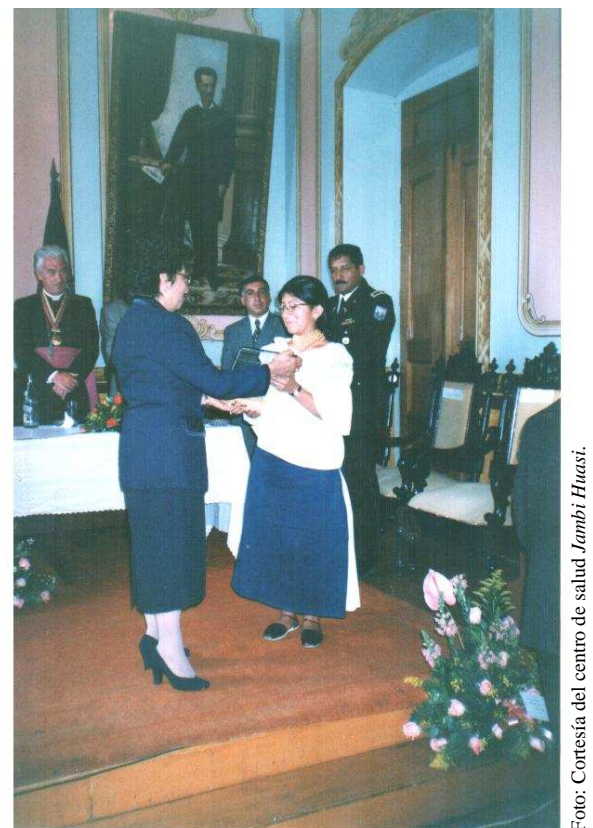

Myriam Conejo recibió un premio del UNFPA, por su trabajo en Jambi Huasi

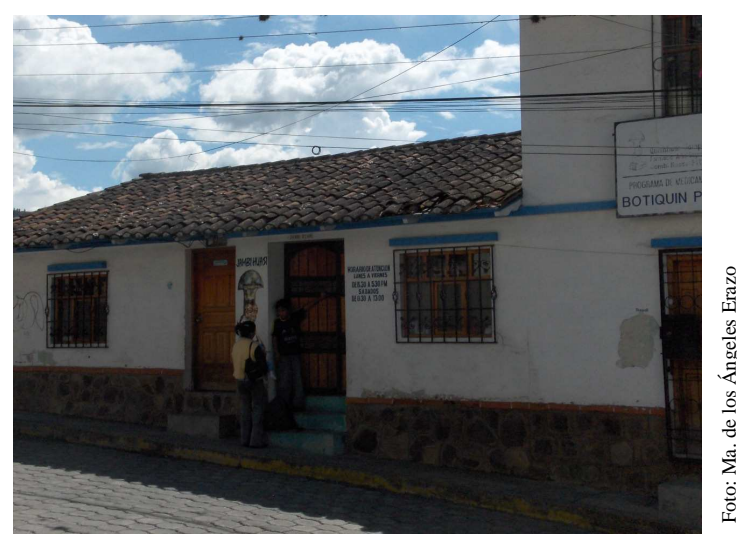

El personal de Jambi Huasi recibió un premio del Municipio de Otavalo, por su aporte a la comunidad 


\begin{abstract}
ANEXO 5
DESCRIPCIÓN DEL PROGRAMA NACIONAL DE “POSTGRADO EN COMUNICACIÓN PÚBLICA DE LA CIENCIA Y TECNOLOGÍA” DEL ECUADOR
\end{abstract}

\title{
1. Antecedentes sobre esta iniciativa en Ecuador
}

Planear el desarrollo de un Programa Nacional de Comunicación Pública de la Ciencia y Tecnología (CPCT) exige un trabajo interdisciplinario e interinstitucional, y la participación de múltiples actores, tales como: representantes del gobierno, universidades, centros de investigación, medios de comunicación y, por supuesto, de la sociedad civil. Solo de esta manera podrá garantizarse el fomento de la cultura científica, la apropiación social del conocimiento científico, la conciencia cívica y la participación ciudadana en esos temas.

Con estos antecedentes, a finales de 2005 se propuso en Ecuador el desarrollo y ejecución de un Programa Nacional de "Postgrado en Comunicación Pública de la Ciencia 
y Tecnología", ${ }^{127}$ que incluye las etapas de Diplomado y Maestría, y que propone la aplicación de un modelo de comunicación democrático y sociocultural.

El diseño de este programa está inspirado en la investigación que sustenta el contenido de esta tesis doctoral. La ejecución de la etapa de Diplomado fue posible gracias al apoyo de la Secretaría Nacional de Ciencia y Tecnología (SENACYT), y de la Fundación para la Ciencia y la Tecnología (FUNDACYT) ${ }^{128}$ del Ecuador.

Este programa ha contado con el auspicio de varias universidades y organismos nacionales e internacionales, como la Organización de Estados Iberoamericanos (OEI); el Convenio Andrés Bello (CAB); la Embajada de Francia; el Instituto de Investigación para el Desarrollo (IRD) de Francia en Ecuador; el Instituto de Periodismo Preventivo y Análisis Internacional (IPPAI) de España; la Universidad Nacional Autónoma de México (UNAM) y la Universidad de Salamanca (USAL), entre otras universidades.

\footnotetext{
${ }^{127}$ La autora de esta Tesis, María de los Ángeles Erazo, participó en el diseño y coordinación de este programa de Postgrado durante el año 2006. Desde enero hasta agosto de 2007 dirigió la ejecución del programa nacional de "Diplomado en Comunicación Pública de la Ciencia", a nivel nacional, y sigue participando como docente en las etapas de Diplomado y Maestría.

${ }^{128}$ De 1994 hasta la presente fecha, la SENACYT ha sido el organismo rector de la política científica y tecnológica en el Ecuador; mientras que la FUNDACYT ejercía las funciones ejecutivas y operativas, hasta finales del año 2006. Porque, en septiembre de 2006, a través del Decreto Ejecutivo No 1829, se estableció la creación del Consejo Nacional de Ciencia y Tecnología (CONACYT), para que éste asuma las responsabilidades que antes ejercía la SENACYT; mientras que esta Secretaría pasó a ser el órgano ejecutivo y operativo del Sistema Nacional de Ciencia, Tecnología e Innovación del Ecuador. Tal decisión llevó al término de las relaciones entre SENACYT y FUNDACYT, y a la consecuente desaparición de FUNDACYT. El CONACYT no llegó a consolidar sus funciones y, por decisión de la Presidencia de la República, desde finales de 2007 la SENACYT está adscrita a la Secretaría Nacional de Planificación y Desarrollo (SENPLADES) del Ecuador. Todos estos cambios administrativos impidieron que el Programa Nacional de "Postgrado en Comunicación Pública de la Ciencia y Tecnología” siga contando con auspicio económico del gobierno a través de SENACYT, en la etapa de la Maestría, como sí ocurrió en la etapa del Diplomado.
} 
La ejecución de este proyecto es de fundamental importancia para lograr la articulación, consolidación y fortalecimiento del Sistema Nacional de Ciencia, Tecnología e Innovación del Ecuador. Aspira ser el centro de capacitación de futuros líderes de este Sistema, así como de profesionales que apoyarán como mediadores o interfaces entre la comunidad científica, los representantes políticos del país y la sociedad en general. De ahí que sea una gran inversión contar con talento humano capacitado en el Ecuador, desde un enfoque interdisciplinario.

Otra repercusión positiva de este Postgrado es que forma a comunicadores de la ciencia de alto nivel, para que contribuyan en el diseño y desarrollo de encuestas, estudios y proyectos de percepción pública de la ciencia, tecnología e innovación.

Hasta el año 2006, ni en Ecuador ni en otros países de la región Andina había espacios de capacitación académica en esos temas, menos a nivel de Diplomado o de Maestría. Por tal razón, al formular este proyecto se propuso convertir el programa de Diplomado en Maestría y ampliar su oferta académica hacia otros países, especialmente a los de la región Andina.

\section{Características del Programa de Postgrado en CPCT}

Este postgrado ofrece el título final de "Magíster en Comunicación Pública de la Ciencia y la Tecnología", y el título intermedio de "Diploma Superior en Comunicación Pública de la Ciencia". Ambos títulos tienen la aprobación del Consejo Nacional de Educación Superior del Ecuador (CONESUP).

Inicialmente, este programa fue concebido solo para la etapa de "Diplomado en Comunicación Pública de la Ciencia”, con apoyo de la SENACYT y de la FUNDACYT. Con afán de que la ejecución del Diplomado beneficie a todo el Ecuador, a mediados de 
2006 ambas entidades convocaron a concurso público a todas las universidades ecuatorianas que tienen escuelas o facultades de periodismo o comunicación. Las universidades seleccionadas fueron: Universidad Central del Ecuador (en Quito); Escuela Superior Politécnica del Litoral, ESPOL (en Guayaquil), Universidad Nacional de Loja (en Loja) y Universidad de Cuenca (en Cuenca). Con respaldo institucional de SENACYT, FUNDACYT, y de las universidades seleccionadas para la ejecución del Diplomado, se decidió proyectar el alcance de este programa hasta el nivel de Maestría.

En septiembre de 2007 culminó la ejecución del Diplomado en las universidades seleccionadas de Quito, Guayaquil y Loja. La Universidad de Cuenca decidió postergar la fecha de inicio del postgrado, con el fin de ampliar su convocatoria.

En enero de 2008 empezó a ejecutarse la etapa de "Maestría en Comunicación Pública de la Ciencia y Tecnología" en la Universidad Central del Ecuador y, posteriormente, inició su ejecución en la Universidad Nacional de Loja. Luego de que concluya la segunda edición del Diplomado en Guayaquil, a finales de 2009, la ESPOL también iniciará con la etapa de Maestría.

\section{Objetivos del Postgrado}

\subsection{Objetivo general:}

El Programa Nacional de "Postgrado en Comunicación Pública de la Ciencia y la Tecnología" tiene como objetivo la formación de personal especializado en el campo de la Comunicación Pública de la Ciencia y la Tecnología, a partir de Estudios de Ciencia, Tecnología, Sociedad e Innovación (CTS+i), que incluyen: filosofía, sociología, antropología e historia de la ciencia, entre otras disciplinas. 


\subsection{Objetivos específicos:}

Al concluir el programa, los profesionales que lo hayan aprobado estarán en capacidad de:

- Impulsar de manera creativa y crítica la Comunicación Pública de la Ciencia y la Tecnología (CPCT) en proyectos de ciencia, tecnología e innovación.

- Planificar, dirigir, promover y ejecutar proyectos innovadores, relacionados con la CPCT.

- Asesorar a instituciones y organismos encargados del diseño y coordinación de políticas relacionadas con ciencia, tecnología e innovación.

- Analizar desde una perspectiva crítica e interdisciplinaria el vínculo entre ciencia y valores; por ejemplo, a partir de la bioética en temas de biotecnología.

- Trabajar en parques temáticos, centros de investigación, universidades, medios de comunicación y en cualquier institución interesada en comunicar públicamente los conocimientos científicos y tecnológicos.

- Fortalecer los vínculos de comunicación entre actores del Sistema Nacional de Ciencia, Tecnología e Innovación.

- Aportar a la creación de nuevos espacios de comunicación pública de la ciencia y la tecnología.

\section{Programación académica}

Este programa académico ofrece módulos relacionados con Estudios de Ciencia, Tecnología y Sociedad; con técnicas, talleres y estrategias que promueven la adecuada 
aplicación y evaluación de proyectos de CPCT. Su malla curricular se divide en los siguientes tres módulos.

- I Módulo: Se refiere a "Estudios de Ciencia, Tecnología y Sociedad" (Estudios CTS); comprende filosofía, sociología, antropología e historia de la ciencia, entre otras.

- II Módulo: Titula "Estudios de la Comunicación Pública de la Ciencia".

- III Módulo: "Estrategias de Comunicación Pública de la Ciencia". Comprende talleres de comunicación pública de la ciencia, periodismo científico, escritura creativa y comunicación narrativa.

El Diplomado se desarrolla a lo largo de un semestre y se divide en 3 módulos que, en total, suman 16 créditos ( 256 horas en modalidad presencial). Su primera edición inició en marzo de 2007 y culminó en agosto del mismo año. La Maestría supone una duración de dos años, tiempo en el cual se cumple con la ejecución de 65 créditos (1040 horas en modalidad presencial) y se da continuidad a los 3 módulos del Diplomado.

\subsection{Primera etapa: Diplomado en Comunicación Pública de la Ciencia}

\begin{tabular}{|r|l|r|r|}
\hline \multicolumn{1}{|c|}{$\mathbf{N}^{\mathbf{1}}$} & \multicolumn{1}{|c|}{ Asignatura } & Horas & Créditos \\
\hline $\mathbf{1}$ & MÓDULO I: Ciencia, Tecnología y Sociedad & 16 & 1 \\
\hline $\mathbf{2}$ & Cuistoria de la ciencia I. & 16 & 1 \\
\hline $\mathbf{3}$ & $\begin{array}{l}\text { Programa Nacional de Ciencia, Tecnología e Innovación (PNCTI) y Sistema Nacional de } \\
\end{array}$ & 16 & 1 \\
\hline $\mathbf{4}$ & Giencia, Tecnología e Innovación (SNCTI) - I. & 16 & 1 \\
\hline $\mathbf{5}$ & Grandes temas de la ciencia y de la CPC I: "Biomedicina y Bioética I”. & 16 & 1 \\
\hline & & & 16 \\
\hline
\end{tabular}




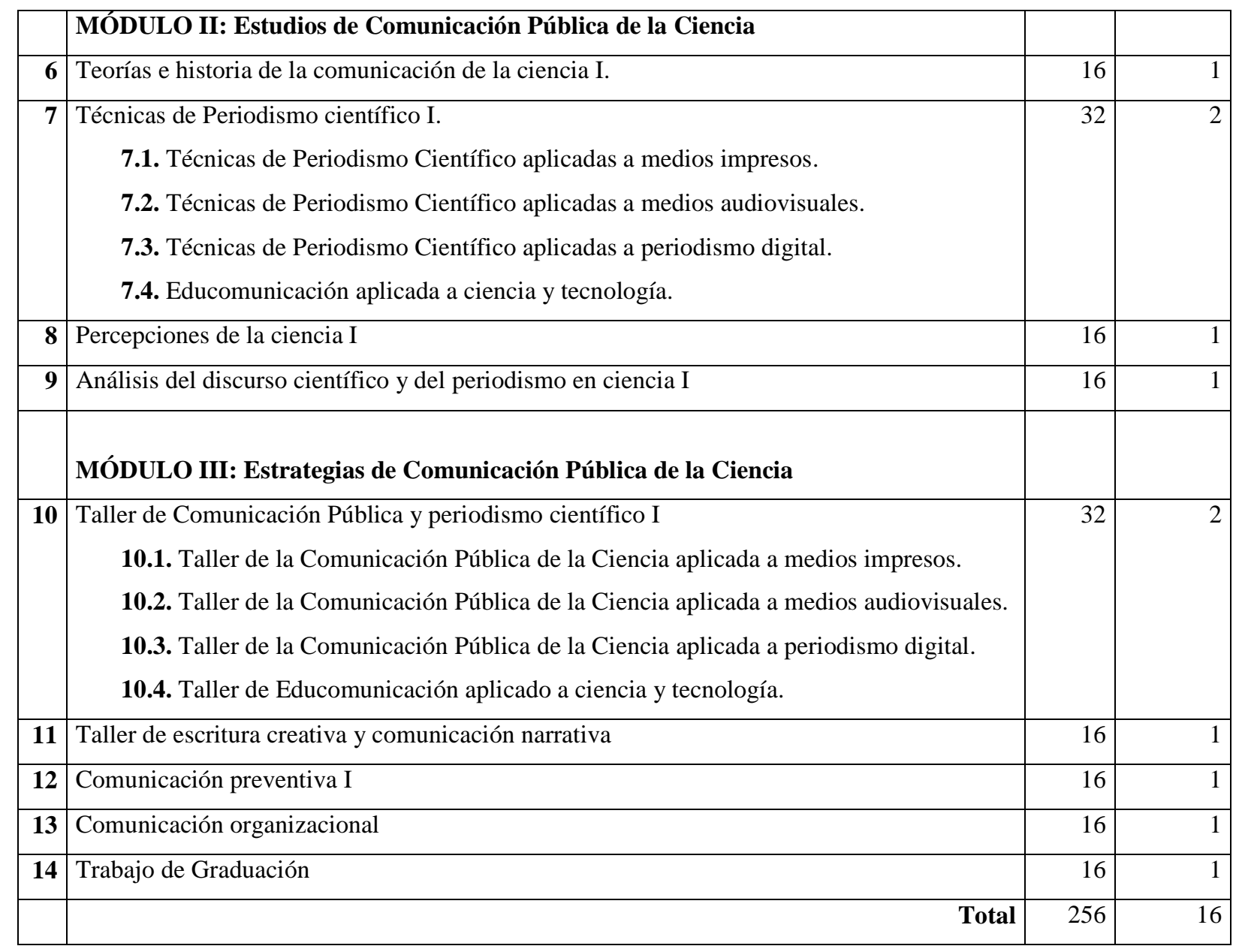

Los profesores nacionales y extranjeros que han sido seleccionados para dictar las clases de este Postgrado tienen experiencia previa como docentes de programas similares. Todas las clases se dictaron en la modalidad presencial.

\subsection{Segunda etapa: Maestría en Comunicación Pública de la Ciencia y la Tecnología}

\begin{tabular}{|r|l|r|r|}
\hline $\mathbf{N}^{\mathbf{0}}$ & \multicolumn{1}{|c|}{ Asignatura } & Horas & Créditos \\
\hline & \multicolumn{1}{|c|}{ MÓDULO I: Ciencia, Tecnología y Sociedad } & & \\
\hline 15 & Historia de la ciencia II. & 32 & \\
\hline 16 & Filosofía de la Ciencia y la Tecnología. & 32 & 2 \\
\hline
\end{tabular}




\begin{tabular}{|c|c|c|c|}
\hline 17 & Sociología de la Ciencia y la Tecnología. & 32 & 2 \\
\hline 18 & Cultura científica y tecnológica II. & 32 & 2 \\
\hline 19 & $\begin{array}{l}\text { Programa Nacional de Ciencia, Tecnología e Innovación (PNCTI) y Sistema Nacional de } \\
\text { Ciencia, Tecnología e Innovación (SNCTI) - II . }\end{array}$ & 32 & 2 \\
\hline 20 & Éticas en las prácticas de la investigación científica y en la práctica tecnológica. & 32 & 2 \\
\hline 21 & Metodología de investigación en Comunicación Pública de la Ciencia. & 32 & 2 \\
\hline 22 & Grandes temas de la ciencia y de la CPC II: “Tierra, medio ambiente y desarrollo II”. & 16 & 1 \\
\hline 23 & Grandes temas de la ciencia y de la CPC II: "Biomedicina y Bioética II". & 16 & 1 \\
\hline 24 & Grandes temas de la ciencia y de la CPC II: "Ciencias sociales y humanas". & 32 & 2 \\
\hline & MÓDULO II: Estudios de Comunicación Pública de la Ciencia & & \\
\hline 25 & Teorías e historia de la comunicación de la ciencia II. & 16 & 1 \\
\hline 26 & $\begin{array}{l}\text { Técnicas de Periodismo científico II. } \\
\text { 26.1. Técnicas de Periodismo Científico aplicadas a medios impresos. } \\
\text { 26.2. Técnicas de Periodismo Científico aplicadas a medios audiovisuales. } \\
\text { 26.3. Técnicas de Periodismo Científico aplicadas a periodismo digital. } \\
\text { 26.4. Educomunicación aplicada a ciencia y tecnología. } \\
\text { 26.5. Técnicas de periodismo de investigación aplicadas a periodismo científico. }\end{array}$ & 80 & 5 \\
\hline 27 & Percepciones de la ciencia II. & 32 & 2 \\
\hline 28 & Análisis del discurso científico y del periodismo en ciencia II. & 48 & 3 \\
\hline & MÓDULO III: Estrategias de Comunicación Pública de la Ciencia & & \\
\hline 29 & $\begin{array}{l}\text { Taller de Comunicación Pública y periodismo científico II. } \\
\text { 29.1. Taller de la Comunicación Pública de la Ciencia aplicada a medios impresos. } \\
\text { 29.2. Taller de la Comunicación Pública de la Ciencia aplicada a medios audiovisuales. } \\
\text { 29.3. Taller de la Comunicación Pública de la Ciencia aplicada a periodismo digital. } \\
\text { 29.4. Taller de Educomunicación aplicado a ciencia y tecnología. } \\
\text { 29.5. Taller de periodismo de investigación aplicado a periodismo científico. }\end{array}$ & 80 & 5 \\
\hline 30 & Taller de escritura creativa y comunicación narrativa II. & 32 & 2 \\
\hline 31 & Comunicación preventiva II. & 32 & 2 \\
\hline 32 & Comunicación organizacional II. & 16 & 1 \\
\hline \multirow[t]{2}{*}{33} & Tesis de Grado. & 128 & 8 \\
\hline & Total & 752 & 47 \\
\hline
\end{tabular}


La mayoría de las clases se dictan en la modalidad presencial, pero también se ofrece algunos en la modalidad semipresencial y a través de educación virtual, con aval del Consejo Nacional de Educación Superior (CONESUP) del Ecuador.

\section{Destinatarios:}

- Periodistas que cubren la fuente de educación, ciencia y/o tecnología.

- Profesionales de Periodismo, Comunicación Social o Audiovisual.

- Profesionales de ciencias exactas e ingenierías.

- Profesionales de ciencias sociales y humanas.

- Investigadores que quieran comunicar públicamente sus investigaciones.

\section{Estudio de mercado que justificó la ejecución del Postgrado en CPCT}

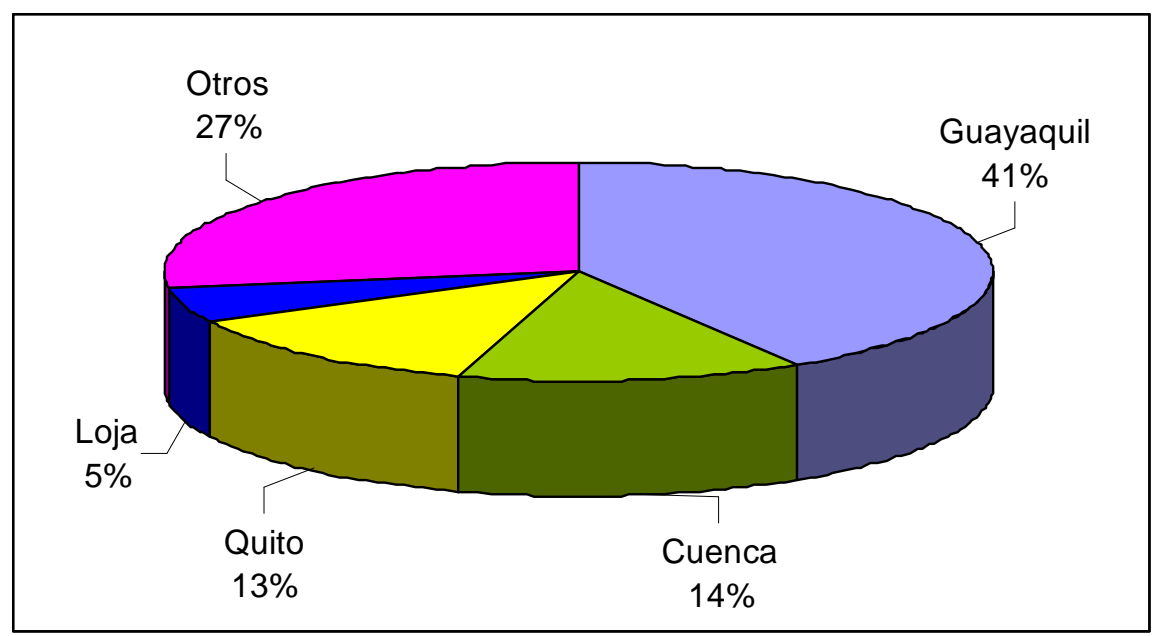

La muestra estuvo conformada por 850 encuestas aplicadas en todo el Ecuador; especialmente en ciudades cercanas al lugar donde están ubicadas las universidades ejecutoras del programa. 


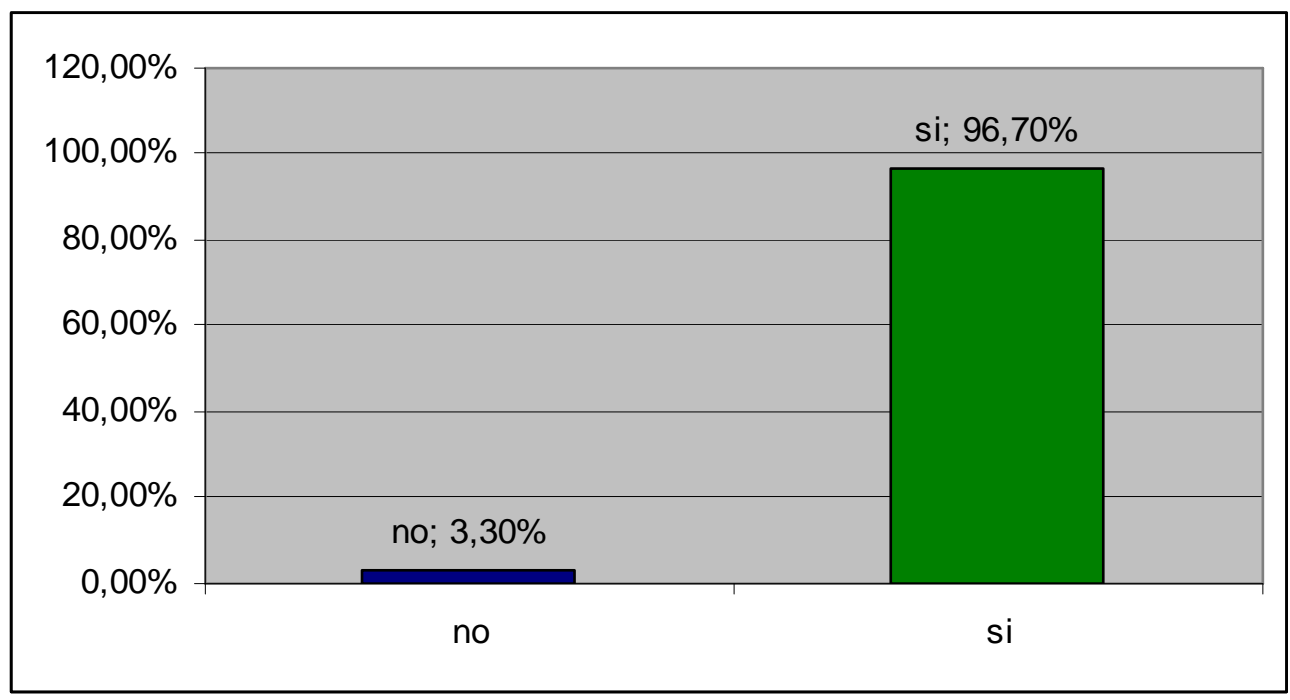

El 96.7\%, de encuestados respaldó la propuesta de ejecución del "Diplomado en Comunicación Pública de la Ciencia” en Pichincha, Guayas, Azuay, Loja y provincias aledañas del Ecuador.

\begin{tabular}{|l|r|r|}
\hline \multicolumn{1}{|c|}{ ¿Qué cargo ejerce actualmente? } & Frecuencia & Porcentaje \\
\hline \hline Profesional en periodismo & 163 & $19,9 \%$ \\
\hline \hline Profesional en comunicación social & 72 & $8,8 \%$ \\
\hline \hline Profesor & 139 & $17,0 \%$ \\
\hline \hline Profesionales ciencias de la educación & 56 & $6,8 \%$ \\
\hline Profesional en ciencias exactas & 117 & $14,3 \%$ \\
\hline $\begin{array}{l}\text { Profesional de instituciones } \\
\text { gubernamentales }\end{array}$ & 70 & $8,6 \%$ \\
\hline $\begin{array}{l}\text { Profesional en ciencias sociales y } \\
\text { humanas }\end{array}$ & 58 & $7,1 \%$ \\
\hline \hline Investigador científico & 46 & $5,6 \%$ \\
\hline Profesional de Instituciones no \\
gubernamentales, ONG
\end{tabular}




\section{Áreas de mayor interés}

\section{Frecuencia Porcentaje}

Estrategias de comunicación pública de la ciencia y la tecnología.

Política Nacional de Ciencia, Tecnología e Innovación (PNCTI).

Indicadores de ciencia, tecnología e innovación.

Estudios filosóficos y sociales de la ciencia y la tecnología.

Sistema Nacional de Ciencia, Tecnología e Innovación (SNCTI).

Taller de prensa escrita sobre temas de ciencia

y tecnología.

Taller de radio sobre temas de ciencia $y$ tecnología.

Taller de periodismo digital sobre temas de ciencia y tecnología.

Periodismo, museología y divulgación de la ciencia.

Taller de televisión sobre temas de ciencia y tecnología.

Estrategias de periodismo científico para oficinas de información o comunicación.

\begin{tabular}{|r|r|}
\hline 232 & $28,0 \%$ \\
\hline 164 & $19,8 \%$ \\
\hline 150 & $18,1 \%$ \\
\hline 134 & $16,1 \%$ \\
\hline 131 & $15,8 \%$ \\
\hline 118 & $15,2 \%$ \\
\hline 116 & $14,2 \%$ \\
\hline 116 & $14,0 \%$ \\
\hline 106 & $12,8 \%$ \\
\hline 102 & $12,3 \%$ \\
\hline 3 & $0,4 \%$ \\
\hline
\end{tabular}

Otros

\subsection{Resultados del Estudio de Mercado}

- El 97\% de los encuestados respaldó la ejecución del "Diplomado en Comunicación Pública de la Ciencia" y, el 60\%, estaba dispuesto a cursarlo.

- Profesionales del periodismo y de la comunicación fueron los más interesados en cursar el "Diplomado en Comunicación Pública de la Ciencia".

- Las áreas de estudio de mayor interés fueron: Estrategias de Comunicación Pública de la Ciencia y la Tecnología, y Política Nacional de Ciencia, Tecnología e Innovación. 


\section{Etapas de ejecución del programa}

Primera fase ( $1^{\circ}$ año):

- Estudio de mercado.

- Diseño de la malla curricular del Diplomado y de la Maestría en Comunicación Pública de la Ciencia.

- Selección del equipo docente.

- Confirmación de los convenios previstos con varios organismos nacionales e internacionales.

- Proceso de aprobación del proyecto ante CONESUP.

- Elaboración del material académico.

- Compra de recursos bibliográficos.

- Promoción del Diplomado.

- Inscripción, selección y matrícula de profesionales.

\section{Segunda fase $\left(2^{\circ}\right.$ año $)$ :}

- Desarrollo de cursos teóricos y prácticos del Diplomado.

- Seminarios y conferencias magistrales.

- Visita a centros de investigación.

- Elaboración de boletines mensuales.

- Realización de prácticas profesionales (optativa).

- Recepción y calificación de trabajos mensuales, de informes (a quienes realicen prácticas) y del trabajo de graduación. 
- Publicación de actas con calificaciones.

- Clausura del Diplomado.

- Evaluación de impacto del Proyecto de Diplomado.

- Promoción de la Maestría.

- Inauguración de la Maestría.

- Desarrollo de cursos teóricos y prácticos.

\section{Tercera fase $\left(3^{\circ}\right.$ y $4^{\circ}$ año):}

- Desarrollo de cursos teóricos de la Maestría.

- Seminarios y conferencias magistrales.

- Visita a centros de investigación.

- Elaboración de boletines mensuales.

- Opción de realizar prácticas profesionales.

- Recepción y calificación de trabajos mensuales, de informes (a quienes realicen prácticas) y del trabajo de graduación.

- Publicación de actas con calificaciones.

- Clausura de la Maestría.

- Evaluación de impacto de la Maestría. 


\section{Informe general sobre el diseño y desarrollo del Programa Nacional de “Diplomado en Comunicación Pública de la Ciencia" en el Ecuador. ${ }^{129}$}

\subsection{Información General:}

Nombre del Programa Nacional: "Diplomado en Comunicación Pública de la Ciencia”.

Entidades proponentes: Secretaría Nacional de Ciencia y Tecnología (SENACYT) y Fundación para la Ciencia y Tecnología (FUNDACYT).

Inicio del programa: Enero de 2006.

Selección de universidades ejecutoras: Abril de 2006.

Instituciones seleccionadas para la ejecución:

1. Universidad Central del Ecuador, a través de la Facultad de Comunicación Social, en Quito.

2. Escuela Superior Politécnica del Litoral (ESPOL), a través de la Escuela de Diseño y Comunicación Visual, en Guayaquil.

3. Universidad de Cuenca, a través de la Escuela de Ciencias de la Comunicación Social, en Cuenca.

4. Universidad Nacional de Loja, a través de la Carrera de Comunicación, en Loja. Aprobación del CONESUP: 14 de diciembre de 2006.

\footnotetext{
${ }^{129}$ La ejecución de la etapa de "Diplomado en Comunicación Pública de la Ciencia" fue dirigida, a nivel nacional, por la autora de la presente tesis doctoral.
} 
No de Registro del CONESUP: RCP.S17.No.318.06

Convocatoria a inscripciones: Desde diciembre de 2006.

\section{Inauguración del Diplomado:}

- En la Universidad Central del Ecuador: Jueves, 22 de marzo de 2007.

- En la Universidad Nacional de Loja: Viernes, 30 de marzo de 2007.

- En la ESPOL: Viernes, 6 de abril de 2007.

\subsection{Cronograma de actividades cumplido de enero a diciembre de 2006}

\begin{tabular}{|c|c|c|c|c|c|c|c|c|c|c|c|c|}
\hline Actividades & Mese & de $\mathbf{E j}$ & cució & & & & & & & & & \\
\hline Descripción & $\begin{array}{l}\text { Ene. } \\
2006\end{array}$ & Feb & Mr. & Ab. & Ma & Jun. & Jul. & Ag & Sep. & Oc & Nov & Dic \\
\hline Coordinación del proyecto & $\mathrm{X}$ & $\mathrm{X}$ & $\mathrm{X}$ & $\mathrm{X}$ & $\mathrm{X}$ & $\mathrm{X}$ & $\mathrm{X}$ & $\mathrm{X}$ & $\mathrm{X}$ & $\mathrm{X}$ & $\mathrm{X}$ & $\mathrm{X}$ \\
\hline $\begin{array}{l}\text { Selección de universidades } \\
\text { ejecutoras del proyecto }\end{array}$ & & & & $\mathrm{X}$ & & & & & & & & \\
\hline Estudio de Mercado & & & & & $\mathrm{X}$ & $\mathrm{X}$ & & & & & & \\
\hline $\begin{array}{llll}\text { Resultados } & \text { del } & \text { Estudio } & \text { de } \\
\text { Mercado } & & & \\
\end{array}$ & & & & & & & $\mathrm{X}$ & & & & & \\
\hline Diseño curricular & & & & & & & & $\mathrm{X}$ & & & & \\
\hline $\begin{array}{l}\text { Elaboración del documento } \\
\text { presentado al CONESUP, para la } \\
\text { aprobación del programa }\end{array}$ & & & & & & & & & $\mathrm{X}$ & & & \\
\hline $\begin{array}{l}\text { Trámite ante el CONESUP, para } \\
\text { conseguir la aprobación del } \\
\text { programa de Diplomado }\end{array}$ & & & & & & & & & & $\mathrm{X}$ & $\mathrm{X}$ & \\
\hline Promoción - Diplomado & & & & & & & & & & & & $\mathrm{X}$ \\
\hline $\begin{array}{l}\text { Confirmación de convenios con } \\
\text { organismos coauspiciantes }\end{array}$ & & & & & $\mathrm{X}$ & $\mathrm{X}$ & $\mathrm{X}$ & $\mathrm{X}$ & $\mathrm{X}$ & & & \\
\hline Selección del personal docente & & & & & & & & & $\mathrm{X}$ & $\mathrm{X}$ & & \\
\hline
\end{tabular}




\subsection{Dificultades registradas durante el año 2006}

- La principal dificultad que impedía avanzar con la ejecución del programa fue el tiempo de espera que supuso la transición, a SENACYT, de las responsabilidades y compromisos que había asumido FUNDACYT con las universidades ejecutoras del proyecto.

- Otra dificultad registrada fue la tardanza en la firma de convenios entre FUNDACYT y las universidades ejecutoras del Diplomado, porque tardaron los procesos de aprobación legal en esas universidades.

- El tiempo de espera que supuso el proceso de aprobación del programa académico en el CONESUP también limitó avances del programa, durante el año 2006. Porque la falta de este aval impedía avanzar con varias actividades previstas en el cronograma de actividades, como era la promoción del Diplomado, el proceso de inscripción y matrícula de estudiantes, y la consecuente ejecución de clases.

- Una de las limitaciones que reportaron profesionales extranjeros, para colaborar como docentes del Diplomado, era que no disponían de tiempo libre como para quedarse más de una o dos semanas en Ecuador, a fin de cumplir con las horas de clases asignadas por cada asignatura.

- Tardó mucho la firma de un Ademdum o una ampliación del plazo del Convenio de Ejecución del programa de "Diplomado en Comunicación Pública de la Ciencia", No 2005984. Este documento se firmó el 15 de febrero de 2007, al final del acto de presentación oficial del programa de "Maestría en Comunicación Pública de la Ciencia y Tecnología", que se llevó a cabo en el "Salón Los Próceres", de la Cancillería. Pero 
fue a finales de junio de 2007 cuando el nuevo titular de SENACYT, Dr. Jaime Tola, aprobó la ejecución del presupuesto destinado para el programa de Diplomado.

\subsection{Soluciones propuestas}

- Concentrar en una entidad la coordinación general del programa de "Diplomado en Comunicación Pública de la Ciencia”. Por decisión de las cuatro universidades, esta responsabilidad fue asumida por la Dirección de Investigación y Postgrado de la Universidad Central del Ecuador, a través de la directora del programa, María de los Ángeles Erazo, y del Dr. Rolando Sáenz, en calidad de Director de Investigación y Posgrado de la Universidad Central del Ecuador.

- Para facilitar la ejecución de algunas asignaturas teóricas, que requieren del apoyo de docentes extranjeros, se sugirió programar clases en modalidad semipresencial, o a través de videoconferencias, en la etapa de Maestría. 